\title{
The war garden victorious, by Charles Lathrop Pack .... 1919
}

Pack, Charles Lathrop, 1857-1937

Philadelphia, Pennsylvania: J. P. Lippincott Company, 1919

https://digital.library.wisc.edu/1711.dl/RYL2O5G72JSO68D

Based on date of publication, this material is presumed to be in the public domain.

For information on re-use, see

http://digital.library.wisc.edu/1711.dl/Copyright

The libraries provide public access to a wide range of material, including online exhibits, digitized collections, archival finding aids, our catalog, online articles, and a growing range of materials in many media.

When possible, we provide rights information in catalog records, finding aids, and other metadata that accompanies collections or items. However, it is always the user's obligation to evaluate copyright and rights issues in light of their own use. 

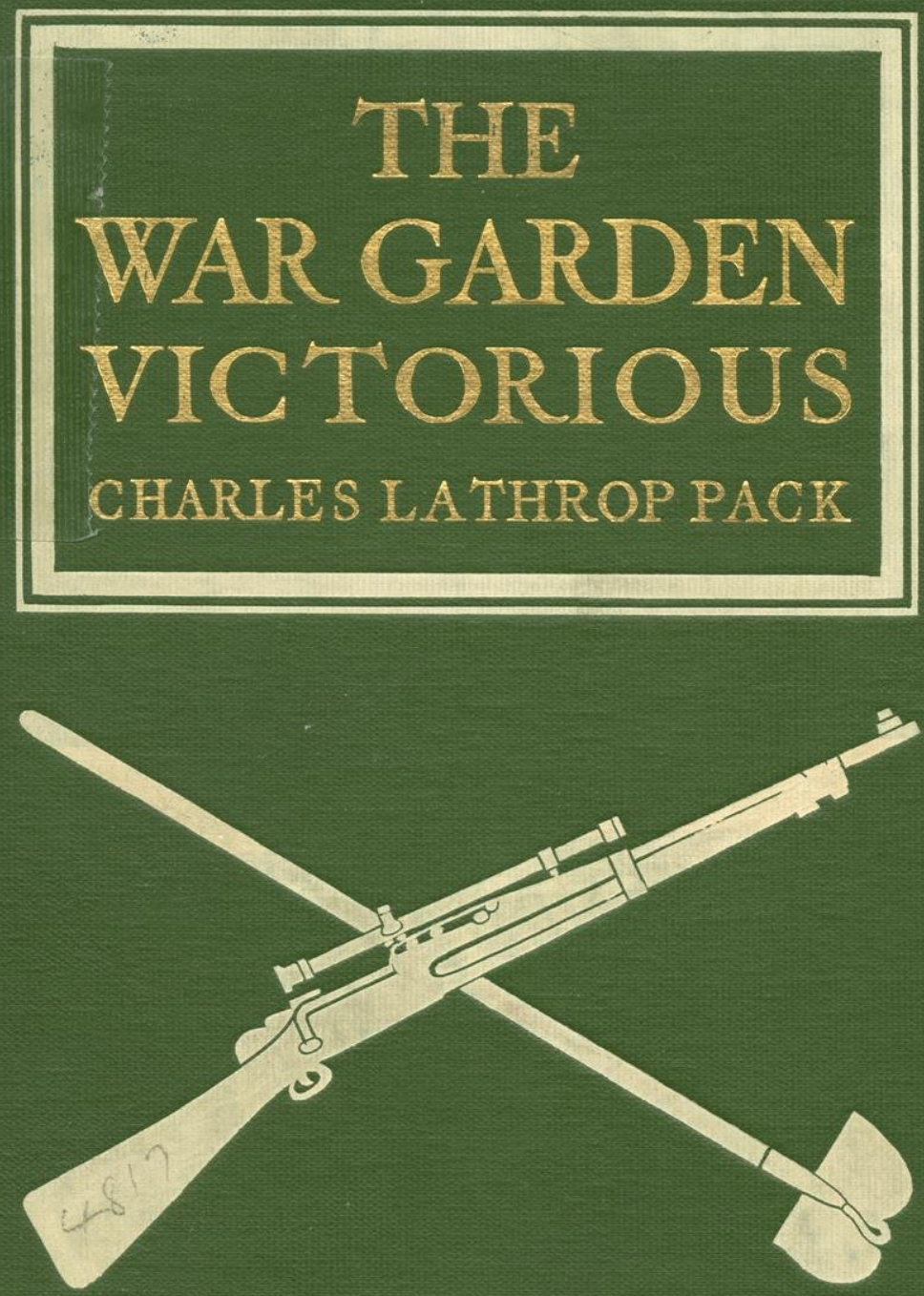
Library

of the

University of Wuisconsin 


\section{NATIONAL WAR GARDEN COMMISSION}

\author{
CHARLES LATHROP PACK \\ PRESIDENT \\ PERCIVAL S. RIDSDALE \\ SECRETARY ANDTREASURER \\ NORMAN C. MCLOUD \\ ASSOCIATE SECRETARY
}

\author{
MARYLAND BUILDING \\ WASHINGTON, D. C.
}

\author{
LUTHER BURBANK, CALIF. \\ P. P. CLAXTON, U. S.COM'R OF ED. \\ DR. CHARLES W. ELIOT. MASS. \\ DR. IRVING FISHER, CONN. \\ FRED H. GOFF, OHIO \\ JOHN HAYS HAMMOND MASS. \\ FAIRFAX HARRISON, VA. \\ HON. MYRON T. HERRICK, OHIO \\ DR. JOHN GRIER HIBBEN. N. J. \\ EMERSON MCMILLIN. N. Y. \\ CHARLES LATHROP PACK. N. J. \\ A. W. SHAW, ILL. \\ MRS. JOHN DICKINSON SHERMAN. ILL \\ CAPT. J. B. WHITE, MO. \\ HON JAMES WILSON, IOWA
}

March 20, 1919.

To the Librarian:

In sincere appreciation of the co-operation of your Library in the successful developwent of the War Garden Movement, I am sending you, with my compliments, a copy of the book "The War Gardens Victorious." This book is a record of the inception and the development of the home and community garden movement under the National War Garden Commission, which devoted itself to securing the planting of War and Victory Gardens on vacant lots and slacker land for the purpose of raising vegetables to overcome the food shortage during and immediately succeeding hostilities.

This book is not for sale. It is issued to those who aided so serviceably in this economic work. I trust you will find it interesting and worthy of a place on your shelves.

Yours very sincerely,

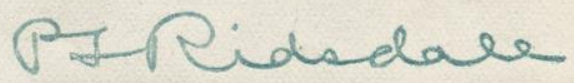

MCL:MLN .

Secretary. 







\section{THE WAR GARDEN VICTORIOUS}

ITS WAR TIME NEED AND ITS ECONOMIC VALUE IN PEACE 



\title{
The War Garden Victorious
}

\author{
BY \\ CHARLES LATHROP PACK
}

ILLUSTRATED

PRESS OF

J. B. LIPPINCOTT COMPANY

PHILADELPHIA 
CoPYRIGHTED II BY THE NATIONAL WAR GARDEN COMUSSIIN 
224817

APR 281919

$\begin{array}{ll}\text { PA } & S B \\ \text { PAR } & 83 \\ & B 3 \\ 1919\end{array}$

THIS book is dedicated to the War Gardeners of the United States and Allied countries in admiration of their success in adding to the world's supply of food during the World War.

With che compliments of the author Shank Lathofo Pack. 



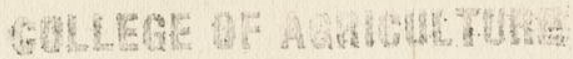

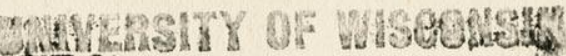 MAOMISOIS \\ CONTENTS}

CHAPTER

PAGE

I. How the National War Garden Commission

Came into Being ................. I

II. The Story of the War Garden $\ldots \ldots \ldots \ldots$ I2

III. How War Gardens Helped ............ 24

IV. Types of War Gardens $\ldots \ldots \ldots \ldots \ldots \ldots \ldots \ldots \ldots$

V. Uncle Sam's First War Garden ......... 46

VI. How Big Business Helped ............ 53

VII. How the Railroads Helped ............ 68

ViII. The Army of School Gardeners ......... 73

IX. Community Gardening $\ldots \ldots \ldots \ldots \ldots \ldots \ldots .79$

X. Coöperation in Gardening ............ 89

XI. War Gardens as City Assets ........... 96

XII. The Part Played by Daylight Saving ....... 105

XIII. The Future of War Gardening ........... Io9

XIV. Conserving the Garden Surplus .......... I2I

XV. Community Conservation ............ 126

XVI. Conservation by Drying .............. I 34

XVII. Why We Should Use Dried Foods ......... I45

XVIII. The Future of Dehydration ........... I 55

XIX. Coöperation of the Press $\ldots \ldots \ldots \ldots \ldots \ldots \ldots$ i6 65

\section{APPENDIX}

“War Gardening," Victory Edition, i9i9

“Home Canning and Drying," Victory Edition, igig 



\section{COLOR PLATES}

PAGE

"Every Garden a Munition Plant" .........Frontispiece

A Poster Spreading the Idea of Militant War Gardens.... I2

A Poster for 1919, Symbolic of Victory ............ I4

A Poster Which Was Used in 1918, and Which, Amended-

Following Germany's Defeat-Was Also Forceful in I919 I6 



\section{ILLUSTRATIONS}

PAGE

A First-Year War Garden $. . \ldots \ldots \ldots \ldots \ldots \ldots \ldots \ldots, 4$

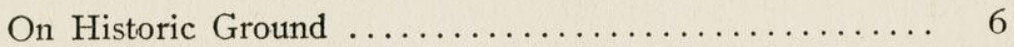

A Typical City Garden ................... 8

A Veteran War Gardener ................... Io

No "Slacker Land" Here .................. I8

One of Cleveland's War Gardens .............. 20

No Wonder She Smiles .................. 22

Garden of a Chicago Amateur ............... 26

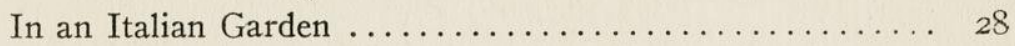

In the Champion Garden City $\ldots \ldots \ldots \ldots \ldots \ldots \ldots \ldots$

Medal in Commemoration of the War Garden ......... 32

The War Gardener's Boast ................ 34

Pioneers in Summer Hotel Gardening ............ $3^{8}$

An Army Garden at the Red Cross Threshold ........ 42

A Prize-Winning Garden ................... 44

“Now, Boys, Show 'Em How to Harvest" .......... 46

“Potatoes Up! Forward March!” .............. 48

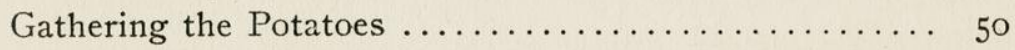

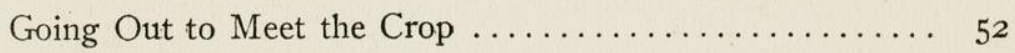

What a Factory Worker Did ................ 54

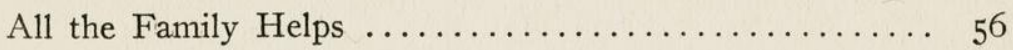

A Versatile Manufacturing Concern .............. 60

War Garden Display in Bank Window ........... 62

Nationality Made No Difference ............... 64

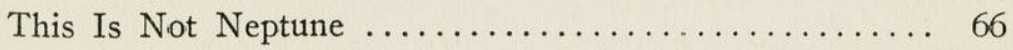

On Pennsylvania Railroad Ground ............. 68

Some Railroad " Soldiers of the Soil " ........... 70

Along the East River Front $\ldots \ldots \ldots \ldots \ldots \ldots \ldots \ldots \ldots \ldots \ldots$

One of Cleveland's School Gardens ............. 76 
Planting a Community Garden $\ldots \ldots \ldots \ldots \ldots \ldots \ldots \ldots$. 80

Boy Scouts Raised the Food ................ 82

"Papa, See Me Hoe?” .................... 84

Raising "Food F. O. B. the Factory Door" .......... 86

A Polyglot Assembly ..................... 90

Down in "The Yards" ..................... 94

'Midst Towering Skyscrapers $\ldots \ldots \ldots \ldots \ldots \ldots \ldots \ldots . \ldots \ldots$

War Garden on Boston Common .............. IO2

"County Fair" in Bryant Park ................ I04

No Age Limit on Patriotism ................ I06

Prize-Winning Canning Team in Iowa ............. I Io

The Question Is: Does It "Jell”? . . . . . . . . . II

Received Certificate Number One .............. II4

Interior of a Bank, Not a Fine Grocery . . . . . . . . I 6

Getting the Winter Supply Ready ............. II8

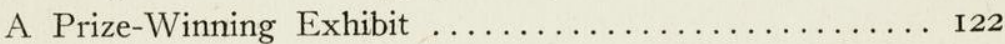

Girl Scouts Can Can, Too ................. 126

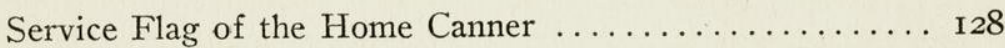

Achievement Club Girls ................... I30

He Is Not Lecturing; He Won the Canning Contest . . . . . I I 34

Preparing to Dry Vegetables ................. I36

A Montana Prize Canner ................... I 38

They Helped to Can the Kaiser ............... I40

Food Goes with the Flag $\ldots \ldots \ldots \ldots \ldots \ldots \ldots \ldots \ldots \ldots \ldots \ldots \ldots \ldots \ldots$

Toothsome Viands at Dried Food Luncheon .......... I48

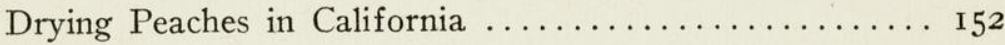

Preparing Raisins for the Market ............. I56

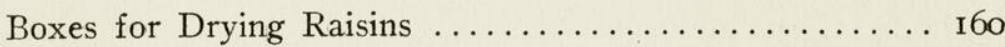

The Knights of Printers Ink Heard the Call for Food ..... I66

Typical Headings from News Sheets ............ I70

How Newspaper "Copy" Was Sent Out ......... I72

With Picture and Type the Press Urged Gardening ..... I76 


\section{THE WAR GARDEN VICTORIOUS}





\section{THE WAR GAR D E N V I C T O R I O U S}

\section{CHAPTER I}

HOW THE NATIONAL WAR GARDEN COMMISSION CAME INTO BEING

The Need of Making Every Garden a Munition Plant

$7 \mathrm{HE}$ war garden was a war-time necessity.

This was true because war conditions made it essential that food should be raised where it had not been produced in peace times, with labor not engaged in agricultural work and not taken from any other industry, and in places where it made no demand upon the railroads already overwhelmed with transportation burdens.

The knowledge that the world faced a deficit in food, that there existed an emergency which could be met only by the raising of more food, was apparent to every well-informed and thinking man and woman during the early months of 1917 .

The author, wishing, as every patriot wished, to do a war work which was actually necessary, which was essentially practical, and which would most certainly aid in making the war successful, conceived the idea in March, 1917, of inspiring the people of the United States to plant war gardens in order to increase the supply of food without the use of land already cultivated, of 
labor already engaged in agricultural work, of time devoted to other necessary occupations, and of transportation facilities which were already inadequate to the demands made upon them.

In March, therefore, some weeks before the United States entered the war, he organized for this work a commission known as the National War Garden Commission.

What were the causes which led to the world's lack of food and the need of a largely increased production by the United States to prevent world starvation?

When the drums sounded the call to the colors in the summer of 1914, three million Frenchmen shouldered their rifles and marched away from a large proportion of the five million farms of France; and mostly these were one-man farms. Russia, a nation almost wholly agricultural, mobilized perhaps eight millions of men. All the men of fighting age in Belgium were summoned to the army. England, possessing only a "contemptible little army," straightway began a recruiting campaign which within a few years swelled the ranks of her military forces to five millions. Germany called out her entire fighting force of military age, an army of several millions. Austria, Bulgaria and Turkey likewise mobilized their full fighting forces. Altogether, twenty or thirty million men were called away from their usual pursuits. The vocation of the majority of them was farming. Thus, at one stroke, practically all the farms in the embattled nations were swept clear of male workers. 
At the same time the harvests were maturing or already ripe for the sickle; and over these laden acres swept the millions of soldiers, trampling, burning and destroying vast stores of food. In Belgium and France on the west front, and in Hungary, East Prussia, and Russia on the east, thousands upon thousands of cropbearing acres were devastated and laid waste.

In a few short weeks this was the situation: the food supply was largely decreased, vast areas of farming land were rendered unproductive, and the farms were practically stripped of their accustomed tillers. The world's food supply was thrown entirely out of balance. Ordinarily the food-supply system was as nicely adjusted as the parts of a watch. Production was balanced against consumption. Given markets were supplied from given sources.

So unfailing was this system that each of the belligerent nations absolutely depended upon other nations for certain parts of its food, and had received its expected supply as unfailingly as our daily milk and newspapers are delivered at our doors. Thus England procured most of her sugar from Germany, and Italy got wheat from Russia, by way of the Dardanelles. At one stroke, this nicely balanced system was destroyed.

Worse than the wrecking of the system of distribution was the unbalancing of production itself. Millions of farms, stripped of their male workers, necessarily became either wholly unproductive or able to raise but a fraction of their normal output. In a moment's time, as it were, the food production of Europe was 
lessened by millions and millions of bushels. Since food production is not, like Aladdin's palace, the creation of a night, this inevitably meant a shortage in the world's food supply. Before the European deficit could be made good by increased production elsewhere, months and perhaps years must elapse.

Then came the submarine, further to complicate matters. By hundreds of thousands of tons the world's shipping was sent to the bottom of the sea, so that in a short time the food situation wore an entirely new aspect. No matter what mountainous piles of provender might accumulate in the distant parts of the earth, it was not available for the nations at war. Ships could not be spared for long and distant voyages. If the $120,000,000$ people of the Entente nations were to have food, if they were to procure enough to keep them from actual starvation, that food must come from the nearest markets. Only by sending their ships back and forth from these markets, back and forth like shuttles in a loom, could food be transported rapidly enough to keep this great population from starvation. Prior to the war England had produced but one-fifth of her own food supply, France one-half of hers, and Italy two-thirds of what she consumed, and now their home production was fearfully decreased. The nearest possible markets where food could be produced were in North America, and principally in our own country. Thus the burden of feeding the Entente fell very largely upon the United States. Whether we wished to undertake the task or not, Fate had saddled the burden upon our backs, 


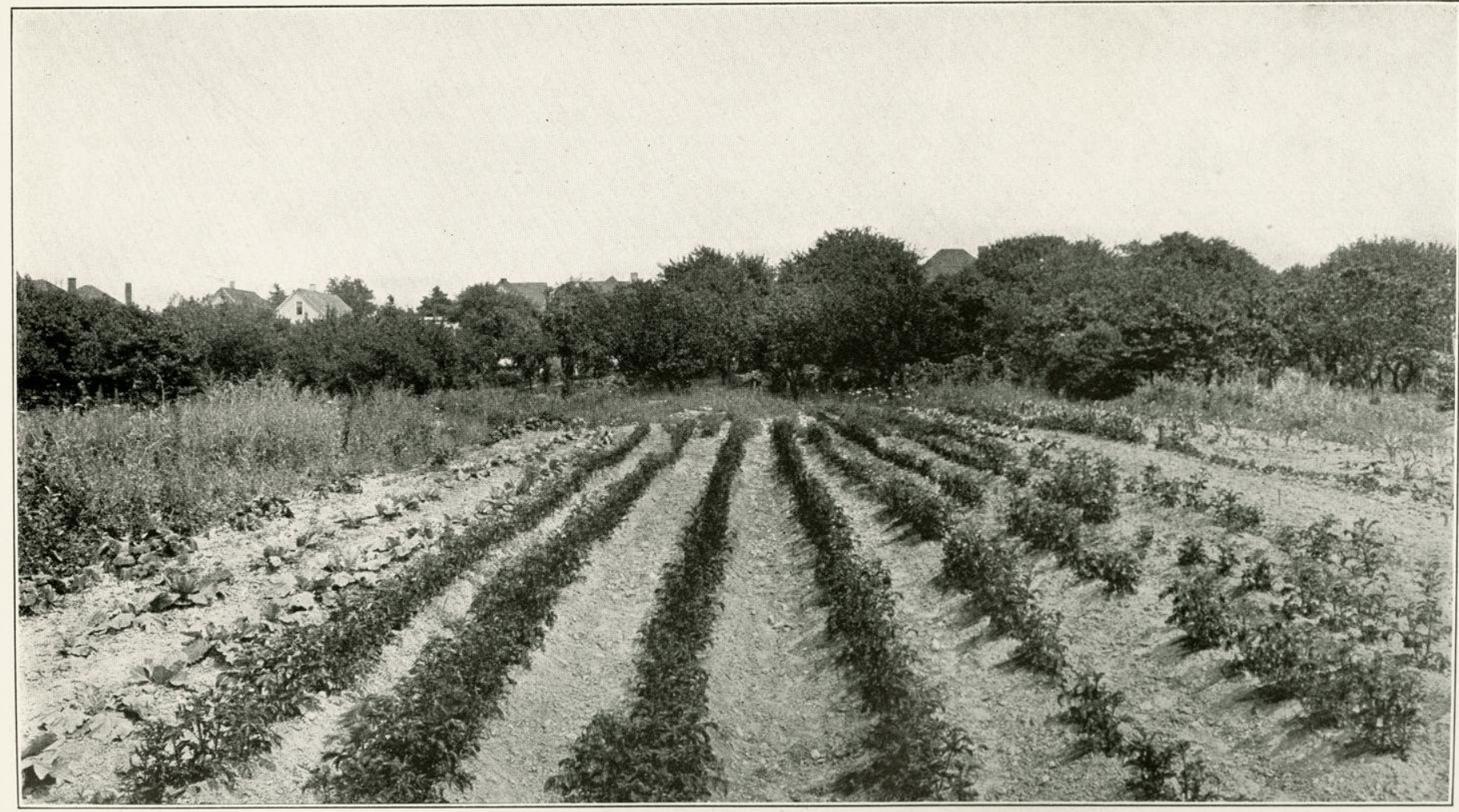

A FIRST-YEAR WAR GARDEN

This plot, formerly a grass and weed overgrown tract, was cultivated by one of the employes of the Eastman Kodak Company, Rochester, New York, who organized a Home Gardeners' Association which was enthusiastically and patriotically supported. The work was encouraged by an exhibit of garden and canned products held by the company. 

This fact, however, was not patent immediately. At least it was glimpsed only by those of keen penetration. In every country there were some accumulated stores. These served to delay the approach of actual hunger. Then came the year, 1916, which was, agriculturally, the most disastrous year the world has known, in recent times. Crops failed everywhere. European production decreased terribly. Our own fell off by hundreds of millions of bushels. What was left of accumulated surpluses was eaten up. The great drain on our food resources wiped out our surpluses also, for, in effect at least, we had pooled our food resources with our fellows in Europe. Thus both Europe and America found themselves living a handto-mouth existence.

It was barely an existence, at that-at least for our allies in Europe. So terrible had the food shortage there become that the daily rations had been cut to the minimum that would sustain life and strength. The peasant population of continental Europe, which means a large part of the people, lives principally upon wheat in one form or another. In France bread is literally the staff of life, normally constituting 52 per cent. of the Frenchman's food. Yet the French bread ration was successively lowered until at one time it reached seven ounces a day per capita. In Italy, the sale of macaroni was entirely prohibited in certain districts, and the bread ration was cut to eight ounces a day. Hard-working laborers were allowed fifteen ounces. In both of these countries even the bread ration of the 
soldier was sharply reduced - a measure to which resort is had only in situations of direst necessity. Indeed, many well-informed persons attribute the disaster of 1917 on the Italian front to the lowering of morale consequent upon the cutting of the bread ration. The soldier well knew that if his food was cut his family must be well-nigh starving to death.

All Europe had to resort to meatless days. French milk production, as early as 1916 , had fallen off sixty per cent. Dairy products were so scarce in England that cream could be secured only upon a physician's certificate declaring it necessary to the health of the recipient. Sugar consumption had to be rigidly restricted. The English, who before the war were the greatest users of sugar in the world, with an average consumption of something like ninety-three pounds a person a year, were restricted to twenty-six pounds per annum, and this ration was later cut to twenty-four pounds. The French were limited to thirteen pounds a year, and the sugar ration of the Italian was drastically cut to nine pounds a year. That is to say, persons of these nationalities were allowed to buy the quantities named when the foods were to be had, but often the food was not to be had. There were entire districts in France, for instance, where for days no bread at all was to be obtained and not much else. The actual consumption, therefore, was less than the ration allowed. Our own consumption, too, was sharply reduced. Through meatless and wheatless days our use of wheat and flesh was greatly lessened, while the high prices of butter, eggs, 


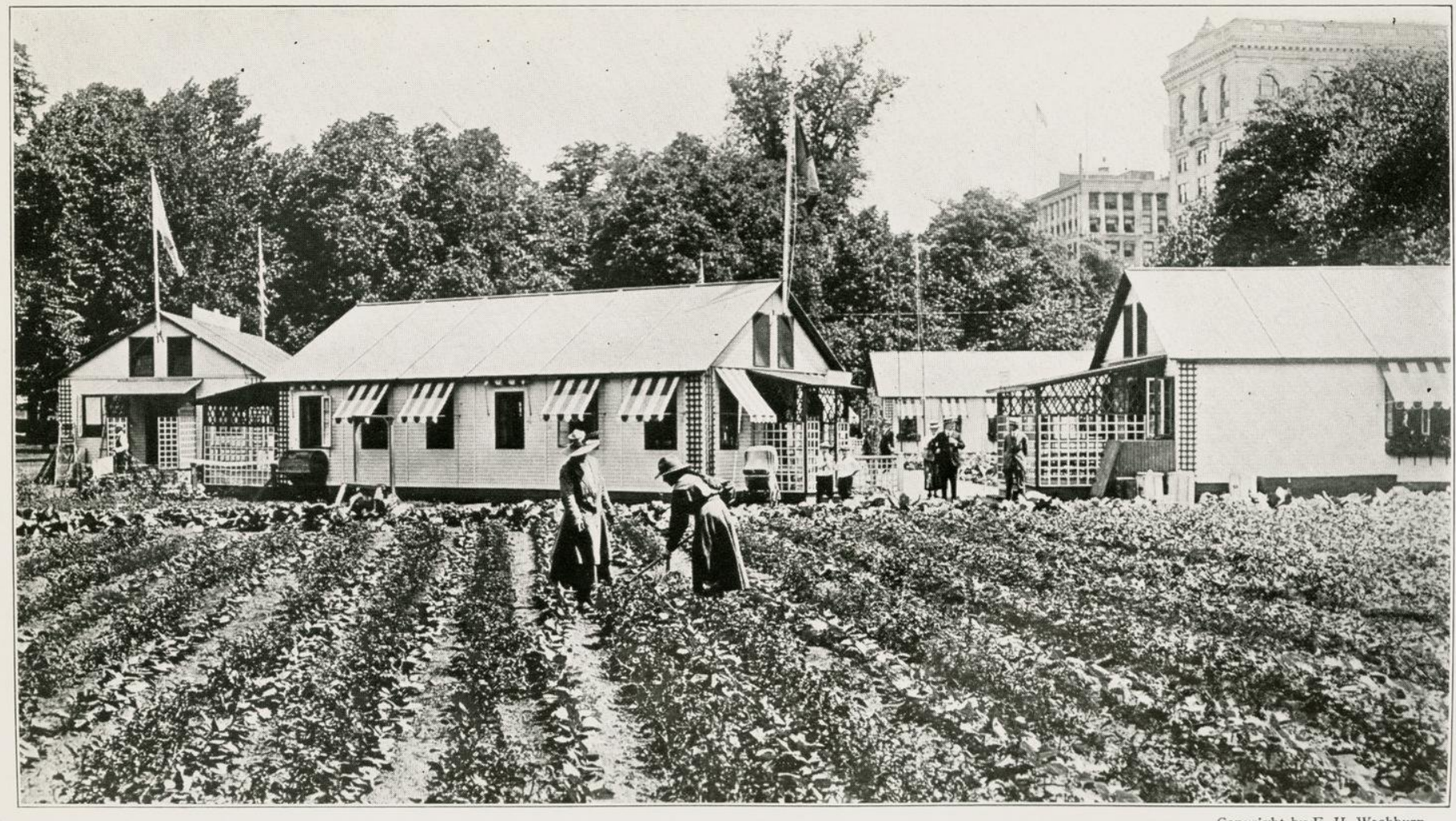

ON HISTORIC GROUND

Copyright by E. H. Washburn.

Boston Common was credited with having one of the finest demonstration war gardens in the United States in I918. This shows the quarter-acre section given over to potatoes, with Girl Scouts assisting in the cultivation. The gardens were planted by the Women's City Club, with experts on hand to give instruction and advice to visitors. 

milk and other foods very materially aided in cutting consumption generally.

Lessened consumption, however, was not enough. There had to be increased production. Obviously Europe could not raise any more food than it was raising. Since America was the only country from which it was possible for Europe to draw food, it became necessary that we should enlarge our yields. The children of Israel could not make bricks for Pharaoh without straw; and when we attempted to create food for famishing Europe we experienced similar difficulty, though our shortage was of man-power. For a decade or more there had been a tremendous exodus from our farms. Our farmers cried for help, but their cry went unheeded until we found ourselves facing hunger. Then it was too late. It would have been as easy to put Humpty Dumpty together again as to bring back to the farm the thousands of boys and men who had been lured away by high wages in town and factory. How enormous had been this exodus from the farms we cannot tell accurately; but we know, from surveys made by the state, that, a decade ago, Pennsylvania had 160,000 farm hands as against 80,000 in 1918 ; and that in New York State in 1918 there were 45,000 fewer farm hands than in 1917 , and 40,000 fewer farm girls. Every agricultural section of the nation was short-handed. When the crisis came, when the production of more food was absolutely imperative if the forces fighting for freedom were not to be starved into surrender and submission, our farms were found stripped of helpers. Our agri- 
cultural system, weighed in the balance, was found wanting. The war drums which had called 3,000,000 men from the farms of France, had also created the lure of high wages in munition plants, and further robbed the farms of America. When the appeal went out to our farmers to produce more food they replied in a memorial to the President, that under existing conditions the previous rate of production could hardly be maintained, let alone increased - a prophecy which later proved true.

In the lexicon of the typical American there is no such word as "cannot." Keen-eyed Americans who saw the situation as it really was, decided that if the mountain would not go to Mahomet, they would see that Mahomet went to the mountain. The mountain in this case was labor, and Mahomet the space necessary for the production of food. These men, with that vision without which the people perish, possessed imagination. They saw little fountains of foodstuffs springing up everywhere, and the products of these tiny fountains, like rain-drops on a watershed, uniting to form rushing streams which would fill the great reservoirs built for their compounding. The tiny fountains were innumerable back-yard and vacant-lot gardens. The problem was to create these fountains.

This could be accomplished only by the systematic education of the people, the one hundred million people of the United States. Such a huge educational campaign could be carried out only through the customary channels of publicity-the daily press, the periodicals, 


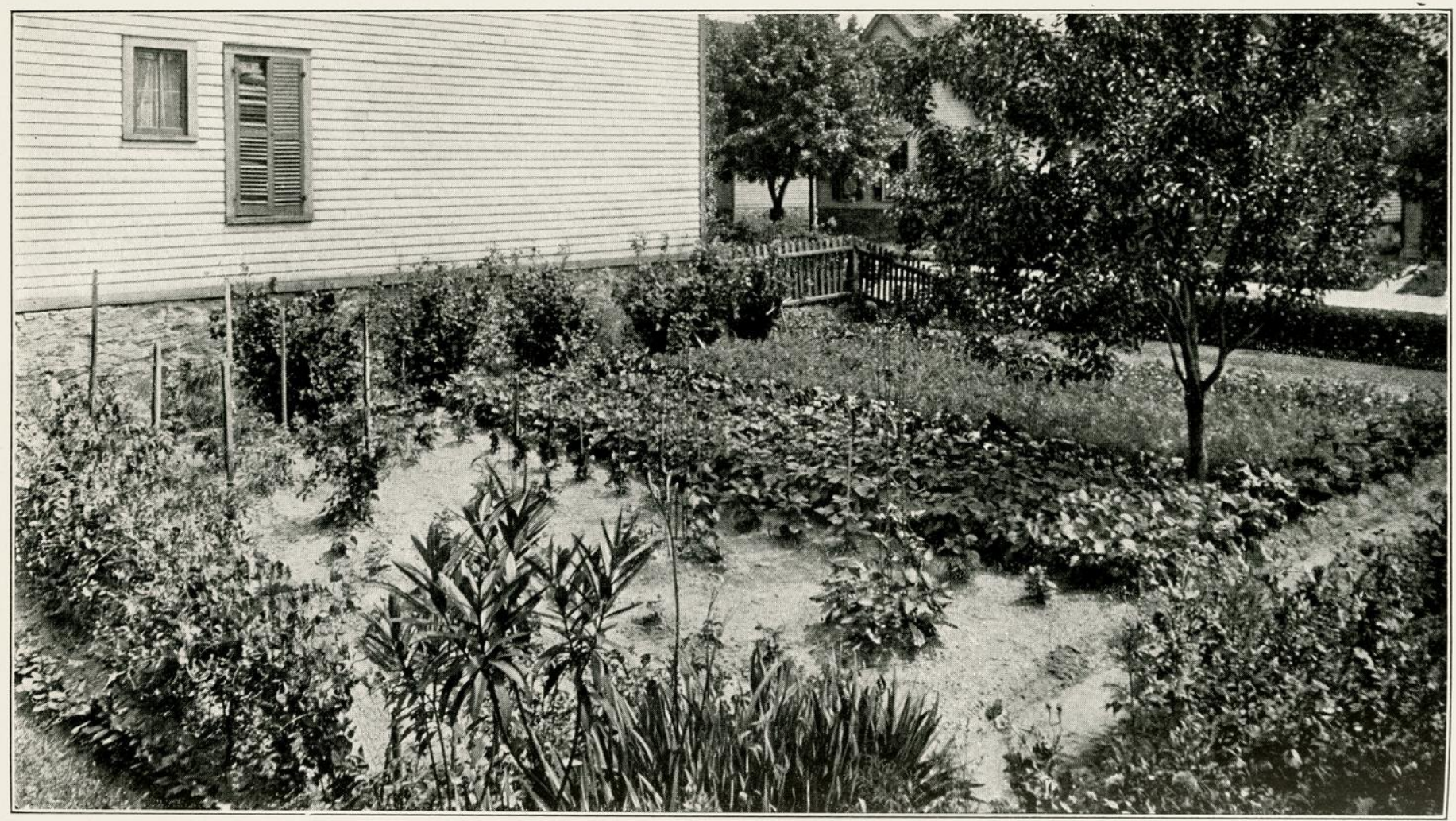

A TYPICAL CITY GARDEN

Every large community throughout the country contains hundreds of plots like this which can be turned into valuable gardens. This one is in the city of Rochester, New York, which had more than 15,000 war gardens in I9I 8 . A big exposition was held in the Fall which att
of many thousands of people, not only in the city, but throughout that entire section of the state. 

the bulletin-boards, and other usual avenues. Oddly enough, it is usually hardest to influence man for his own benefit. The matter of home food production was no exception to the rule. Before the people would spring to the hoe, as they instinctively sprang to the rifle, they had to be shown, and shown conclusively, that the bearing of the one implement was as patriotic a duty as the carrying of the other. Only persistent publicity, only continual preachment, could convince the public of that. Hence it was necessary that the campaign of education be well-conducted and continuous. This called for the creation of an organization to back the movement and assure its standing. The author, therefore, realizing the need of developing latent resources of food supply, and after consultation with other men who were eager to do their duty in the circumstances, conceived and organized the Commission.

This organization consisted of Charles Lathrop Pack, President, of New Jersey; Luther Burbank, California; P. P. Claxton, United States Commissioner of Education, Washington, D. C.; Dr. Charles W. Eliot, Massachusetts; Dr. Irving Fisher, Yale University, Connecticut; Fred H. Goff, Ohio; John Hays Hammond, Massachusetts; Fairfax Harrison, Virginia; Hon. Myron T. Herrick, Ohio; President John Grier Hibben, Princeton University, New Jersey; Emerson McMillin, New York; A. W. Shaw, Illinois; Mrs. John Dickinson Sherman, chairman of the Conservation Department of the General Federation of Women's Clubs, Illinois; Capt. J. B. White, Missouri; Hon. James Wil- 
son, former Secretary of Agriculture, Iowa; Assistant Secretary of Agriculture, Hon. Carl Vrooman, (for the year 1917); P. S. Ridsdale, Executive Secretary, who was also Executive Secretary of the American Forestry Association, with the Conservation Department of which the Commission was affiliated, and Norman C. McLoud, Associate Secretary.

The sole aim of the National War Garden Commission was to arouse the patriots of America to the importance of putting all idle land to work, to teach them how to do it, and to educate them to conserve by canning and drying all food they could not use while fresh. The idea of the "city farmer" came into being. In every part of the country were communities where land and labor were already together, where it would be necessary to move neither the mountain nor Mahomet. Near every city were vacant lots, "slacker lands," as useless as the human loafer, to whom, perhaps, Mahomet must be brought. Whether the land to be cultivated was a back yard or a vacant lot, it was a potential source of food supply, and the raising of food on these areas would solve many problems besides that of food production. Food raised by the householder in his yard or a near-by lot, was "Food F. O. B. the Kitchen Door." There were no problems of transportation or distribution to be solved in such food production.

The creation of an army of soldiers of the soil presented much the same difficulties presented by the creation of any other army. First of all there was the matter of recruiting. This was a purely volunteer move- 


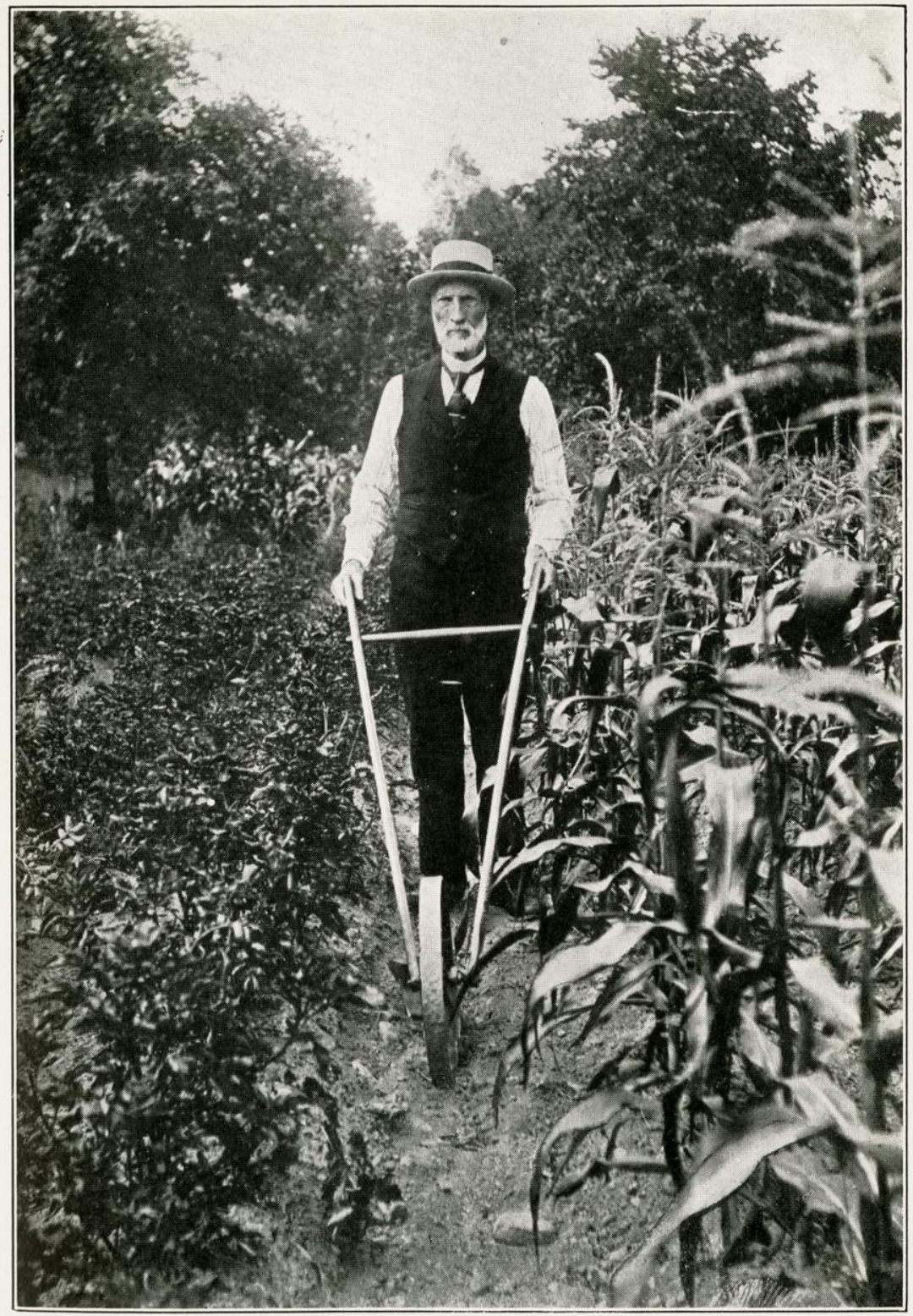

A VETERAN WAR GARDENER

There were hundreds of men and women throughout the United States who had passed the three-score-and-ten mark who tilled and cared for their own garden plots. This is Lewis Hunt, of Pearl River, New York, eighty-one years of age, who on his half-acre back yard raised a large supply of vegetables, while his daughter canned the surplus for winter use. 

ment and all recruits must come through voluntary enlistment. Then it was necessary to point out the importance of the work and to create enthusiasm for gardening. Next, it was necessary to train the recruits. Intelligent instruction had to be furnished, for many of these new soldiers of the soil had never before handled a hoe or a garden fork. As the campaign progressed it was found that the best results could be obtained by organizing communities. Hence it became necessary to outline methods for community organization. So unexpectedly great was the response to the campaign that it proved essential to turn attention to the matter of food conservation, to the preservation of surplus products which the garden campaign had brought into being. The function of the Commission, therefore, was to awaken interest in both food production and food conservation and to provide instruction along each line of endeavor. 


\section{CHAPTER II}

THE STORY OF THE WAR GARDEN

How American Gardeners Sowed the Seeds of Victory

WHILE the organizers of the War Garden Commission were optimistic and looked forward confidently to the accomplishment of large results, they little dreamed that the war-garden movement would grow so rapidly. The war-garden idea struck a patriotic chord. The American people answered the call to help win the war by producing food in their back yards with the same unanimity and enthusiasm they had shown in responding to each other appeal the country had made for service. One reason for the prompt and eager response to the National War Garden Commission's appeal to "Sow the Seeds of Victory," was that immediately after the United States entered the war everybody was patriotically desirous of rendering help in some form. Millions of people realized that they would never be able to take part as actual soldiers in the great task of overthrowing Prussian militarism. Because of this they wanted to take an active part in some effort which would show tangible results in the struggle for right and justice.

War gardening offered the opportunity. Although small home plots might not produce large amounts of food, such gardens made possible the saving of some of the wheat and meat and other foods which were 


\section{WAR GARDENS OVER THE TOP}

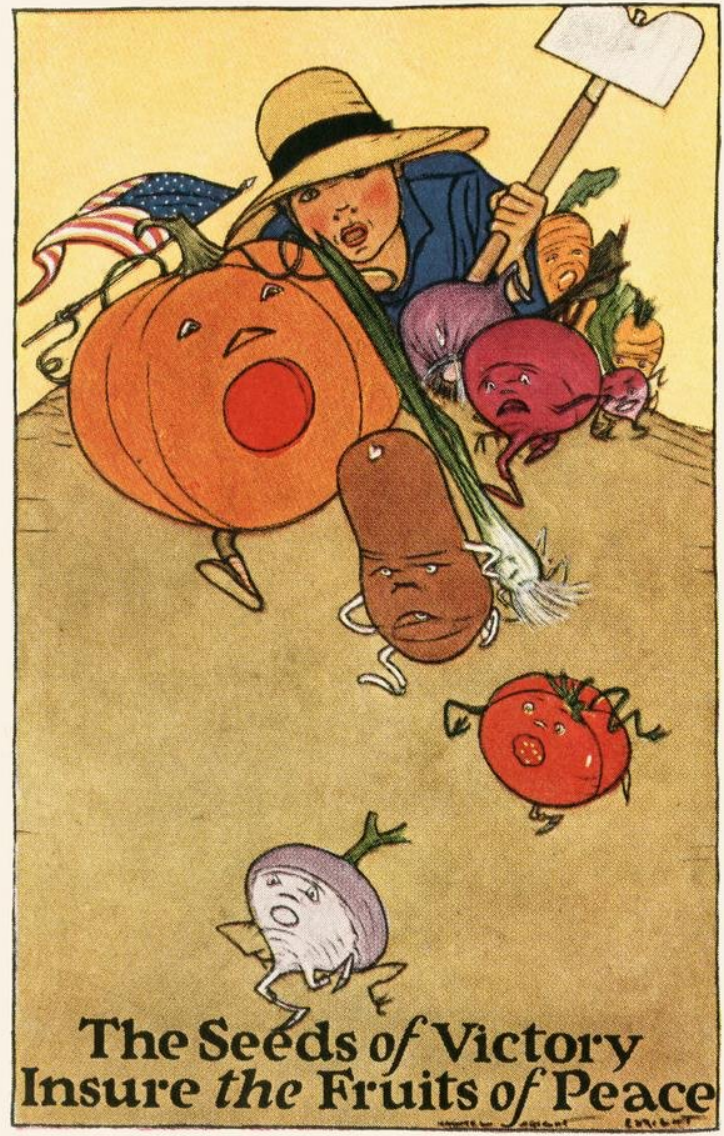

Copyright, 1919, National War Garden Commission.

FOR FREE BOOKS WRITE TO NATIONAL WAR GARDEN COMMISSION Charles LathropPack, President Percival S.Ridsdale, Secretary A POSTER SPREADING THE IDEA OF MILITANT WAR GARDENS 

needed by our army and which were practically the only kinds of food that could be shipped to our allies. Every pound of beef that could be saved through the growing of food at home, it was realized, would bring victory just so much nearer; and in fact, without food conservation, there was positive danger that the Central Powers would be able to have their way.

The food shortage faced by Great Britain, France, and Italy during the winter of $1917-18$, the seriousness of which was not realized by the people of this country until long after the danger was passed, showed the wisdom which led to the saving of every particle of food. The ability of the United States to respond so magnificently to the appeal of the late Lord Rhondda, then Food Controller of Great Britain, for 75,000,000 additional bushels of wheat early in 1918, was made possible in part by substituting in the dietary, wargarden products for the customary commercial supplies.

Once embarked upon participation in the war it became evident that this nation would need to exert every ounce of her power in the prosecution of the conflict. In various localities anti-loafing laws were speedily enacted to put every man to work. Since food was even more necessary than man-power, it was of still greater importance to put to use every particle of "slacker land"-idle soil so located that it could be worked. In our cities and towns, where the manpower was available to cultivate these areas, were thousands upon thousands of acres of idle real estate.

Few people realized the enormous aggregate acre- 
age thus standing useless. There was probably no town in the United States that did not have within its boundaries at least fifty acres of idle soil. In the larger communities where garden space was needed most, the aggregate area of vacant lots was astonishing. A survey made in Minneapolis, shortly before the war began, showed more than 5,000 acres in vacant lots. In 1917 a survey disclosed $\mathbf{1 8 6 , 0 0 0}$ vacant lots in greater New York. Altogether there were hundreds of thousands of idle acres in or near our towns and cities - the only places where labor was available for working them; and much of this land was suitable for gardening. It was of the utmost importance, therefore, to place these areas under cultivation.

In Great Britain steps had been taken very early in the war to utilize similar open spaces for the production of food. Parliament passed a law providing that any untaxed land which was not being used for the production of food might be taken over by the authorities and parceled out to those who were able and willing to raise food. Millions of "Allotments," as they were called, were asked for, and the production of vegetables increased incredibly. Thus the British were able in I9I 8 to produce all the potatoes they needed, and even to send a slight surplus to France. America possessed vast areas, in the aggregate, of these idle lands; but the importance of utilizing them for food production had not been generally realized, until pointed out by the Commission.

"Put the slacker land to work" became a slogan of the 


\section{WarGardensVictorious}

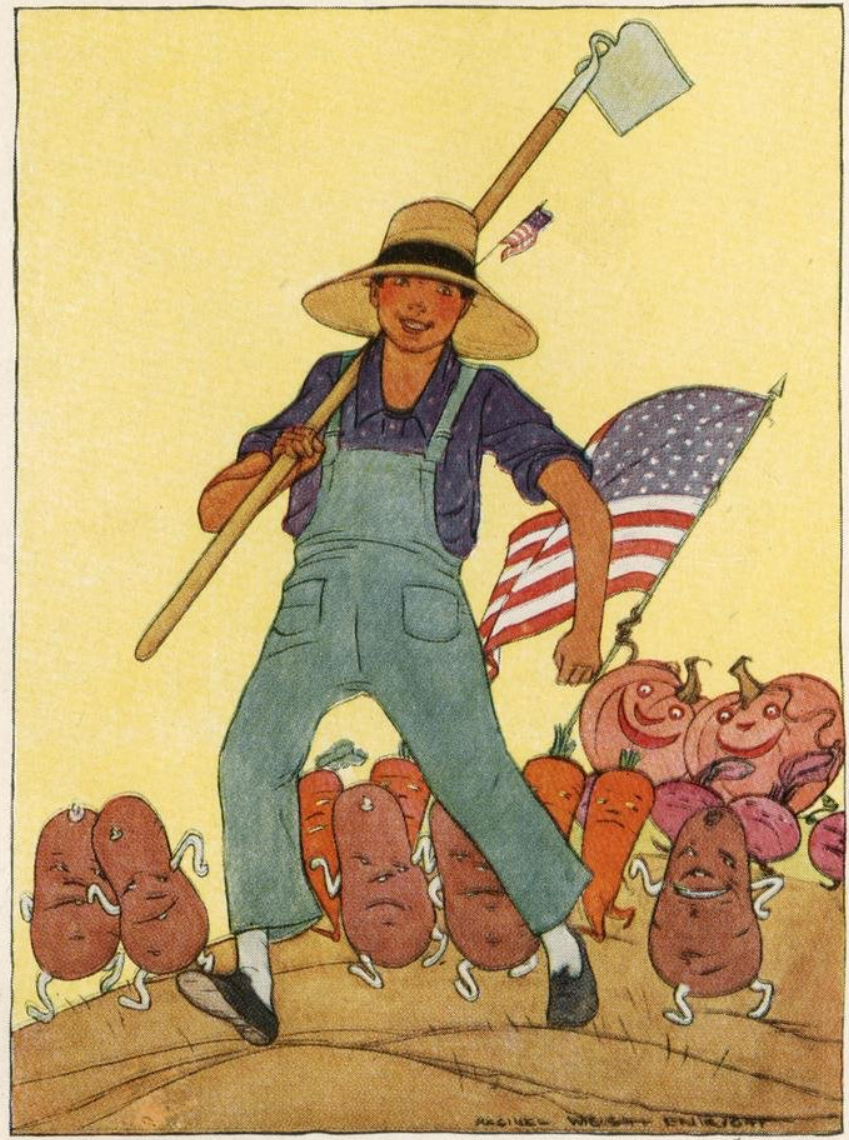

Copyright, 1919, National War Garden Commission.

\section{Every War Garden a Peace Plant-}

- Charles Lathrop Pack.President.

NATIONAL WAR GARDEN COMMISSION WASHINGTON, D.C.

A POSTER FOR 1919, SYMBOLIC OF VICTORY 

National War Garden Commission; and in response to its energetic campaign toward this end, the people in I917 put to work more than $3,000,000$ pieces of such uncultivated territory. In 1918 they ferreted out additional vast areas. The total number of war gardens for this latter season is conservatively estimated, after a careful survey, at 5,285,000.

With war's destruction occurring to an undreamed of and terrifying extent, involving the destruction of all kinds of material wealth as well as food, it soon became apparent that food shortage was only one of many shortages the world was facing. Conservation of everything became a crying need. The war garden offered an opportunity for conservation along many lines. First came the conservation of food itself. The daily ration of a soldier in our army consists of about four and a quarter pounds of food. A million soldiers would require at least 4,250,000 pounds of tood a day. At this rate a year's supply of food for a million men would weigh I, 55 I,250,000 pounds-and we were planning to raise an army of four or five million men. To take from the ordinary channels of trade the colossal supplies necessary to feed such an army, with no extra food to replace that thus subtracted, would mean that householders would be forced to pay ruinously high prices for the food that remained. War gardening offered an opportunity to offset, in part, this tremendous drain on our commercial supplies, to eke out those supplies and make them go farther-which is really conservation in its truest sense. 
War gardening promised to make many other things go farther. There was the matter of labor. There was only so much labor in existence. As the primary requisite of war, food would have the first call on labor, although other things besides food were needed. Cannon and shells and rifles and cartridges and uniforms and innumerable other articles were demanded in incomprehensible quantities. After taking four or five million men away from productive industry, obviously we should not have sufficient man-power left to create all that was needed of these various supplies. War gardening, by adding to the food supply, released for work on these lines men who otherwise would have been necessary on the farms. In short, war gardening conserved labor by making labor go farther.

The conservation, however, did not end with lessening the number of men needed on the farms. Commercial foods must pass through many hands before reaching the consumer. They must go through the hands of the farmer, the railroader, the wholesaler, the retailer, the city deliveryman. For instance, a cabbage bought in the market is handled by almost all the men enumerated. A cabbage grown in the back yard is "Food F. O. B. the Kitchen Door." No one needs to handle it except the person who produces it for he or she is also the one who eats it. Suppose that the average backyard garden produces only a hundred pounds of food, which is a ridiculously small estimate, as a single bushel of potatoes weighs sixty pounds. Based on this the $5,285,000$ war gardens of 1918 yielded at least 


\section{What are YOU doing?}

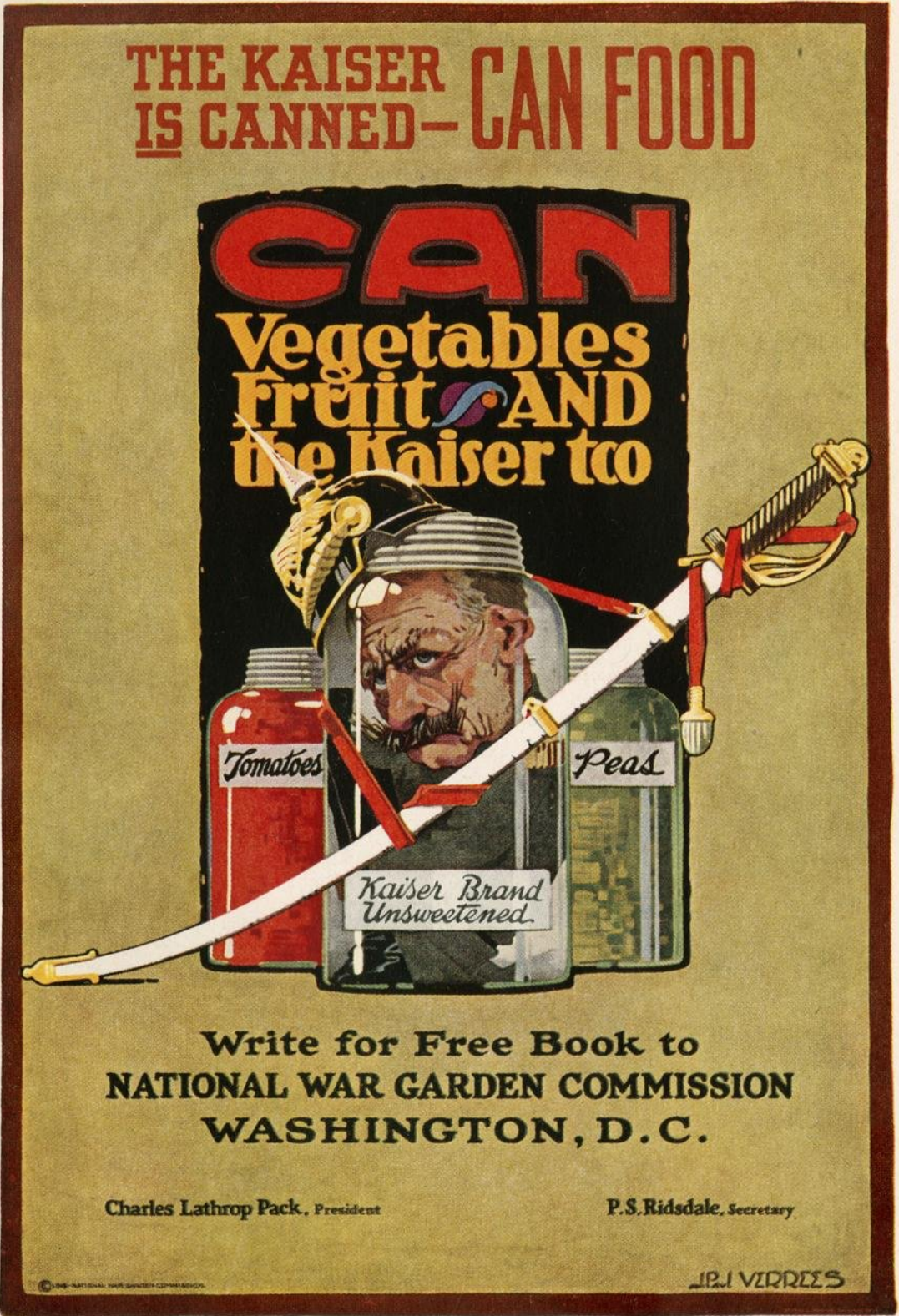

A POSTER WHICH WAS USED FIRST IN 1918 AND WHICH, AMENDED -FOLLOWING GERMANY'S DEFEAT-WAS ALSO FORCEFUL IN 1919 

$528,285,000$ pounds of food. Actually, as we shall see later, the yield was many times as great. Yet the handling of that vast weight of provender called for hardly a single public carrier of goods. The army of men which otherwise would have been needed to transmit this food from producer to consumer was thus released for other essential labor. It probably would not be possible to figure just how much was accomplished in this manner by the war gardeners of the United States; but it is safe to say that the men thus released for other work numbered many thousands.

While this conservation of labor was being accomplished there was a concurrent saving in still another way, through the release of thousands of freight-cars, motor-trucks, and wagons, for purposes other than the hauling of food. This saving, too, was most vital. At a time when every freight-car in the country was urgently needed for the hauling of raw materials to be used in the manufacture of munitions of war, for the transportation to the seacoast of finished products, and for hauling lumber and supplies to cantonments and army camps, it was essential that not one foot of freight space should be wasted. War gardening released thousands of cars for these essential needs. This saving, it must be remembered, involved also the conservation of coal and steam-power required in hauling, and prevented, as well, a great amount of wear and tear on railroad tracks and equipment.

To secure all these ends a campaign of education was necessary. This campaign had to be extensive in 
range and intensive in method. As an educator of the masses there is no power equal to the public press; and from the start, the Commission, had the cordial coöperation of the newspapers and periodicals of the entire country. Inspiration and detailed instruction were furnished through the columns of the daily newspapers. Articles and feature stories which dealt with various phases of war gardening and sought to stimulate the movement to the utmost were also prepared and sent broadcast.

These appeals soon bore fruit. Requests for instruction in gardening and in the organization of community gardening movements poured in from all sides. To the requests the Commission responded with carefully prepared pamphlets which gave the information desired. In addition, representatives of the Commission visited innumerable cities and towns to confer with the local chambers of commerce or other organizations which were directing gardening campaigns. As a result of this propaganda, war gardens sprang up as though by magic. Gardening came to be the thing.

In order that all this enthusiasm might be transmuted into substantial accomplishment, it was necessary that the army of would-be gardeners should have instruction, for many of them had never before handled a hoe or wielded a fork. Daily garden lessons were prepared therefore for the daily press. These lessons were short and simple, shorn of useless technicalities, but carefully prepared by experts. They were lacking in nothing essential. They gave the fundamentals of good garden practice, which would enable even a be- 


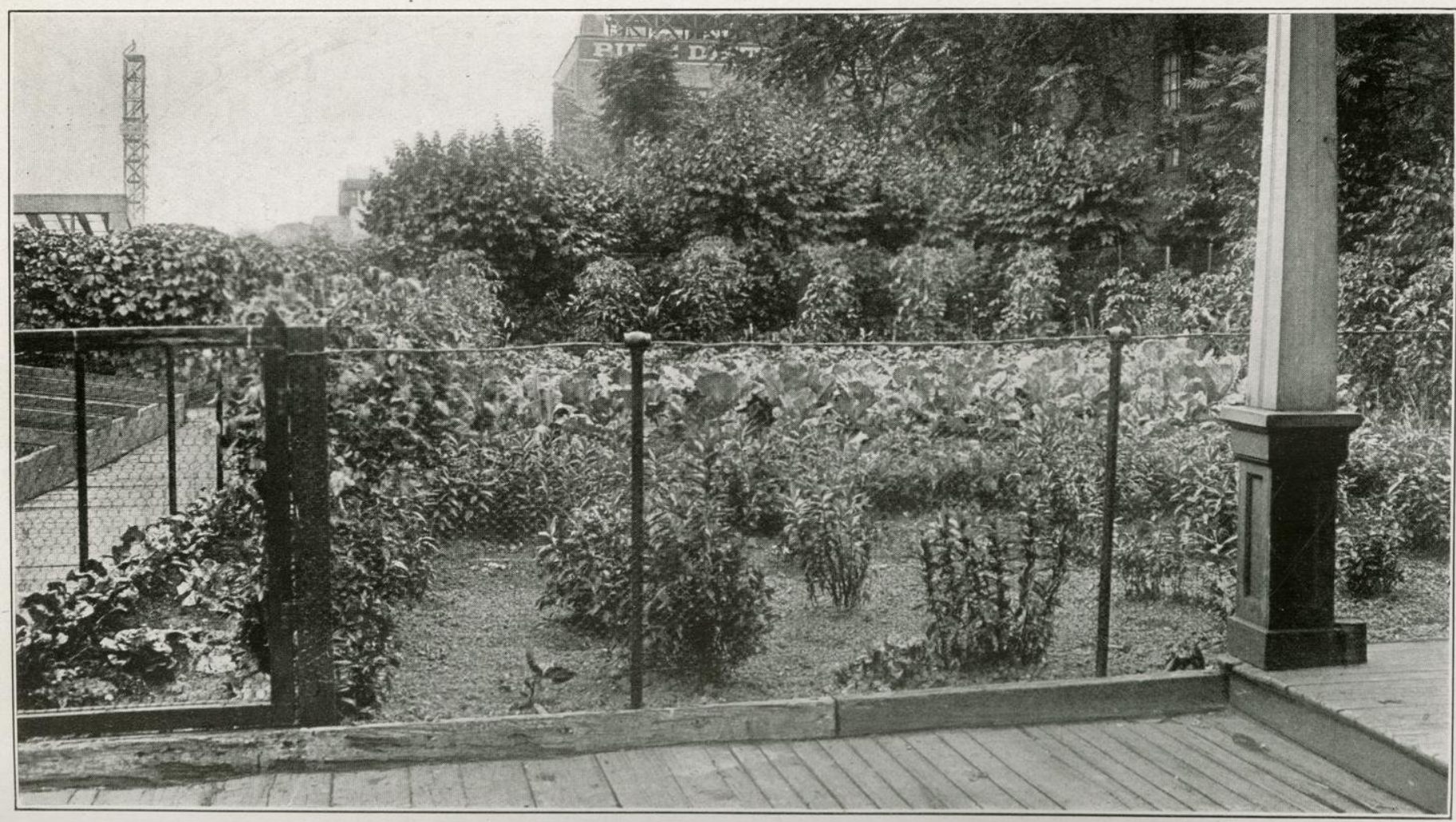

NO "SLACKER LAND" HERE Not a square foot of the vacant space has been allowed to go to waste. Vegetables are growing right up to the edge of the walks and the walls of the surrounding
buildings. This home food producer in East Liberty, Ohio, could almost gather his garden products without stepping off the porch. 

ginner to make a success of his endeavor. In addition a book was printed explaining how to plant and care for the different vegetables. A copy of this book was free to any one upon request and several million copies have been given away in response to requests. Many copies were also distributed through the agency of libraries, chambers of commerce, trade bodies, women's clubs, banks, manufacturing concerns and the like. Thousands of letters of appreciation prove how helpful were these books.

To encourage the conservation of garden products canning and drying manuals were prepared and distributed through the same channels which had handled the garden books, and daily lessons on canning and drying were sent to the newspapers for publication. The results were most gratifying. Editors everywhere devoted generous space to the articles sent them, including news stories, technical matter on canning and drying, and ample illustrations. Cartoonists, paragraphers, and writers of comics also made gardening their theme; and some of their productions the Commission scattered broadcast, to keep alive the interest in home food production and preservation.

The prose poem, sopopular these days, was used tocatch the eye and arouse the interest of "city farmers." Here is one, entitled "Let's Dig and Dig and We'll be Big:"

When I go down the village street in my perambulations, most every other chap I meet is asking for donations. They're seeking funds for Red Cross work, for hospitals and motors; they're holding up with con- 
stant jerk, all wives and kids and voters. I'm helping out from day to day, with no delays or pauses, tobacco funds, Y. M. C. A. and other worthy causes. I'm told that war bonds I must buy, in twos and fours and dozens, enough to make a full supply for all my aunts and cousins. For war stamps, too, those signs of thrift, I dig into my pocket, to give my Uncle Sam a lift in cleaning up his docket. I'm taxed for building wooden ships with good, old-fashioned rigging, and in my little daily trips I'm constantly kept digging. I dig to pay tobacco tax, and tax for railway travel. I'm always chipping from my stacks; they keep me scratching gravel. But I've no kick for those who come with all their pleas beguiling. It never makes me sad nor glum. They always find me smiling. I know that I'm too old to fight; I can't be caught renigging. So I regard it just and right that I should keep on digging. And then besides, it's proved to me that every man is bigger if he will teach himself to be a willing war-time digger. It's not enough for us to sing about the joy of giving. We've got to dig for everything we need to keep on living. We've got to dig in our back yards for carrots, beans, and 'taters; we've got to dig both long and hard as garden cultivators. So take your trusty hoe and spade and start your spring-time sowing. Just dig and get a garden made and set the foodstuff growing.

In order to catch the attention of the man in the street, several striking posters were prepared by the Commission and placed in conspicuous places in communities in every part of the land. On bulletin-boards, in railway stations, libraries, stores, at factory entrances, and even in clubs, banks and commercial houses, these striking posters met the eye. They were also repro- 


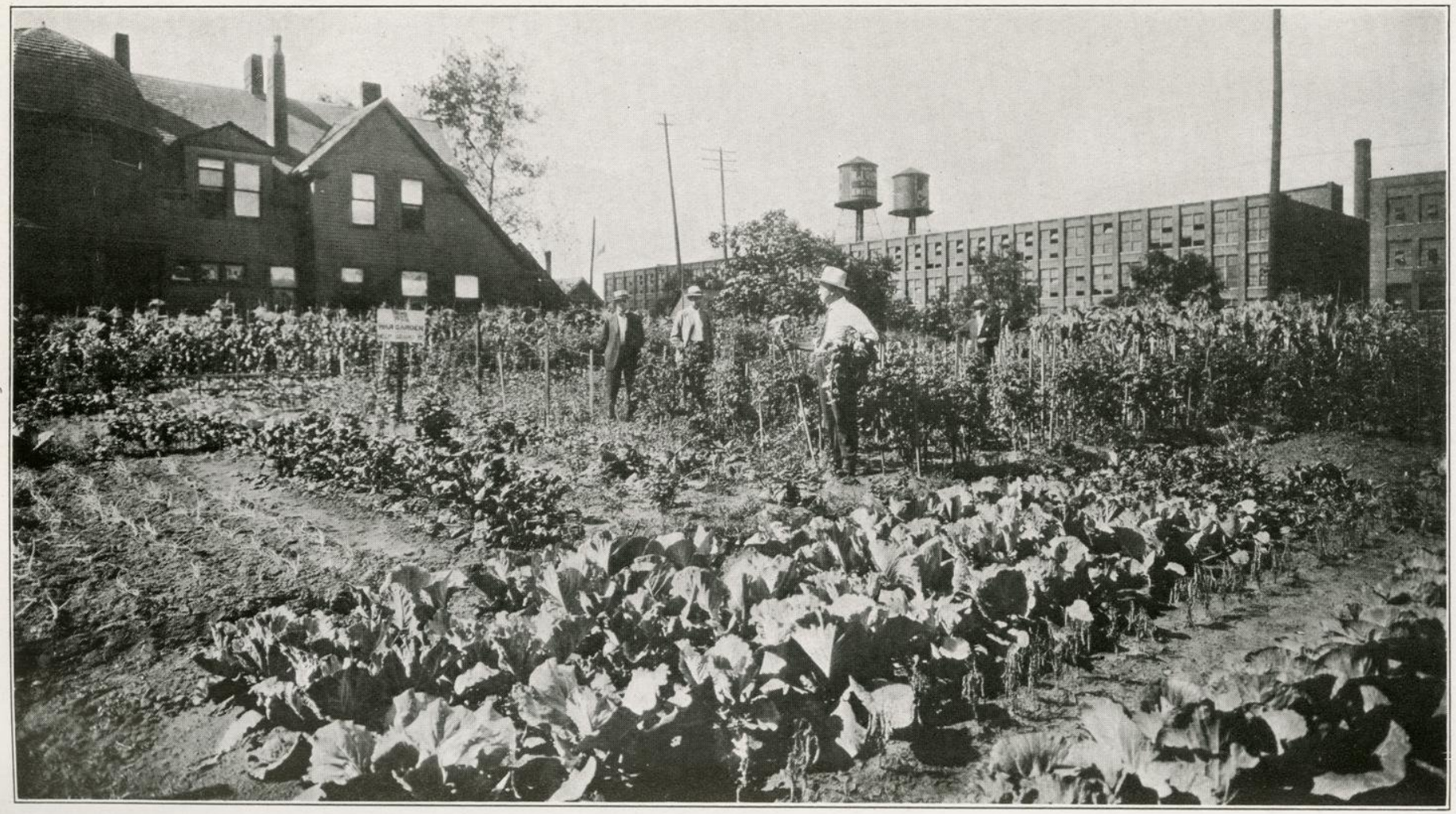

ONE OF CLEVELAND'S WAR GARDENS

Working under pressure to produce munitions for the armies did not keep the great industrial centers from developing their war gardens. Cleveland was notable for its success in "growing munitions of war at home." The Xavia garden on East Sixty-third street is here pictured as a typical home munition plant. 

duced in newspapers and magazines and thus scattered throughout the length and breadth of the land. Many were even sent to foreign lands in answer to requests for help in stimulating gardening.

These posters were the work of artists of national reputation. One of the posters, most beautiful in its richness of coloring and most striking in its patriotic appeal, was drawn by James Montgomery Flagg. It was entitled: "Sow the Seeds of Victory." At the bottom it bore another of the slogans of the Commission: "Every Garden a Munition Plant." This poster without doubt was a powerful influence in persuading many an American citizen to get into his back yard and help grow some of the "ammunition" needed in fighting the enemy. Another poster, by Frank V. Du Mond, showed the Goddess of Victory. Maginel Wright Enright created two striking posters for the Commission. They were entitled: "War Gardens Over the Top," and "War Gardens Victorious."

One of the posters used by the Commission in arousing the war gardeners of the country to the importance of conserving vegetables for future use, was popularly known as the "Can the Kaiser" poster. Most appropriately this famous poster was the work of a Belgian, J. Paul Verrees, a soldier-artist, who was wounded in one of the early battles of the war while helping to defend his country, and who, incapacitated for further military service, later came to the United States to follow his profession.

One of the most inspiring and satisfactory features 
of the rapid growth of the war-garden movement was the spread of the idea to foreign countries. Advice was gladly given to foreign inquirers, the Commission furnishing detailed information concerning the methods which had resulted in such general enthusiasm for war gardening in the United States. In response to numerous requests which came to the Commission from all parts of the world, large quantities of printed matter, including garden and canning books, posters, and pamphlets, were sent broadcast throughout the world.

"Kia Ora," the Maori way of saying, "Salutations to you all," was the greeting which came to the Commission from far-off New Zealand, in a letter of thanks from F. Carr Rollett, of the Auckland Herald, for data and material that had been sent. From Buenos Aires, Argentina, on the opposite side of the globe, C. D. Middlebrook, of the Sociedad Anonima La Blanca, wrote a hearty letter of appreciation for posters and other literature sent, saying that the posters were prominently displayed on the occasion of the entertainment of two hundred American bluejackets who visited this South American capital. "Down here we appreciate this class of propaganda," said Mr. Middlebrook, "and we are in a position to exhibit the posters where they can readily be seen by the public. Practically every American home and sympathizer displays them. We will do our part in making this propaganda public.",

From South and Central American countries, from Cuba, India, China, Japan, the Philippines, Alaska, Hawaii, South Africa, and from a number of European 


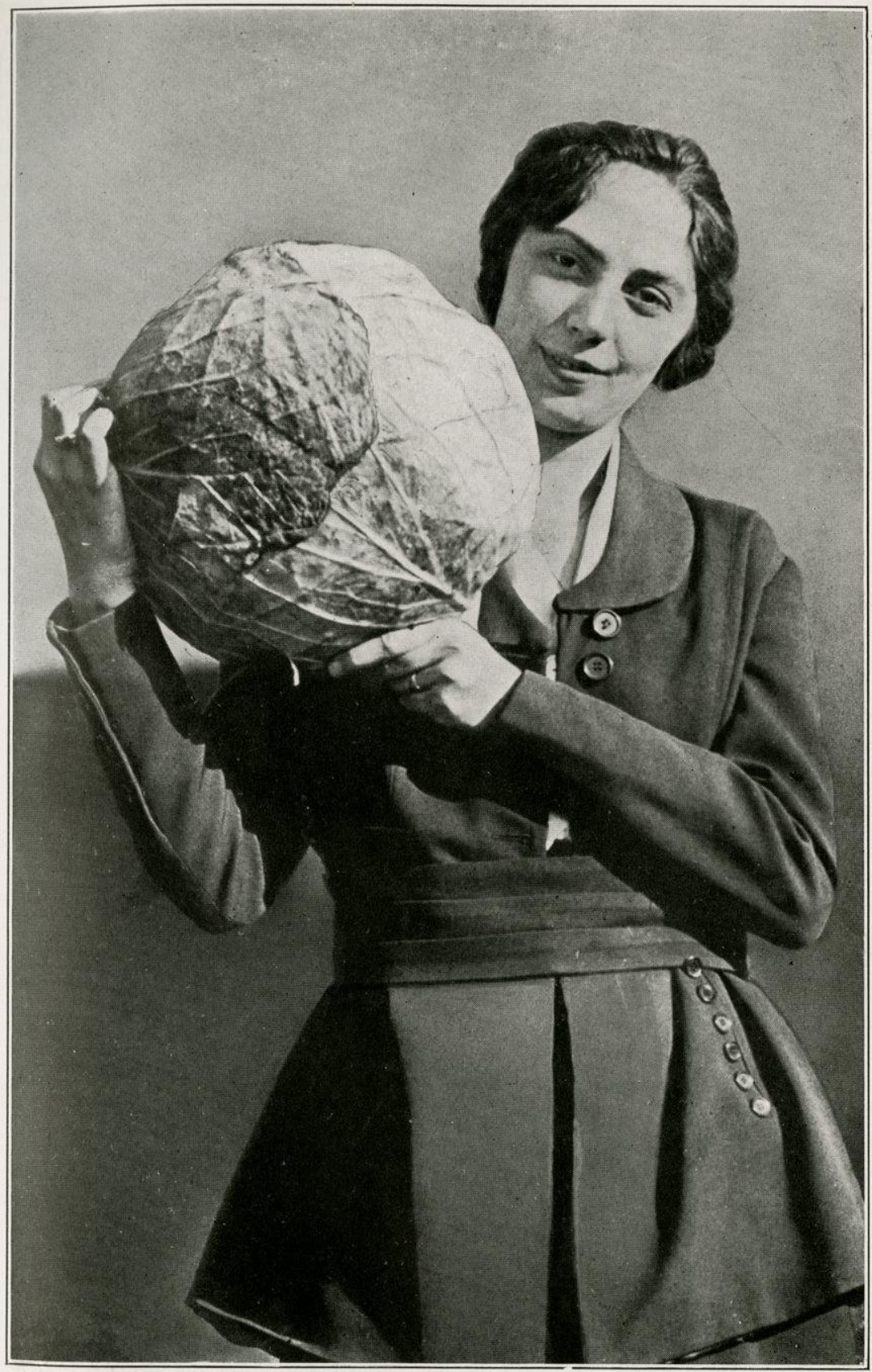

NO WONDER SHE SMILES:

Courtesy Minneapolis Journal.

Thousands of men and women who had never before the war raised a cabbage or a potato were just as much pleased as is Miss Dorothy Primm, of Minneapolis, over the results of their labor. They found that even amateurs could succeed. 

nations came requests for information and instruction on war gardening. Even Lord Rhondda, as British Food Controller, cabled a request for 5,000 copies of the Commission's book on gardening.

No new movement could have spread with such rapidity and been rewarded with such results as were achieved, had it not been for the loyal and whole-hearted manner in which state, county and town committees and officials of all sorts, as well as numerous individuals, coopperated with and supplemented the work of the Commission. With this help the results surpassed the most sanguine anticipations of those who initiated the war-garden movement. The first season saw the planting in the United States, according to the Commission's estimates based on reports from all parts of the country, of approximately 3,500,000 home food producing lots. The reports gathered in 1918 showed the number had increased to $5,285,000$ war gardens.

Furthermore, there was more intensive cultivation and a greater proportion of large-yielding gardens in I9I 8 than during the preceding year. The food value of the 1917 products was estimated at something like $\$ 350,000,000$. In the second year the value reached an estimated total of $\$ 525,000,000$.

It is estimated, likewise, that as a result of the garden and canning campaigns, there were put up and stored away on pantry shelves in 1917 more than $500,000,000$ quarts of canned vegetables and fruits; while in 1918 the number of such jars is believed to have been fully I, $450,000,000$.

Assuredly tall oaks from little acorns grow. 


\section{CHAPTER III}

\section{HOW WAR GARDENS HELPED}

Every Gardener Became a Soldier of the Soll

THAT the "three R's" mean to preparation for a life of peace, the three M's become in the conduct of war. These three M's stand for men, money and munitions. In its broadest sense, the term munitions includes everything needed by an army, and of all an army's needs the basic and most important is food.

The quantities of food required by our army are huge. Dietitians estimate that the average man needs, daily, food that will furnish 3,500 calories. The United States army ration allows 4,700 calories to each man, and the unusual exertions demanded of our soldiers make it quite necessary that they have this generous allowance of food. With less they might lack that abundant supply of muscular and nervous energy upon which their very lives depend.

Stated in terms of avoirdupois, the United States army ration is slightly in excess of four and a quarter pounds of food a man per diem. Four pounds of food does not seem like a great quantity. It allows each soldier twenty ounces of fresh beef a day, or its equivalent in fresh mutton, bacon, fish, turkey or other meat; eighteen ounces of flour or bread; twenty ounces of potatoes with proportionate amounts of other vege- 
tables; 3.2 ounces of sugar; 2.4 ounces of beans or I.6 ounces of hominy or rice; and prunes, apples, peaches, jam, milk, coffee, butter, and so forth, in smaller quantities.

When these amounts are multiplied by a million, the total bulks as huge as the Rockies. It means $4,250,000$ pounds of food daily, for seven days a week, and for fifty-two weeks each year. To feed an army of $1,000,000$ men for one month, according to the quartermaster's department of the United States army, there are required 973,000 pounds of butter, I,000,000 cans of corned beef, I,000,000 cans of corned-beef hash, $2,000,000$ cans of beef, $2,400,000$ pounds of coffee, $3,000,000$ pounds of sugar, $6,000,000$ pounds of bacon, $23,000,000$ pounds of frozen beef, $37,500,000$ pounds of flour, and other articles in proportion.

As the United States raised an army of $4,000,000$ men, the quantity of food that had to be provided was four times as great as the amounts named or 3,892,000 pounds of butter, $4,000,000$ cans of corned beef, 4,000 ,ooo cans of corned-beef hash, $8,000,000$ cans of beef, $9,600,000$ pounds of coffee, $12,000,000$ pounds of sugar, $24,000,000$ pounds of bacon, 92,000,000 pounds of frozen beef, and $150,000,000$ pounds of flour, not to mention the "and so forths." This huge total sufficed to feed our completed army for one month only.

A year's supply for this completed army required, in round numbers, $46,704,000$ pounds of butter, 48,000 ,ooo cans of corned beef, 48,000,000 cans of cornedbeef hash, 96,000,000 cans of beef, II $5,200,000$ pounds 
of coffee, I44,000,000 pounds of sugar, $288,000,000$ pounds of bacon, $\mathrm{I}, \mathrm{IO} 4,000,000$ pounds of frozen beef, and $1,800,000,000$ pounds of flour.

So huge are these figures that to the average person they are meaningless, but that these army demands constituted a terrific drain on our commercial food supplies was .evident to everybody. Practically all of this food was food diverted from its accustomed channels. Not an ounce of it went to the feeding of the civilian population which formerly had practically all of it. At the same time, if our allies were to be saved from utter collapse through hunger, and our own country saved from the plight of having to carry on the war single-handed and alone, it was essential that greater quantities of food be sent to Europe than America had ever before exported. After the war ended, and it became necessary, in some measure, to provide for the population of the enemy countries, still larger demands for food for export were to be expected. The very causes that had produced these conditions had, as we have seen, so stripped the farms of men that a food production commensurate with the needs of the situation was an impossibility.

"Those who cultivated the soil could hardly do more than they were doing," said Luther Burbank, a member of the National War Garden Commission, in speaking of the matter. "It was becoming evident that food, which before had been taken as a matter of course, was in reality the foundation of all life, all knowledge, all progress. What could be done? It became 


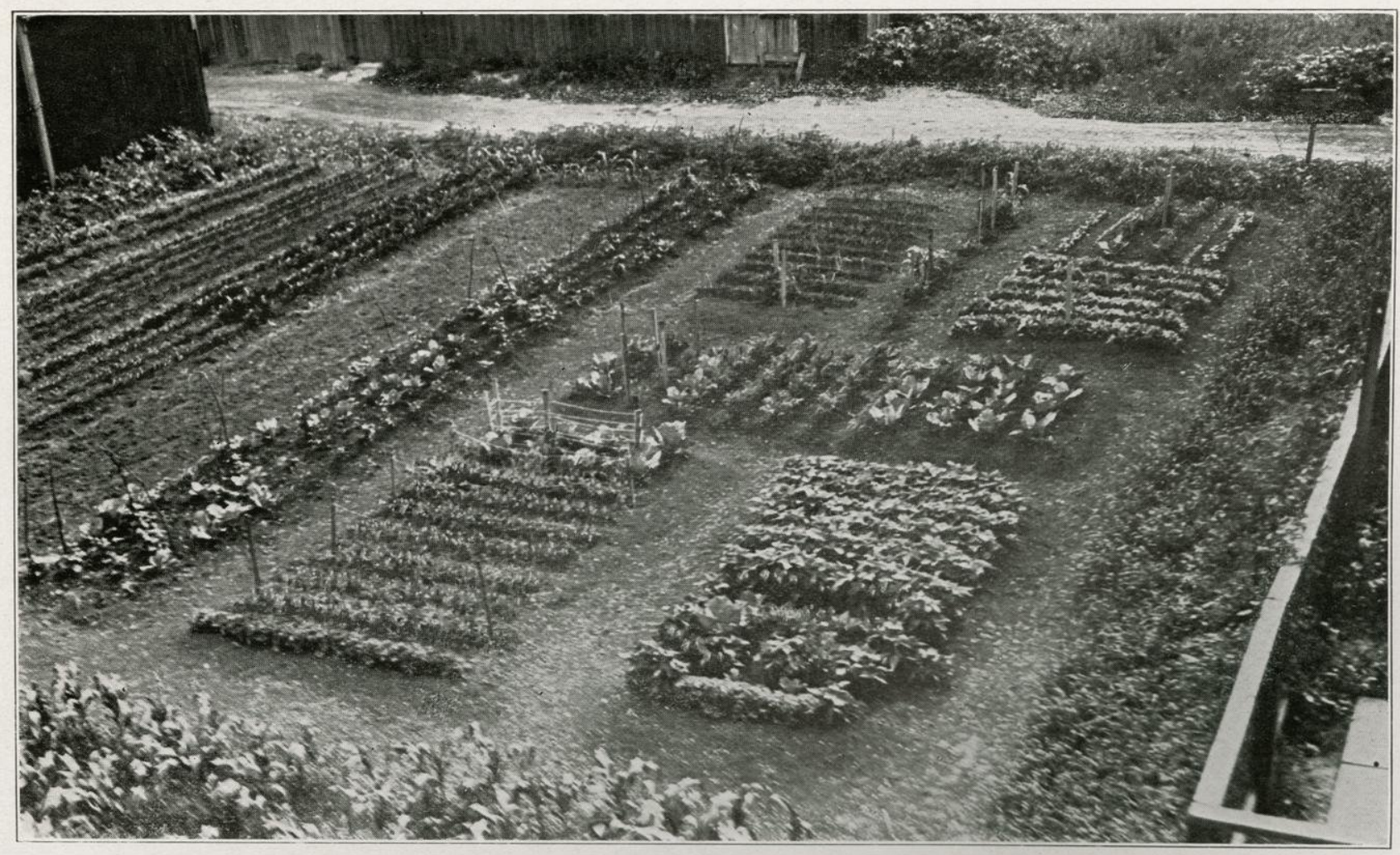

GARDEN OF A CHICAGO AMATEUR

W. E. Babb, a newspaper reporter in the Illinois metropolis, decided in the spring of 1918 that he would give war gardening a trial although he had doubts as to what the results would be. What he accomplished is only partly shown in the picture, for he carried off a first prize of $\$ 100$. Contrast his orderly looking plot with the weed-covered tract across the road. 
और 
necessary to conserve carefully what already had been produced, and then produce more. Agriculture and horticulture had not generally been taught in the schools; the old hit-or-miss plan of farming was all too common; the home garden was neglected and the school garden a novelty. To the call both to conservation and to increased production, the American people have responded nobly. How quickly they have changed their attitude, how splendidly they have made good by adapting themselves to the new conditions! When the war garden movement was started, the problem of food production was on the way to be solved."

Here, then, was the all-impelling, the all-important reason back of the home food production movement. This was the outstanding motive above all others which made the war garden a thing not only to be desired but actually to be demanded. Our allies and the neutrals, as far as possible, as well as our own people and our army, must be fed-this was the cry from the tower-top, this the call of hungry peoples which had to be answered. Our task was Herculean!

There was one great difficulty in the road to accomplishment: the problem of common psychology. It is recorded that when God called Moses to lead his fellows forth from Egypt; Moses replied: "Who am I, that I should go unto Pharoah, and that I should bring forth the children of Israel out of Egypt?" Even so did the average American regard the appeal made to him to raise food and save the world from starvation. The difficulty was that the average American, like the 
deliverer of Israel, lacked imagination. He could not visualize the collective contributions of millions of backyard and vacant-lot gardens. He was like the little girl, who, when asked to save a slice of bread to help feed the army, replied: "Papa, I don't see any reason why I should save a slice of bread. It can't feed an army." Her father took her down to the harbor in New York City and showed her a great transport at the wharf, waiting for food to carry to Europe. He then told her that if every little schoolgirl in the United States saved a slice of bread a day, their combined savings would fill eight large transports every week. Her blue eyes opened wide as the great truth flashed upon her, and after that she didn't want to eat anything at all.

In his nursery days, the average American had learned that

Little drops of water, little grains of sand, Make the mighty ocean and the pleasant land.

Unfortunately, however, that infantile lesson had been put away with other childish things when he became a man. The task the National War Garden Commission set itself was to make the average American feel the full truth, the actual force, of that childhood jingle. The truth - the truth that was to set us freewas striking enough. Among the garden records of the National War Garden Commission is the story of a certain garden in Pennsylvania, which was very much like other American back-yard gardens in many respects. 


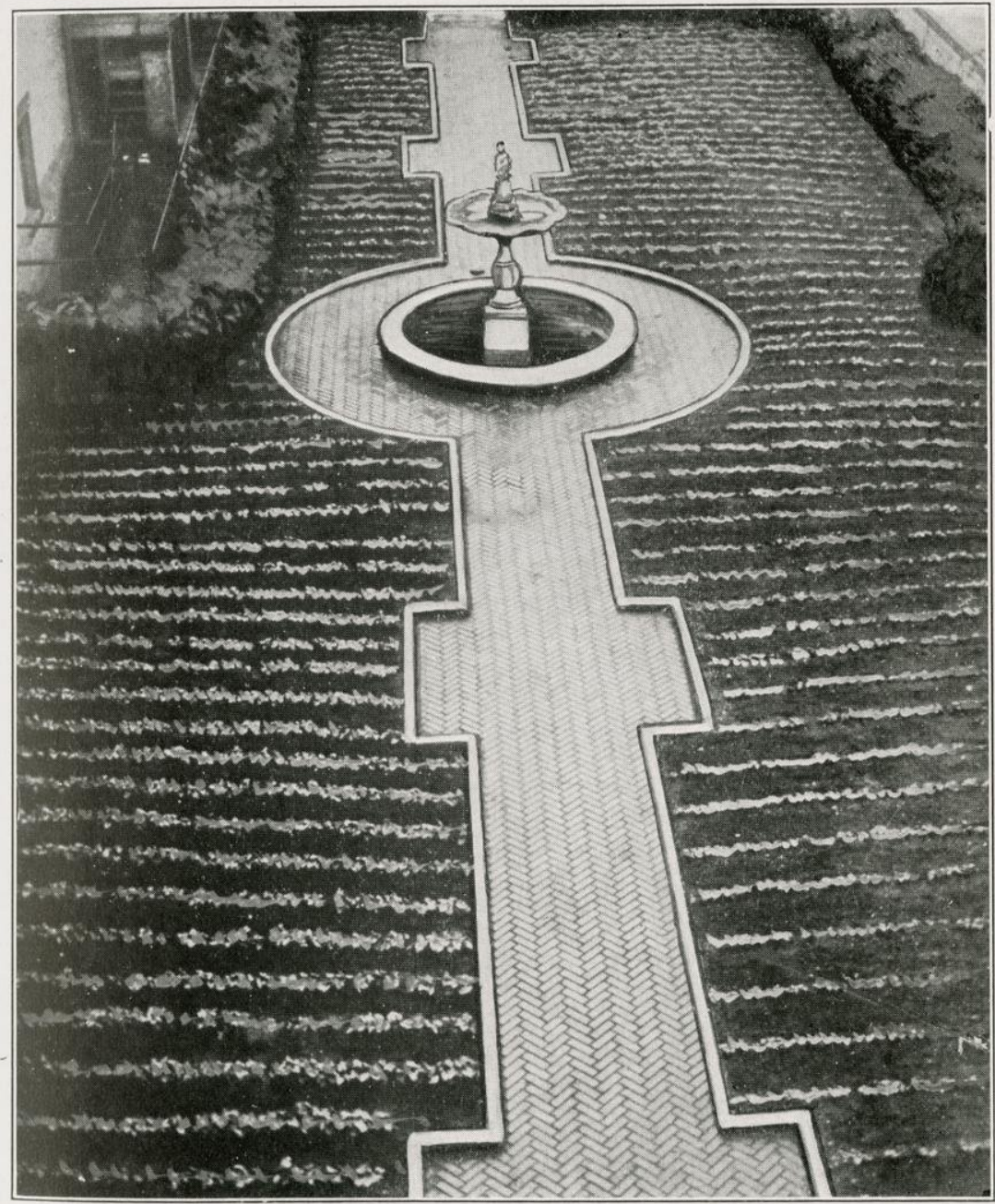

IN AN ITALIAN GARDEN

In New Haven. Connecticut, the side lawn of a handsome home was converted into a food plot. In addition to growing a lot of vegetables, so delighted was the owner that she said never again would her family be without the pleasure which this experience had given them. 

In size it was $40 x_{4} 0$ feet. The gardener kept a careful record during one entire year of the quantities of food produced in that garden. His figures are as follows:

Beets -25 bunches

Carrots-2 pecks

Radishes-I 5 bunches

Rutabagas - 64

Early peas -32 quarts (pods)

Potatoes -7 pecks

Cabbage-20 heads

Cauliflower-I4 heads

Tomatoes -6 baskets

Bunch beans-21/2 pecks

Telephone peas-40 quarts (pods)

Peppers $\rightarrow 9$ dozen
Cucumbers-roo

Celery - 450 stalks

Rhubarb-Io bunches

Scallions -12 bunches

Parsley-used freely

Dried beans for winter use- 20 quarts

Peaches, from two trees in corner of garden $\rightarrow$ baskets

Lettuce-equivalent of 60 heads

Horseradish-all desired

Onion sets -3 quarts

Onions dried- $1 / 2$ bushel

Pole beans-108 quarts

If this production, such as could be had from any ordinary back-yard garden with good soil, were reduced to pounds and ounces, it would be found that this one yard had yielded considerably more than half a ton of foodstuffs. It is reckoned that there are more than $20,000,000$ families in the United States. If every family could have a garden, and each garden could yield half a ton of food, the total annual production would aggregate $10,000,000$ tons, or almost twice as much in weight as we normally shipped to Europe in a year in pre-war days. Of course it was not possible for each of our $20,000,000$ families to have a garden, but with 45 per cent. of our people living in the country or in small towns, and with such vast areas of vacant lots in the larger cities, it would be entirely possible to have $10,000,000$ war gardens. These gardens, could they produce at the rate of this Pennsylvania garden, would yearly supply in weight as much food as before the war we annually shipped to Europe. 
Such were the possibilities of garden production that stimulated the National War Garden Commission to maximum effort.

Of course, garden food does not possess, pound for pound, anything like the food value of the concentrated foods sent to our allies and to our armies, but garden food is provender, and it is wholesome food. Peas and beans are great meat-conservers; potatoes, both sweet and white, important cereal-savers; and a little larger bulk of many garden products, such as potatoes, will take the place of a smaller quantity of meat or other concentrated foods. To figure out the exact food values of the total products that might be raised in our gardens is of course both impossible and unnecessary. The point is that millions of pounds of food could be produced right in our own yards and in neighboring vacant lots and that by eating these foods we should so lessen the demand on our commercial supplies that these would be sufficient to meet the heavy demands upon them.

To reach the entire population of the United States, to convince one hundred million people of the necessity of gardening, and to convince them to the point of action, was such a colossal task that the Commission hardly dared to hope for the creation of more than one million war gardens during the first year of its activities. Yet the estimated total was in excess of $3,000,000$; and in 1918 a very careful canvass set the number of such gardens at $5,285,000$.

What these war gardens actually accomplished to- 


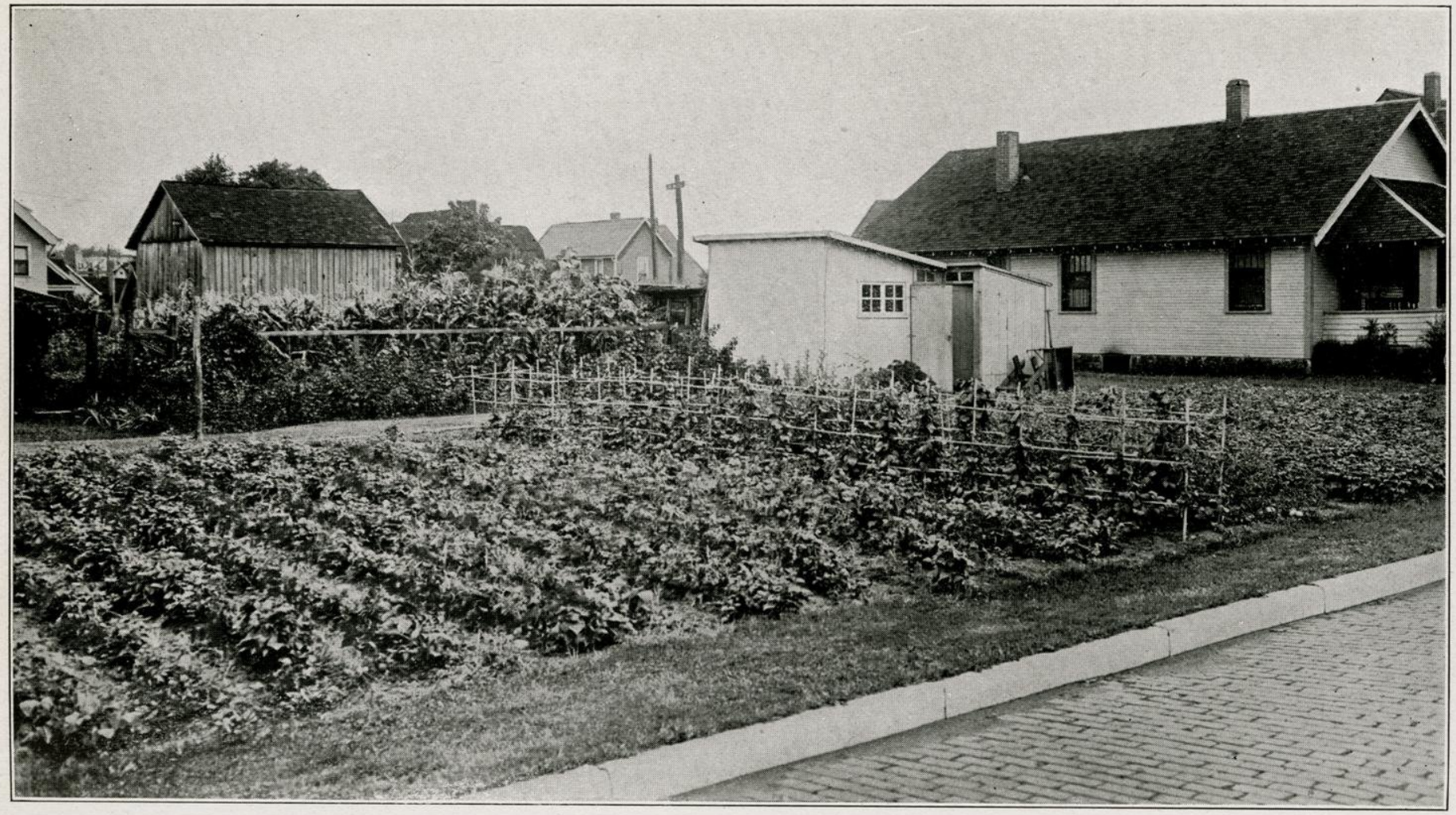

IN THE CHAMPION GARDEN CITY

This is a small home garden in Marion, Indiana, which boasts of holding the record in the United States for a city of its size in number of war gardens. With a population of only 29,000 persons, it had $14,08 \mathrm{I}$ vegetable plots, or almost one for every two inhabitants. Louis De Wolf,
chairman of the War Garden Association there, was very active in the work. 

ward feeding the army was shown by a careful estimate as to the amount of food which they added to the nation's larder. This was reckoned in 1918 as having a value of $\$ 525,000,000$. Taking into consideration equivalent food values, it was figured on a conservative basis that our 1918 war gardens grew food equal in body-building power to the meat ration required by an army of $1,000,000$ men for 302 days; the bread ration for 248 days; or the entire ration for $\mathbf{I} 42$ days. This wonderful saving of commercial supplies made the war-garden movement eminently worth while from this standpoint alone.

Munitions represent only one of the three M's. Money is another. Money makes the army as well as the mare go. The value produced by home gardeners went far to meet the increasing demands for money due to the war. To realize the wonderful financial possibilities of war gardening is almost as difficult as to grasp the possibilities of food production. The products of the little Pennsylvania garden already referred to were worth, according to the records of the gardener, $\$ 63.50$. That valuation was made at pre-war prices. The same products, in 1918 , would have been worth

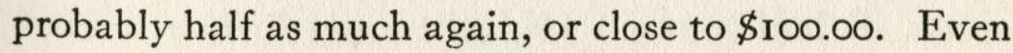
if its products were worth only $\$ 50.00$ that sum would have enabled the gardener to buy, with the money saved by gardening, a Liberty Bond.

Suppose all our war gardens averaged as well, what would be the result? The $5,285,000$ gardens of 1918 would have yielded $\$ 264,250,000$. Actually, the re- 
sults were almost double that figure, the estimated value of our war-garden crops for 1918 having been $\$ 525,000,000$ ! A half billion dollars! Enough to cover the expenses of the Red Cross, the Y. M. C. A., and all other similar war-work agencies for a long time; or to build 500 great ships; or to pay for one-tweltth of the fourth Liberty Loan issue!

In thousands of cases his war garden meant to its owner the difference between ability and inability to subscribe to a war loan. There were more than $21,000,-$ oo subscribers to the fourth Liberty Loan. The estimate of war-garden production means that the money saved through war gardening enabled at least onefourth of these subscribers to become holders of their country's war-purpose bonds.

Of the three M's there yet remains the third-men. Just as money saved through gardening can be used for the purchase of bonds instead of food, so labor saved in one field can be shifted to another. Specifically, men released from food handling were free for service elsewhere. And the name of the men so released through war gardening is legion. The products of the little Pennsylvania garden already discussed, weighed in excess of half a ton. Had these products not been raised at home, it would have been necessary to bring their equivalent to the gardener's home. He has a family of three. Families of three do not buy food in half-ton lots-seldom even in one-hundred-pound lots. To put an equivalent amount of food in his home, therefore, would have required many trips on the part of a 

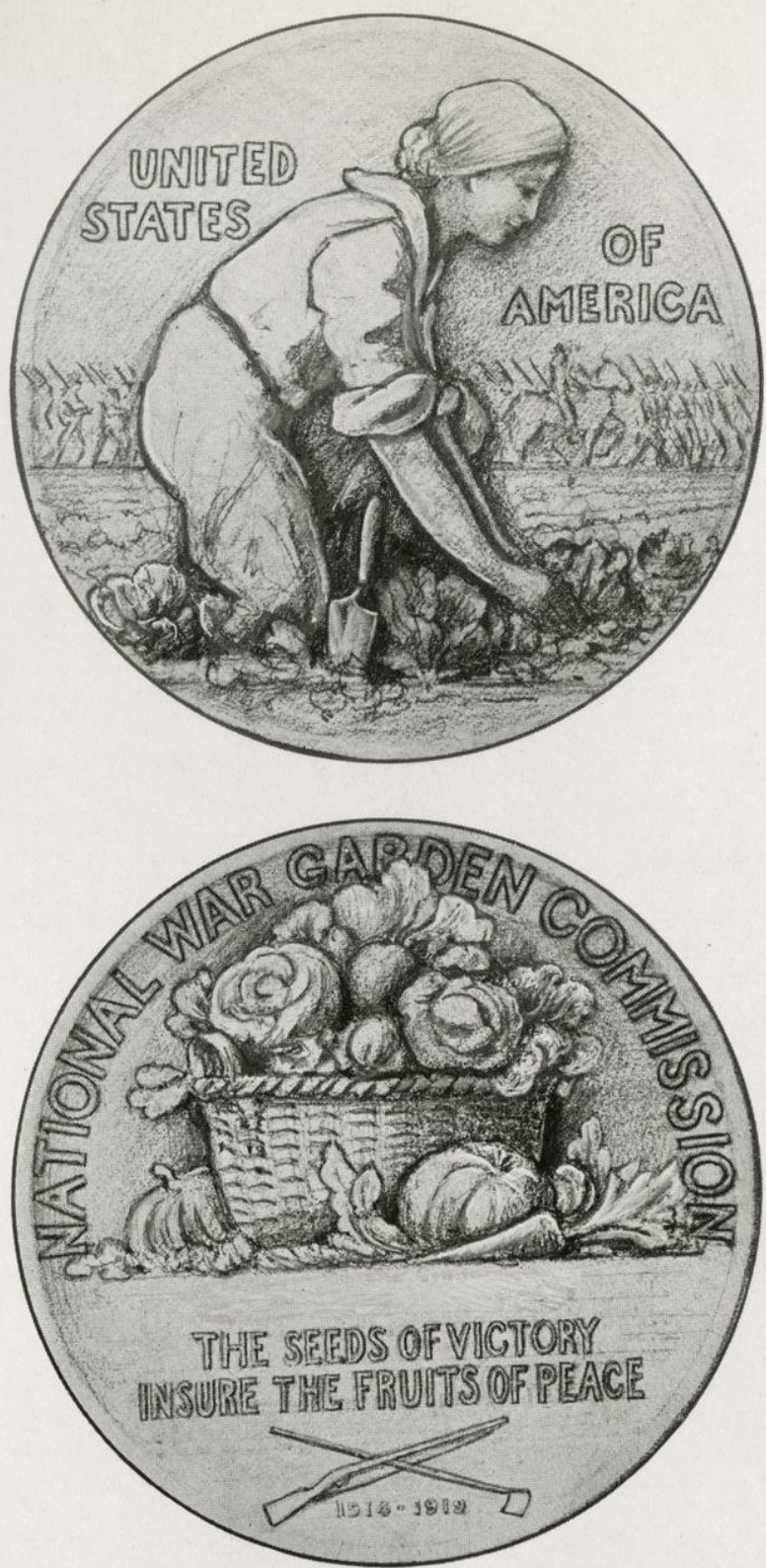

MEDAL IN COMMEMORATION OF THE WAR GARDEN

In recognition of the war time service of the War Garden a commemorative medal was struck by the National War Garden Commission for presentation to the rulers of the United States, England, France, Belgium and Italy. The illustration at the top of this page shows the obverse of this medal. The lower picture is a reproduction of the reverse. 

deliveryman, certainly not less than twenty-five. If every war gardener who made enough out of his garden to buy a Liberty Bond also saved his deliveryman twenty-five trips, the total saving of labor was enormous. The number of persons employed, before the war, solely to wait on other persons, was beyond belief. Soon after the United States entered the war, merchants began to face a readjustment of their business. It was estimated that in New York City alone simplification of delivery and clerk systems would release 100,000 men for service in the army. In the aggregate, war gardening aided to an incredible extent in this readjustment.

Nor are these all the benefits conferred by war gardening. Nothing is more essential to success in war than the creation and maintenance of an ardent patriotic spirit. War gardening fostered this spirit by enabling so many individuals not actually in the army to do something tangible in the struggle. Millions of patriots joined the army of the soil because of their deep love for their country, and their desire to help in the hour of need.

Many of the slogans sent ringing throughout the country by the Commission breathed the spirit of America and of democracy. That spirit spoke from the Commission's posters and other matter. War gardeners were called on by the beautiful figure of Liberty to "Sow the Seeds of Victory." Another slogan, a clever paraphrase on the title of a famous song, told them to "Keep the Home Soil Turning." West Virginia started the message: "Food Must Follow the Flag," which became a household word throughout the United 
States. The Marion (Indiana) War Garden Association placed it squarely up to the home food producers in this fashion: "Earn the Right to Stay at HomePlant a Garden." The honored title of "Soldier of the Soil" gave the home tiller the feeling that he, too, was performing a service for his country although he was not wearing the uniform; and when he was informed that "Every Garden is a Munition Plant" he knew that he was helping the boys over there to fight their battles, for "The Seeds of Victory Insure the Fruits of Peace." The patriotic spirit is contagious and the war gardener helped mightily to spread it.

Of especial value to the nation in its days of need was the habit of thrift engendered and built up into a common trait by home gardening. Before the war, it is estimated, there were only 300,000 bond-buyers in the United States. More than 21,000,000 people subscribed to the fourth Liberty Loan. The significance of that fact is splendidly summed up in a single sentence by Fred H. Goff, president of the Cleveland Trust Company and a member of the National War Garden Commission. "A nation that saves," says he, "is a nation saved." Truly, war gardening is as full of hidden blessings as the widow's cruse was of oil. 


\section{WE HAVE A War Garden}

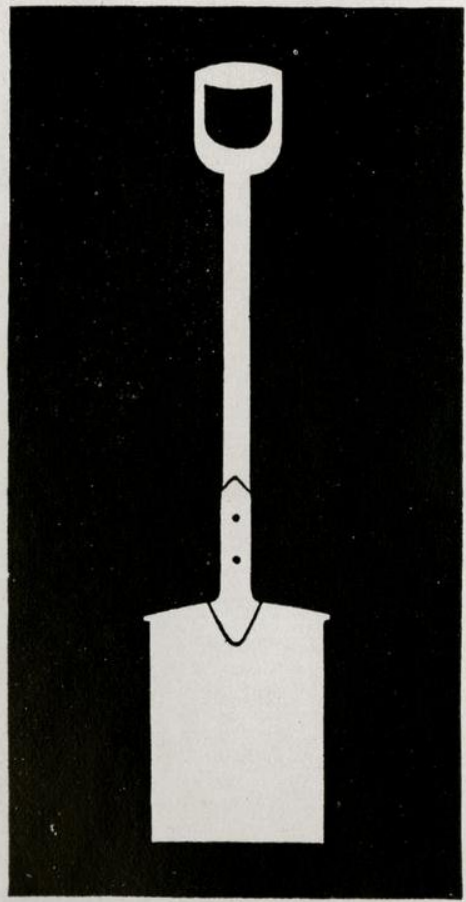

\section{National War Garden Commission}

WASHINGTON, D.C.

To war gardeners throughout the United States the National War Garden Commission furnished window hangers, printed in green to symbolize growing vegetation. These were proudly displayed in the front windows of several million homes. 



\section{CHAPTER IV \\ TYPES OF WAR GARDENS}

How Different People Planned to Plant and Win the War

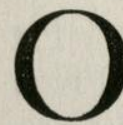

$\mathrm{N}$ plaster and ash-filled ground only a few feet above the rumbling subway in New York City was a war garden. From this little vegetable plot in Bryant Park, where land is valued at something like $\$ 20,000$ a square foot, to the tiny garden along the railroad right of way near the tops of the White Mountains, is a far, far cry. Yet both spots had their war gardens. The one in Bryant Park was a demonstration garden, started solely for educational purposes. Here representatives of the National War Garden Commission preached the gospel of gardening and freely gave helpful advice and garden primers to passing inquirers. On the other hand the tiny garden on the cloud-capped slope of the White Mountains was wholly utilitarian. A patriotic hand had planted it, and loving fingers tended it, in the hope that it would bring forth, perhaps, a few dollars' worth of food; in the belief that its product would lessen, though ever so little, the pressure on our commercial food supplies, from which alone our allies could draw sustenance.

The same spirit of helpfulness, of readiness to "do one's bit" animated countless other Americans. So the war garden was found in tiny clearings beside the 
logging camps of Louisiana, in irrigated plots among the arid sands of New Mexico, in the rugged iron lands of Minnesota, and on the open, fertile stretches of

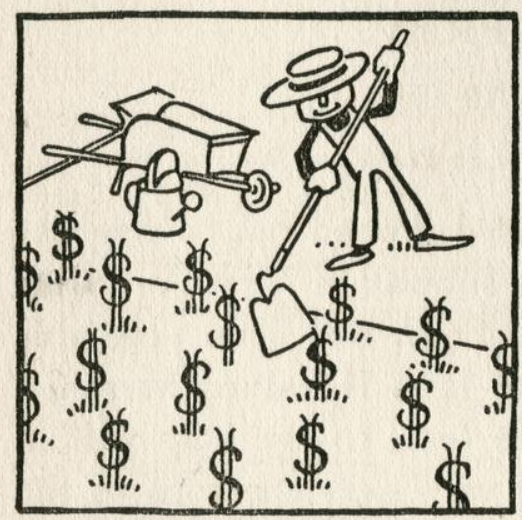

Victory gardens produce dollars the Middle West. Even the lighthouse-keeper at Santa Cruz, California, planted a little garden under the shadow of his protecting shaft. From coast to coast, and from lake to gulf, little areas that had been barren as the desert suddenly blossomed like the rose. Behind each of these innumerable gardens was a heart animated by the desire to serve God and country.

When the National War Garden Commission sent forth the slogan "Plan to Plant and Win the War," the majority of gardens started in response were of the individual type. Like stars in a mighty flag, they dotted the rolling landscape from ocean to ocean.

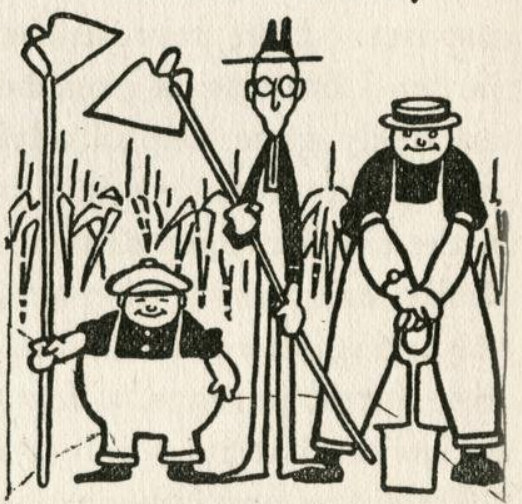

There is no distinctive type of victory gardener

There were few town and village homes that did not have some space available for war gardening. Even in densely populated cities, a goodly proportion of the inhabi- 
tants each had at command at least a few square feet that could be cultivated. And urban dwellers by the hundred thousands found vacant lots near their homes which could be utilized for food production. This great host of individuals, each working like his fellows for a common purpose, carried on what, in the aggregate, was a vast farming operation.

In no previous war did women play so great a part as they did in the world war. Not only did hosts of them make munitions in factories, but other hosts joined the

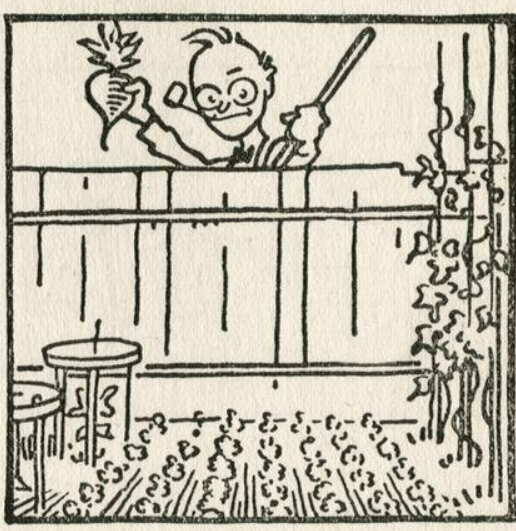

Draw on your back-yard type of bank men in the production of that other sort of munitionsthe kind that grows in gardens. With the women who served as nurses, ambulance drivers, canteen helpers, and munition makers, should also be ranked the women gardeners. In thousands of instances women gardeners cultivated entirely, even to the extent of doing the digging, the home food plot, while in thousands of other instances they shared with the men the task of caring for the war gardens.

Thousands of letters have come to the National War Garden Commission from women gardeners. In order that the fine service rendered by such women may not be forgotten, some of these communications are included in this record. A letter from Mrs. T. J. Ulery, 
of Seattle, Washington, whose husband wore his country's uniform, well shows the spirit that animated these women gardeners:

"Thanks for the war vegetable gardening booklet you sent me in the spring," she says. "My husband is in the navy and I have two small babies, but that did

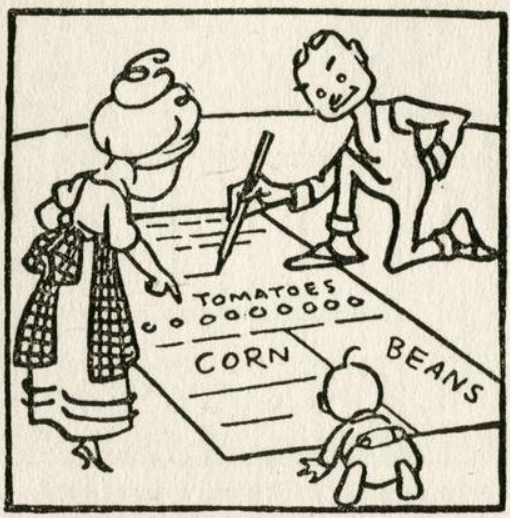

This type of green goods will cure the blues not keep me from raising a garden. We have a plot fifty by two hundred feet, and every inch is in something. I wish you could see it. I weigh ninety-eight pounds but I am going to do my bit. Now I wish you would send me your home canning and drying book."

From Mrs.G.P.Dutcher, of Arlington, Massachusetts, came this other typical communication: "I was seventyeight years old on March thirty-first. I expect to raise what beans I need for a family of three for the next year. I did it last year and did all my own planting."

We see the significance and worth of this woman's service when we realize that a day's rations for one million United States soldiers includes 75,000 pounds of beans, and that we raised an army of approximately four million men! This enormous demand for beans had to be met from commercial supplies that could be increased, because of labor shortage, only slightly above the pre-war production. So we had the army 


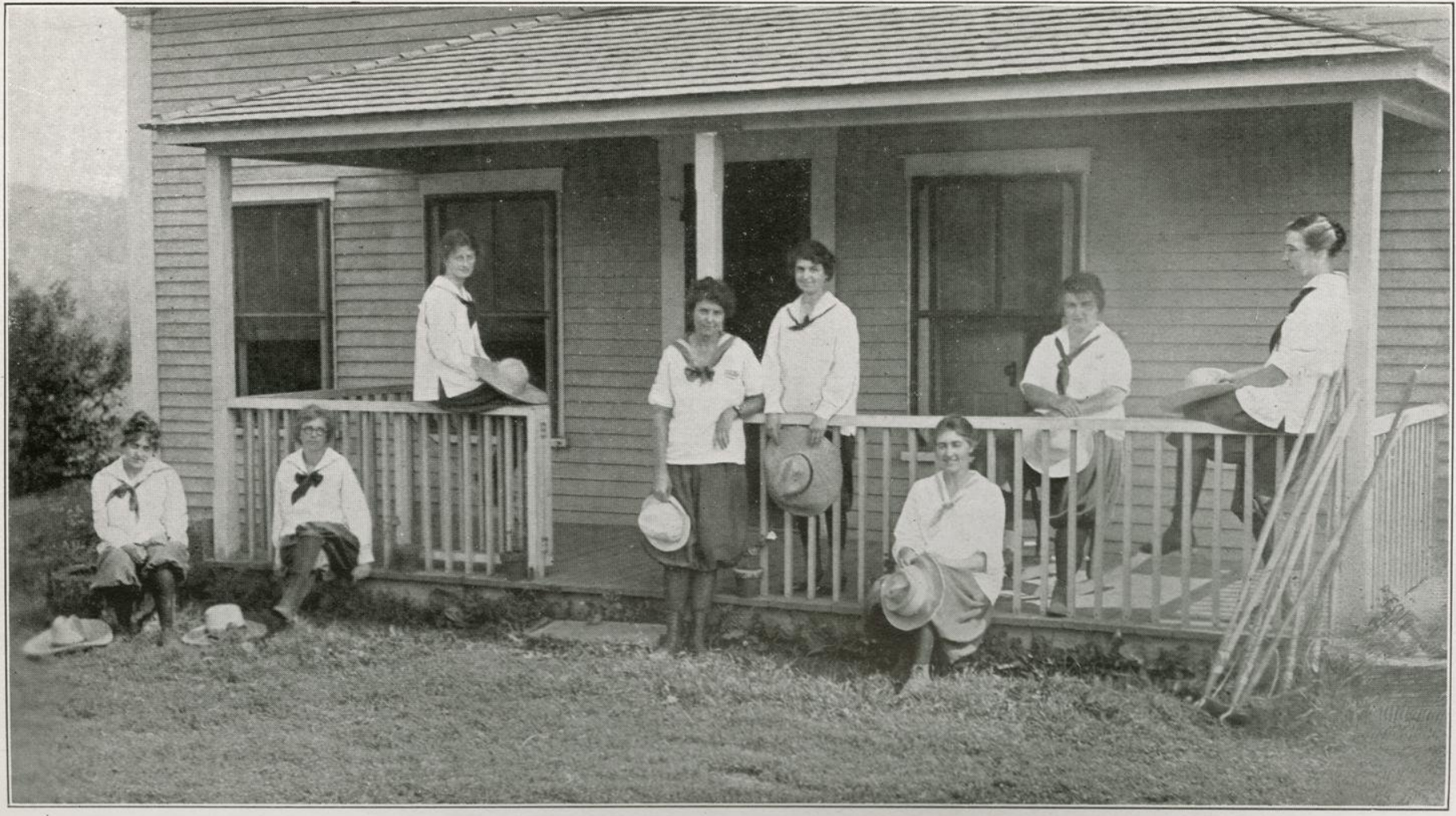

PIONEERS IN SUMMER HOTEL GARDENING

A patriotic and healthful way of spending their vacation was discovered by this group of school teachers and office workers who early in the summer of I9I8 went up to northern New Hampshire and raised vegetables to supply the table of a large summer hotel, "The Balsams," at Dixville Notch. This shows them in front of the comfortable cottage which they occupied. Their three-acre "war garden" was close by. They alternated by twos as housekeepers. 

bidding against the civilian population, with the resultant tremendous increase in price. Assuredly this old lady was doing her share toward remedying the situation. And that is exactly what was done by the cultivator of every war garden.

Few of the women gardeners had reached their allotted three score years and ten. Most of our women gardeners were younger, and among these younger women soldiers of the soil none performed a more interesting or val-

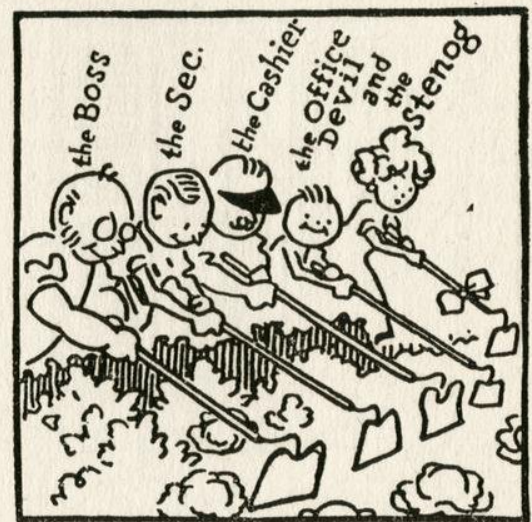

An office type of victory garden uable service than the eight school teachers and office workers who ventured, like the pioneers of old, into a new

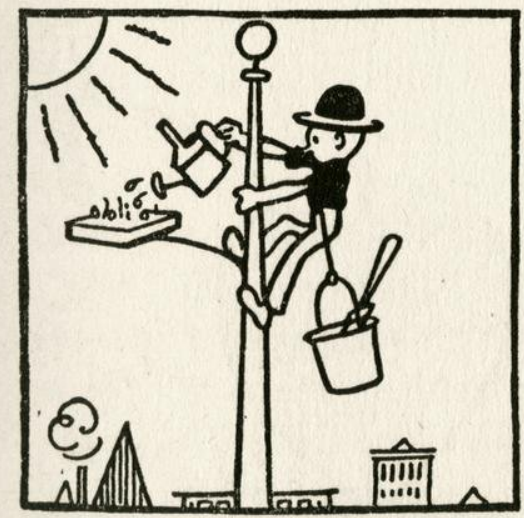

Suit your type of garden to your job country, blazing the way for those who should come after them. Their chosen field of garden effort was the raising of vegetables for a summer hotel.

Up at the Dixville Notch, in the White Mountains in northern New Hampshire, is a magnificent summer hotel, The Balsams. It was customary to ship in from a considerable distance the bulk of its vegetable supply. 
Last summer the eight young women referred to cultivated a three-acre garden at Dixville Notch, on the property of the hotel corporation. They lived in one

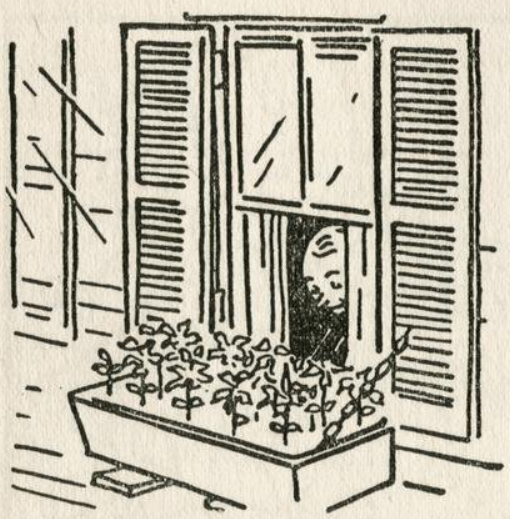

Where there's a will there's a victory garden type

of the company's attractive little houses which looks out over a great expanse of country. From Brooklyn, New York, Lakewood, New Jersey, Rockland, Maine, and Keene, New Hampshire, came these young women farmers. They were farmers in more than name; for in addition to cultivating their large vegetable garden, they found time to assist the neighboring men farmers in making hay, cultivating potatoes, and performing other farm labor.

The desire to serve, not the wish to have a good time, led these young women to engage in this work; and so successfully did they perform their tasks that the hotel management promptly arranged to continue and

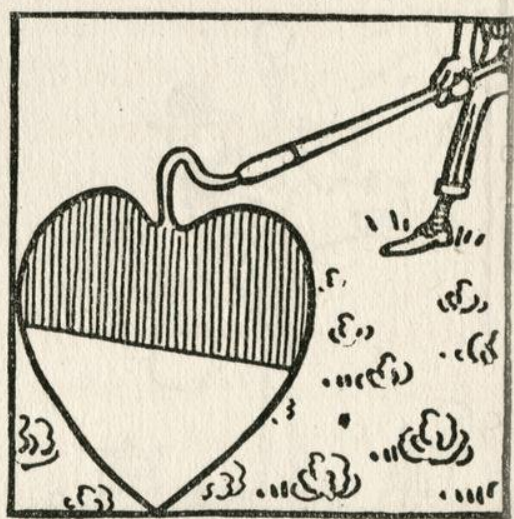

Put your heart into your own type expand the work in future years. Thus, in addition to upbuilding themselves physically in the most gratify- 
ing way, these young women opened the way for others of their sex to perform service at once essential and useful. How useful may be judged when we realize that but for their work it would have been necessary to haul hundreds of bushels of garden-stuff long distances over the steep mountain grades. The carspace and fuel thus saved were applied to the hauling of shells and cannon and other supplies that our soldiers so much needed. If "they also serve who only stand and wait," how much greater is the service of those who labor while they wait.

Since the labor of these

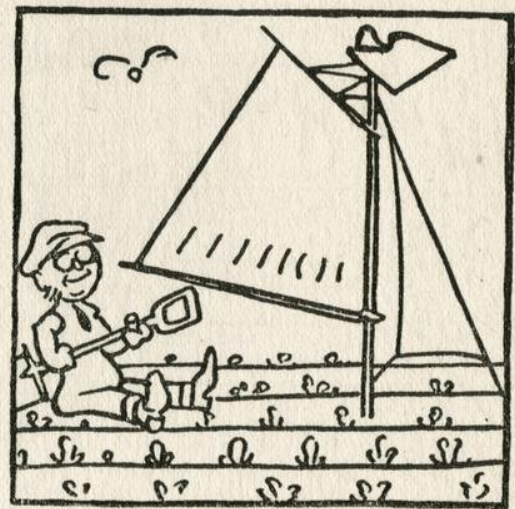

Every type can have smooth sailing young women marks a new phase of food production, in this country, a phase that is certain to appeal more and more to tired school teachers, clerks, and other indoor workers, it may not be amiss to tell in detail of the life of these girls at Dixville Notch.

Their home was in a cozy little cottage, from the windows of which one could look off in any direction on most beautiful mountain scenery. It was situated only a few miles south of the Canadian border, in a region whose towering mountains are pine-clad and gemmed with clear, cool lakes and embroidered with foaming mountain brooks. The girls received regular monthly wages from the hotel, but provided their own 
meals, with the privilege, however, of purchasing supplies from the hotel at favorable rates. Two at a time they kept house, while the other six looked after the gardens.

None of these girls had had any previous experience worth mentioning in the cultivation of the soil. Yet they made very rapid progress in the art of gardening.

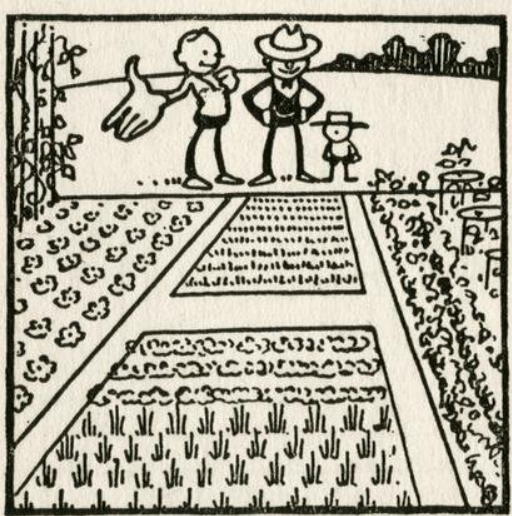

A type of victory garden to brag about

Their success was undoubtedly due to the fact that they stuck to a few staple crops and did not attempt too diversified gardening. They raised peas, lettuce, radishes, carrots, beans, and other common vegetables. Upon beginning their work they received instructions from the hotel farmer, Henry Bemis, who looks after some of the larger tracts of land owned by the hotel management, which are given over almost exclusively to the raising of hay for the dairies. Such instruction was not long necessary, however, as the young women farmers speedily acquired considerable skill.

Even gardening and haying did not occupy all their time. One rainy day, when no gardening could be done they went to a neighboring farm where there were several thousand bushels of potatoes which had begun to sprout. The visitors started "sprouting" with a will and at the end of the day had averaged twentyfive bushels each. They were told that ten bushels had 


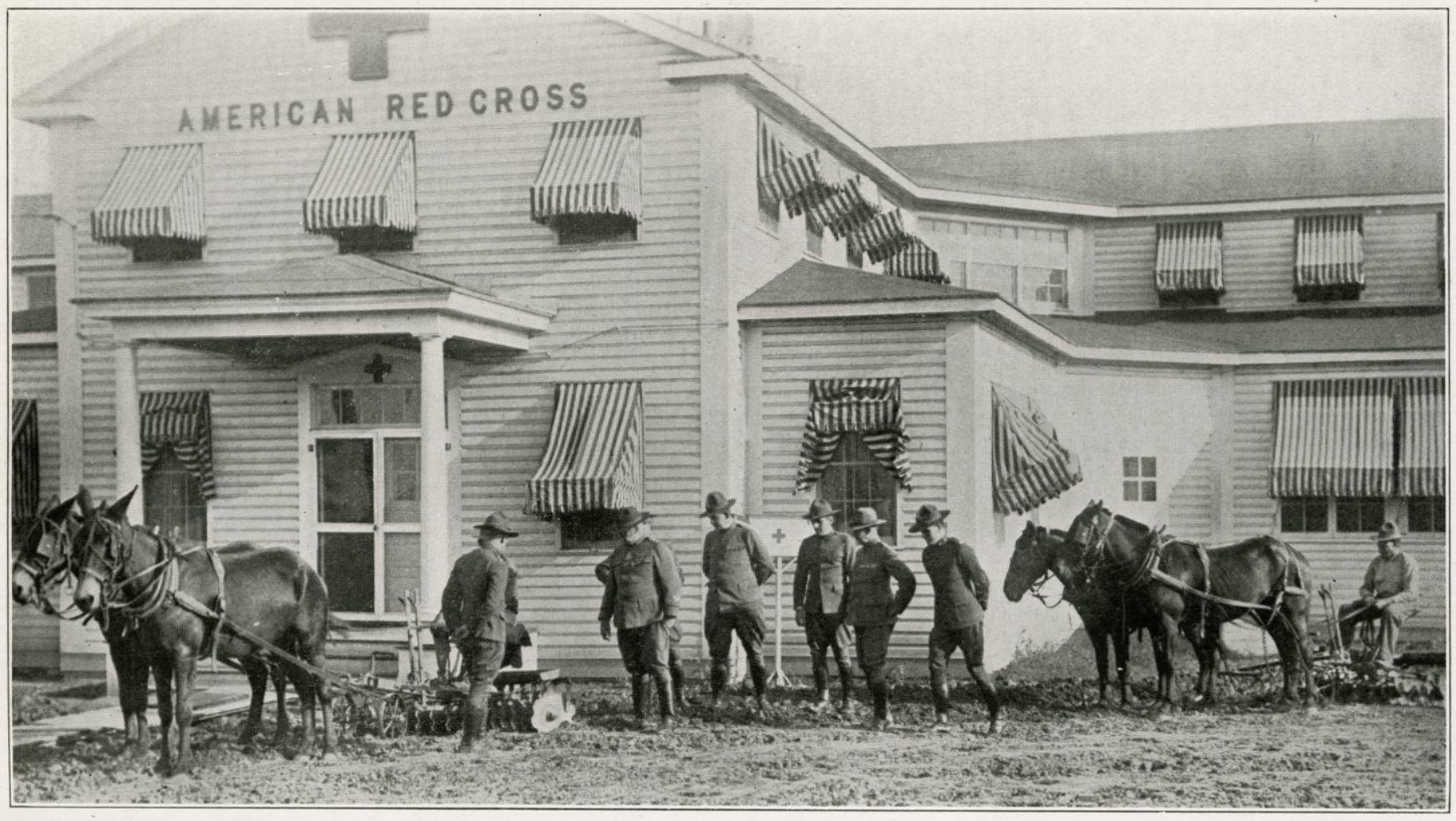

AN ARMY GARDEN AT THE RED CROSS THRESHOLD

Copyright Western Newspaper Union

The Camp Dix soldiers carried their farming operations to the very door of Red Cross headquarters. In this picture Major General Scott, Camp Commander, (near center awning) is inspecting the work of cultivation as conducted by Lieutenant John $\mathrm{F}$. Bonner, farm officer,

(at extreme left). General Scott took a deep interest in the Camp Dix war garden. 

always been regarded as a fair day's "sprout." They continued at this task until the entire lot of potatoes was finished. Then they assisted other farmers whose potatoes were sprouting; for labor had become as scarce on New Hampshire farms as it was on farms everywhere else.

Thus these women not only blazed a trail for their sisters, but proved what thousands of other women are proving in industry-that woman not

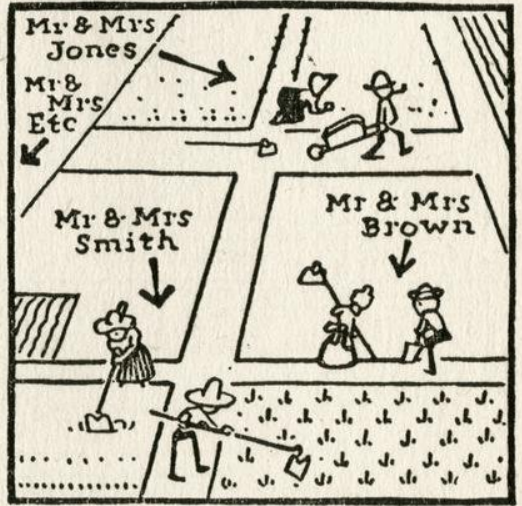

The community type of victory garden only is not an inferior workman, but that her nervous make-up enables her to work faster than man. These

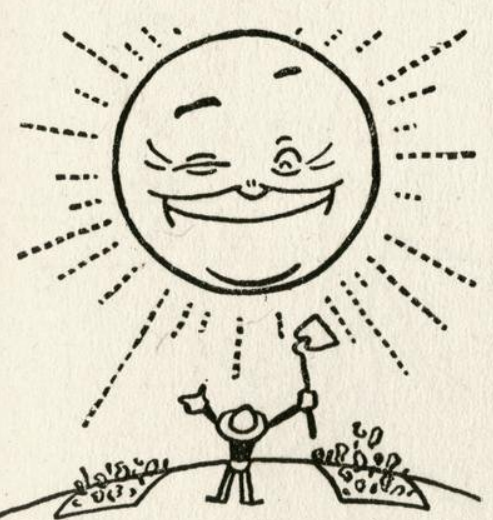

The sun shines for all types of garden women gardeners did their share in the fight for freedom-not merely that political equality for which men and women struggled on the fields of Europe, but that greater freedom, human equality. Even to that cause has the war garden contributed materially. If the work of these young women proved anything, it was that in union there is strength. The strength that comes from union it was found advantageous to utilize in many another 
war garden, by operating it on the community plan. Instead of allowing each gardener to till his own land, it was better, where possible, to have a large area prop-

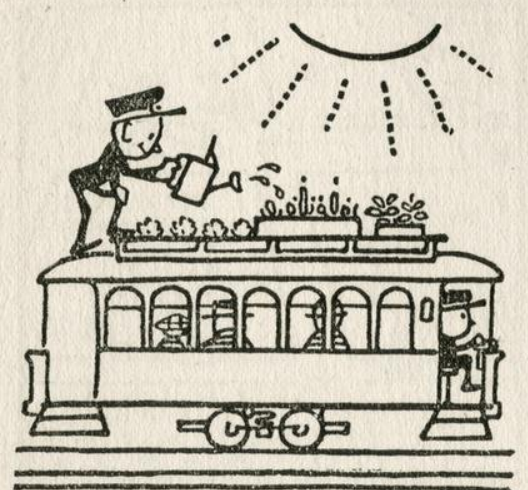

The crowded city has many types erly plowed and harrowed and then allow the gardener to care for his individual plot. The advantages of such community action proved great. The land was uniformly and properly prepared and at small expense. Community gardening made for both better gardens and better communities, for the spirit of emulation at once led each gardener to do his best, while common toil for a common end made for better understanding and better acquaintanceship; and sympathetic understanding is the rock upon which democracy is founded.

Much of the gardening done by employés of factories and business houses was of the community sort.

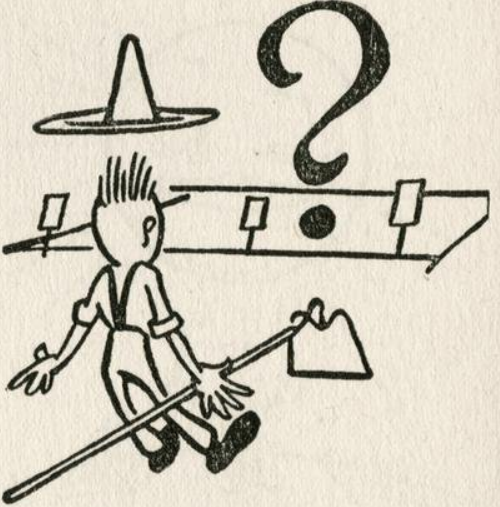

The well-worked type involves no doubt Unused tracts of land lying near mill or shop, and not needed for business purposes, were divided among employés for gardening, after being properly plowed and 


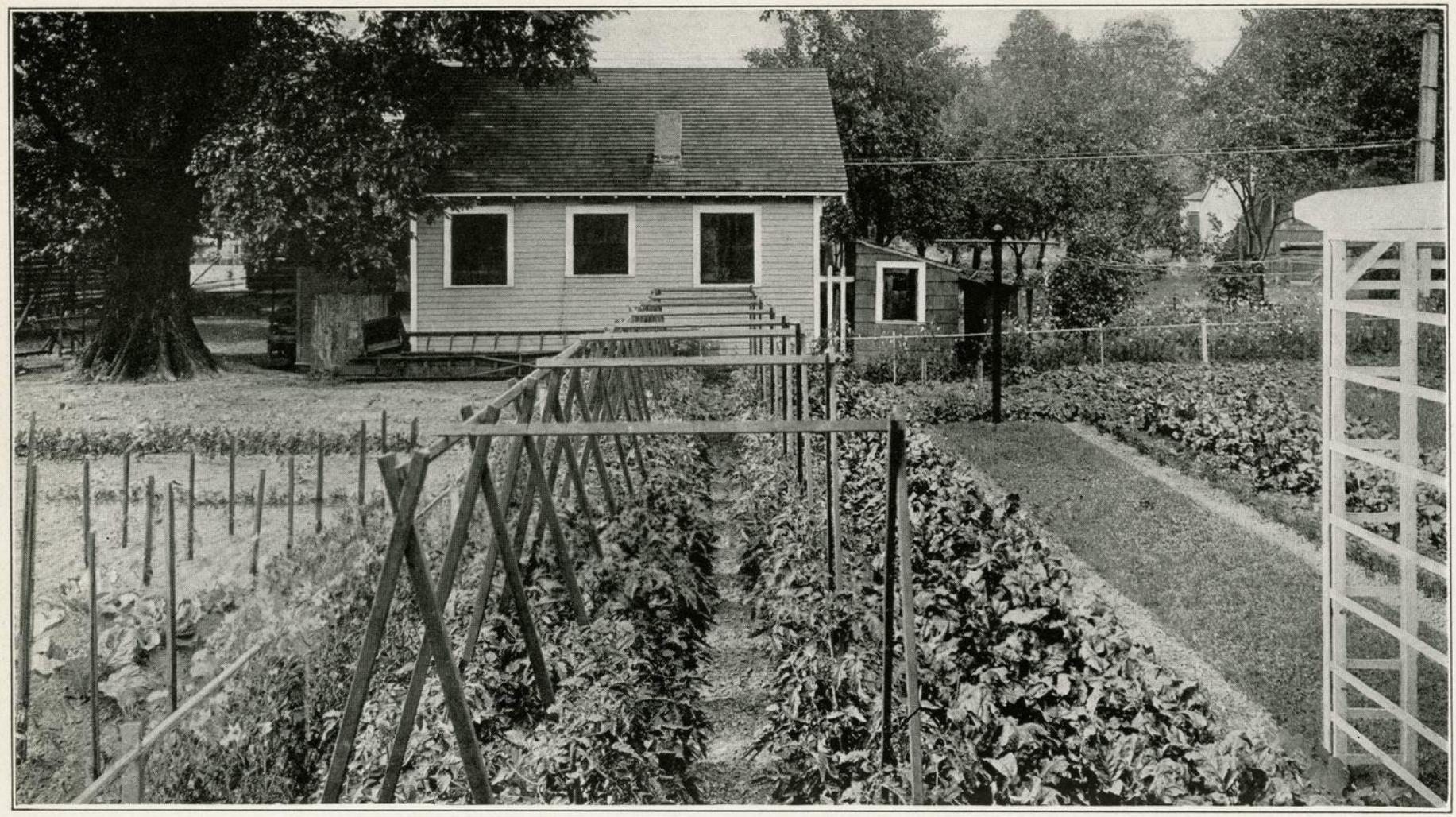

A PRIZE-WINNING GARDEN

First award was given to this vegetable plot in the contest among the six hundred war gardeners of the Eastman Kodak Company, Rochester, New York. Condition of plants, orderly arrangement and cultivation shown were among the factors considered in judging the merits of the various gardens. 

harrowed. Often it happened that the land available would not accommodate all the men applying for plots, and in such cases employers frequently leased additional near-by lands and turned them over to their employés. The mutual interests so engendered created a more friendly feeling of coöperation not only among the men themselves, but also between the management and the employés. This was particularly true where, as happened in many cases, the heads of large concerns became fellow-gardeners with their employés. Burns has told us the secret of democracy in a single sentence: "A man's a man for a' that!" When men get together and work together for a common end, they learn the fundamental lesson of democracy. Thus the community war gardening which sprang up in so many parts of the land accomplished more, far more, than the production of so much provender, useful as that strictly utilitarian end undoubtedly was. Unquestionably, community gardening will continue. It will be the peace-time descendant of the war garden. 


\section{CHAPTER V}

\section{UNCLE SAM'S FIRST WAR GARDEN}

How the Boys at Camp Dix Went Over the Top

W

ITH the mention of the word "war" there immediately flashes across the mind a vision of long lines of soldiers marching through streets crowded with flag-waving civilians; or of those same long lines drilling, wheeling, and maneuvering on the camp parade-ground; or of stern-taced fighters with bayonets fixed charging across a smoke-clouded field toward the enemy's positions. It was most appropriate and fitting, therefore, that the term "war garden" should come to be associated with actual soldiers.

It was at Camp Dix, New Jersey, that the first sureenough war garden was planted. At that big army cantonment there was begun the first big undertaking in the United States whereby the American army started to help feed itself.

Early in the spring of 1918 the National War Garden Commission, coöperating with the conservation and reclamation division of the Quartermaster-General's office, effected the plans which promptly led to the planting of a four-hundred-acre war garden at Camp Dix, that city of 48,000 or more soldiers where men were being prepared for overseas duty. This was a demonstration garden which was not only the largest but also the most picturesque the country had seen. It was not 


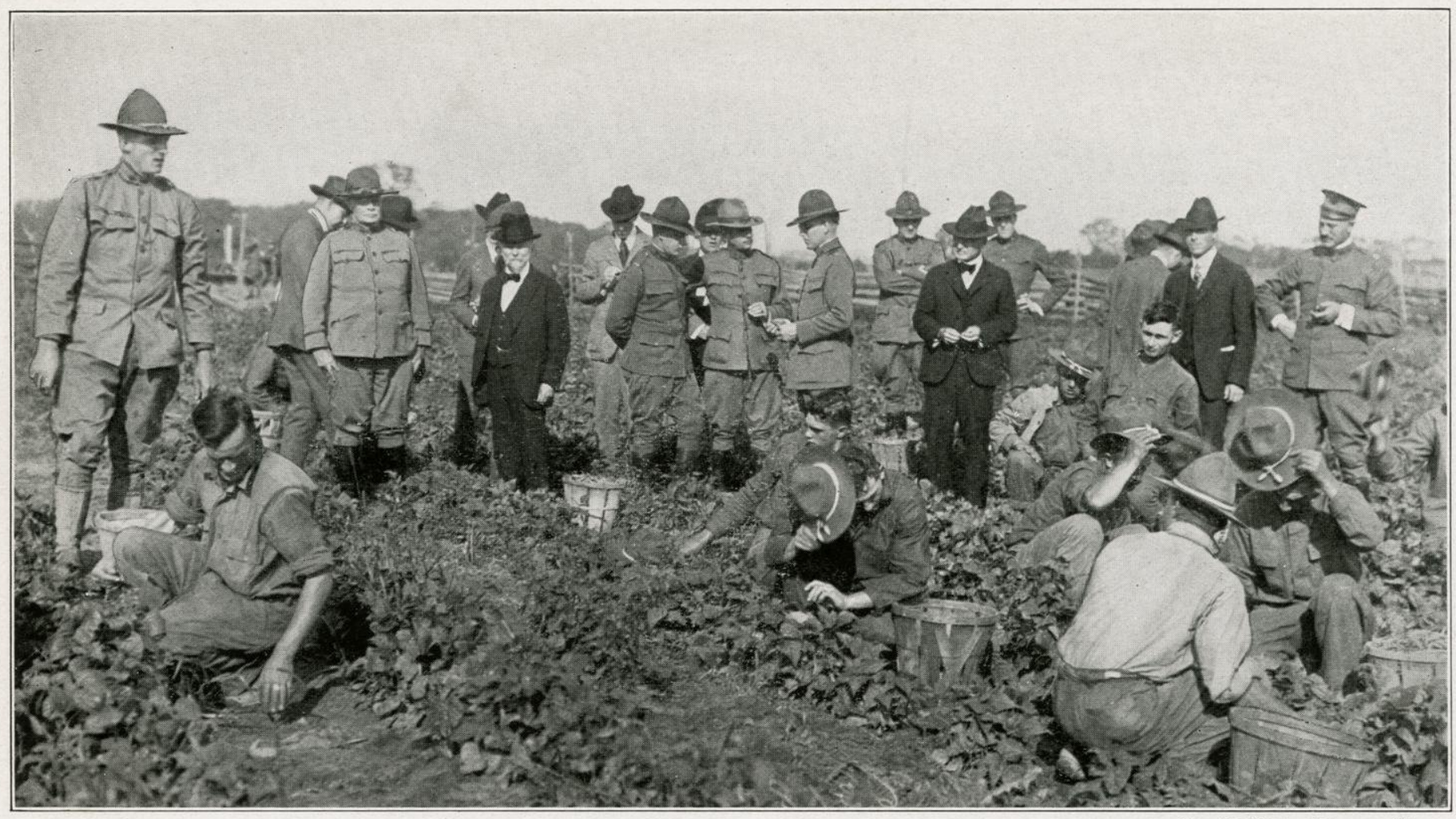

“NOW, BOYS, SHOW 'EM HOW TO HARVEST!"

Copyright Western Newspaper Union.

This is what Sergeant Noel, on the left, is saying to the bean pickers in the Camp Dix war garden, whose work is being inspected by Major General Scott, commanding officer, other army officials and a group of visitors. President Charles Lathrop Pack, of the National War Garden Commission, is standing by the side of General Scott. The young officer behind him is Lieut. John F. Bonner, in charge of the farm. 

only great in size, but in the consequences that were to come from it. This important innovation in methods of supplying the quartermaster's store with part of the food needed, not only had the backing of the officers in charge, but also received the hearty commendation of the Secretary of War. It proved of value in many ways.

At practically all the army camps, there were considerable amounts of land not required for actual military purposes. These plots varied from a few hundred to several thousand acres. There was, however, no fund available under the War Department or army appropriations which could be used for the purpose of placing this land under cultivation and carrying on the work.

At Camp Dix there were 400 acres inside the reservation which could be immediately utilized for food production. Colonel J. S. Fair, assistant to the Acting Quatermaster-General, and head of the conservation and reclamation division, helped to work out and gave his active support to the plan of planting a garden at this place. When it was found that the land could be used and that Lieutenant-Colonel Edmond Tompkins, then Camp Quartermaster, had the men available, the National War Garden Commission secured nine big motor-trucks and rushed over from Philadelphia, thirty miles distant, thirty plows and other garden tools, seeds, fertilizer, and other needed material. The final arrangements were completed on one day, and on the following day the supplies were on hand.

The Commission's demonstration war garden at 
Camp Dix was a success from the start. It furnished an inspiration and gave impetus to the work all over the United States; and soon similar plots growing "Food F. O. B. the Mess Tent Door" were under way in a number of other camps. Thousands of war gardeners redoubled their efforts because of the knowledge that the men in the American army were doing similar patriotic work. "Over the Top with the Boys at Camp Dix!" became a new slogan which aroused genuine enthusiasm and put new spirit into the back-yard and vacantlot tillage.

After the Commission had provided the means for starting the project, Lieutenant-Colonel Tompkins placed it in the hands of Captain E. V. Champlin, conservation and reclamation officer of the camp, and the latter selected as farm officer Lieutenant John F. Bonner, an energetic young officer who was a graduate of an agricultural college and who had also enjoyed a practical farming experience.

Major-General Hugh L. Scott, commanding officer at Camp Dix, took a keen personal interest in the project. He made several trips of inspection over the gardens, accompanied on two of these occasions by Mrs. Scott, to see how the work was progressing and to encourage the young officers in charge. He expressed his appreciation to Captain Champlin and to Lieutenant Bonner, actively in charge of the farm enterprise, and to their assistants, for the excellent results they were obtaining. His interest caused the boys to work with an added will. 




"POTATOES UP! FORWARD MARCH!'

Copyright Western Newspaper Union.

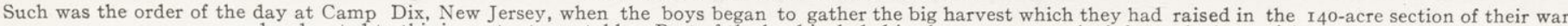

garden devoted to this important vegetable. Part of the land included in the cantonment had formerly been rich
farming land. Several thousand bushels of potatoes were stored for winter use. 

One hundred and forty acres were planted to potatoes, both early and late varieties; seventy acres to beans; forty to corn; twelve to beets; twelve to onions; eight to cucumbers; five to tomatoes; one to cabbage; and other areas to a variety of vegetables. The land on which the camp was located had been farms, on which there were a number of orchards. These were cared for and the fruit gathered. In addition, about three hundred tons of hay were harvested. The garden even included an acre of broom-corn, which the supply officer in charge of purchasing brooms figured saved many a dollar. The boys, however, maintained that their reward from this particular corner of the garden came from the help rendered in "sweeping on to Berlin."

Aside from the food produced, the Camp Dix war garden was of benefit in other ways. It afforded healthful outdoor work for convalescents and other men who were not physically fit for active military training, but who after a few weeks or months of this exercise were able to go back into the fighting ranks. Colonel F. B. Beauchamp, inspector of the southern command of the British army, who had come to the United States on a tour of inspection of the camps here, pointed out what this form of work was accomplishing for many men in the British army, and how thousands of them were being so benefited by the regular living in the camps and the life in the open that they were able to return to service on the battle-field.

In addition to using convalescents and men not physically capable of service overseas the camp garden 
afforded opportunity for putting "conscientious objectors" and alien enemies to work at some useful noncombatant form of labor. Among the first 150 men assigned to the war-garden work at Camp Dix were a number of Germans and Austrians, two Turks, and representatives of other nationalities. Drafted men of this sort, having declared themselves unwilling to take up arms against their own countrymen, were almost without exception happy and contented in their work as food producers. In some cases alien prisoners were transported to army camps to till the gardens. The first lot was sent from Fort Oglethorpe, Georgia, to Camp Devens, Massachusetts, for this purpose. At the camp, under guard, they cultivated a war garden of ninety acres. There were one hundred of these prisoners, most of whom had been taken from interned German vessels.

As a result of the immediate success of the Camp Dix project, plans were made for greatly extending this form of war gardening in 1919. The work had proved its worth as an adjunct to army life. A number of military men who had not approved of the plan at its inception were converted by the excellence of the results obtained and gave it their support. The experience gained in the first year, coupled with the greater demand which it was known that there would be for food, made it desirable that this scheme be carried out on a broad scale. It was realized that it would furnish much relief in supplying the army and the nation with food. 


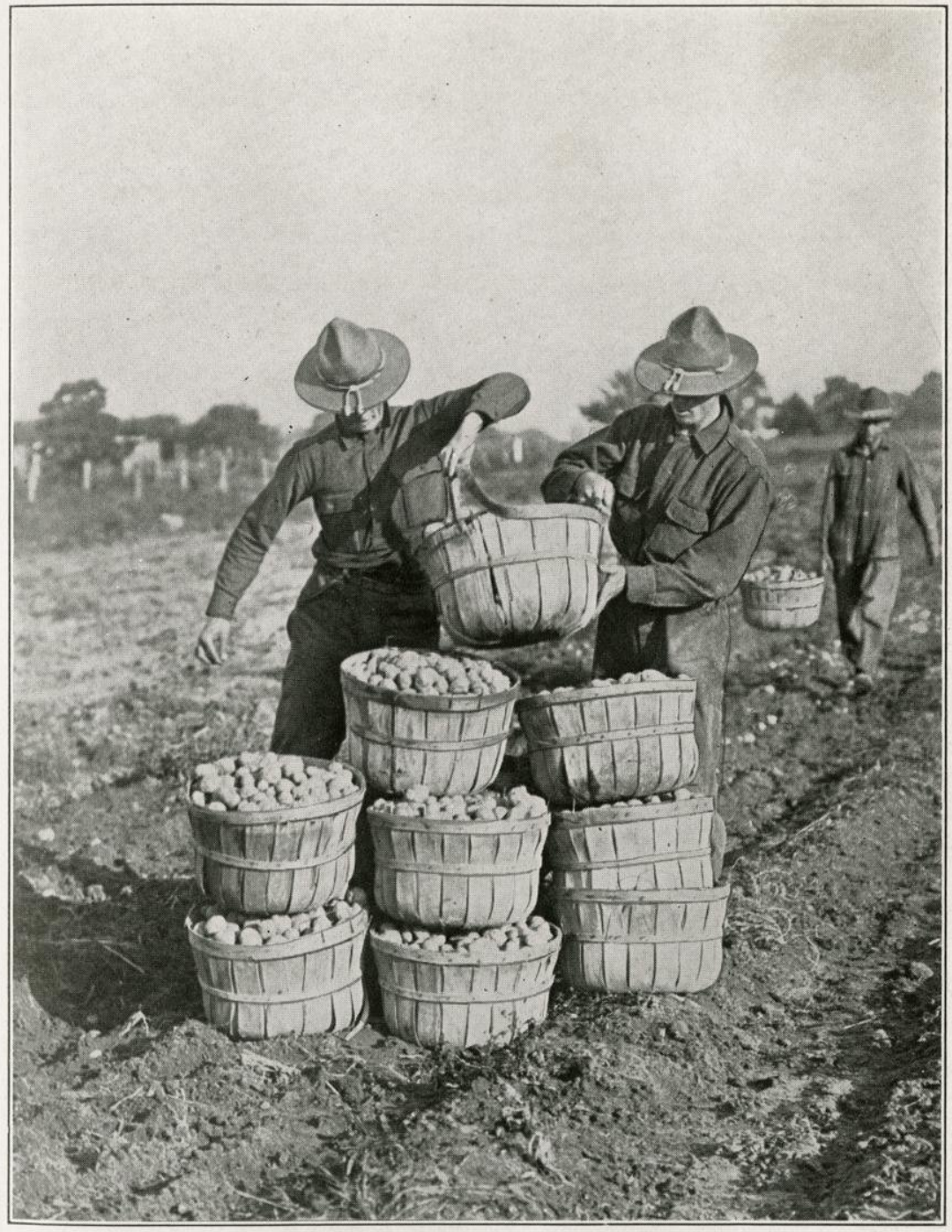

Copyright Western Newspaper Union.

GATHERING THE POTATOES

This staple article formed the principal crop from the 400-acre war garden which was inaugurated at Camp Dix, New Jersey, by the National War Garden Commission in coöperation with the Quartermaster General's Office of the army. More than 5,000 bushels of the tubers were grown. 

Shortly after the Camp Dix war garden was started, Secretary Baker gave the undertaking his hearty endorsement in the following letter addressed to the National War Garden Commission:

The War Department finds much satisfaction in the creation of war gardens at various army camps by the Conservation and Reclamation Division of the Quartermaster-General's office. Food production at these camps has been the subject of some concern with the Department. The large areas of tillable land within many of the military reservations have been regarded as offering potential food production on a large scale, and I feel that the army is to be congratulated that the utilization of this space has now taken concrete form.

Camp war gardens will serve more than one useful purpose. The production of food at the mess door is of great importance in that it not only lessens the army's demand on the usual sources of supply but eliminates transportation as well.

To the National War Garden Commission I extend the thanks of the Department for its quick response to the appeal of the Quartermaster-General's office for coöperation. Not confining itself to mere compliance with the letter of the request, the Commission entered fully into its spirit. At a time when funds were not available through Government channels the Commission voluntarily provided seed, fertilizers, and equipment which made possible the establishment of a war garden of 300 acres or more at Camp Dix. For this generous contribution and for swift action to overcome the handicap of a late start I take pleasure in making this acknowledgment and in expressing the hope that the Camp Dix war garden of the National War Garden Commission will prove an unqualified success. 
Thus, in teeming army camps and on isolated mountain-tops, on the wide reaches of the prairies and in sun-splashed openings in the dusky forests; beside roaring factories and in sequestered nooks on which deer and bear peer shyly from near-by leafy coverts, there have sprung up innumerable war gardens. In riding across the country one sees them beside the railroad right of way, in back yards, small and great, on lawns and in open fields, in every conceivable place and of every imaginable size-sees these living emblems that tell, as truly as the tiny Liberty Loan button on the coat-lapel, where the owner stands and what he stands for, because a war garden is a service badge of living green. 


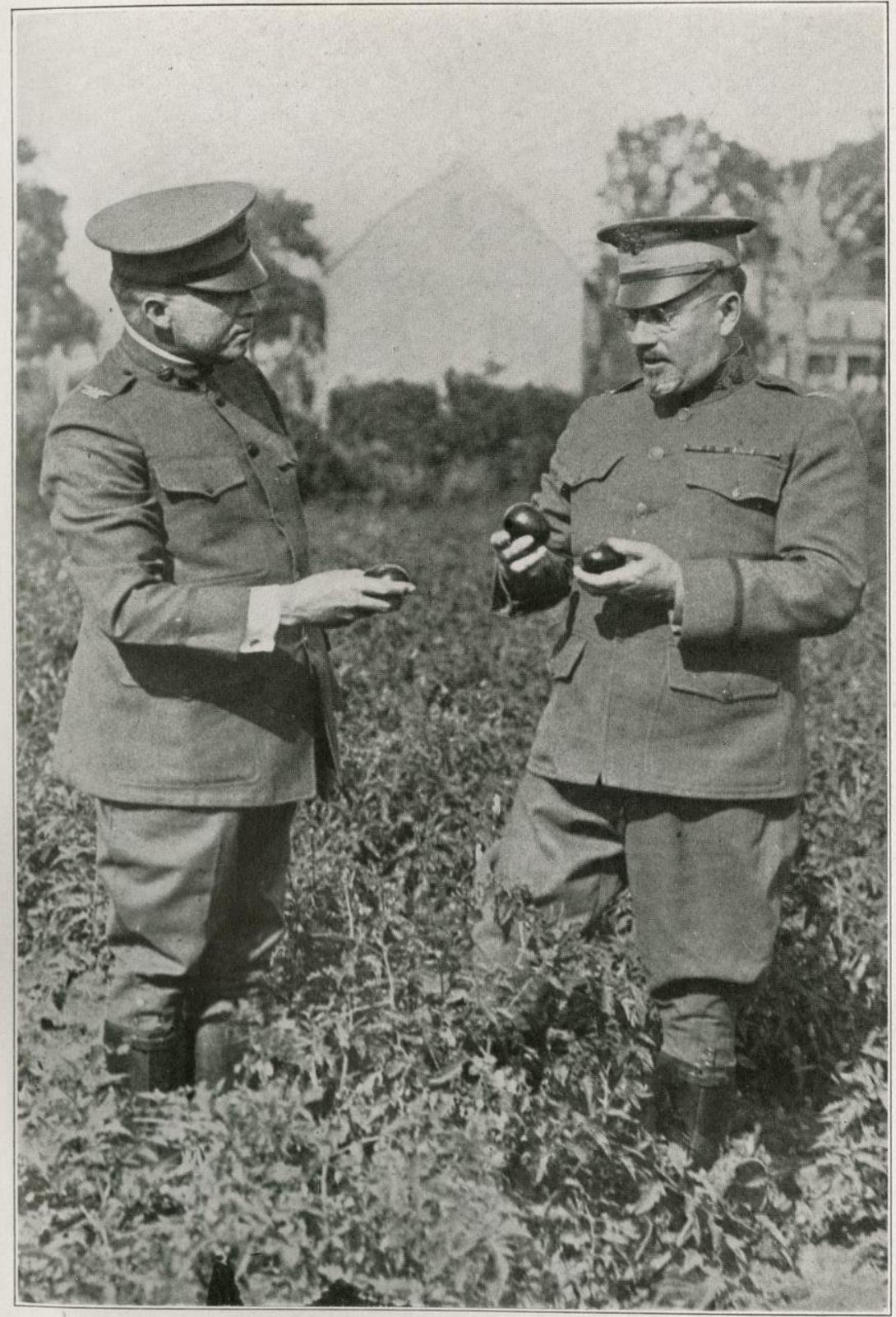

Copyright Western Newspaper Union

GOING OUT TO MEET THE CROP

As "the man who feeds the army" Col. J. W. McIntosh, chief of subsistence, was deeply interested in the demonstration war garden made by the soldiers at Camp Dix. His interest in the food supply prompted him to go into the fields at Camp Dix and the camera caught him as he helped camp Quartermaster Tompkins pick tomatoes. Col. McIntosh is at the left. 



\section{CHAPTER VI}

\section{HOW BIG BUSINESS HELPED}

Organized Effort to Can the Kaiser

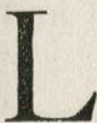

IKE that young man of great possessions who came to Christ, inquiring, "What shall I do to be saved?" hundreds of men who possessed or represented immense wealth, captains of industry and leaders of big business, came forward in this present-day struggle against pharisaism and demanded: "What can we do to help?" In their desire to back up the government, they were ready to do anything possible to increase the efficiency of either their works or their workers.

Even before the war began, a few manufacturing concerns had started community gardening among their employés, though the number of such enterprises was small. Once the war-time need of food was pointed out, however, business and industrial plants in every part of the country organized their men for garden production.

Happiness has been defined as a by-product of labor. Straightway the concern engaged in the war-garden movement found that it, too, had a valuable by-product, and that was increased efficiency among the workers. It was not alone through the addition of certain amounts of food products to the nation's supplies that war gardening proved valuable. It reacted 
on the spirit of the workers themselves. It built up a feeling of good-fellowship not previously existing. It engendered a spirit of coöperation that carried over into the work of the shop. It created that intangible and invaluable thing, esprit de corps. It was productive of many good results throughout entire communities, which were reflected in the general financial and social conditions within those communities.

No less marked were the gains from the employers' point of view. The contented workman is the efficient workman; and gardening, by providing better food than can be had in the markets, and by virtually adding to the worker's income, makes him more contented. Money that otherwise would have to be spent for food can be used for the purchase of those small comforts and luxuries that make for added happiness in the home.

Of great worth, too, is the recreational value of gardening. The toiler in a noisy mill, or the worker in a smoky forge or factory can find no avocation, no recreation, that will build him up physically and refresh his energies as will the cultivation of a plot of ground.

Unexpectedly enough, also, war gardening resulted in a lessening of the labor turnover. One striking testimonial on this latter point was contained in a report to the Commission from a busy manufacturing city in the Middle West. "Workers here," said this report, "refused to leave the city to take work at higher wages elsewhere because they had planted fine war gardens and were so proud of them they would not leave them." 


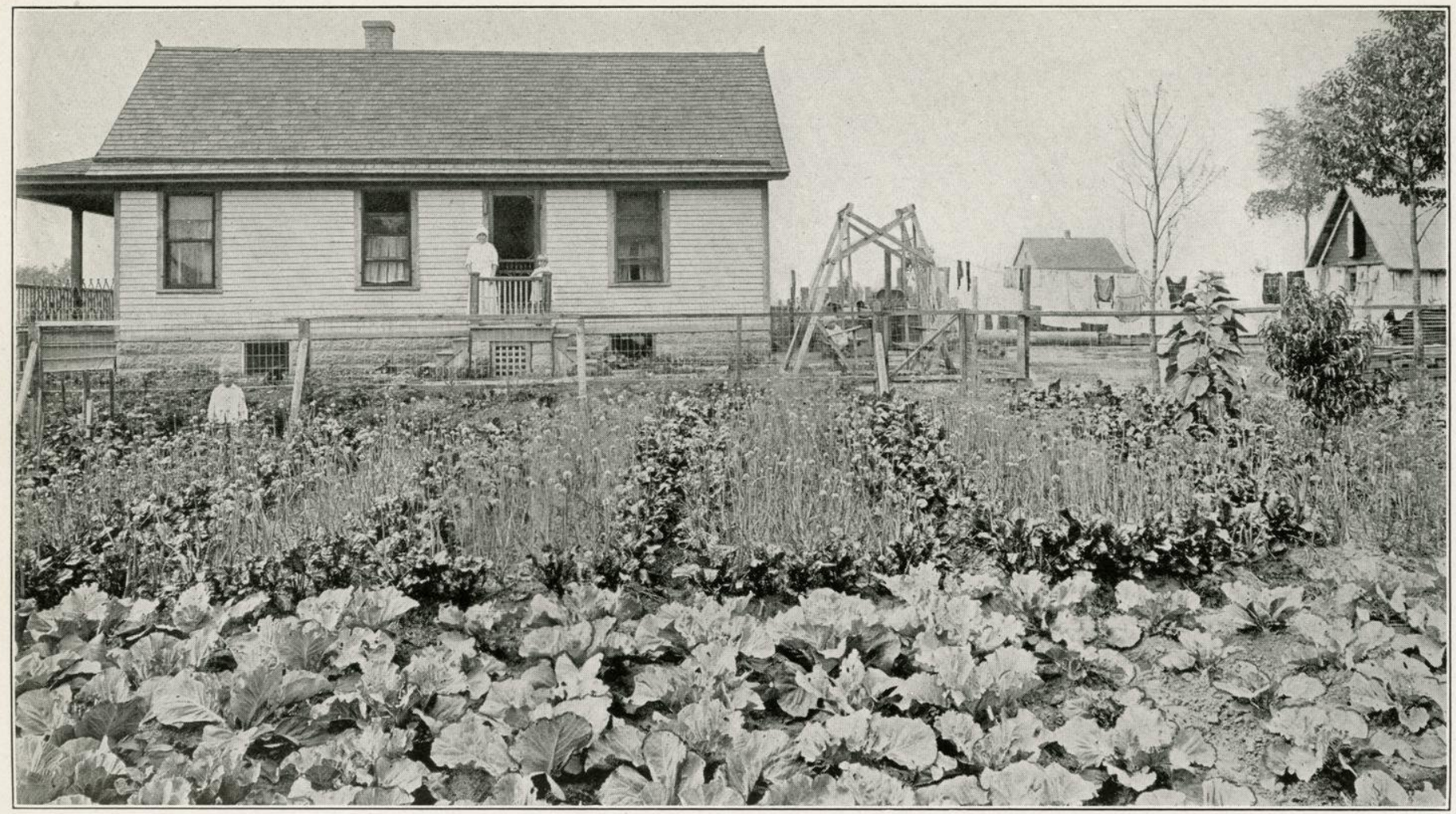

WHAT A FACTORY WORKER DID

Here is a corner of a fine war garden, covering in all about an acre of ground, which was intensively cultivated by an employe of the Eastman Kodak Company, Rochester, New York. It was an inspiration to hundreds of other workers who vied with each other to make their plots as productive
as possible. Great enthusiasm was shown throughout the entire city in this form of war work. 

Moreover, the knowledge that his employer is interested in his welfare inevitably creates a kindlier feeling on the part of an employé toward his employer. When officials of large concerns worked side by side with their men in the faciory gardens, as many far-seeing managers did, a sympathetic understanding sprang up that could have been created in scarcely any other way. War gardening gave opportunity for the "personal touch" which manufacturing on a large scale and collective bargaining have almost eliminated from modern industry.

Perhaps these things can best be made clear by quoting a captain of industry. Speaking not only for himself, but also for other leaders of "big business," the superintendent of Foster, Merriam \& Company, of Meriden, Connecticut, wrote as follows to the National War Garden Commission, after war gardening had been tried out for a year at his plant:

Besides the material gain, the garden work promoted a fine spirit of democracy and fellowship among the men. Everybody, from the president to the humblest employé, had a garden plot. And officers and employés, working together as they did, found mutual interests and fellowship there. The employés took a great deal of interest in the work and kept the entire ten acres in perfect shape, free from weeds, and well cared for at all times. Owing to the interest manifested and the good results obtained, it will be necessary to secure additional land next year.

Among the large companies which helped their men in this way was the Carnegie Steel Company. Here is 
what the superintendent of one of the Carnegie plants wrote the National War Garden Commission:

The plots were taken by men in all classes of employment. Laborers, skilled operators, clerks, and executives-a large number of them without previous experience-went into the work. A great variety of produce was raised. Much spirit and rivalry developed among the gardeners, this being increased by the offer of prizes for the best gardens. In spite of the fact that the river twice flooded part of the gardens during the growing season, two of the prizes were taken by workers in the flooded areas. The general average of the gardens was above eighty per cent., and thirteen of them above eighty-four per cent. Only one was adjudged a failure. The committee of judges was compelled to revisit the gardens twice after the first marking in order to decide on the winners, and even then had to place several of them on a par.

The gardens were not only an assistance to livelihood and a decided profit to the average worker, but were also an inspiration and fascination, as well as a means of pleasure and healthful education and exercise.

From the rock-bound coasts of New England to the far-flung shores of the Pacific, the war gardens of the workers in industry stretched in an almost unbroken line. The lumber camps of Washington and Oregon and the mining settlements of Arizona boasted their war gardens. The iron, cement and motor-car makers of the Middle West had their garden plots. The copper regions of Michigan, the shipyards of Texas, and the roaring mills of the East, all beheld the sudden upspringing of great gardens. 


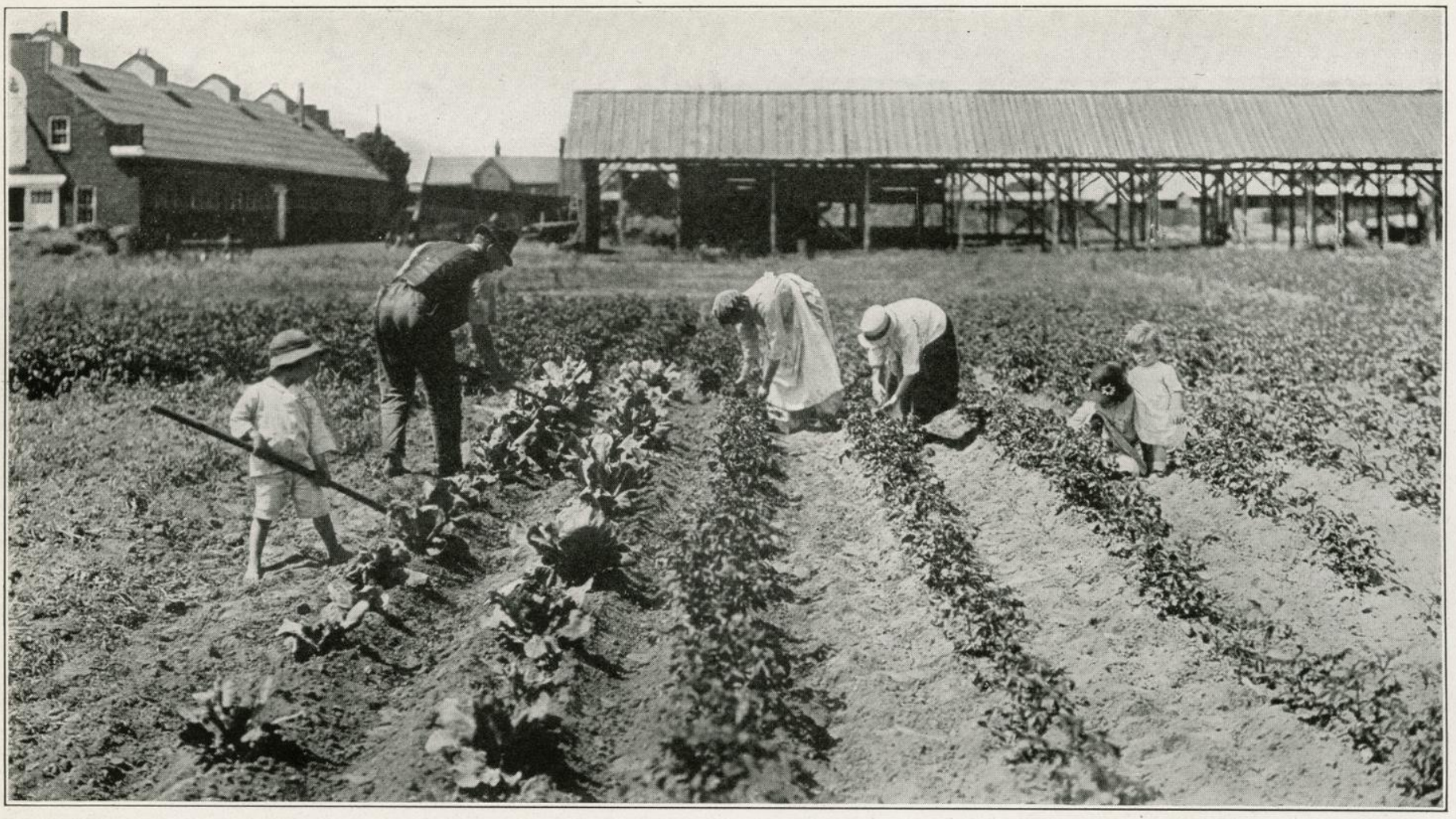

ALL THE FAMILY HELPS

Here is shown an employe of the Oliver Chilled Plow Works at South Bend, Indiana, with the rest of the members of his family, industriously employed in the garden. This company furnished several large tracts for its men, and hundreds of them took advantage of this opportunity to help themselves and their country at the same time. 

"Our purpose is to encourage the raising of fresh vegetables at the mills and logging camps of this state and Oregon where employés are engaged in the production of essential war material for shipping and aircraft purposes," was the inspiring word from Robert B. Allen, of Seattle, secretary of the West Coast Lumbermen's Association. C. S. Williams, vice-president of the F. B. Williams Cypress Company, of Patterson, Louisiana, reported thus to the Commission:

We are pleased to advise that practically every available piece of land that we own around the plant is being used for war gardens for our employés. There seems to be a great interest in home gardening throughout this territory. We have never seen the land so entirely and carefully cultivated. Hardly a family is without a garden. Almost every one of our men has a garden. The books you sent were quickly taken and have been of great service to our people. They are now planning a great canning campaign.

One of the most interesting instances of this eagerness to help both the country and its employés, was furnished by the Inspiration Consolidated Copper Company, of Inspiration, Arizona. Before a thing could be planted, it was necessary to dig five artesian wells to furnish the water needed for the two hundred and seventeen acres of war gardens cultivated by the miners in the first year of the enterprise. The land was situated 3,300 feet up in the mountains. The region was arid. The employés were cosmopolitan. Italians, Chileans, Mexicans, Indians, Finns, Swedes 
and other nationalities were represented in the polyglot assembly. Few of them spoke much English, and more than seventy per cent. of them spoke no English at all. It was necessary not only to instruct them, but to translate and print bulletins and lesson-sheets in a number of languages.

A garden expert from the Arizona Agricultural Station was engaged to take charge of the enterprise. The double-crop system was employed so that as soon as one crop was harvested another was started. If any war gardener was found who did not take proper care of the plot assigned to him, the ground was taken from him and given to another. A market was established to which the growers could carry any of their surplus product and have it sold for them without charge for the service. Nothing was permitted to go to waste, and the food which could not be used at once was canned or dried and stored for future use. On account of the climate most of the conservation was by the drying process. The amount of food grown was large and the saving in this instance was particularly great because of the distance of the mining center from great supply markets.

Something as to the methods used by other corporations in promoting the war-garden movement among their workers may here be of interest. From $\mathrm{Mr}$. Luther D. Burlingame, industrial superintendent of the Brown \& Sharpe Manufacturing Company, at Providence, Rhode Island, comes an instructive report.

This concern opened the war-garden campaign by 
posting a notice on the shop bulletin-boards, announcing a chance to serve country and family by helping to meet the serious shortage in the food supply, and informing the men that the company would furnish land, and plow and fertilize it free for those who would raise crops. Cards for applicants were furnished to the clerks in each department of the shop.

The plots were divided into several groups, in order that the men might secure gardens as near as possible to their places of residence. After the drawing, the numbers of the gardens were filled in on the cards. The required requisitions for fertilizer and seed went through the supply department. The supplies purchased were obtained at wholesale prices, the men being charged only enough above cost to pay for the handling and accounting.

To each gardener was given a card which bore his name, address, and the number of his garden plot, to constitute proof that he or any member of his family carrying it had a right to the particular plot designated. These cards were issued for the protection of both gardens and gardeners. Printed on them were the following rules:

I. Members shall keep their plots weeded and as free from bugs and injurious insects as possible.

2. Members shall not throw refuse on neighboring plots, or in paths. After harvesting, lots are to be cleaned, and refuse taken to places provided.

3. Members shall not plant closer than 12 inches from the boundary line. Any one working your lot must show this card. 
A gardening club was organized with elected officers representing as far as possible the different departments of the shop and different plots of land. The general administration of the project was in the hands of the shop industrial department, but the gardening club was consulted and asked to pass on many matters which had to do with the satisfactory carrying-on of the work, thus giving them something to say as to what should be done. Part of the plowing was done with a tractor. The land was divided into individual plots each containing from 2,000 to 2,500 square feet; and stakes were set diagonally at the corners of each plot with the number of each plot showing at each corner. At the largest garden center a tool-shed about sixteen by thirty-six feet in size was erected where running water was available and a man placed in charge so that tools could be given out on check. This shed was open from daylight to shortly before working hours each week-day, again at noontime, and from six o'clock in the afternoon until dark. It was also open on Saturday afternoons and to some extent on Sundays. A slight charge was made those who desired to hire tools instead of buying their own.

To supervise the gardens and give general instructions to the men who had not previously had gardening experience, a practical farmer with training in an agricultural college was employed. As at other plants throughout the country the gardens in many cases became family affairs, and all the members of a family took part either in work or in supervision. 


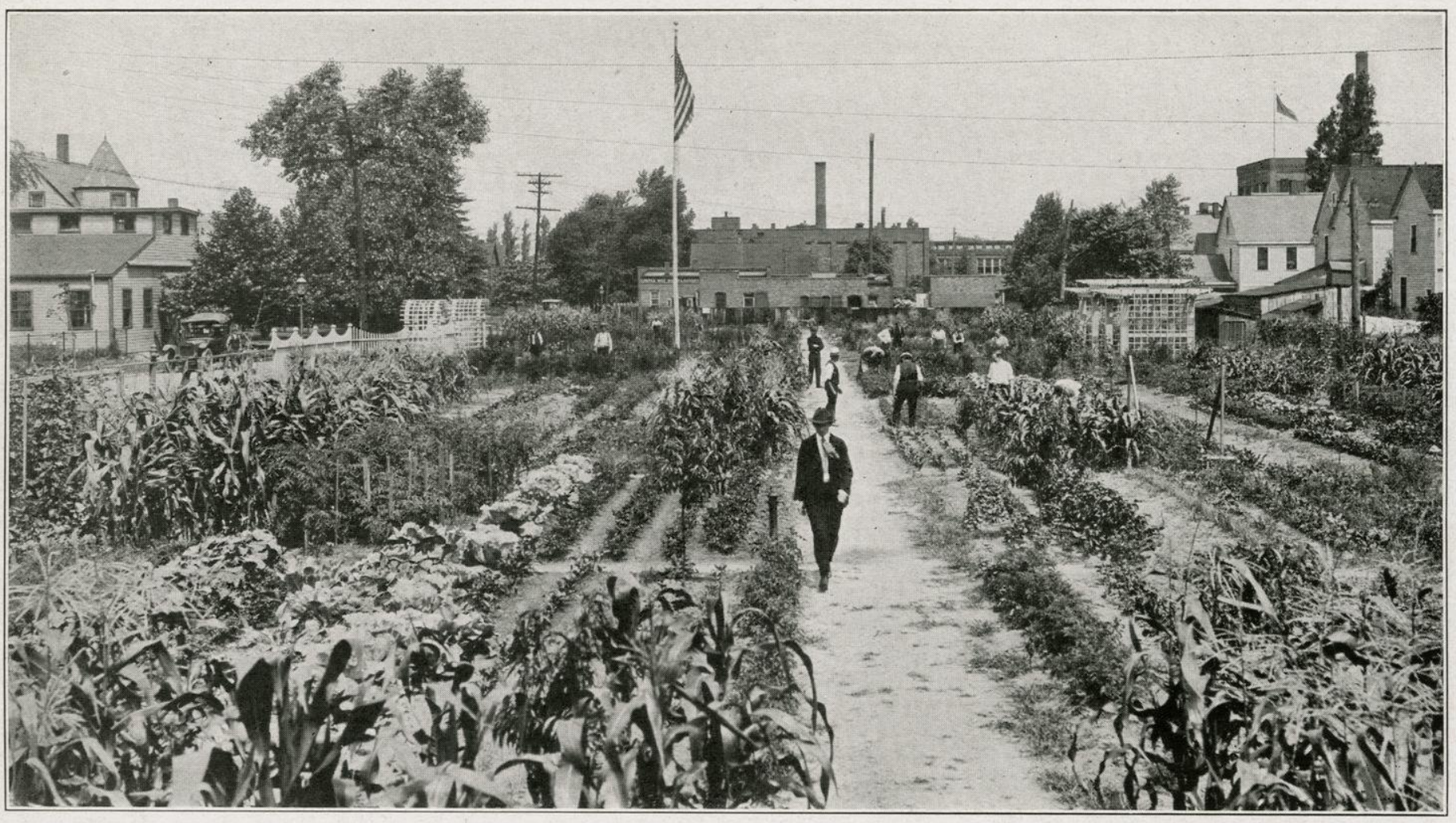

A VERSATILE MANUFACTURING CONCERN

In this war garden of the Globe Machine and Stamping Company, Cleveland, Ohio, the shop employ es raised a wide variety of vegetables in sight and sound of the shop. The list included cabbage, sweet corn, onions, parsnips, tomatoes, beans, peppers and fifteen other varieties of things to eat. 

"As the season advanced," said Mr. Burlingame, "a spirit of good-fellowship and the forming of new acquaintanceships among those who found themselves cultivating neighboring gardens, were features which added to the value of the garden project. It was sometimes found that a laborer working side by side with a foreman could, from the gardener's standpoint, turn the tables, become instructor, and set the pace. When illness prevented some man from working and there were no members of his family to help out, shopmates volunteered and cared for his garden or even harvested his crops for him. Otten gardens cultivated by men having had experience adjoined those where the workers were beginners. In such cases the best good-will was shown in giving and taking advice and instruction."

Regular inspections of the gardens were made and records kept. If a garden showed signs of being neglected, a notice was sent to the workman and this tended to spur the food growers on to keep their plots in such excellent condition that there would be no need for criticism. The men took their work very seriously. Some swamp land which had never been cultivated and which was considered absolutely useless for garden purposes was reclaimed and produced excellent results. The largest crop of potatoes in a single garden, twenty bushels, was raised on a lot which the gardener enlarged by digging up land which had been a dump beyond the plowing. A number of prizes which were offered by the company for the best crops both as to size and quality aroused keen and friendly rivalry and 
had much to do with stimulating the progress of the undertaking. An exhibition was held in a shed at the factory at the close of the season.

In the first year of this work, 1917, there was grown in 500 gardens covering thirty acres of land, food valued at $\$ 10,000$. This added to the food supply of the workers 4,000 bushels of potatoes, 254 bushels of beans, 223 bushels of tomatoes, five and a half tons of turnips, more than two tons of carrots, three tons of cabbage, and nearly a ton of parsnips, besides a large quantity of other vegetables.

Similar statistics were gathered by the Firestone Tire and Rubber Company, of Akron, Ohio, as to the value of the crops produced by the Firestone workers on a tract of forty acres. The average value per acre of these crops was $\$ 280$. The men raised $\$$ I $4,205_{2}$ worth of food. The total expenses were $\$ 3,024$. The net profit was $\$ 11,182$. It was figured out that the men earned on the average almost a dollar an hour for the time spent in cultivating their plots, the exact figures being ninety-four cents an hour.

Gratifying as these financial rewards were, the workers were perhaps even better pleased with the realization that they were aiding in bringing victory nearer. They knew that they were cutting market and grocery bills by raising a part of their own supplies; but they also realized that to win the war, "food must be kept following the flag."

No class of people in the country was in a position to realize more fully the immense value of war gardens 


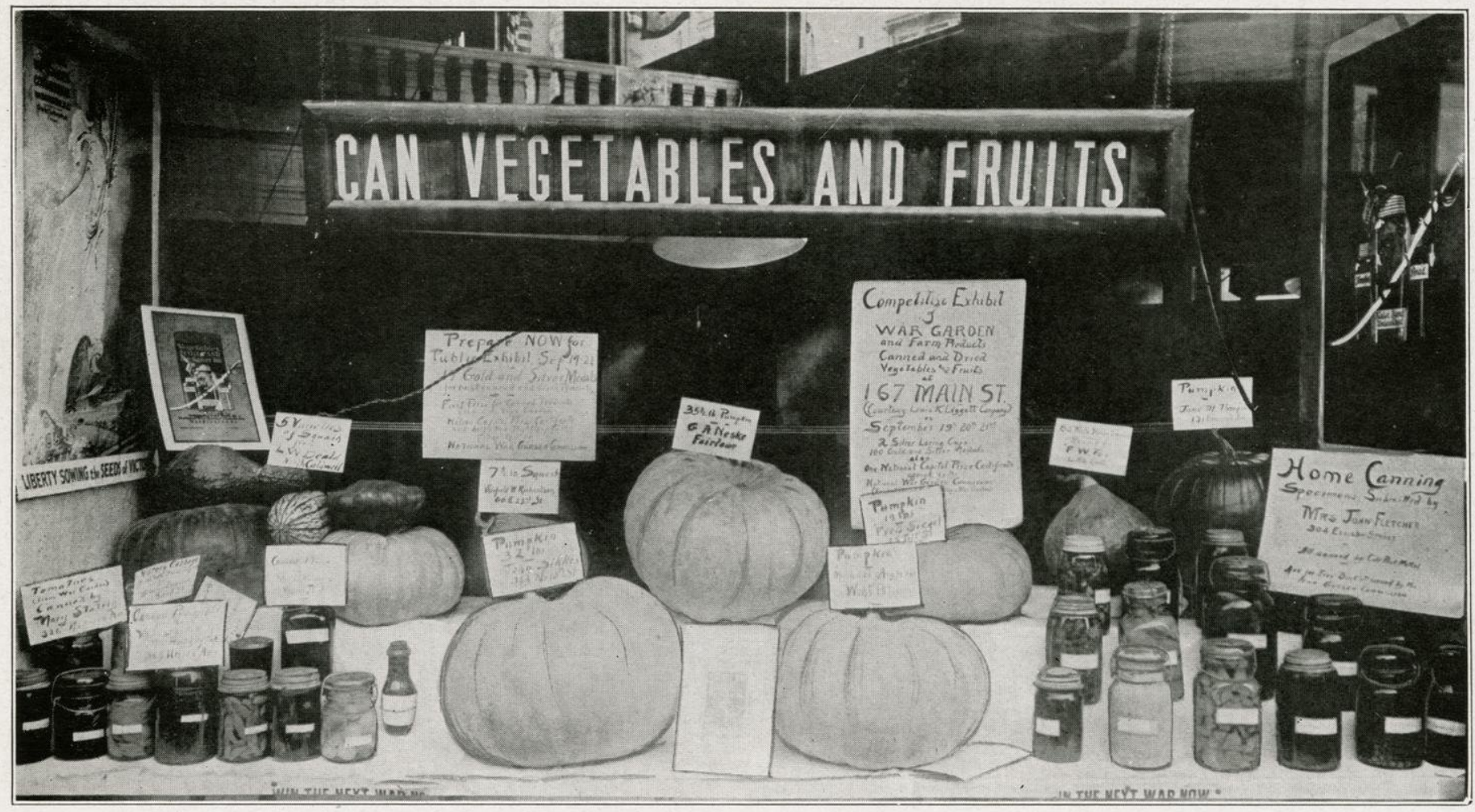

WAR GARDEN DISPLAY IN BANK WINDOW

Hundreds of banks throughout the country assisted actively in the drive for home-grown food, just as they did in the other patriotic calls which the nation made to them. The Paterson Savings Institution, of Paterson, New Jersey, was one of those which distributed garden booklets, furnished by the National War Garden Commission, to its patrons, and held an exhibit of resulting products which attracted great interest. 

in another direction than the manufacturers and their employés. This was in the saving effected in transportation facilities. These men knew better than any others the urgent demand which essential war shipping was making on freight-cars. They saw and handled daily the vast quantities of raw materials and finished products which had to be hauled. They knew there was a shortage which could not be made up entirely. They were cognizant also that gardening would result in a considerable conservation of carrier space which could help to fill the demand. If hundreds of thousands of workmen in all parts of the United States were growing much of their own food right near their homes, it required no argument to prove that long lines of cars would be released for other service.

The industrial promotion of the war-garden movement was not confined to manufacturers. Railroads, large insurance companies, public utilities in many sections, banks, and those engaged in numerous other lines of industrial and commercial activity, were equally enthusiastic and active in forwarding the movement. Gas companies opened demonstration kitchens and gave out thousands of books and other printed matter. Water companies in many places throughout the West, where the land required irrigation for cultivation, furnished water free to all those who announced their intention of planting war gardens. Banks which helped so unselfishly and patriotically in other campaigns, urged home food production upon their patrons by handing to them leaflets pointing out the national 
need and the pressing importance of this work, and by giving out also instruction books from the Commission telling the city farmer how to proceed.

Praise must be extended to business as a whole for the part it has taken in aiding in the cultivation of war gardens by the nation's army of workers. A list of the concerns which have helped in this way would be practically all inclusive. Among the big nationally known companies which have been especially active in this form of war work are the Oliver Chilled Plow Company, Du Pont de Nemours \& Company, the American Rolling Mill Company, the American Woolen Company, the General Electric Company, the United States Steel Corporation, the American Optical Company, the American Cast Iron Pipe Company, the American Steel and Wire Company, the J. I. Case Plow Works, the Universal Portland Cement Company, the Oliver Iron Mining Company, the Ford Motor Company, the Solvay Process Company and the Eastman Kodak Company.

Employés at the various mills of the American Woolen Company planted in 1918 a total of 1,229 acres of gardens; and Mr. William M. Wood, the president of this big manufacturing concern which made large quantities of clothing to help keep the American soldiers warm, expressed his gratification at this other way in which the employés were working to help their country.

As to some of the benefits to the workmen themselves, the moral strength which they gain from their employ- 


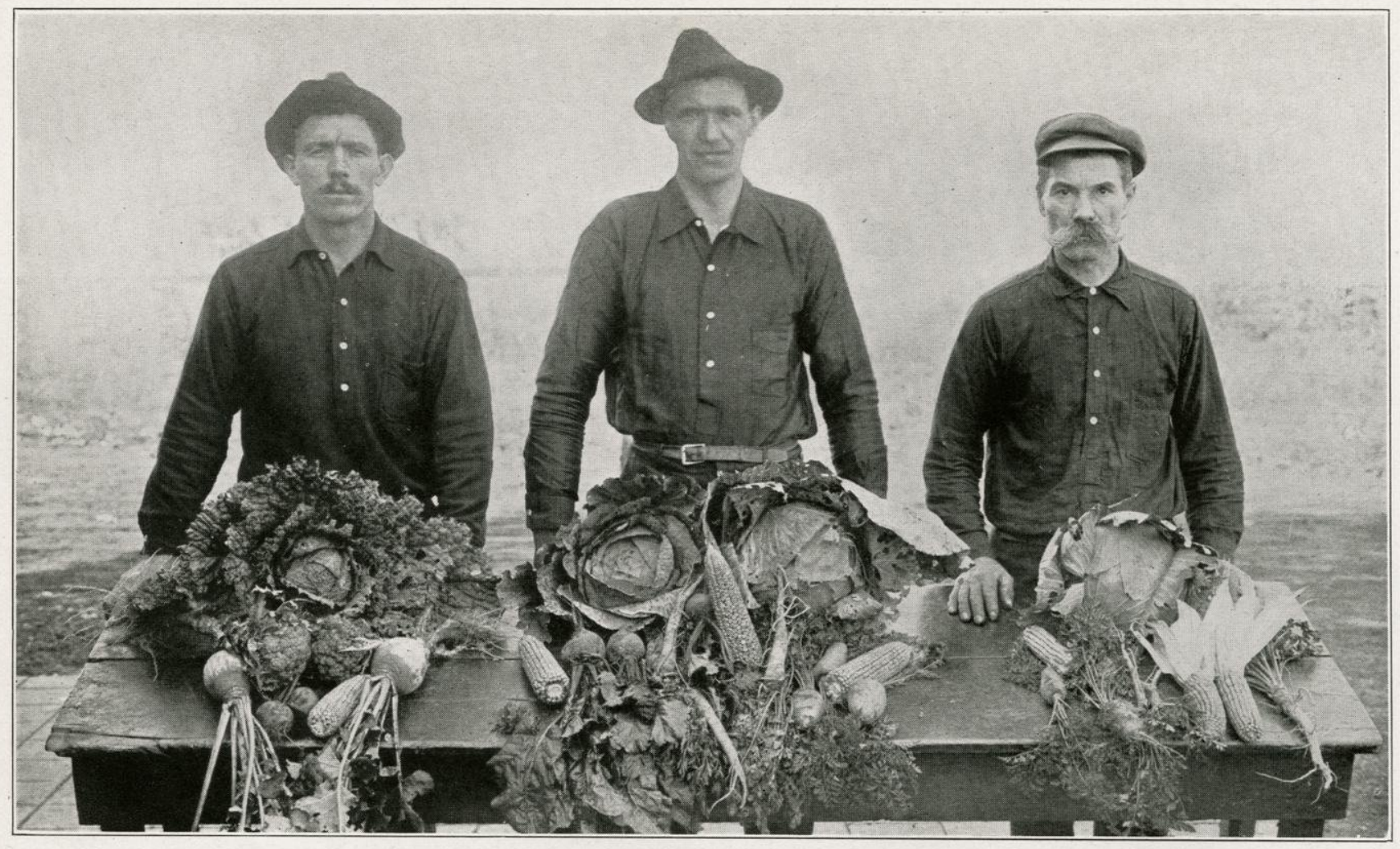

NATIONALITY MADE NO DIFFERENCE

Here are shown former citizens of three different countries, but all Americans now, who helped through their war gardens to win the war. They are employes of the Oliver Chilled Plow Company, South Bend, Indiana, which furnished land and otherwise assisted its men to take care of their home food needs. These men show by their satisfied look how much they appreciated this help. 

ment in this side occupation of gardening, their release from the narrowing and confining work in which they often are engaged, it is appropriate to quote from an article by Professor Irving Fisher of Yale University, a member of the Commission, in which he says:

A laboring man sees his work sweep by him, a peg in a shoe, a bolt in an automobile, and since he is not able to visualize his part in the product, his work ceases to be interesting and becomes drudgery. He wants to shorten his hours; and the employer, whose work is interesting, whose work is his life, cannot understand why the employé is always trying to shirk, whereas he himself is willing to work twelve or sixteen hours a day. The reason is that in one case the instinct of workmanship is satisfied and in the other case it is not.

Here we have summarized in a telling way one of the best possible arguments in favor of the upbuilding, the strengthening, and the continuation of war gardening among the employés of mills, factories and shops. The tasks they are performing in most cases do not satisfy their "instinct of workmanship." They do not finish their day's labor and go home with the feeling that they have taken a step forward, that they have accomplished something which will add to their value to themselves, their families, the community and the country.

A man who is a cog in a vast machine cannot put individuality into the driving of continuous pegs into a shoe; but when he gets outside the walls of the factory into the little forty by sixty vegetable plot he is cul- 
tivating under the shadow of the mill, he can put himself into this work. It is for his own good. What he grows there will be his own property. It will go to support himself and his family. How much or how little of it there will be depends upon himself, upon how intelligently and how faithfully he cares for the plants. He takes an interest in watching every development from day to day because he is to reap the reward. This work is his own. It means that he will take a deeper interest thereafter in the work he is doing for his employer. It is only natural that a man should feel a more real concern and show greater pride in doing something where he will share in the profit. It is not in any sense disparagement to a workman to say that he cannot display the same sense of gratification in his regular work.

There is greater diversity in the cultivation of a garden than in most other tasks. It offers, in fact its successful prosecution demands, good judgment and the display of sound sense. This is healthful exercise for the mind, which makes it more alert and more able to grasp and figure out other problems arising every day of the workman's life. Combined with this mental activity is the invigorating bodily exercise than which there is none better than digging in the earth and getting close to nature.

While the reports to the National War Garden Commission show that the methods adopted by various manufacturing concerns which encouraged gardening among their men differed somewhat in detail, as would 


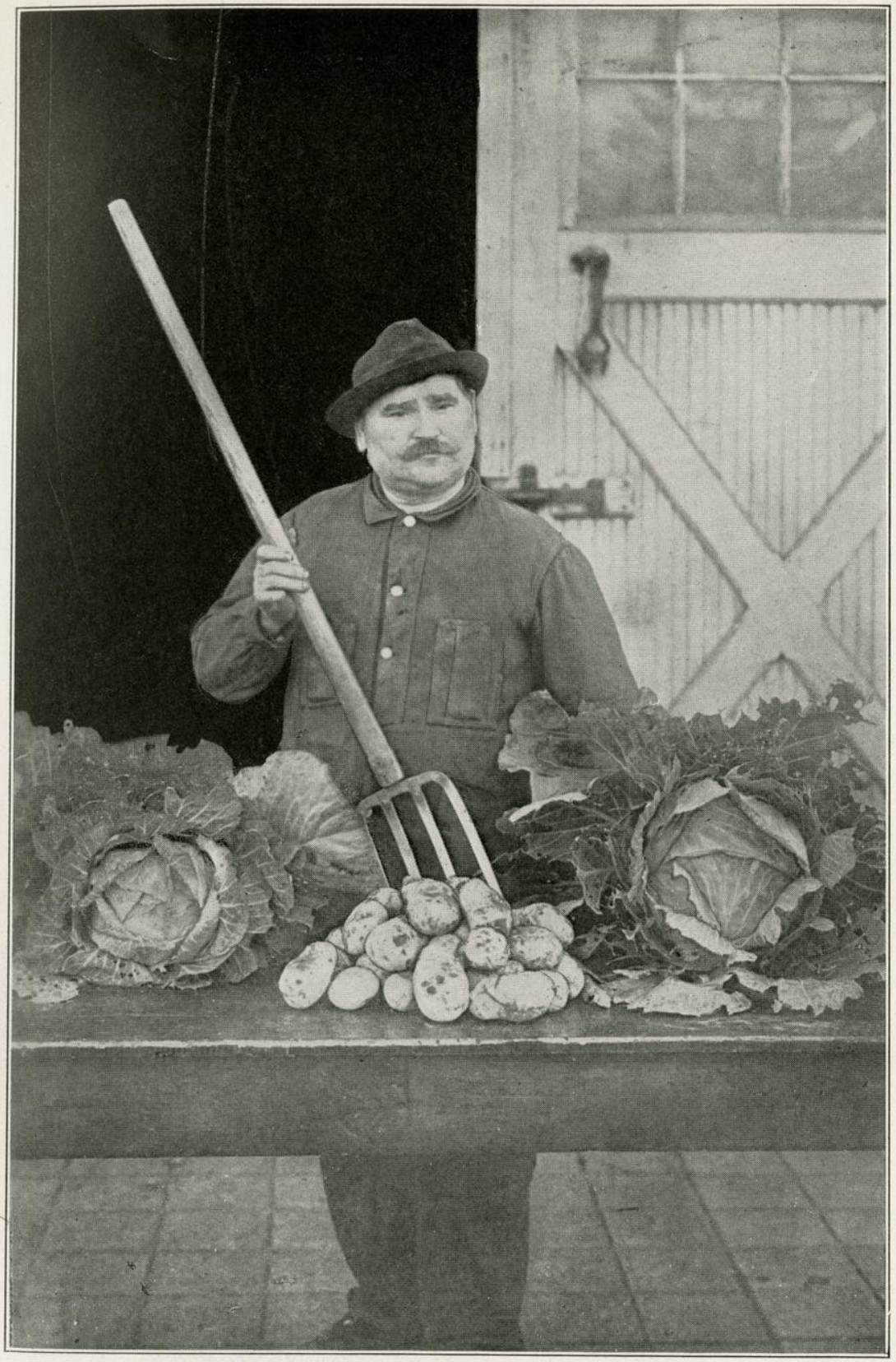

THIS IS NOT NEPTUNE!

Joe Borzell, an employe of the Oliver Chilled Plow Company, South Bend, Indiana, was proud to pose for his picture with some of the fine potatoes and cabbages he had raised in his war garden. It is plainly to be seen that some of the company's other workers who had gardens had to show extra fine results to beat this man's products. 

of necessity be the case, still the fundamental principles were the same; and the results obtained, chief among them better contentment among the men, were everywhere alike. The Commission feels that no other single phase of its work has been of greater and of more lasting benefit than the stimulus it has been able to give to the wonderful growth of factory gardening. Increased food production by this means is of immeasurable value to the nation, to the community, to the employer of labor, and to the individual. In congested industrial centers it is particularly desirable that every possible relief be given to freight transportation systems; and the raising of large quantities of food " $F$. O. B. the Factory Door" affords great help in that direction. Business men have seen the advantage of this movement and will continue to encourage and expand gardening among their employés. 


\section{CHAPTER VII}

\section{HOW THE RAILROADS HELPED}

War Garden Activities of Management and Employes

\section{$A^{s}$}

soon as America became a belligerent the railroads of the country sought to help relieve the food shortage and the traffic situation by encouraging the cultivation of all vacant lands along their rights-of-way. They called on their employés to plant this unused acreage wherever it might be found. To railroad managers the double value to be gained was quickly manifest. The movement would not only add to the nation's food supply but be an important and direct factor in relieving the demands on the carriers for the hauling of freight. The result was that nearly all the railroad lines ran through gardens of growing vegetables which were soon seen flourishing everywhere, along the tracks, around the cosy little watchboxes of the crossing flagmen and even alongside station platforms.

The railroads furnished the land to their men free of charge or at nominal rental, and in many cases further assisted them by supplying quantities of seed and by aiding in the preparation of the soil. They placed posters in their stations calling attention to this opportunity for patriotic service, and distributed tens of thousands of copies of gardening and canning manuals furnished them by the National War Garden Commis- 


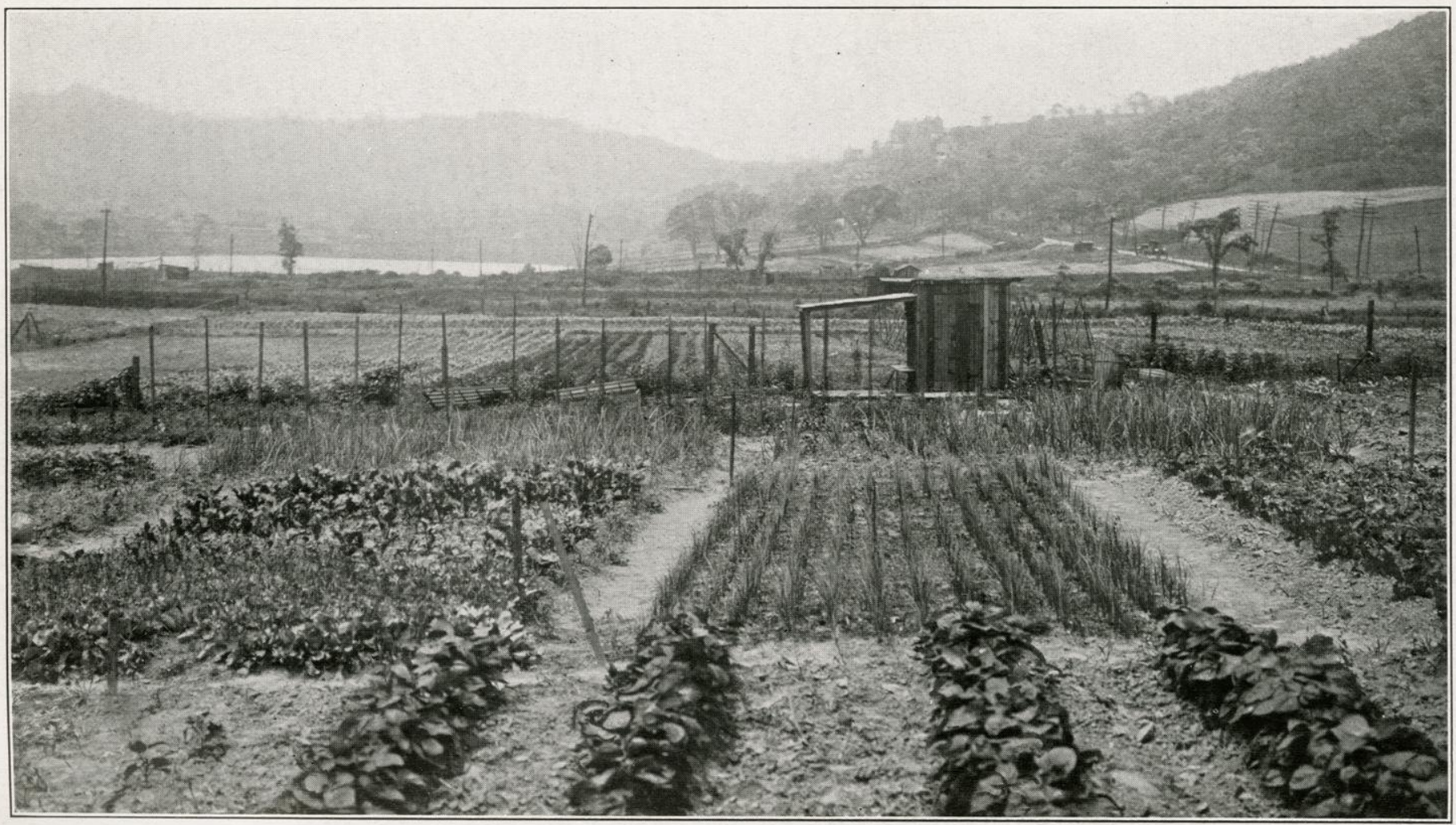

ON PENNSYLVANIA RAILROAD GROUND

This is a fine example of what was done by many of the employes of railroads in raising vegetables on ground which formerly had been lying idle. The companies aided by distributing garden books among the men, by placing war-garden posters on bulletin-boards directing attention to the value of this work, urging the workers to apply for land, and in various other ways. This scene is at Pitcairn, Pennsylvania. 

sion. The Pennsylvania Railroad alone, on its lines east of Pittsburgh, gave out during the season of 1918 more than 20,000 copies of these instruction booklets. The division superintendents and their assistants acted as the distributing agents. In addition they frequently assisted in other ways in helping to arouse the entire local and community interest in this work. Through the posters, displayed conspicuously on bulletin boards, the attention of hundreds of thousands of other persons besides railroad employés was called to the urgent need of war gardens and of conserving food. Local station agents were also a powerful factor in the work. Not only did they encourage the company employés to engage in gardening but they assisted in other ways to arouse interest.

As a sample of what the railroads did in this direction, here is an extract from a general notice, signed by R. L. O'Donnel, assistant general manager of the Pennsylvania Railroad, which was posted along all the lines of that road. This was addressed "To all employés of the Pennsylvania Railroad." It said:

Owing to the interest shown, and the substantial results obtained by employés of the Pennsylvania Railroad in the cultivation of war gardens last year, the Management will renew for the present season the arrangement by which vacant land belonging to the Company may be available to employés for garden purposes, at a nominal rental. . . All employés who are able to do so, are urged to take advantage of these opportunities by cultivating war gardens this spring and summer, thus assisting our country in the production 


\section{THE WAR GARDEN VICTORIOUS}

of food, and also aiding in a very essential manner to win the war. Employés taking this action will, in addition, be helping themselves in one of the best possible ways. It is for just such purposes as these that the Daylight Saving plan was initiated. Last year the employés of the Pennsylvania Railroad lines east of Pittsburgh raised crops of an estimated value of one quarter of a million dollars. Let us endeavor to surpass this good record in 1918.

Many other railroads deserve special mention for their activity in this line. Among them are the New York Central, the Union Pacific, the Northern Pacific, the Missouri, Kansas \& Texas, the Illinois Central, the Atlantic Coast Line, the Chicago, Rock Island \& Pacific, the Chicago, Burlington \& Quincy, the Long Island, the New York, New Haven \& Hartford, the Missouri Pacific, the Erie, the Boston \& Albany, the Delaware \& Hudson, the Chicago \& Northwestern, the Pere Marquette, the Louisville \& Nashville, the Norfolk \& Western, the Seaboard Air Line, the Chicago, Milwaukee \& St. Paul and the Cleveland, Cincinnati, Chicago \& St. Louis. The New York, Chicago \& St. Louis Railroad Company reported that a number of gardens were planted along its right of way in 1917 and that in 1918 all available land was applied for and assigned for this purpose.

A report from the Buffalo, Rochester \& Pittsburgh Railway showed that more than 2, 100 bushels of seed potatoes were furnished to the prospective gardeners, and that the men not only planted these but bought more for themselves, besides buying seed for other 


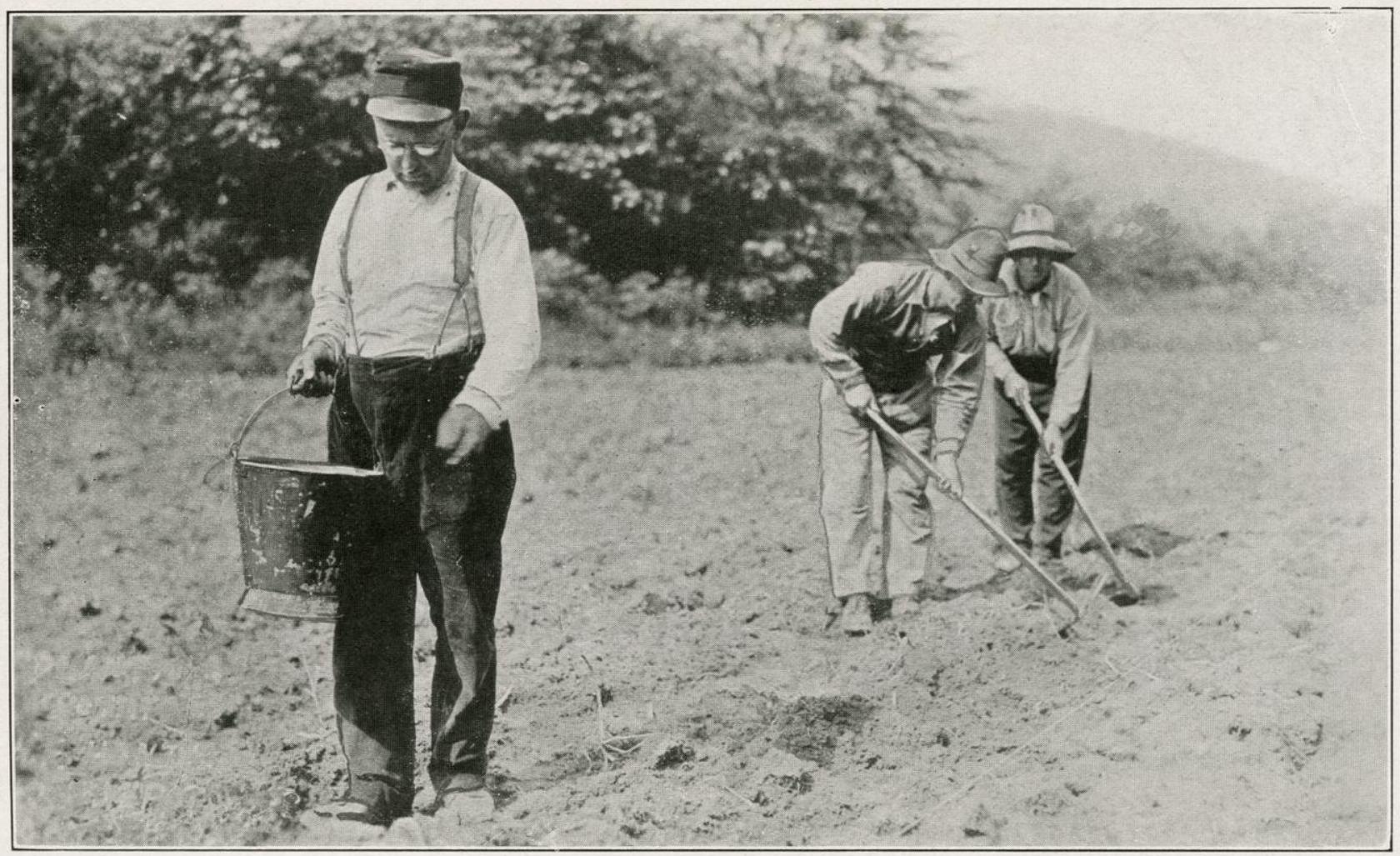

SOME RAILROAD "SOLDIERS OF THE SOIL"

These are Pennsylvania Railroad employes planting potatoes. No class of workers in the country better realized the value of saving transportation by producing "Food F. O. B. the Kitchen Door" than did these men; and thousands of them availed themselves
of the opportunity to plant land offered them along the right of way. 

vegetables. The resultant yield was 28,000 bushels of potatoes and other garden products to a value of $\$ \$_{1} 5,400$. The Chicago, Burlington \& Quincy reported among other products 3,000 carloads of beans from lands which hitherto had been considered of little value except for grazing purposes.

Plans for the continuation and extension of this work in 1919 have been put into effect by the United States Railroad Administration on all the lines over which it has supervision; and in urging the call of Victory Gardens it coöperates closely with the National War Garden Commission. In response to an appeal sent out by J. L. Edwards, director of the agricultural section of the Railroad Administration, replies have been received from virtually all the regional directors and other officials stating that they would promote the movement to the fullest extent possible. A notable example was the reply from B. F. Bush, regional director of the southwestern region. He said: "I wish to state that the railroads in the southwestern region will again do everything they possibly can in permitting their rights-of-way and station grounds to be used for farming and gardening purposes. During the last season this work was handled on practically every railroad in this region with much success and it will be repeated." Alexander Jackson, agricultural agent of the Chicago, Rock Island \& Pacific, answered as follows: "We feel that the War Garden is a permanent fixture in practically all parts of our territory where gardening is possible." C. L. Hoffman, agricultural agent of the New York, Ontario 
\& Western, sent this message: "I assure you that I shall do all in my power to have the coöperation of all the officials of our roads in an endeavor to increase the victory gardens of 1919 over the war gardens of I918." Similar evidences of activity were received from many others.

New posters were furnished the officials by the Commission to help carry to the railroad men and the public all over the United States the call for continuing and increasing home food production. These posters were placed in stations throughout the country, in the great city terminals and in the stations in small towns, under a general order issued by W. G. McAdoo, Director General of Railroads. The posters thus officially displayed are regarded as one of the most potent factors in reaching the American public with the message of the world's food needs which followed the signing of the armistice. 


\section{CHAPTER VIII}

\section{THE ARMY OF SCHOOL GARDENERS}

How the Children of America were Mobllized by the Government

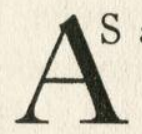

a factor in education the war garden and its successor, the victory garden, have established themselves in a way that will prove a permanent influence in American life. Through the schools millions of children have been awakened to the value of gardening as a patriotic effort of war time and an undertaking worth while at all times. They have been taught that nature is a generous giver who requires only to be encouraged. They have been impressed with the importance of food production and trained into an army of practical producers. The national benefit from such teaching and training cannot fail to be far-reaching in its effects and a lasting force in the lives of the future men and women of America.

In the development of school gardeners two ideas were given consideration. An immediate increase in food production went hand in hand with the educational value of the work. It was not expected, of course, that all school children would become immediate producers, but it was certain that the great volume of work undertaken in the schools would be of appreciable worth in swelling the total of war time food production and of even greater importance in creating a vast army of future citizens trained to intelligent application of the 
principles of thrift, industry, service, patriotism and responsibility. The results have been highly gratifying to those concerned with the undertaking.

For the mobilization of the school children the logical agency wa's theUnited States Bureau of Education of the Department of the Interior. P.P.Claxton, United States Commissioner of Education, approached the undertaking with broad vision and keen foresight characteristic of his administration of educational affairs for the Federal Government. Under his guidance there came into being the United States School Garden Army, mobilized with effective promptness and swung into action under the leadership of J. H. Francis as director. Dr. Francis is an educator of note who was drafted into this important work by Commissioner Claxton, and he brought to bear on the enterprise perception and aggressiveness which achieved results of national importance in comparatively brief time.

President Wilson was keenly interested in the United States School Garden Army. His cordial endorsement was expressed in a letter to Secretary Lane which served as the corner stone of the structure and an inspiration to the children of America. This letter was as follows:

My dear Mr. Secretary:

February 25, 1918.

I sincerely hope that you may be successful through the Bureau of Education in arousing the interest of teachers and children in the schools of the United States in the cultivation of home gardens. Every boy and girl who really sees what the home garden may mean will, 


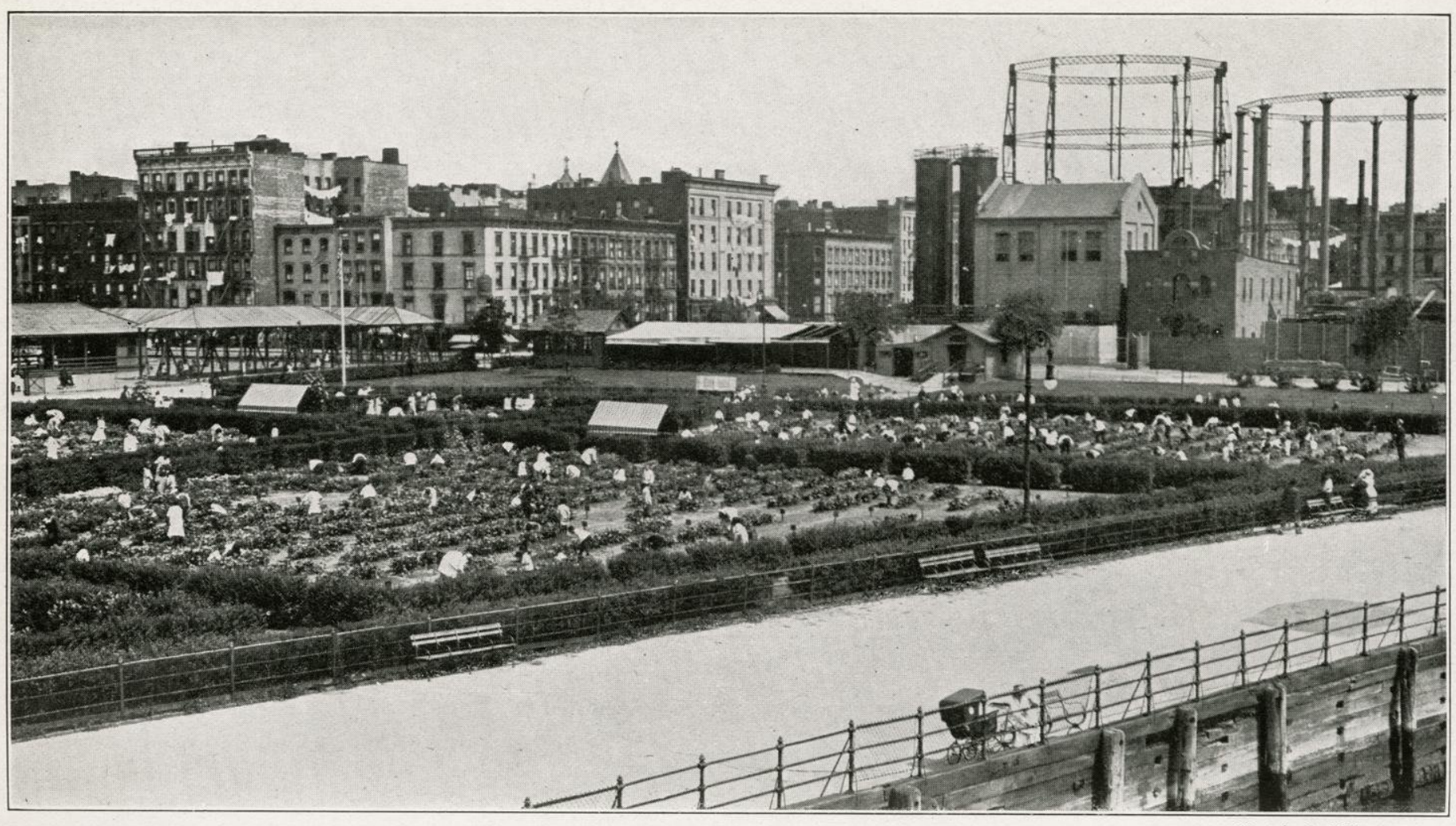

ALONG THE EAST RIVER FRONT

Supervised by competent instructors the school children of New York City produced some excellent results in the gardens which they planted in various sections of the city. The very orderly one here shown, with a large number of children industriously engaged, is in Thomas Jefferson Park, II 4 th Street and East River. 

I am sure, enter into the purpose with high spirits, because I am sure they would all like to feel that they are in fact fighting in France by joining the home garden army. They know that America has undertaken to send meat and wheat and flour and other foods for the support of the soldiers who are doing the fighting for the men and women who are making the munitions, and for the boys and girls of Western Europe, and that we must also feed ourselves while we are carrying on this war. The movement to establish gardens, therefore, and to have the children work in them is just as real and patriotic an effort as the building of ships or the firing of cannon. I hope that this spring every school will have a regiment in the Volunteer War Garden Army.

Cordially and sincerely yours,

WOODROW WILSON.

Hon. Franklin K. Lane,

Secretary of the Interior.

From the outset the United States School Garden Army allied itself with the National War Garden Commission for the conduct of the work for which it had been organized. This affiliation covered not only food production through gardening but also the work of food conservation through home canning and drying.

One of the first requisites of the newly formed army was that its membership should be reached with technical instructions so compiled as to be authoritative and so presented as to be easily understood. To accomplish this the United States School Garden Army utilized the publications of the National War Garden Commission. 
In response to official request, these were furnished by the Commission in sufficient quantities for circulation among the schools of America. The Commission's book "War Vegetable Gardening" was made the standard book of instructions and it reached every school in the land through the machinery of the United States School Garden Army. In similar way the Commission's book on canning and drying was distributed and given official recognition in the educational world.

The satisfactory results achieved through the coöperation of the two organizations was given expression by Director Francis in the following letter to the Commission under date of October 5 th, I9I8:

My dear Mr. Ridsdale:

I do not feel that I should allow the Garden season of 1917-1918 to close without acknowledging to you the very great service the National War Garden Commission has rendered the United States School Garden Army organization, and telling you that we deeply appreciate the cordial, earnest way in which you have coöperated with us in working out our problem.

For 1919 the work of the United States School Garden Army was further expanded and standardized. Perceiving the value of school coöperation through the Bureau of Education, the National War Garden Commission prepared special printings of the victory editions of these books.

These are for the exclusive use of the United States School Garden Army. On the front cover of the school edition of each book appears a reproduction in the 


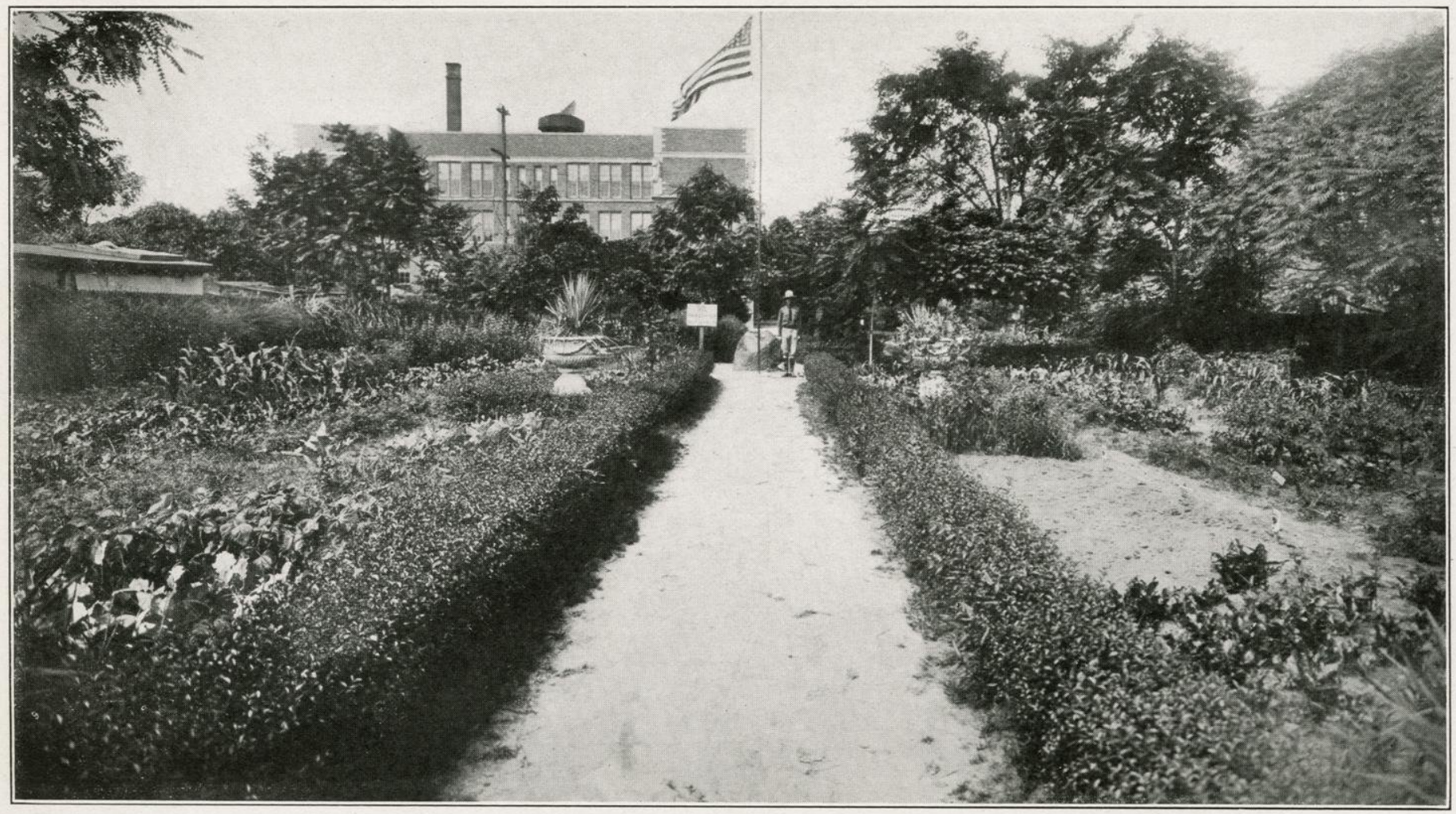

ONE OF CLEVELAND'S SCHOOL GARDENS

Is it any wonder pupils take a pride in a garden like this? The picture shows the fine state of cultivation on the grounds of Rosedale school, in Cleveland. The combination of landscape beauty with vegetable growing commends itself to general attention. 

original colors, of the poster by Maginel Wright Enright, which has become known as the pictorial trademark of the Army. This poster presents Uncle Sam as the Pied Piper of the Gardens, at the head of an army of children bearing garden tools as their weapons. As an introduction the books carry an official proclamation to the schools of America, calling on them for further work in the cause of food production and conservation. In his proclamation Director Francis says:

The food problems of peace give renewed emphasis to the demand for food production. With the ending of the conflict came the necessity for feeding many millions more of the people of Europe. Food Administrator Hoover tells us this country must send $20,000,-$ ○o tons of food overseas during the year ending July I, I9I9. To make this possible it is essential that production be carried on to the utmost of our possibilities. The farms have lost a large proportion of their manpower. Some one must take the places of the men who have left the farms and of the women who have gone into channels of industry in which they were not previously employed.

The boys and girls of America must help to do this. There is a mighty army of them, thirty to fifty million strong, who have heads, hearts, and hands, leisure time and patriotism to spare. There are also hundreds of thousands of acres of tillable land uncultivated. The problem is, therefore, to get these two factors together. It is a problem requiring careful, efficient organization. The organization is here, one of the most powerful in the country-the public school system of America. To build another capable of doing the work in hand would require years and cost millions. School gardens and 
school-supervised home gardens have received serious attention, but only a negligible part of the work has been undertaken. The school system should and must undertake the work with seriousness and determination and give the world results that are real and adequate.

Superintendents of schools must make their schools a vital, an actual, force in giving more food to the world and in conserving what is produced. They must do this in addition to talking and writing about this somewhat spectacular and highly interesting phase of the school's part in the war. And this is their work, not to be sublet to other agencies who by the very nature of the problem can not solve it but can only contribute to its solution.

Commissioner Claxton and Director Francis are deeply gratified at the success of the garden movement among the school children and greatly impressed with its promise for the future. The interest thus awakened and the practical knowledge thus acquired by the young gardeners, they regard as one of the most important national benefits of the war and one which will be of immeasurable worth in its influence on American citizenship. 


\section{CHAPTER IX \\ COMMUNITY GARDENING}

Putting "Slacker Lands" to Work

MERICAN war gardening, like every other de-
velopment in life, has gone through a process of
evolution. Because the exigencies of the situation necessitated haste, that evolution has been rapid. Contending with the most wonderfully organized force the world has ever seen, it was necessary, since so much depended upon the American war garden, to apply to it the principle of the best organization, and to unify it in order to strengthen it. As a result there speedily came into existence the community garden.

Many are the advantages gained through community gardening. To begin with, community gardening is practically the only method by which all available garden space can be put to work. Genuine community gardening, where all available lands are surveyed and allotted to gardeners, hardly falls short of land conscription. Community gardening played no small part in helping to win the recent war. To get enough food to win, the Allied peoples had to utilize every possible garden spot. In America back-yard areas were readily worked by patriotic owners. The enormous areas of "slacker lands," idle, vacant town lots, could not be put to work without considerable difficulty. At the very least, the owner's permission had to be 
secured before a lot could be farmed; and the average man was either too diffident or too lacking in initiative to secure such permission. On the other hand, the average lot-owner did not care to be repeatedly annoyed by requests from various individuals for the use of his idle lands. Both of these difficulties were obviated through real community gardening. The lot-owner dealt with known, responsible representatives of the gardening organization and had to give his consent but once; while the would-be gardener, far from having to seek a plot, was assisted to find one.

Community gardening is also important in that it effects a saving of labor. In preparing the land, for instance, a team of horses or a tractor can plow a large number of gardens in one day. Where the ground is in large plots, a team can readily prepare one acre in a day. One acre will contain slightly more than twentyone gardens each forty by fifty feet-a good size for a family plot. By plowing the tract with a team, the cost to each of the twenty-one gardeners is small. To dig by hand a plot forty by fifty feet, particularly if manure is to be turned under, requires many hours of hard labor. If the gardener has at his command for gardening no time other than the after-work hours of the evening, it will take him several days merely to get his seed-bed prepared.

Again, when a group of people are together cultivating a large plot of land, they can often purchase their supplies, including fertilizer, implements, and seed, at wholesale rates, and thus effect a considerable financial 


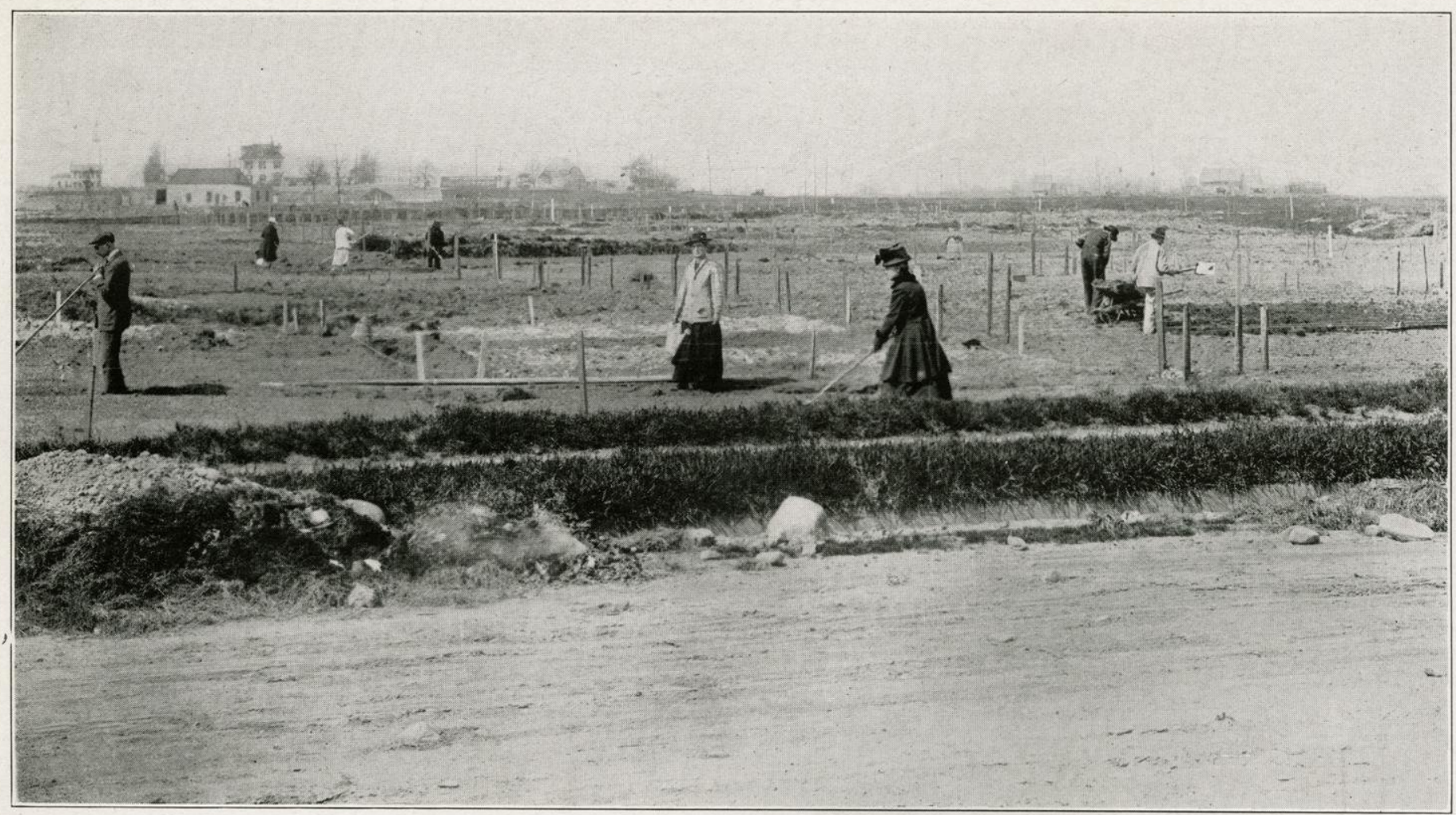

PLANTING A COMMUNITY GARDEN

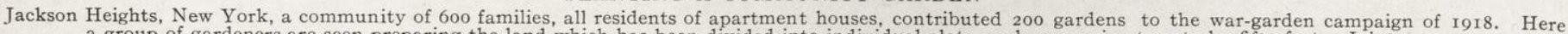
a group of gardeners are seen preparing the land which has been divided into individual plots, each measuring twenty by fifty feet. Joint arrangements were made for watering; jointly owned sprayers were used to fight insects and blight; and a "vigilance committee" which included all the gardeners took turns in protecting the plots from petty thefts and depredations. 

saving. One implement will often serve for two or more gardeners, the gardeners arranging to use it at different times. Employés of factories who have worked together in this way have found the community system of much benefit. Other groups too have found it equally helpful.

Community gardening also makes it possible for expert supervision to be provided. A group of scattered individuals would probably find it difficult to engage the services of a skilled gardener to help them in their planting and cultivating. At slight expense to each person involved, a community group of gardeners can employ some expert to look over their gardens once or twice a week, or as often as is found necessary, and to guide them in all problems of cultivation.

Some groups of community gardeners may be fortunate enough to have among them a man trained in gardening, who is willing to give them the benefit of his experience without charge. In other cases it may be necessary to pay the supervisor in some way for his instruction. In any event, whether the community group possesses a trained gardener or not, all the members will be able to gain a certain amount of benefit from the experiences of their fellows. Each will possess some bit of information which will be helpful to the others.

Another gain to the community workers is the friendly rivalry which is aroused by close contact with fellow food producers. Each acts as a pacemaker to the others. Each strives to make his plot "the best." $\mathrm{He}$ begins by aiming to keep his garden freer from weeds 
than his neighbor's. This means that he gives it better and more intensive cultivation and in so doing he is certain to increase his yield.

"Well, John, how many bushels of potatoes do you expect to get off your lot?" is the question which one gardener asks of his side-partner.

"Oh, I think I'll have five bushels," is the reply.

"Well, I'll bet you a good cigar that I beat you by a bushel," is the friendly banter.

"You're on!" And so it goes.

Each of them turns to and digs a little harder than he did before. Then darkness overtaking them, they walk home together discussing the ways of bugs and the wherefore of wilt and blight.

The value of such good-natured encouragement and cheer is not to be taken lightly. Always this marching forward together, with a brother's hand on the shoulder, has made the work of life easier and has added to the output of the workers.

In community gardening the question of organization is always an important one to be considered. This is true no matter what the size of the undertaking, whether it includes the working out of plans for an entire city or for a single group of workers in one large plot. In starting a new enterprise of this sort it must be known how much land is available for cultivation, the location and character of the land, the kind and quantity of manures and fertilizers readily procurable, what skilled directcrs can be secured, and the probable number of gardeners. 


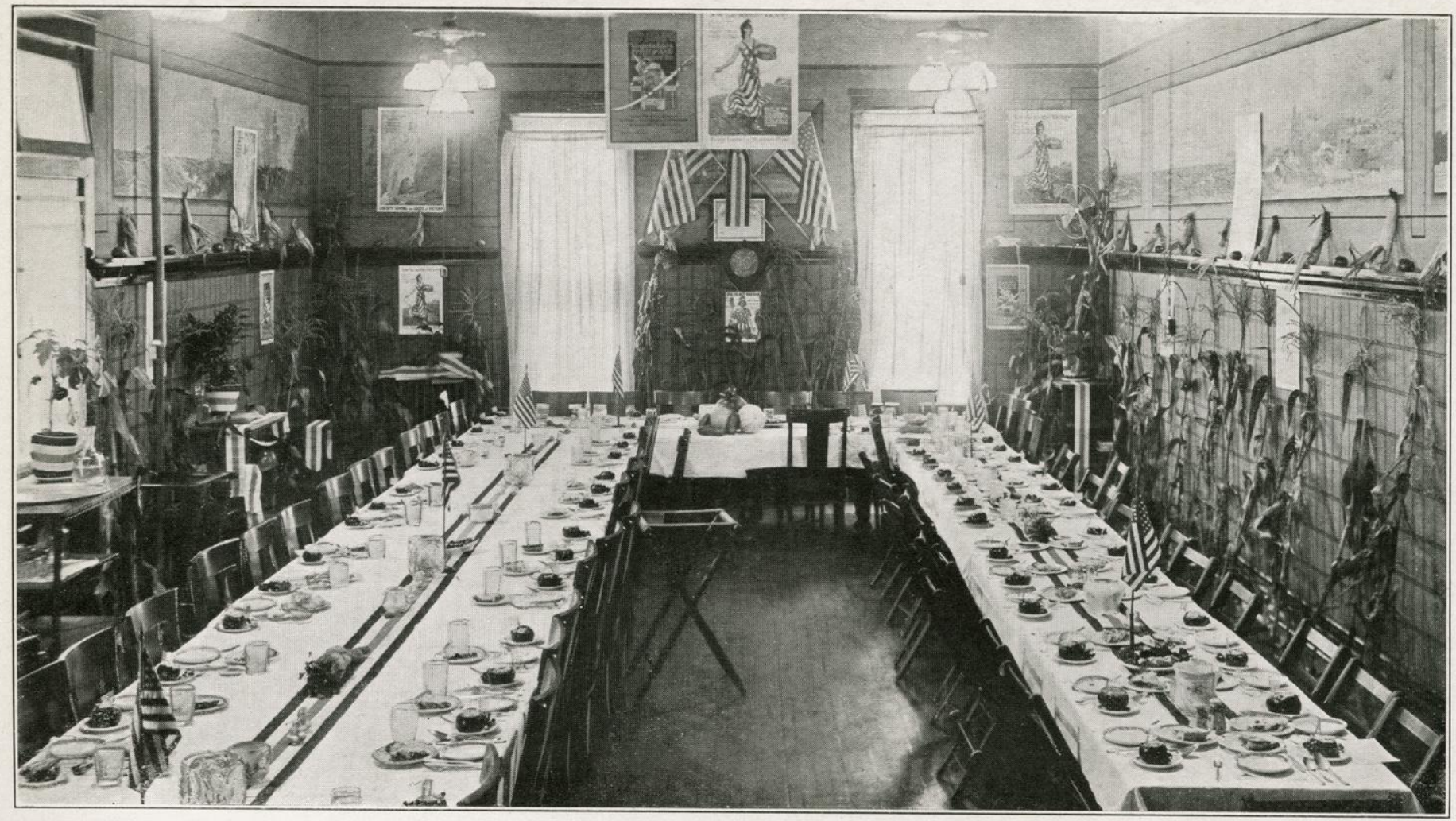

BOY SCOUTS RAISED THE FOOD

The menu of the luncheon given by the Kiwanis Club of Marion, Indiana, to celebrate the city's achievements in a war-garden way, was made up almost exclusively of products grown by the Boy Scouts and newsboys in their plot. Most of the decorations, too, came from the gardens. 

When the problem is being worked out, whether for the first time or for a realignment of forces and apportionment, an inventory of the town's gardening resources should be taken. A survey for this purpose can be made by existing agencies, or a special force or committee can be appointed for the purpose. A complete community survey in a town should include all lands within the district, private yards as well as vacant lots. The Chamber of Commerce, the Board of Trade, or the Civic Club is naturally the nucleus for such an effort; but the school board or a church or political club can conduct the work just as effectively. The local Council of Defense, the Mayor's War Committee or a similar organization should help. Through these agencies communities in all parts of the United States were intensively organized for the war-garden campaign conducted in 1917 and again in 1918.

When it is known that there is such united effort back of a movement, it gains in strength and prestige and there is greater stimulus to the individual worker. People will enter with more vim and enthusiasm into a task which has the backing and support of all their fellow-townsmen. Public meetings should be held to enlist interest and to secure more general coöperation. At these meetings there should be addresses by some of the leaders in community thought, in addition to discussion of the work by those who are more directly concerned with its operation and guidance.

In making a survey of the available garden space in a city or town, there are certain well-established meth- 
ods of procedure which have been found most helpful. Survey forces should be selected, one for each district in the community. Each should have a leader and assistants. In many successful surveys these forces have consisted of senior classes in high schools, of Sunday school classes, of troops of older Boy Scouts, or of other boys. A certain day was selected for the work and this fact well advertised through the newspapers and by announcement in other ways. Large-scale maps showing the different parcels of land simplified the work. Each leader, with his assistants, was made responsible for a certain district. Then cards were prepared for the information as gathered. On these cards questions similar to the following were printed:

I. Name, address, and telephone number of landowner.

2. Whether land is a back yard or vacant lot.

3. Location of plot.

4. Approximate area in square feet.

5. Condition of the plot.

6. Whether owner will cultivate it or rent or lend it.

7. On what terms and conditions. owner will rent or lend.

Other inquiries as to the amount of fertilizer available at different points, the quantity of seed likely to be required, also the demand for tools and other supplies, usually are made at the same time. With all these cards filled out and arranged alphabetically, the committee is in possession of a complete and comprehensive survey of all the garden space available in the 


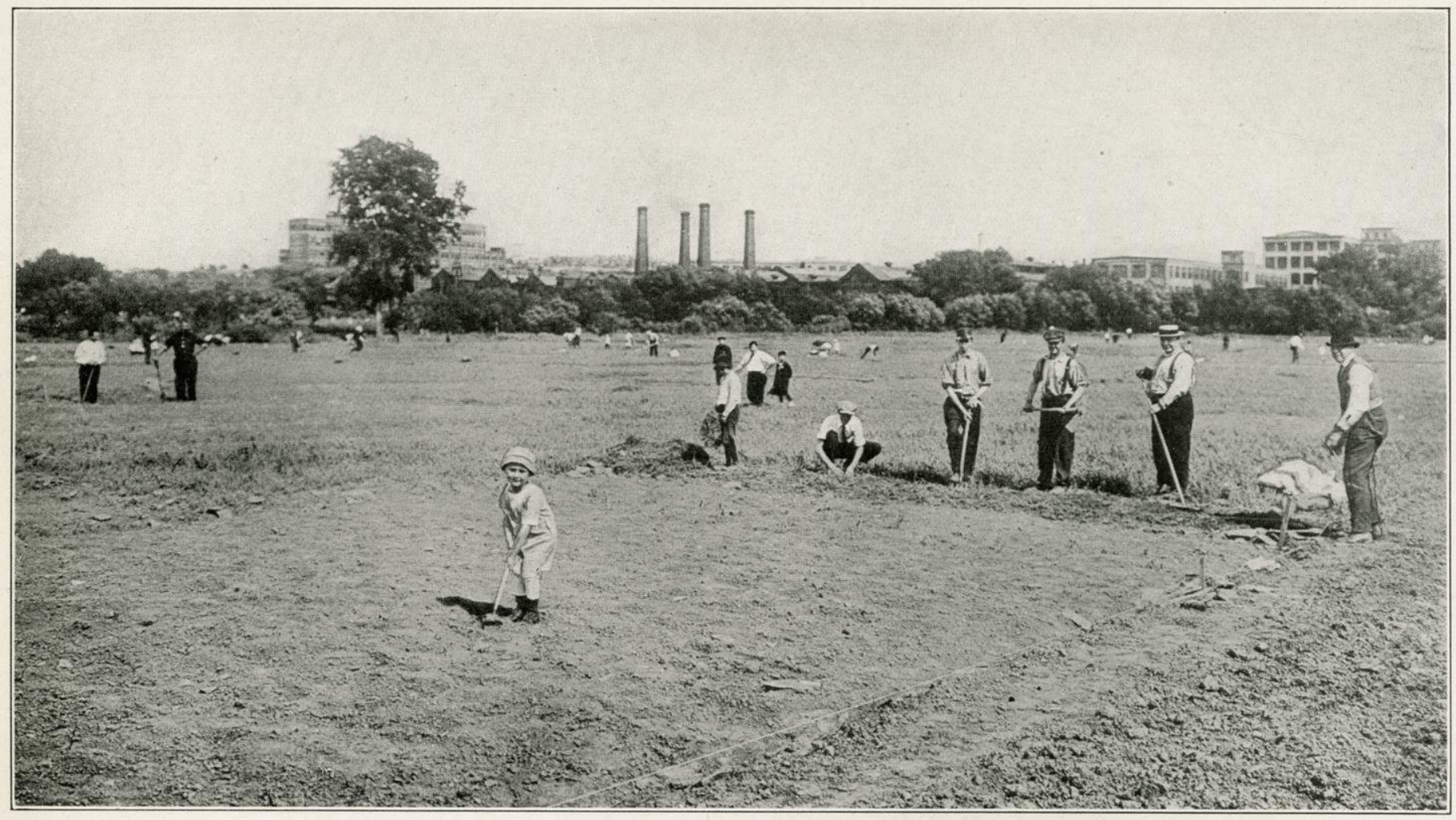

"PAPA, SEE ME HOE?"

With the children to inspire and help them in many instances, employes of industrial and manufacturing concerns all over the United States tilled and cultivated their individual and community gardens. Large tracts of land were divided into small plots. These are a group of such workers at the General Electric Company, Schenectady, New York, which gave to its men for garden purposes a large piece of river- 

community. Meantime, the committee can receive applications from those desiring gardens, and assign convenient plots as soon as arrangements can be made with the owners. Thus it is possible, with comparatively little difficulty, to provide for the working of every foot of available garden land in the community.

In the gardening itself there should likewise be coöperation. In every town may be found retired farmers or experienced truck growers or a county agricultural agent; and arrangements should be made with some such trained worker to give advice and instruction as to selecting the crops best suited to the soil and as to the details of planting and cultivation. Where such individual is not available, sometimes it is desirable to raise a fund that may be used to hire a garden expert to supervise the work. Where possible, the cost of supervision should be borne from a general fund raised by the organization in charge. If this is not practicable, the individual gardeners should pay it in proportion to the size of their plots. The supervision should extend over the entire gardening season.

A group of gardeners should be organized just as any other association is organized, with its executive head and its directing committees. Various problems are bound to come up each season, and these can be handled better through committees than if the individuals themselves or a few of them attempt to solve them. The executive head should have general supervision of the work and for this reason should be, if possible, some person who is familiar with gardening. 
Committees should arrange for purchasing seed, fertilizers, and other necessary supplies for the entire group. This coöperative spirit will save time and money to all concerned and will bring better results. Reduced rates usually can be secured when garden supplies of any sort are bought in considerable quantities.

In dividing a large tract into a number of individual plots, it should be remembered that an average size of forty by sixty feet is about as much as is needed for one family. This should give an ample supply of vegetables not only for summer use but to provide a surplus for canning and drying purposes and for winter storage. After a large piece of land has been divided and allotted, it must be understood that for garden purposes the lot assigned is the property of the person or family to whom it was given, and it should be protected as such. Each plot should be numbered. In assigning plots the fairest way is by drawing numbers.

As a specific instance of organized community gardening, the story of garden production in Marshalltown, Iowa, in 1918, is of interest. Marshalltown is a city of approximately 20,000 people. Mayor S. H. Reilly, sensing the crisis in the food situation, called upon the county agricultural agent to determine the amount of space within the city that could be put into gardens. The county agent's survey revealed a fine farm within the city limits, for the aggregate area of the unused vacant lots which could be put to work exceeded seventy-five acres. The county agent found, moreover, 300 tons of stable manure suitable for fer- 


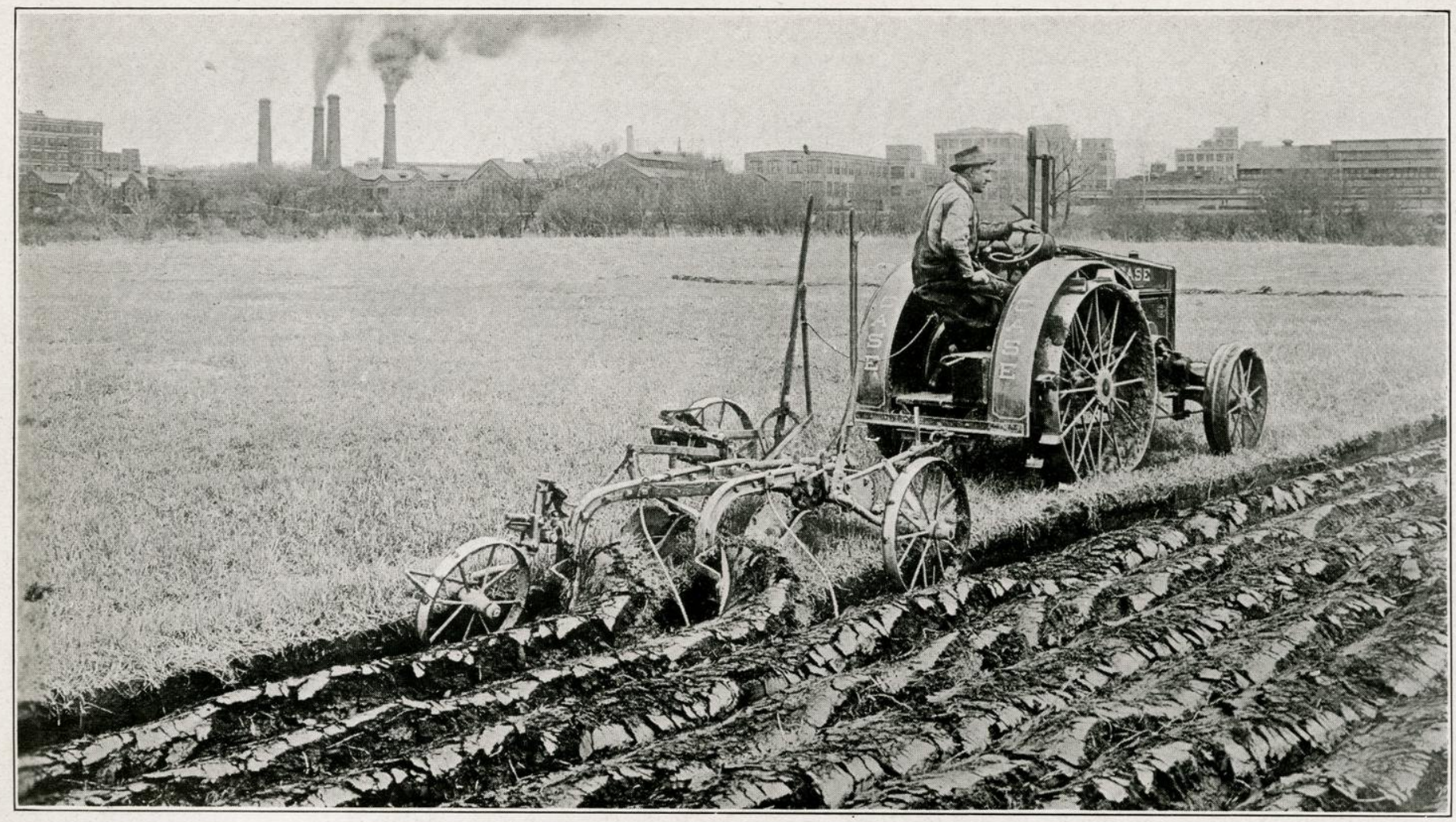

RAISING "FOOD F. O. B. THE FACTORY DOOR"

While the smoking stacks indicated that the manufacturing plants were busy turning out the ammunition needed to win the war, the industrial workers were also turning vacant tracts of land into food "munition plants." This scene at the General Electric Company's works at Schenectady, New York, shows land being prepared for the men, more than 1,500 of whom planted gardens on the area provided them for this purpose. 

tilizer which was going to waste. This was enough to provide four tons for each acre. The survey completed, arrangements were speedily made with the owners whereby the unused lands could be put to work.

The county agent's survey also revealed things other than land and fertilizer. He discovered that many 1917 gardens had been failures because the gardeners were ignorant of agricultural principles. They had tried to raise vegetables in soil not suited to them, and they did not understand cultural methods. Among the residents of Marshalltown were a number of retired farmers. Like Cincinnatus, called from his plow to become a public servant, these farmers were called from their retirement by the Mayor and drafted for public service. They were made garden supervisors for the city. Each was appointed to oversee the work in several blocks and to make sure that the gardens were properly planted and well cared for. In order that seeds might be assured to rich and poor alike, a public subscription was taken to provide money for their purchase. Thus Marshalltown's gardens, like Mrs. Fuzziwig's smile, were both vast and substantial.

To organized community effort was due a large part of the success of the war-garden movement in the United States. Without such help it is certain that the city farming plan never could have attained the overwhelming success with which it has met. The generous thanks of the nation are due the loyal and self-sacrificing local committees and associations which gave of their time and their energy to carrying through the plans which 
resulted in popularizing home gardening. War-garden associations were created to arouse people to the need of the work, to get them started, and to give them guidance and assistance as they proceeded. The coopperation in this community effort came from many sources. Officials of all sorts, almost without exception, gave the movement their endorsement and support and frequently served on the committees while prominent individuals showed equal patriotism in their desire to see vegetables grow where none had grown before.

That the war-garden associations thus formed will be permanent bodies, or continue as committees of the local chambers of commerce, boards of trade, or other bodies, is assured. So excellent has been the work accomplished in this organized way that community effort to aid home food production must continue. With the knowledge and experience already gained, these local committees should become more and more a factor in helping to solve food problems as they arise. Their purpose and their power doubtless will expand; and they will become community centers serving for the discussion and initiation of other methods of food praduction. 


\section{CHAPTER X}

\section{COÖPERATION IN GARDENING}

Unity in the "Second Line of Defense"

$\mathrm{F}^{\mathrm{a}}$

IORTUNATELY the movement to coördinate gardening activities in America, from the outset, met with sympathetic response. Thanks to the loyal coöperation accorded the National War Garden Commission, there was never any question of the success of the garden campaign. Such question as there may have been was merely as to the extent of that success. At no time was there hesitation on the part of those enlisted in the army of the soil as to carrying out the suggestions made to them. In a spirit of loyal and hearty coöperation organizations of all sorts and individuals of all classes throughout the United States worked with the Commission to overcome every obstacle that threatened the success of the food-production campaign.

Merely to tabulate the names of the various clubs, committees, and individuals who helped in this movement would require a volume. Such a list would include hundreds of state, county, and local organizations which through their officers, committees, and branches stimulated the interest of their own members and of others in war gardening. It would contain the names of hundreds of chambers of commerce and other trade bodies; city and county officials; mayors and 
postmasters; school superintendents and college instructors; superintendents of park departments and health officers; women's clubs and home demonstration agents; insurance companies and railroads; lumber and mining companies; banks and business houses; commissions for beautifying cities and tenementhouse inspection officers; lighthouse-service supervisors and bureaus of municipal research; public libraries and church societies; ministers of the gospel and leaders of boys' clubs and many others who were able in various ways to coöperate in spreading the message and in rendering active assistance in getting the vacant places of our cities and towns to work growing food. This service was given in both the production and the conservation campaigns of the Commission.

This coöperation took many forms. In some cases it was of an active and constant character, beginning with the start of the drive to get the war gardeners lined up in the army of the soil and continuing until the last tomato was pulled and the final potato dug; or until the last canned or dried vegetable had been placed on the pantry shelf and the final prizes awarded. In other cases it consisted merely of the distribution to interested parties of a supply of the Commission's gardening or canning and drying manuals, with a word to each home food producer wishing him success in his patriotic work and praising him for his undertaking. More than 4,000,000 of the Commission's books on gardening and canning and millions of its bulletins and leaflets were given interested persons in 1918. 


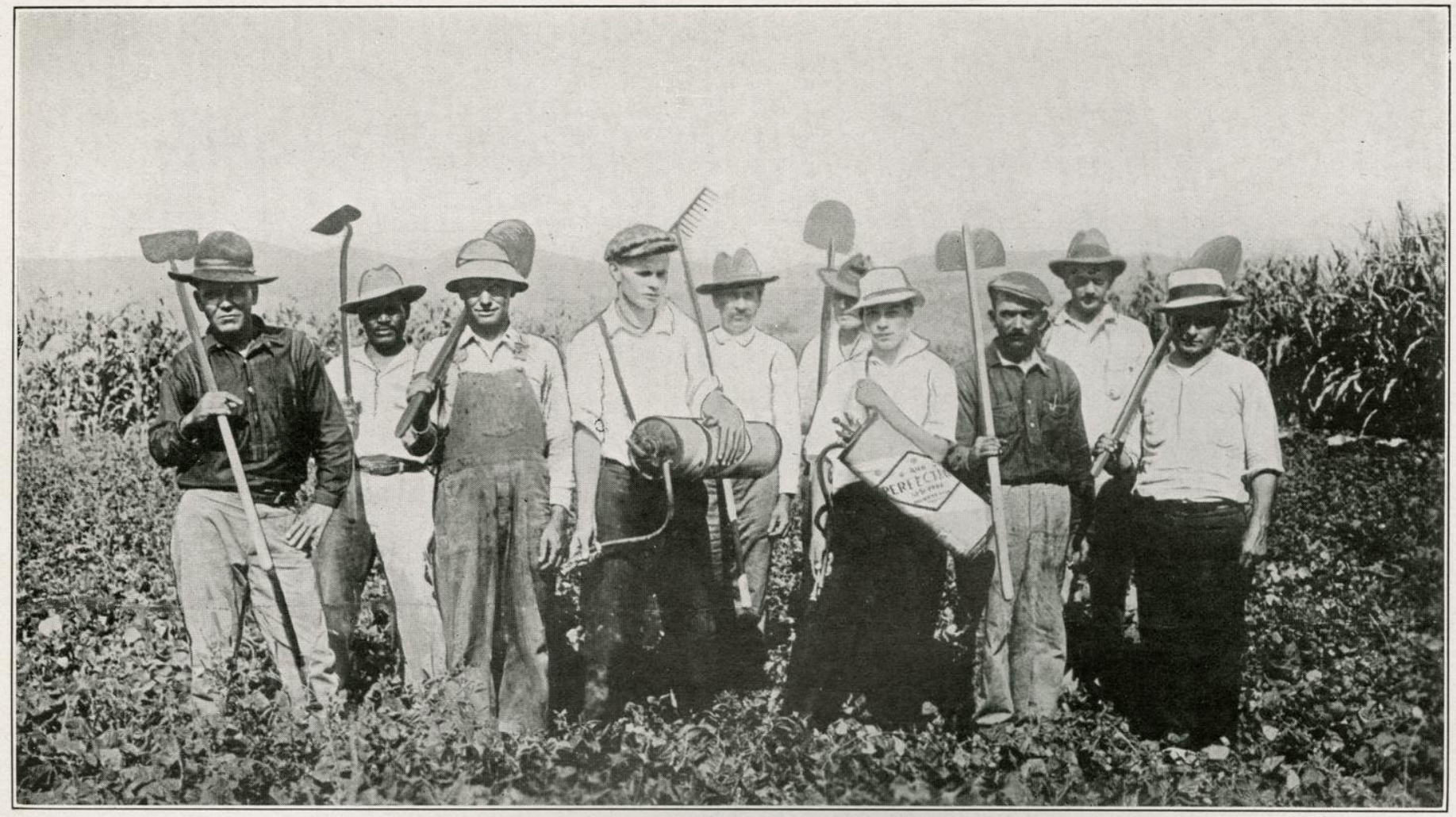

A POLYGLOT ASSEMBLY

Employes of a dozen nationalities were included among the war gardeners of the Inspiration Consolidated Copper Company, in Arizona. It was necessary to print bulletins and instructions in several languages. The company sank five artesian wells to water the arid land which was more than 3,000 feet above sea-level. 

Libraries all over the United States gave most generous support to the work of the Commission. Many made special displays of books on gardening. They placed posters on their bulletin-boards or in other conspicuous places, calling the attention of readers to the need for food and informing them that gardening books and canning manuals could be had for the asking. "The supply you sent us is exhausted, and the demand continues," was the characteristic word the Commission received from a large number of libraries to which consignments of the books had been shipped.

In some cities and towns the work was carried on merely by the popular sentiment in favor of war gardens which was stirred up by appeals in the press and other publications. In many places, however, war garden associations were organized to guide and direct the movement, or voluntary committees undertook to perform this service. The leaders in many cases were familiar with methods of procedure and required little assistance. As a rule, however, they were glad to receive publications giving them detailed information as to how to plan and carry on their work. Again they were pleased to receive instruction books on gardening which they could distribute among the numerous applicants, and this was true even in cities and towns where it was possible to secure the services of paid agricultural experts to take charge of the technical end of the campaign.

Nowhere did the Commission receive more loyal support and hearty coöperation than from the public 
press. Closely in touch with conditions the world over, newspaper editors understood, as perhaps many others could not understand, the gravity of the food situation. In their endeavor to do their share, they gave generously of their news space. Particularly was it necessary to get the appeal for home food gardens before the dwellers in towns, especially in the larger centers of population, for there food was most needed, and there people were least likely to take upon themselves the duty of cultivating the small plots of land at their disposal. Practically all such Americans were reached by the Commission through the newspapers. In fact, practically all Americans were reached. News stories were prepared by the Commission's publicity bureau, setting forth the facts as to the world food situation, and these articles were placed in the hands, not of a few editors, but of hundreds and hundreds. Not only were most of these news stories freely printed, but often they were also prominently featured in such way as to emphasize the message they contained.

After the need of gardening had thus been sufficiently impressed upon the mind of the public, the Commission's staff of experts prepared daily lessons in gardening, which were sent to a great number of newspapers. Hundreds of leading newspapers, from the Atlantic to the Pacific, carried these daily lessons. The Philadelphia North American, to mention only one of many large city newspapers, printed a garden lesson daily for many weeks, publishing it on its front page and displaying it in a special box to attract attention. 
These lessons began with the preparation of the soil and the sowing of seed in the house for early vegetables, and dealt with one or more vegetables daily, setting forth in simple language the proper cultural methods for the vegetables in question, and pointing out the diseases and enemies of the particular products under discussion, together with methods of combating them. Though simple in language and shorn of all useless technicalities, these daily gardening lessons lacked no essential cultural directions; and even a beginner could have become a successful gardener by following carefully the directions given.

The publicity campaign did not end with telling gardeners how to raise vegetables. As soon as the garden season was well started, appeals were made through the newspapers for the conservation of all excess garden products. The necessity for such conservation was first pointed out, and then methods of canning and drying garden products and fruit were set forth simply and completely. These publicity campaigns in the public press went hand in hand with the issuance of the Commission's various books, which were offered free to any one upon request.

Despite the wonderful response of the public to appeals to raise garden products, it was apparent that the need for food increased rather than decreased, because production so constantly fell off in Europe. The constant dripping of water will wear away even the hardest stone, and the Commission believed that the endless repetition of the garden appeal would 
finally move even the most indifferent reader. For this reason its publicity campaign did not end with the gardening season. News stories and garden statistics of all sorts were gathered by the Commission and given to the press. These stories included accounts of the work of individual gardeners, of garden clubs, of communities, and of the organized gardeners in great industries. Likewise the Commission gathered together thousands of cartoons and funny stories and jokes about war gardens and war gardeners, and issued books of these humorous items. The press reproduced this matter the country over and in this way the funnybone of America was tickled with the garden idea. The Commission's publicity work was not confined to the daily press. Feature stories were supplied to many magazines and periodicals as well as to the magazine sections of Sunday newspapers. These articles were more pretentious than those prepared for the dailies. They aimed not merely to be authoritative but to have literary quality as well. They dealt with gardening from many different points of view, but always the lesson was conveyed that more food was needed and that it would have to be raised by the average American, irrespective of his vocation. With these magazine articles, and with many of its newspaper stories as well, the Commission supplied illustrations. Its agents had secured hundreds and hundreds of interesting photographs showing different phases of garden work in almost every portion of the country. These pictures, portraying war gardens from the arid sands of the 


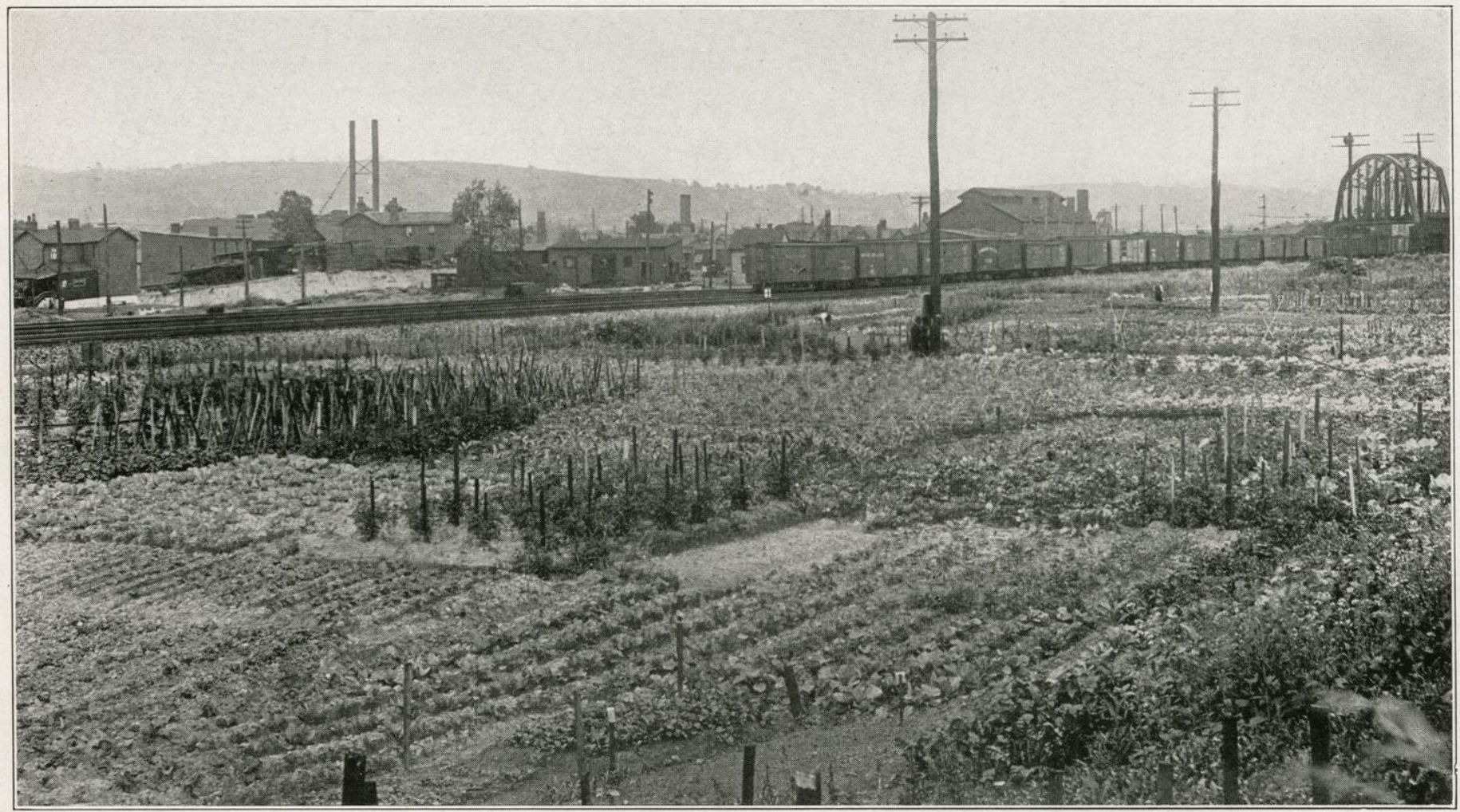

DOWN IN "THE YARDS"

Gardens were grown in thousands of places right by the sides of the railroad tracks, close by the shops and round-houses and up to the very edge of station platforms. Land along the right of way was furnished to employes free of charge or at nominal rental. Here are seen fine examples of such cultivated areas. 

Southwest to the cold mountain slopes of the Northeast and from the rocky coasts of the north Atlantic to the sandy beaches of the Pacific, brought home to every one who saw them the idea that everywhere, in all sorts of places, people of all kinds were toiling to produce food. The moral, "Go and do likewise," was too obvious to be missed.

Whatever would attract attention to the need of gardening, or help the gardener with his work, or assist in putting to work the large areas of "slacker lands," the Commission tried to portray by word or picture in the pages of the daily press, the weekly magazines, and the periodicals of less frequent publication. It stood ready to furnish, and did furnish, gardening and conservation matter of any sort to any one who requested it. Service was the motto of the Commission, and that service was well repaid in the splendid response of the American people to the appeal for gardens. 


\section{CHAPTER XI}

\section{WAR GARDENS AS CITY ASSETS}

\section{A Thing of Beauty Is a Joy Forever}

E

VERY city aims to be as prosperous and progressive as possible and nowadays most people realize that the city beautiful is also likely to be the city commercially worth while. Probably no other one enterprise will add more to a city's beauty than gardening. Gardening, therefore, has double value. It both enriches and beautifies. By the same token it develops civic pride and community spirit.

For these reasons any community should delight in being called a "garden city," whether the name is applied literally or merely in a figurative sense. One result of the war-garden movement is that practically any American community can truthfully be designated by this term.

It is fortunate indeed that this is true. Unity of thought, of action, of ideals, is the crying need of the hour in America. United, we stand; divided, we fall. Probably nothing is more potent as a factor for building up community spirit than gardening, particularly community gardening. A link to bind men together is gardening. It creates common interests. It unites all hands in the common end of producing food. Rubbing elbows in their garden patches, lawyers and laborers, tradesmen and housewives, speedily discover that they 
have much in common. One of the things they have in common is their interest in their community; for each wishes to see it progress.

If the democracy of a nation depends upon the democracy of the individuals who compose that nation, then assuredly the war garden is a forge that is daily strengthening the links in our chain of democracy. Our soldiers, shoulder to shoulder in the trenches, learned, that, whatever their respective stations in life, they are brothers. In a heat a little less intense, but none the less sufficient to weld the strongest souls, our gardeners, too, have fused into a solid unit. Link by link the chain of our democracy has grown stronger.

With it has grown our civic pride-the pride of each community in the progress it is making. One of the progressive things cities are proud of to-day is the extent of their war-garden activities. Just as different communities aimed to be the first "over the top" in a Liberty Loan campaign, and to secure the flag which spoke of patriotic duty performed, so they have been anxious to excel in the number of war gardens they have planted and in the amount of food they have raised to help the boys "over there."

The National War Garden Commission has received from hundreds of cities and towns throughout the United States expressions showing how proud they are of their war-garden records. Typical items of this enthusiasm are these: "Every bit of available land is being cultivated;" "There is scarcely a home here without a war garden;" "All back yards and vacant 
lots are being planted;" "We believe we have the best war gardens in the United States." Each city wanted to make a record in food production. It is through rivalry of this sort that cities progress.

War gardening, again, is an asset to any city in that it adds to that city's material wealth. All food grown adds just so much to a city's wealth. In the first place gardening gives the individual more money. By planting a home garden he reduces his own expenses, saving many dollars on his market and grocery bills. Whether he saves and invests this money in some local enterprise, or spends it for necessities or even luxuries, the community benefits. The money goes into houses and lots, into automobiles, books, furniture, pianos, clothing, into everything, in fact, that modern man needs for his comfort and happiness. Thus while he is helping himself, he is also helping the merchants and the tradesmen of the city. $\mathrm{He}$ is adding to his own and the community's resources.

The financial gain to a city from the war-gardening enterprise is strikingly revealed by figures on the amount of produce raised. A few cases will be illustrative. For instance, Indianapolis estimated the value of its war-garden crop in 1918 at $\$ 1,473,165$, an increase of more than $\$ 600,000$ over the previous year. Denver placed its yield at $\$ 2,500,000$ and Los Angeles at $\$ \mathbf{1}, 000,000$. The figures for a few other cities were as follows: Minneapolis, \$1,750,000; Washington, District of Columbia, $\$ \mathbf{1}, 396,500$; Grand Rapids, Michigan, \$900,000; Salt Lake City, Utah, \$750,000; 


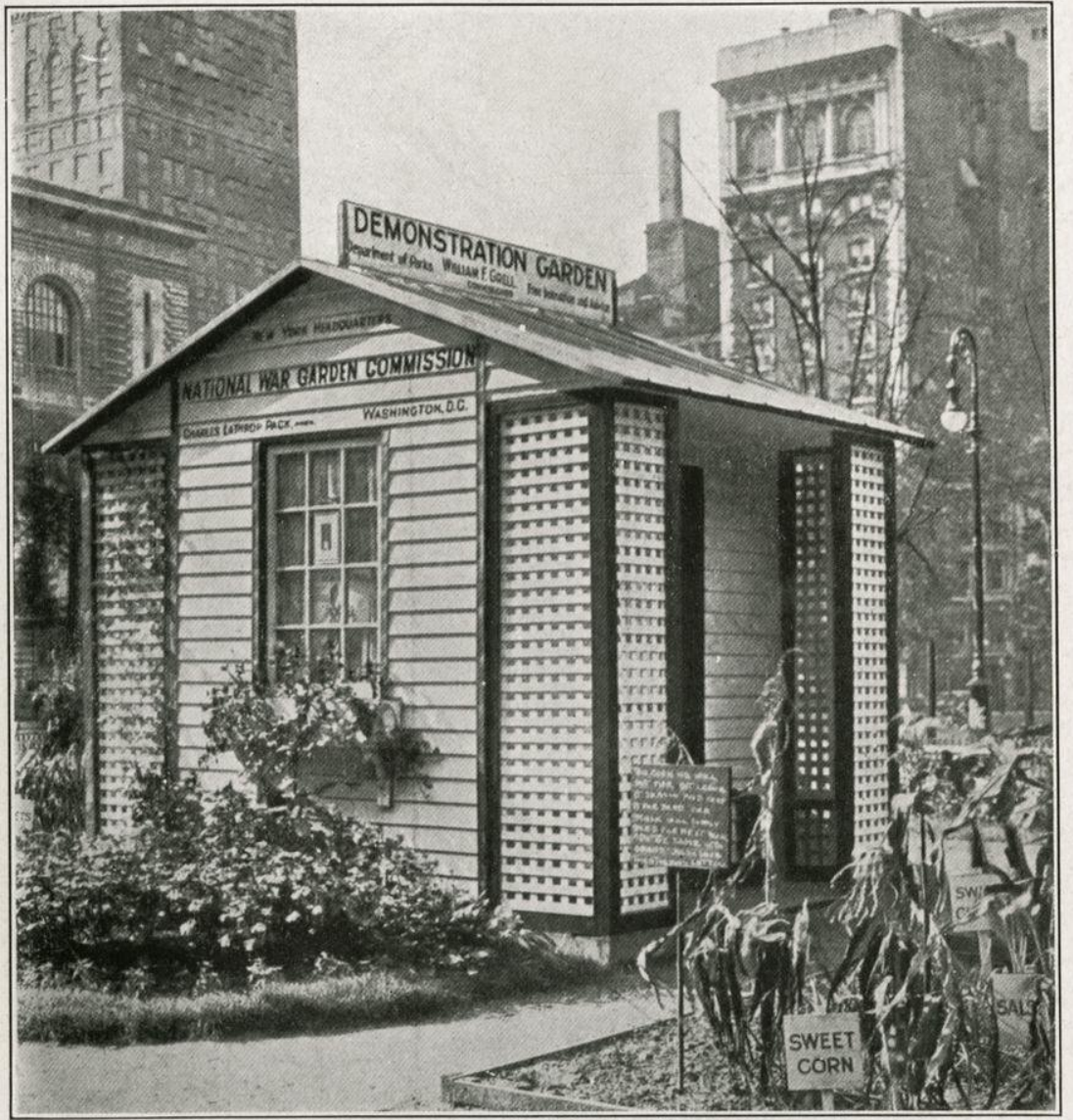

MIDST TOWERING SKYSCRAPERS

In Bryant Park, New York, in the heart of the nation's throbbing metropolis, there was planted a demonstration war garden, and a littie garden house was erected which served as a distributing center for literature of the National War Garden Commission. Formal ceremonies were held at the time of the dedication of the building. 

Louisville, Kentucky, \$750,000; Worcester, Massachusetts, $\$ 750,000$; Oklahoma City, Oklahoma, $\$ 500$,০oo; Dallas, Texas, $\$ 300,000$; Scranton, Pennsylvania, $\$ 450,000$; Rochester, New York, $\$ 350,000$; Pittsburgh, Pennsylvania, \$250,000; Burlington, Iowa, \$250,000; Newark, New Jersey, $\$ \mathbf{I} 60,000 ;$ New Orleans, Louisiana, $\$$ I 25,000; Atlanta, Georgia, \$100,000.

Another gain which comes to a city from war gardening is the improvement in the appearance of the place; and added beauty means added worth. The poet who sang that "a thing of beauty is a joy forever" might have written with equal truthfulnessalthough, of course, we do not expect the minds of poets to run in such practical and commercial channels -that it is also a "thing of value forever." In the long run those improvements which add to the beauty of a city or community add also to its material prosperity and to its civic progress.

For this reason chambers of commerce and other trade organizations do good service for their communities when they urge the cleaning-up of all vacant lots and open spaces and their conversion into gardens. Travelers have noted how much better many towns looked during the past year or two because of the fact that most of the back yards "fronting" on the railroad tracks have been improved into clean, well-kept vegetable plots. The average back yard is bare of flowers, as these are reserved for the place of honor in front of the house; and so a vegetable garden in the space at the rear is highly to be commended as an attraction 
to the place. A person renting or buying a piece of property which displays a healthy and prosperouslooking garden is immediately put into a more favorable frame of mind by the sight of this growing food and is willing to pay more for the place.

As to the vacant lots which straggled and scrambled along many city streets before the days of war gardens, nothing more than a mere statement of fact is necessary to convince any one that the removal of these "sore spots" is advantageous in many ways. These barren lands, with their unsightly briars and weeds, their ugly ash-heaps and piles of litter, detracted not only from the appearance but from the commercial value of all the surrounding property.

In hundreds of cases it was not realized until an actual enumeration was made, how many acres of such unused land there were in a city. There was scarcely a town of any size which did not contain a total of hundreds of acres of such idle, useless land. With little effort these unsightly lots can be converted into rich gardens to help feed the city and the nation. To clean up all such places, therefore, and to put them to profitable use, is a standing advertisement for the city. Furthermore, the example of one city leads to a duplication of the good work elsewhere and an effort to improve on it. Thus the gain of one is the gain of all. The city benefits, the state benefits, the nation benefits.

Cleveland surpassed itself in war gardening. As a result of the very active campaign conducted there under the auspices of the war garden committee, a 
sub-committee of the mayor's advisory war committee, 40,000 war gardens were planted in 1918. The city had set out to make it 25,000 but went far beyond this figure. George A. Schneider, chairman of the committee, mapped out a broad and comprehensive campaign which resulted in a splendid record. Carl F. Knirk, garden director, was untiring in his efforts to make the work a complete success. A survey was made of every vacant lot in the city and its suburbs, with highschool boys aiding in this collection of data in their respective districts. Six paid instructors were engaged and each placed in charge of a certain district. Three tractor plows prepared the ground in the larger tracts.

Other agencies coöperated in the movement. These included women's clubs, schools, business houses, and manufacturing concerns. Western Reserve University introduced a course in home gardening and it was opened to some of the garden clubs and women interested in the work. Many of the industrial plants provided land for their employés and hundreds of fine gardens were the result. The companies also encouraged their men in the conservation of their garden products. Thousands of the Commission's war vegetable gardening and canning and drying books were distributed to the city's home food growers through the Cleveland Public Library and the Cleveland Public Schools and through the Cleveland Trust Company, the Citizens Savings and Trust Company, the Superior Savings and Trust Company, the Guardian Savings and Trust Company, and other public-spirited institutions. 
Even a beautiful city park system loses none of its charm when a part of it is turned to utilitarian purposes. Historic Boston Common was none the less attractive to the passer-by during the season of 1918 because a fine demonstration war garden was growing at one side of it. Even when the necessities of war do not make it such an important and desirable prospect, a trim and well-cultivated series of vegetable plots such as displayed their patriotic beauty there, would not detract from the natural beauty of the landscape.

Potomac Park, in the shadow of the tall and stately Washington Monument, was a constant source of pleasure to the thousands of automobilists who sped along the river driveway. In the afternoon and twilight the sight of hundreds of war gardeners cultivating their vegetable patches in sight of the White House and the majestic dome of the Capitol was a picture never to be forgotten. Down at the lower end of the Chesapeake Bay near where busy transports were loading their precious human freight and their supplies for France, the Commission on Beautifying the City of Norfolk took charge of the war-garden campaign and conducted it to a successful conclusion, adding more than $\$ 200,000$ worth of vegetables to the food wealth of that rich truck-growing section of the country.

In New York City an extremely interesting war garden was growing in Bryant Park. There in the heart of the great metropolis, shaded by over-towering sky-scrapers and beside the majestic public library, a small war garden spoke its message to the world. This demonstration plot was under the direction of 


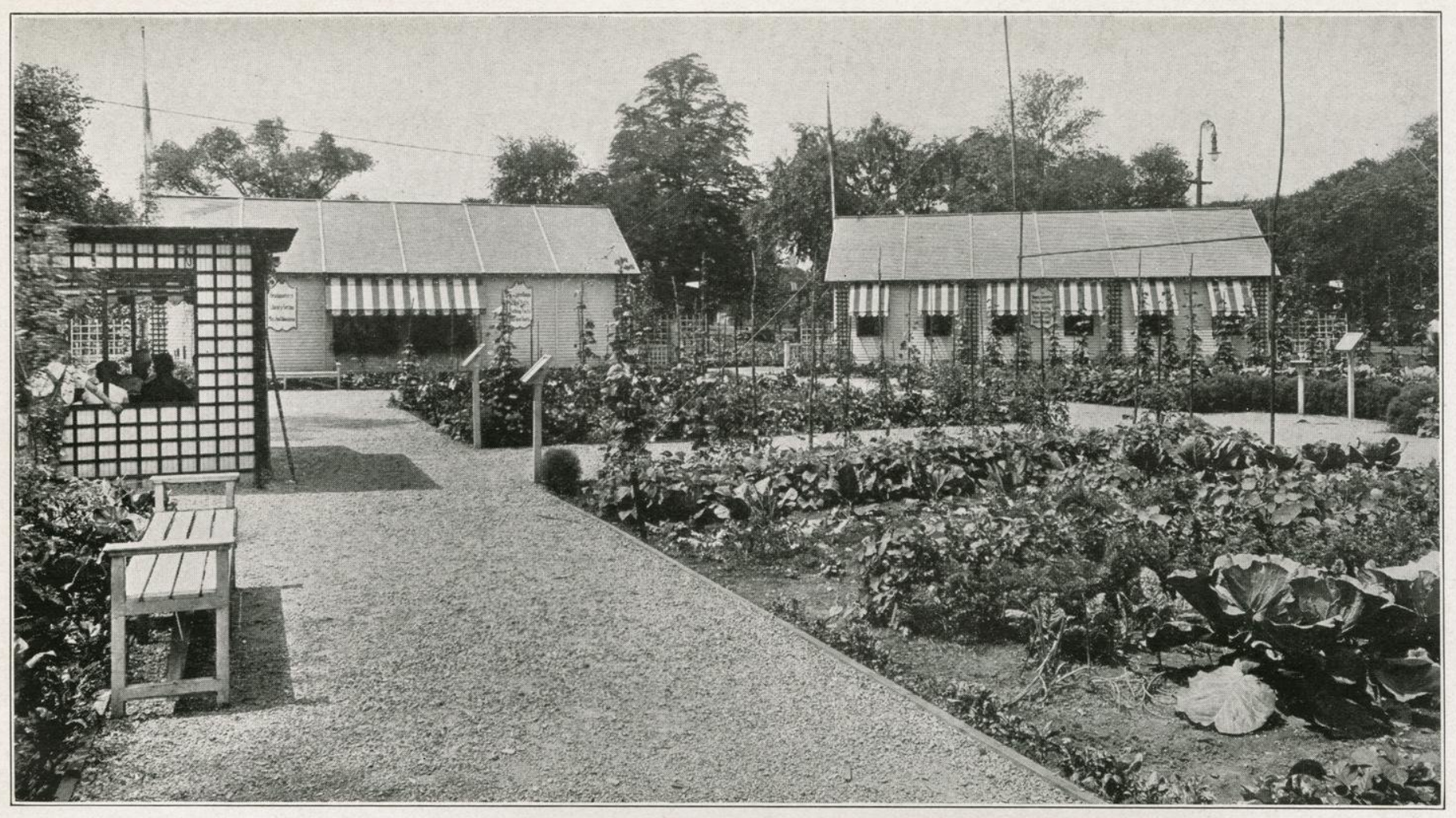

WAR GARDEN ON BOSTON COMMON

There were hundreds of visitors daily at this fine demonstration garden and the adjoining food cottages, and the result was partly shown by the fact that there were more than 30,000 war gardens in Boston in I9I8. In this series of gardens on "The Common" there were thirty-five varieties of vegetables, practically everything except corn being included. Miss Anna Biddle Frismouth with several assistants was in charge of the gardens for the Women's City Club. 

A. N. Gitterman, chairman of the war garden committee of the Department of Parks for the Borough of Manhattan. The little garden-house which stood there was dedicated in the spring of 1918 , and from this center were distributed large quantities of the National War Garden Commission's books and other literature to help the "city farmers" of Greater New York. The work of this garden, like that of the millions of other war gardens throughout the country, was helping to keep the light burning on the Statue of Liberty at the entrance of this great harbor of a free country.

In his report at the end of the season to William F. Grell, Park Commissioner of the Borough of Manhattan, Mr. Gitterman said:

We maintained two demonstration gardens, one at Union Square, Fourteenth Street and Broadway, and the other at Bryant Park, Forty-Second Street and Sixth Avenue, where headquarters are maintained in a model garden-house which was donated to the city by the National War Garden Commission of Washington. This garden has been a great success from its dedication when President Pack turned the first spade of earth in this most valuable garden-plot in the world.

Intensive gardening was here profitably demonstrated as is shown by the results achieved in the limited area allotted to each variety. Small blackboards explained each operation in the little garden when the supervisor was working, planting, weeding, cultivating, thinning, spraying, or picking. In addition, information in detail was given on the special bulletin-board concerning insects and their control, weeds and their relation to agriculture, spraying formulæ, seed varieties, plant diseases, and other garden data of interest to the war gardener. 


\section{THE WAR GARDEN VICTORIOUS}

In the Borough of Manhattan there was an increase, according to the report, of seventy per cent. in the wargardening activities of 1918 as compared with the year preceding. In 1919 it is expected that every available vacant lot will be planted.

More than one hundred and sixty loads of manure were furnished during the season of 1918 and delivered to the gardens from the various riding academies near Central Park.

The demonstration garden in Union Square had soil but a foot in depth over the subway roof and this served to impress upon the minds of pessimistic owners of vacant land the value of cultivation even under a handicap, as the results obtained from this one foot of soil were considerable.

A constant stream of visitors recorded their names and addresses in the guest-book at the little gardenhouse in Bryant Park. People from almost every city in the United States and a great number from European countries inspected the place.

Cities, as well as individuals, can entertain angels unaware, and many a community that encouraged war gardening purely as a patriotic measure, has found that city farming is a paying as well as a patriotic activity. Bread cast upon the waters, in the form of gardening efforts to help a famishing world, has returned after many days as a rich reward in increased civic wealth and betterment. Decidedly, war gardens are an asset to any city. 


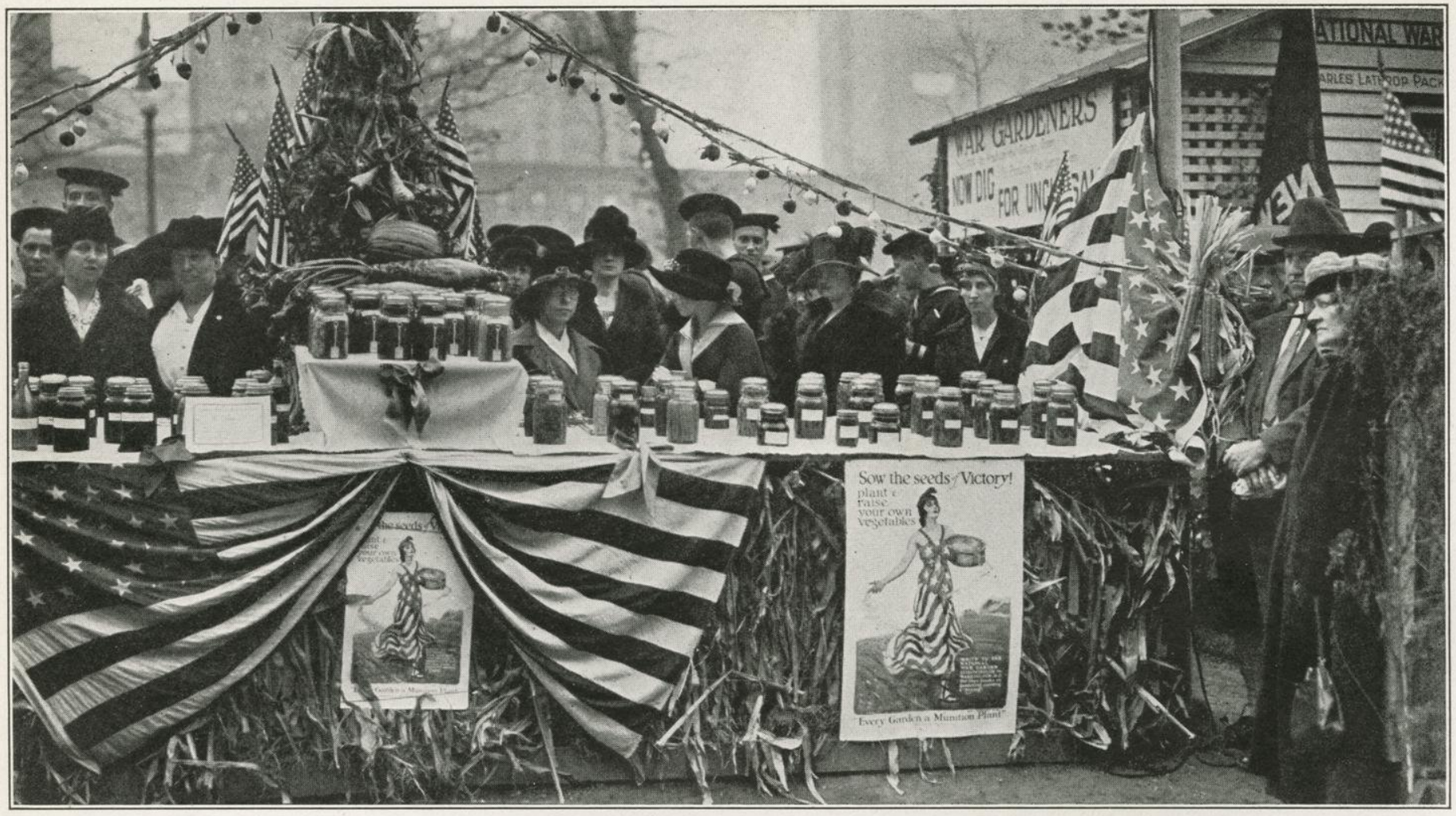

"COUNTY FAIR" IN BRYANT PARK

Photo. New York Herald.

An exhibition of canned products was held in the war garden on Forty-second street, New York, and eleven of the Commission's National Capitol Prize Certificates were awarded to prize-winners in the various subdivisions of Manhattan. These were presented by President Charles Lathrop

Pack, the blue ribbon going to Mrs. I. C. Kahn, at left of table decoration. 



\section{CHAPTER XII}

\section{THE PART PLAYED BY DAYLIGHT SAVING}

How "City Farmers" Were Enabled to Take Time by the Forelock

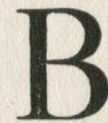

ECAUSE of the Daylight Saving Law war gardens added far more to the nation's food supply in the season of 1918 than would have been possible otherwise. This law was in operation during seven months of the year, from the last Sunday in March until the last Sunday in October. The impetus which this gave to the movement and the material gain resulting therefrom were almost inestimable. That the measure increased by many millions of dollars the value of the food grown is undoubted.

An idea of what this extra hour of daylight meant to the war gardeners of the country may be gathered from the actual amount of working time it presented as a free gift to the home food producers. This extra hour given each afternoon to the war gardener meant a total of 182 hours during seven months of twentysix working days each. Multiplying this figure by the number of war gardeners in the United States$5,285,000$-it gives the stupendous aggregate of $961,870,000$ hours of time, or 329,407 years of eighthour days.

More than 300,000 years were thus added to this one industry alone by a single piece of legislation, laws similar to which had been adopted by fifteen other 


\section{THE WAR GARDEN VICTORIOUS}

countries before the United States followed their example in the spring of 1918.

To secure the passage of the Daylight Saving Law the National War Garden Commission used its influence, and many of the leaders in the war-garden movement throughout the country urged upon Congress the vital need and the value of this statute. The congressional committee which had the measure in charge showed its realization of the effect the law would have on gardening by mentioning it most prominently in its report. This document said in part:

In view of the increased food production which will be brought about under the bill, the comfort and the convenience which it will bring to laborers and the public generally, and the saving of expenses, especially relating to light and fuel, it is believed by our committee that the measure should be enacted.

That the measure accomplished all that was expected of it, and was of inestimable value in helping the United States in its gigantic war preparations, is the testimony of the nation. In a statement on the subject at the conclusion of the first year's operation of the law, Senator Calder of New York, author of the bill, called particular attention to its benefit to war gardeners. He said:

The Daylight Saving Law which became effective on the last Sunday in March has more than fulfilled the prophecies of its advocates. It has really turned one hour of night into day. People live by custom. They rise in the morning by the clock; they eat their meals 


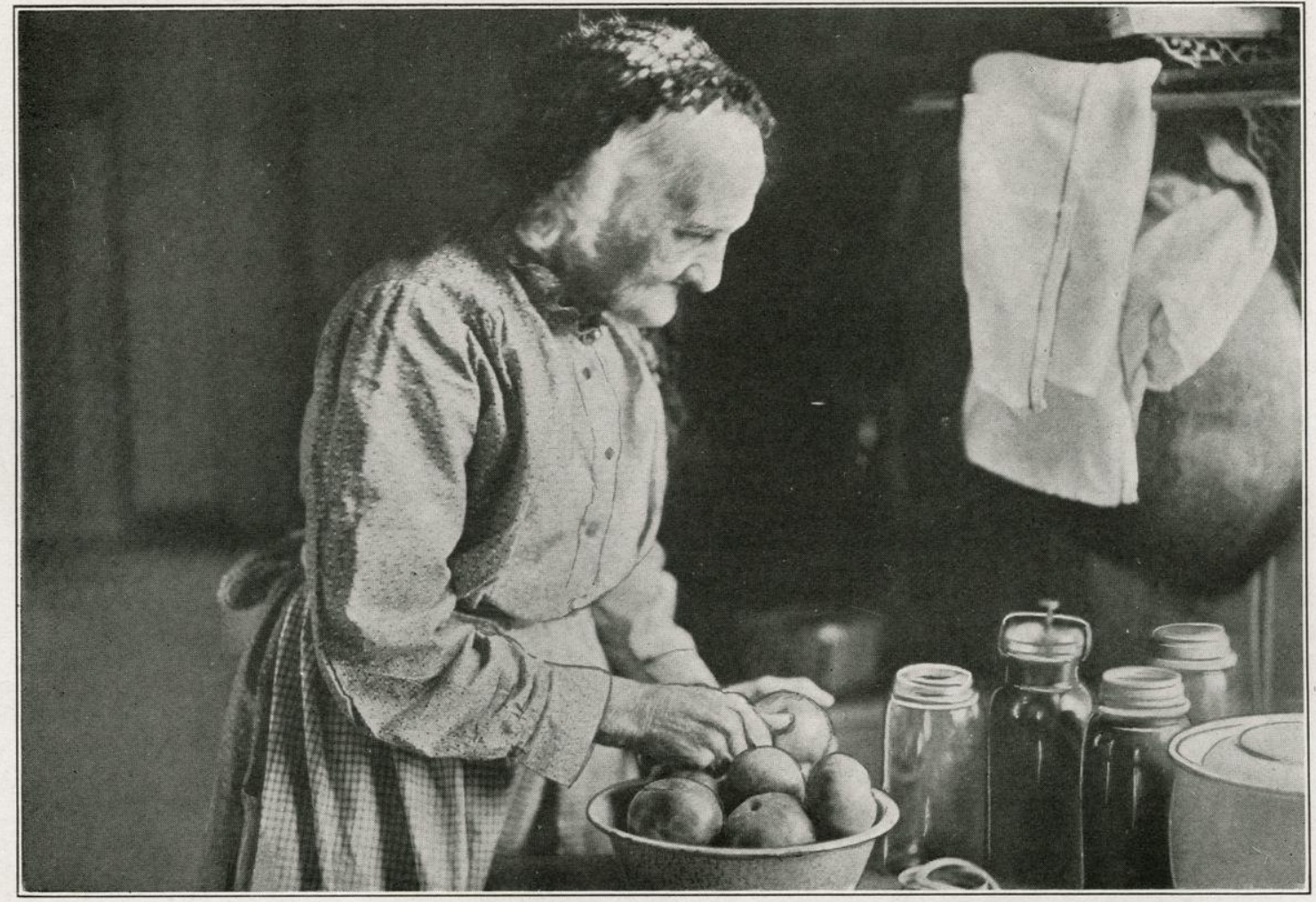

NO AGE LIMIT ON PATRIOTISM

Although more than ninety years of age, Mrs. Thomas L. Edwards, of Oberlin, Ohio, looked after her own war garden and did all the work except the initial plowing. Then when canning time came she put up a lot of vegetables for herself and sent some as a Thanksgiving present to relatives. She was born in Wales and had a number of nephews and grand-nephews at the front. 

by the clock, and go to bed by the clock, so that during the time this law has been in operation a vast majority of the people of this country have been awake one hour more of daylight and asleep one hour more of dark than they were formerly. This additional hour of daylight has been most helpful to the men, women, and children of the nation who have taken advantage of it to plant war gardens, thereby not only relieving the strain upon the farm but to a very considerable degree tending toward economy in family expenditures. It has also saved in gas and electric bills not less than ten per cent. of the money formerly spent for this purpose. In addition, it has saved during its seven months of operation this year at least one million tons of coal. It has afforded in the construction of cantonments for our army, in the manufacture of munitions and war supplies of every character, and in the building of ships one hour more of daylight for the men engaged in these industries.

It is a universal practice for working men and women to begin their day's labor at eight o'clock and in some industries at seven o'clock in the morning. They cannot be induced to work before seven o'clock, but, with the long evening produced by this law, those wholabor have been induced to work additional hours at night where the exigencies of the occasion demanded it. Without question this bill has been most helpful in the great war work in which this nation was engaged.

The Daylight Saving Law will be in effect again in I9I9 and each succeeding year unless it is revoked by further legislation, for the bill as passed provided that "at two o'clock antemeridian of the last Sunday in March of each year the standard time of each zone 


\section{I08 THE WAR GARDEN VICTORIOUS}

shall be advanced one hour, and at two o'clock antemeridian of the last Sunday in October in each year the standard time of the zone shall, by the retarding of one hour, be returned to the mean astronomical time of the degree of longitude governing said zone." Its benefits, therefore, will continue, and as the number of home food producers increases the resulting gain will be greater. 


\section{CHAPTER XIII}

\section{THE FUTURE OF WAR GARDENING}

The Fruits of Peace to Spring from the Seeds of Victory

OMING events, we are told, cast their shadows before. Among the prophetic shadows now hovering over us is a finger of cloud which points to vital changes in the business of feeding the world. Indeed, these changes are already taking place. In part they have taken place, but many of us, being of those who have eyes yet do not see, are still unaware that the old order has changed and that the new order of things has come to pass.

No other single occupation born of the war has affected a greater number of people than has gardening. Starting from a mere nothing before the United States entered the war, this form of service grew in less than two years into a new occupation, which numbered its followers by the millions and, in the number of people employed, exceeded any other branch of gainful occupation with the single exception of actual farming.

The fact that such a vast number of American citizens took up this work shows that they appreciated the merit of it, and this is one of the reasons for the confident prediction that war gardening has come to stay. It is something that the world will not willingly let die. Home food production will continue because it has been found worth while; and, like other things 
which this war has demonstrated to be of value and benefit to mankind, it will last.

War gardening will permanently establish itself because its peace-time value will fully equal its war-time worth. This will be true at all times, but more particularly during the first five or ten years of the great reconstruction period. During that period the matter of food production will be of the most pressing importance. It will be on a par with many of the other enormous reconstruction problems which face the world. It will require the continued application of broad thought and effort. There will be no decrease in the demand for food; in fact that demand will really be greater, much greater, than it was during the days of actual conflict.

This will be true because the coming of peace means the restoration of the freedom of the seas, and freedom of the seas means a restored commerce. German savagery and the frightfulness of unrestrained submarine warfare have largely driven the world's ordinary commerce from the seas; and much of that commerce was traffic in foodstuffs. For decades, even centuries, Europe has been dependent upon the remainder of the world for food to eke out its own inadequate supplies. Before the war, for example, England, according to the United States Food Administration, produced but one-fifth of her own foodstuffs, while France raised onehalf of hers, and Italy produced perhaps two-thirds of what she consumed. What was true of these nations was true of the remainder of Europe. Unless food could 


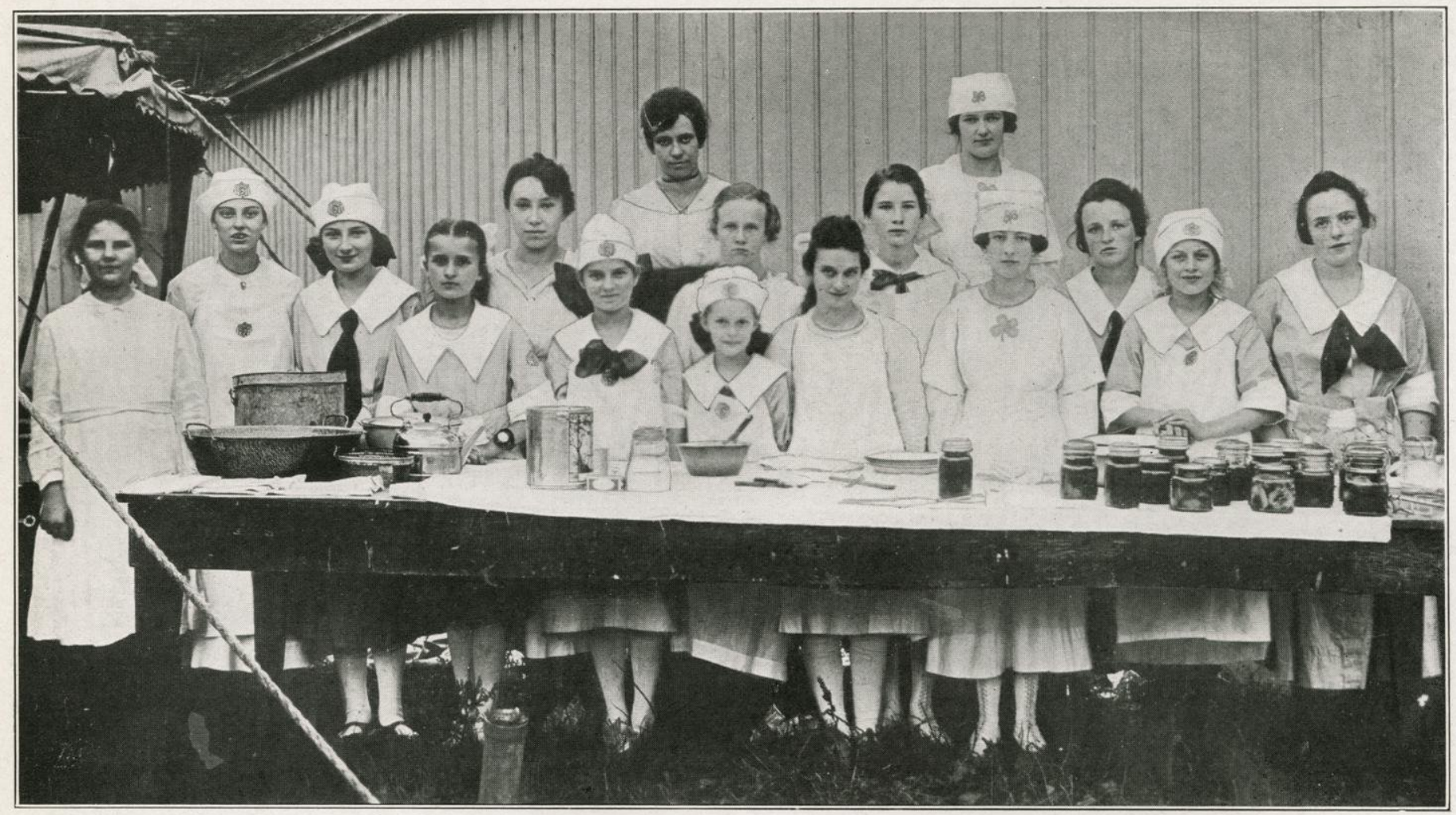

PRIZE-WINNING CANNING TEAM IN IOWA

Under the supervision of skilled home demonstration agents of the United States Department of Agriculture, and other teachers, many groups of girls throughout the country have made excellent records in conserving garden products. Here are shown Miss Julia E. Brekke, home demonstration agent, and the canning team which won first prize at the Clinton County Fair at De Witt, Iowa. 

be obtained from foreign sources, hunger was sure to visit practically every European nation. The shutting off of commerce by German piracy has meant starvation, literal starvation, to multitudes of innocent persons.

The restoration of commerce means that all these starving nations will send their ships to America for food, food, and still more food. The number of these innocent neutral victims of German savagery is put by the United States Food Administration at I80,000,oo persons! Russia, too, is disorganized and starving, and her population numbers $160,000,000$ !

If figures never lie, the burden we must carry in time of peace, as indicated by statistics, is truly appalling. When the war began we were feeding our own $100,000,000$ people and sending abroad a relatively small and constantly decreasing surplus. To our I00,$\infty 00,000$ we had to add the $120,000,000$ people of the Entente allied nations. Speedily we found that our claim that America was "the granary of the world" was an empty boast. Merely to provide food sufficient to enable our allies to eke out their own stores taxed us to the utmost. Only through decreased consumption, by having recourse to wheatless and meatless days, by lessening our use of butter, milk, sugar, and other exportable foods could we send enough to keep our allies from actual starvation.

During the three years preceding the war, our exports of meat were just short of an average of 500 ,$\infty 00, \infty 00$ pounds a year. In 1917 we shipped abroad 
$2,000,000,000$ pounds-an increase of 400 per cent. In the same way our exports of butter in 1913 totaled slightly more than $3,500,000$ pounds. In I9I7 we exported, in round numbers, $26,750,000$ pounds. Before the war our shipments of cheese averaged 2,500,000 pounds. In 1917 they exceeded $66,000,000$ pounds. Our exportation of condensed milk jumped from $16,500,000$ pounds to $259,000,000$ pounds.

If the feeding of our $120,000,000$ allies made such a drain on our resources, what will happen now that I $80,000,000$ starving neutrals also come to us for food; when Russia's helpless $160,000,000$ thrust their hands across the sea to us, even as the sinking Peter appealed to Christ, saying, "Save me or I perish"? Now that peace has come; now that Germany and Austria are again to be admitted to the society of nations, as eventually they must be, how can we prevent their hungry multitudes - another $100,000,000$ souls-from also entering our markets and bidding for our food supplies? Already our former foes are begging piteously for food, and President Wilson has assured them that their appeals will be heeded.

Now that these things have come to pass, we must feed or help to feed, not $220,000,000$ people as during the war, but an additional $440,000,000$. In short, now that the war is ended and commerce restored, we must help to feed two-thirds of a billion of people!

Food Administrator Hoover recognized this condition as inevitable, and when the armistice was signed he was prepared to reckon with it. With the cessation of hos- 


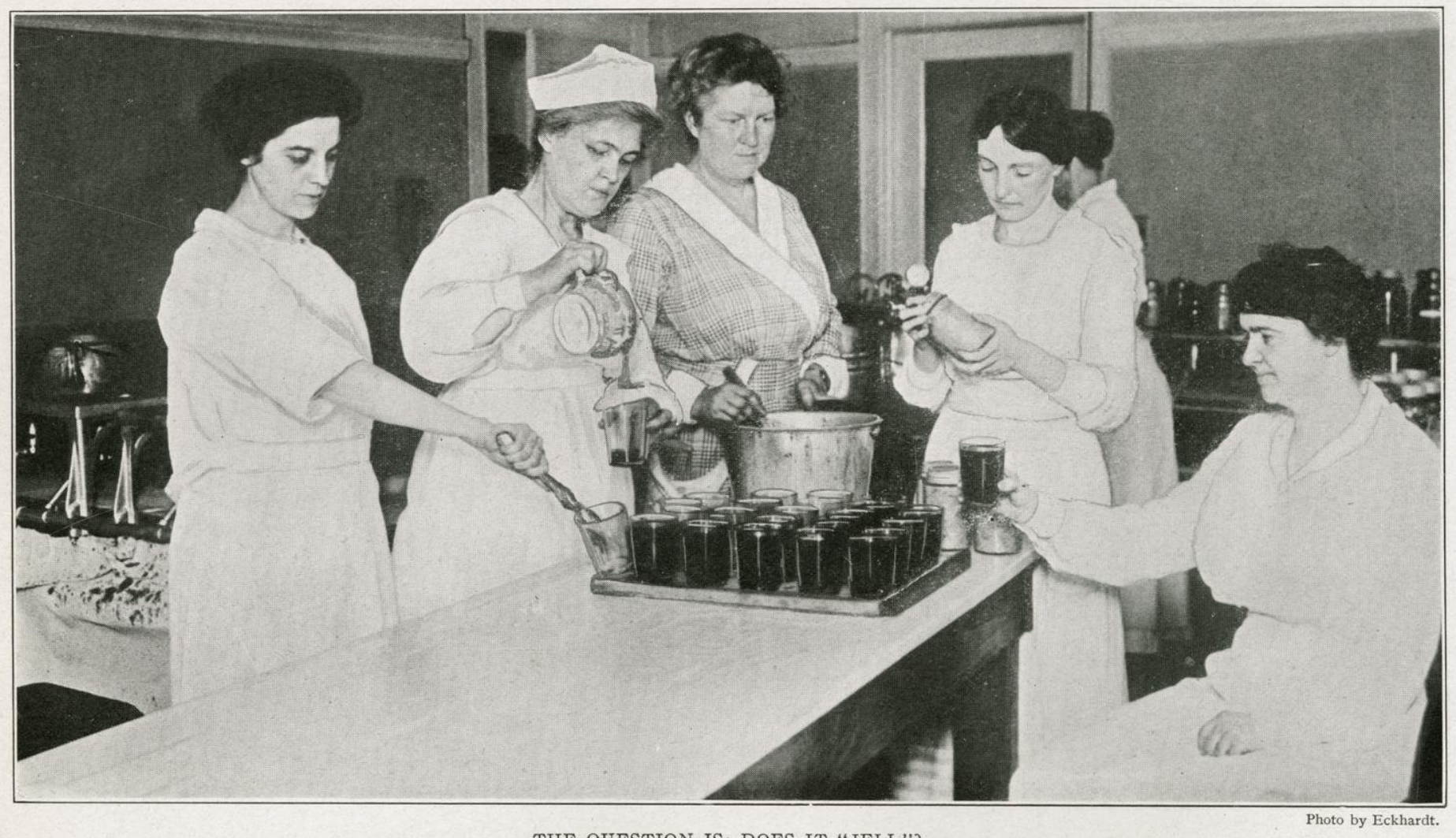

THE QUESTION IS: DOES IT “JELL"?

Mrs. Grace L. Ackley (second from left) is shown explaining the art of jelly-making to a group of other women of Hinsdale, Illinois. The Women's Association of the Union Church found so much food-saving work to do that it appointed a chairman for every day in the week. 

tilities he marshalled the food forces of America and proceeded at once to Europe to join hands with the food forces of England and the Continent to the end that starvation might be prevented. As one of his initial steps, before sailing, he asked that the war gardens of America be maintained and expanded. To the Victory Gardeners, he gave the impetus of his urgent plea for continued effort in the cause of food production.

The signing of the armistice caused complete and peremptory revision of the figures dealing with America's obligations toward meeting the world's demand for food. During the war we had to furnish food for France and Belgium, but they were a France and Belgium greatly reduced in area because of German invasion. Much of their territory and millions of their people were held by the enemy, shut off from their own countries and therefore compelled to depend in part on the invaders for subsistence. To-day these people are repatriated. Their restoration to citizenship has brought the obligation to feed them.

While the direct burden falls on France and Belgium, these countries must look to America for ways and means. By all the ties of international friendship, by a sense of gratitude for the part these countries played in winning the war, by geographical location and by inherent capacity to provide food, America is the one country able to meet the call. We must also provide for the smaller allied nations which have been under German oppression-Serbia, Rumania, Greece, the 


\section{II4 THE WAR GARDEN VICTORIOUS}

Czechs, the Jugoslavs, the starving population of Northern Russia and the people of other countries in Europe.

The revision of figures necessitated by the armistice gave new meaning to America's responsibility. The original pledge made by the United States was I 7,500,000 tons of food to be shipped overseas during the year. This amount of food was 50 per cent. greater than that which was sent the year before. With Belgium and France liberated and millions in south central Europe clamoring for food, the United States undertook to increase its exports from $17,500,000$ to $20,000,000$ tons.

To meet the demands for food America has two sources of supply. Food can be raised only cn the farms, by those who make a business of production, and on the lands of our cities, towns and villages. No other sources exist. The $40,000,000$ acres of farm land under cultivation have already probably reached their maximum of possible production for the immediate present. It is obvious, therefore, that if we are to give the world more food the new supply which will make this possible must come from the only remaining source-the small gardens in our urban and suburban communities.

The changed conditions brought into being by the signing of the armistice caused the National War Garden Commission to continue its work with increased earnestness in 1919. The armistice caused hostilities to be suspended but it did not increase the food supply nor feed the hungry. The world's new demand for food made it imperative that the Victory Gardens meet and surpass the record of the war gardens. To do its share 


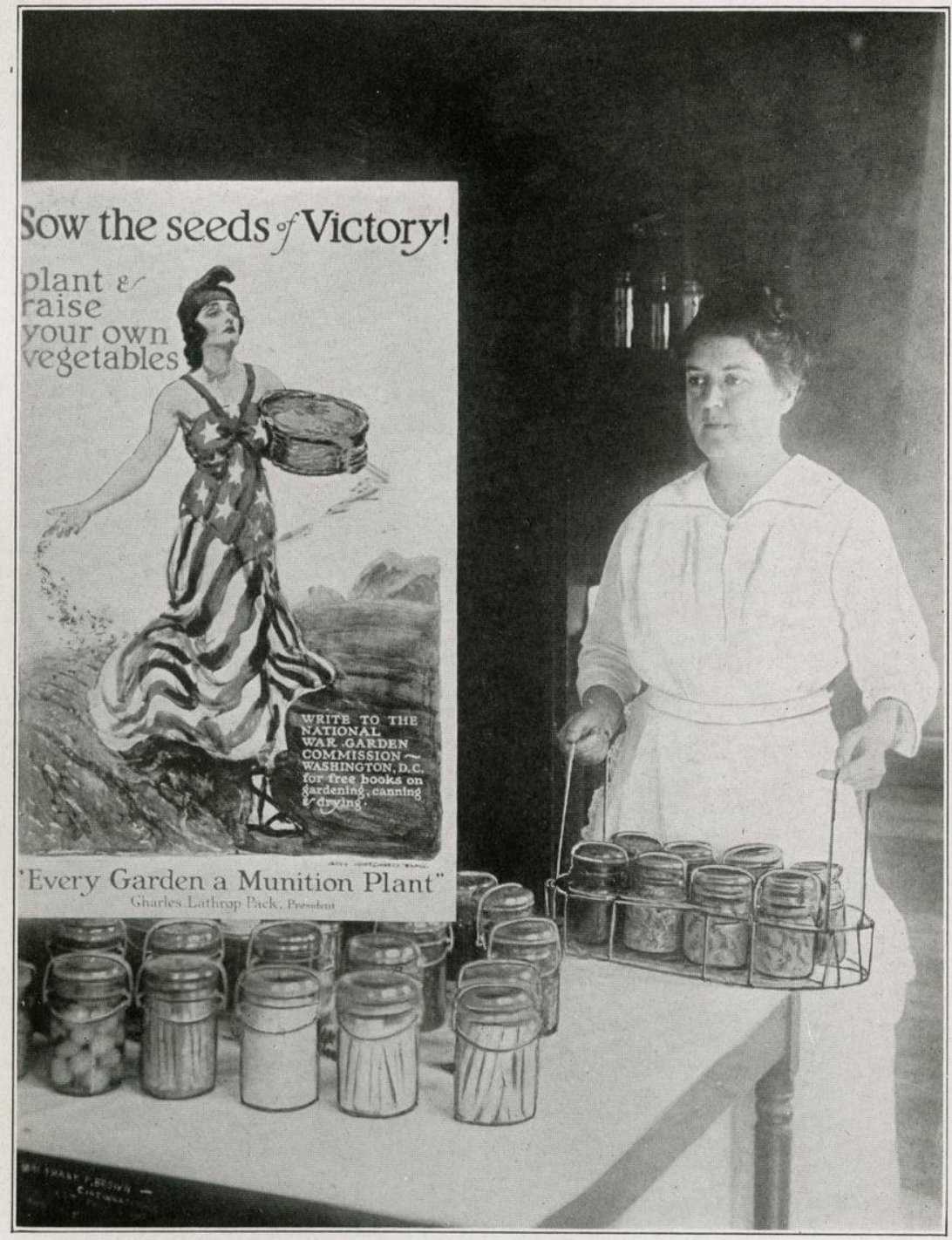

RECEIVED CERTIFICATE NUMBER ONE

Mrs. Frank P. Brown, of Cincinnati, captured first honors with her war-garden display of canned vegetables at several exhibits where she was an entrant. She was awarded the first National Capitol Prize Certificate offered by the National War Garden Commission in I918, to blue-ribbon winners in this class at fairs and exhibits all over the country. 

toward bringing this about, to meet the urgent appeal of Mr. Hoover and to help feed a starving continent, the Commission realized that no relaxation was to be considered and its campaign for 1919 was on a broader and more vigorous scale than during the conflict.

This terrific demand for food will be not a matter of one season only. For years and years we must continue to supply unheard-of amounts of food. Indeed it would have been almost as easy to put Humpty Dumpty together again as it will be to restore Europe's agriculture. The soil of thousands of acres has literally been blown away by high explosives. Practically all the lands in the embattled nations have decreased in producing power through poor handling, neglect, and lack of fertilizers during the war. And of the host of farmers that toiled to feed Europe before the war, millions now lie beneath the soil they tilled, and other millions, maimed and crippled, can never again turn a furrow or harness a horse. As long ago as 1916 the shortage of cattle, hogs, and sheep in Europe totaled II 5,000,000 head; and without livestock to produce manures years must elapse before Europe's production is restored to normal.

Since American farmers cannot produce all the food needed, American gardeners must continue and extend their merciful work of helping to supply the food needs of the world. Instead of lessening their efforts, they will be called upon to add as much as possible to their productive capacity because of the additional mouths to be fed. They are offered a new opportunity to help. 


\section{THE WAR GARDEN VICTORIOUS}

There is no question that the cultivators of our war gardens, now become victory gardens, will continue their labors.

For a decade or two before the war, there was deep study and much discussion of the problem as to how to check the exodus from the farm to the city; but argument and discussion availed nothing, and the exodus continued. In the "city farmer" has been found a partial answer to the stay-on-the-farm idea. Ambitious young men and women will not remain in the country where comforts are denied and where advantages of education and social life are few; but they will be glad to farm in the city. The victory garden has opened the way. By this means almost every one becomes a food producer.

Furthermore, increasing prices will make it desirable to the individual, and the growing demand for food will make it desirable from the country's point of view, that every one help to feed himself. The readjustment which must come out of the war calls for powers as Herculean as those it has been necessary to put forth during the terrible struggle against " $\mathrm{Kul}$ tur." This reconstruction work calls for every bit of man-power that can be found. It is a question not of months but of years before this up-building is completed. In France, Belgium, Poland, Italy, Russia, and other European countries, the rebuilding of cities and churches, railroads and bridges, docks and roads, houses and barns, the remaking of trench-scarred and shelltorn farms, and many other big works, must be per- 


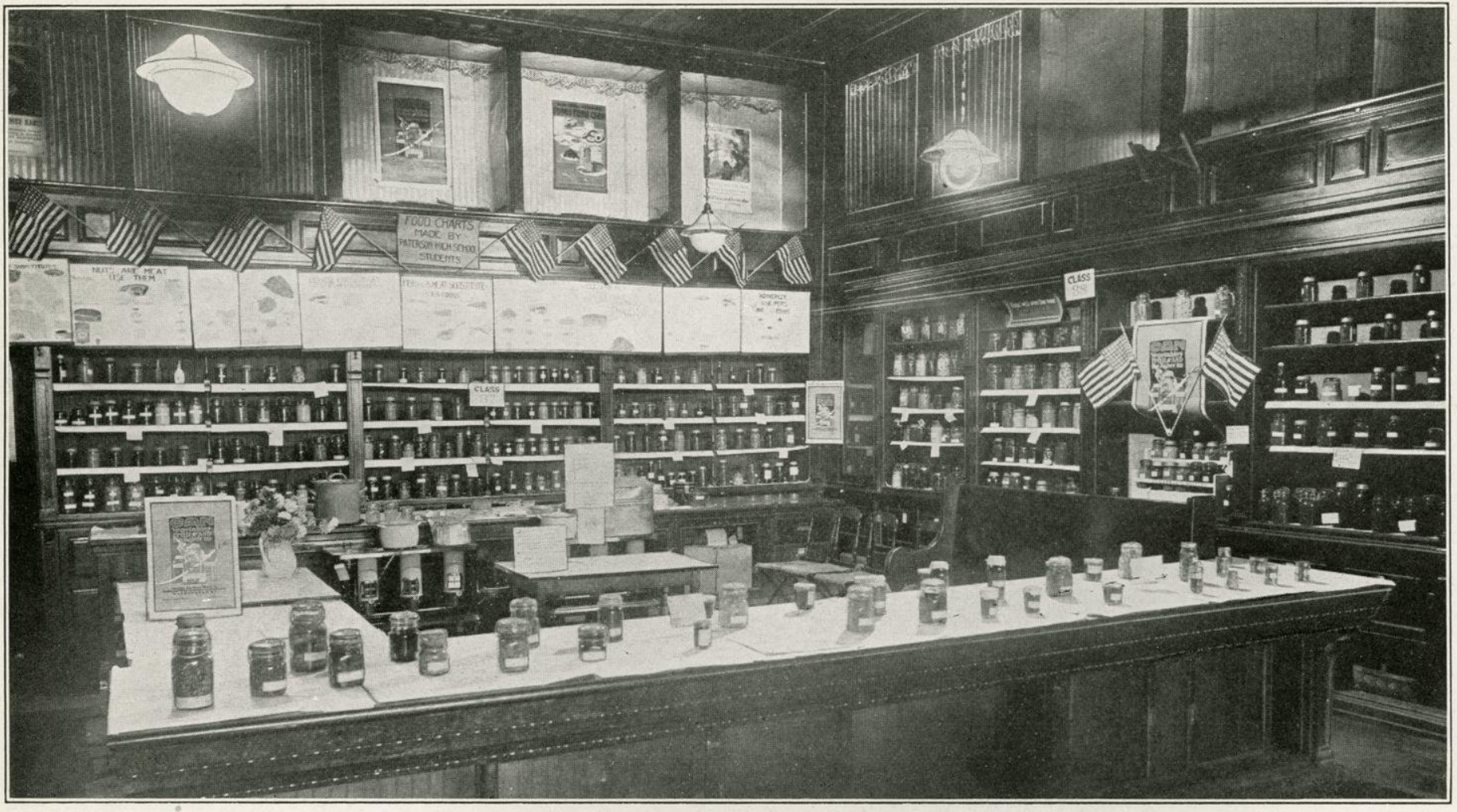

INTERIOR OF A BANK, NOT A FINE GROCERY

This is a view of the war-garden exhibit, a sort of "county fair," which was held by the Paterson Savings Institution of Paterson, New Jersey, and which aroused a very lively and friendly competition among the city farmers of that place. The blue ribbon for the best canned products, and the National Capitol Prize Certificate, went to Mrs. F. H. Thoms. 

formed. So we can look for no huge immigration after the war to solve our labor problem, and that problem is acute. There are no ruined cities to be rebuilt, or devastated farms to be restored in the United States, but there are innumerable construction tasks to be done that have been put aside during the war.

Thousands of miles of road-to mention a single task-will have to be completely rebuilt. The day of the heavy motor-truck as a means of transportation between city and city has come to stay, and for its accommodation there must be a strengthening of roads. This is one of the great tasks awaiting the army of men returning from the battle-fields. The construction of new buildings in our cities, checked by war-time need of material and men, must be resumed and lost time must be made up. Cities will need many improvements which will keep the workers of the world busy, In these and a hundred other ways there will be steady call for the men released from strictly war work.

All these facts point to the increasing value of the victory garden. It will be just as important a factor in the life of the nation and the community after the war as was the war garden during the conflict. The need for gardens will last for many years; and during that time, the value of gardening will have become so apparent that the movement will continue indefinitely. It will have become a habit fixed and firmly implanted in the hearts and lives of the people of the country.

In addition to all this, gardening has been found to be a health measure. It has been used in the rehabili- 
tation of convalescent soldiers. Around the hospitals in Europe, almost since the beginning of the war, vegetable plots have furnished the means for providing easy and pleasant outdoor work for convalescents, which acted as a tonic to their shattered nerves and bodies. Similarly, at the hospitals and army camps in the United States this form of activity was employed to help in the rebuilding of disabled and convalescing soldiers.

In the great reconstruction work at the Walter Reed hospital, which lies in the outskirts of the nation's capital, a fifteen-acre war garden proved of much therapeutic value in the treatment of men suffering from various diseases. In addition to helping them regain their health and strength, gardening trained these men for the future and equipped them to make their own living and become valuable citizens of any community when they should leave active service. Part of the large war garden at Camp Dix, New Jersey, adjoined the base hospital; and potatoes and other vegetables were growing during the season of I9I 8 up to the very porches on which some of the invalids had to sit in their wheel-chairs.

Sailors as well as soldiers need fresh vegetables to eat, but they cannot grow vegetables at sea. To overcome this handicap a movement was started throughout the United Kingdom to give naval men a supply of fresh vegetables whenever they got to port. Navy vegetable rations formerly consisted of potatoes only, and a few dried or canned products which could be kept a long time and stored in small space. The new 


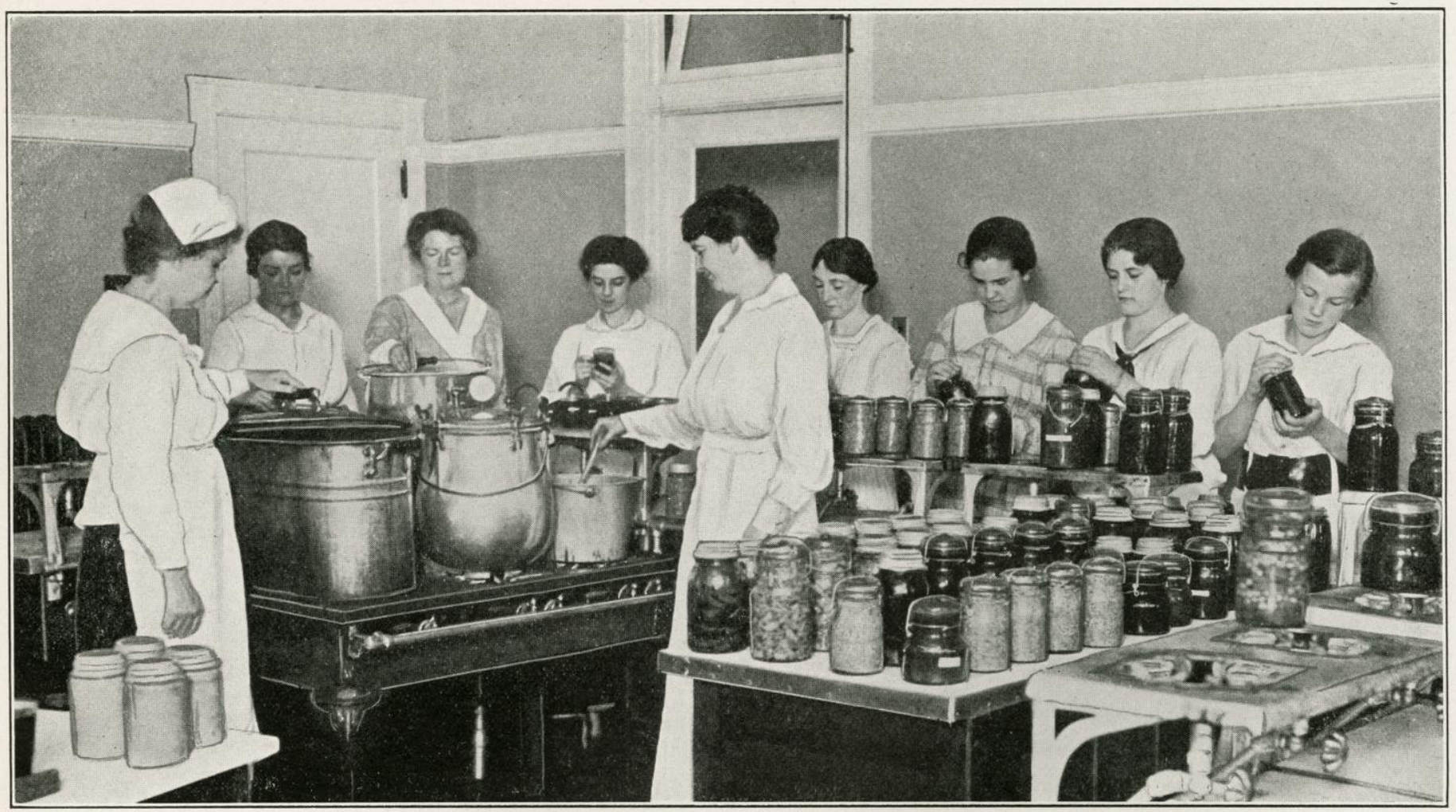

GETTING THE WINTER SUPPLY READY

Photo by Eckhardt.

Under the direction of Mrs. Grace L. Ackley, the demonstration canning kitchen established in Hinsdale, Illinois, was a great success. Some women went for instruction, others took war-garden crops to have them canned there, while still others took their maids so that they might learn how to save food. 

British organization soon had eight hundred branches and collecting depots throughout the United Kingdom. Headquarters were established in London, with Admiral Lord Beresford as president. The patrons included many prominent people, but its members ranged from the owners of large estates, contributing regular supplies weekly, to the small schoolboy with only a tenfoot plot to cultivate. Not long after the work got under way, 300,000 pounds of fresh vegetables and fruits were being furnished weekly to the British navy. In speaking of this work and its value, Rear Admiral Lionel Halsey, third lord of the Admiralty, said:

Those associated with the Vegetable Products Committee can happily feel that this work is of priceless value, for without a vegetable food the men of the fleet could not have so thoroughly performed their work in the past; nor will they be able to do so in the future without a continuance of this splendid work as efficiently and as generously as in the past. Its value may be realized when it is stated that these supplies are an invaluable factor in keeping the men in good health and fitness.

What is true in the case of the stalwart men of the British navy, is true of all other members of society, of high and low degree. There is need for vegetable food. The body is kept in better condition if it does not depend too largely on a meat diet. Victory gardening will add greatly to the proportion of greens which will enter into the diet of the American people.

The future of gardening, therefore, is assured. It is 
such an important economic gain, and its benefits in other ways are so numerous, that the army of home food producers themselves will be its strongest and most ardent champions. Both by practice and by precept they will continue to spread the gospel of "Food F. O. B. the Kitchen Door." Just as the army which has fought for justice, decency, and civilization will see to it that these principles are maintained in every part of the world, so the soldiers of the soil in city, town, and village, millions of whom have tested the worth of gardening, will be its future champions and defenders. It is in these ways that the seeds of victory will insure the fruits of peace. 


\section{CHAPTER XIV}

\section{CONSERVING THE GARDEN SURPLUS}

How Housewives Turned Their Reserves into Preserves

ROM the governments of the Entente Allies and the associated nations, whose territory girdled the earth, came the cry for conservation. There was need for this cry. Never in the world's history was material of all kinds used up in such quantities. More than once, in a three-hour preparation for a short advance, a greater number of shells had to be employed than were fired in the entire Franco-Prussian War. Shells are but a type. Everything was used in unheardof quantities. This was particularly true of food, the basic material upon which the entire structure of victory rested. Speedily it became apparent that everything possible must be saved-old cartridge cases, old shoes, old shells, old clothes, old materials of every sort-and particularly food. This was especially true of food because material like old shoes or old shells could be used repeatedly; but food once eaten was gone forever. As the world's food supply became more inadequate the cry for conservation grew more and more insistent.

"Turn your reserves into preserves!" became the order of the day among the women all over the country. With this as their slogan they made ready by the million to build up a second line of defense which would 
serve as an effective bulwark against the enemy. The call to make "Every Garden a Munition Plant" was supplemented by the women with the motto: "Every Kitchen a Canning Factory." Every facility that could be found was utilized to carry on this effort. Women's clubs everywhere urged upon their members and others the importance of this work. Community kitchens were opened for the convenience and assistance of those who did not have the means or the time, at home, to preserve all the vegetables grown in their gardens.

It was necessary that a certain amount of information concerning new and scientific methods of canning be furnished with the appeals made to women to proceed with the work, so the National War Garden Commission furnished precise and practical instructions. This it did in a number of ways. A comprehensive but concise canning and drying book was prepared by scientific experts and printed by the Commission for free distribution. Several million copies of this manual were given out during the first season of the garden campaign; and an equal number of the improved and revised editions which were issued in 1918 and 1919. These went to hundreds of thousands of individuals who applied for them, to libraries, local canning clubs and committees, chambers of commerce, and other trade bodies, banks, and manufacturing concerns, schools, hundreds of emergency home demonstration agents of the United States Department of Agriculture, and to state, county, and city food administrators. 


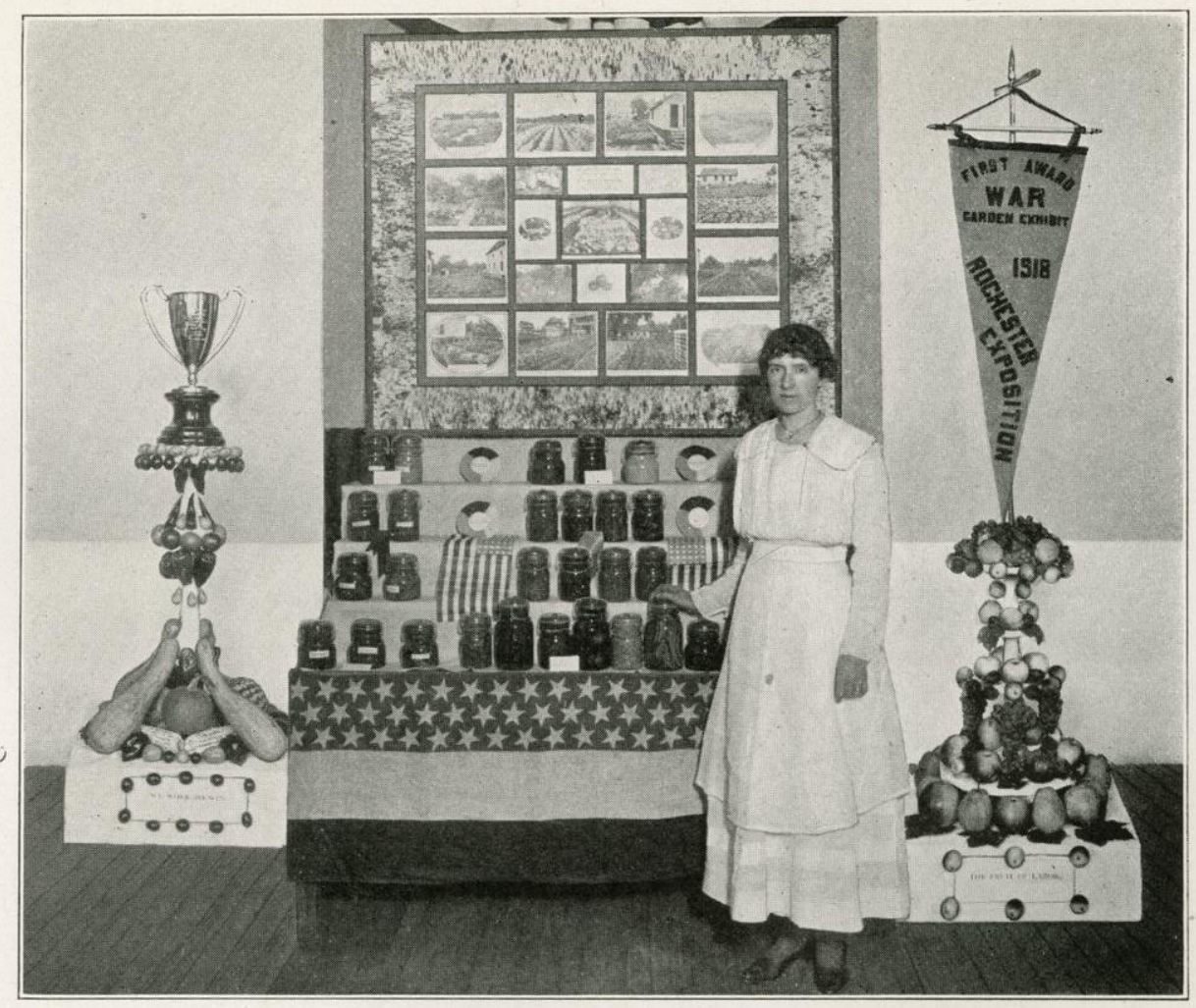

A PRIZE-WINNING EXHIBIT

At the big war-garden exposition held in Rochester, New York, the blue ribbon for best canned vegetables went to the display shown there by the Eastman Kodak Company whose employes had gone into the work of home food production and food conservation most enthusiastically. Mrs. Tillie Baldwin who carried off the company's first prize with her canned vegetables and fruits was also awarded a National Capitol Prize Certificate by the National War Garden Commission. 

A series of canning lessons was prepared by the Commission's experts. These were supplied to the newspapers of the country, hundreds of which ran them as daily instructions. With many of them illustrations were used, showing the various steps in the cold-pack method of canning, and giving other educational hints in pictorial form so as to attract the eye of the home food conserver and make the work plainer. News stories telling what was being done along this line in various sections of the country were published in the daily press; and large numbers of feature articles were written and widely circulated.

To arouse further interest in the work and to encourage the best possible efforts, recognition was accorded by the National War Garden Commission for excellence of product. This was in addition to local prizes and awards and was in the form of National Capitol Prize Certificates which were given to the blue-ribbon or first-prize winners at exhibits and fairs for the best displays of canned vegetables from war gardens. With these certificates the Commission gave money awards, the first year in cash, and the second year in thrift stamps.

Many large manufacturing concerns which had extended aid to their employés in planting gardens held fairs at which the products raised were displayed and prizes awarded in the various classes. At a number of these the Commission's certificate constituted the grand prize which went to the sweepstakes-winner in the canned-vegetable class. Not only did hundreds of 
industrial plants, large and small, provide land for their men, prepare it for cultivation and divide it into small individual plots, but they also made arrangements for the wives of their workers to can their surplus products in kitchens set apart for the purpose and with capable instructors placed in charge to show the women how to obtain the best results.

The appeal to the women of the United States to "Back Up the Cannon with the Canner" met with loyal response. Testimony has been given by prominent officials, governmental, military, and civil that the war could not have been won without the aid of the women. They took places left vacant by men in munition factories, on the farms, and in a hundred other activities. It will never be possible to estimate accurately the extent to which they made victory a certainty. But to no class of women is there due a greater meed of praise than to the silent millions all over the country who helped to save food. While their sisters were working in munition factories, these women in countless numbers were packing away "ammunition" in jars so that the boys in France might always have a. supply. Soon after he landed in France, General Pershing sent a message to America. It said: "Keep the Food Coming." The women of the country obeyed the order. With ladles and spoons instead of bayonets, with wash-boilers in place of tanks, and with cans and jars as their weapons instead of hand-grenades and bombs, they performed valiant service.

They made a fine start in 1917 when, from the 
surplus products of the millions of war gardens, they preserved something like $500,00 \mathrm{c}, 000$ quart jars of vegetables and fruits. In the following season they far surpassed their previous record and, according to estimates, stowed away approximately I,450,000,000 quart jars of garden produce. 


\section{CHAPTER XV \\ COMMUNITY CONSERVATION}

How American Cities Backed up the Cannon with the Canner

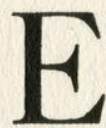

NORMOUS as was the quantity of food packed away in cans by American housewives in the summer of 1918, the quantity so conserved represented only a fraction of the surplus of American war gardens. Home canning could not begin to take care of the excess, and therefore, in order that the Scriptural injunction be followed and "nothing be lost," it was necessary to establish conservation on a community basis, just as it had been found helpful to stimulate production through community gardening. These organized forms of conservation took the shape of community markets for the distribution, and community canneries for the preservation, of the garden surplus.

Though the Commission limited its efforts along these lines to the furnishing of instructions for conserving food, the work of the community centers for the sale of garden surplus proved most helpful and is worthy of mention. The usual custom was for the community club or other organization conducting the market to charge ten per cent. for selling the products. Many war gardeners found the community markets an excellent medium for disposing of surplus vegetables not needed for home consumption. Purchasers, too, were 


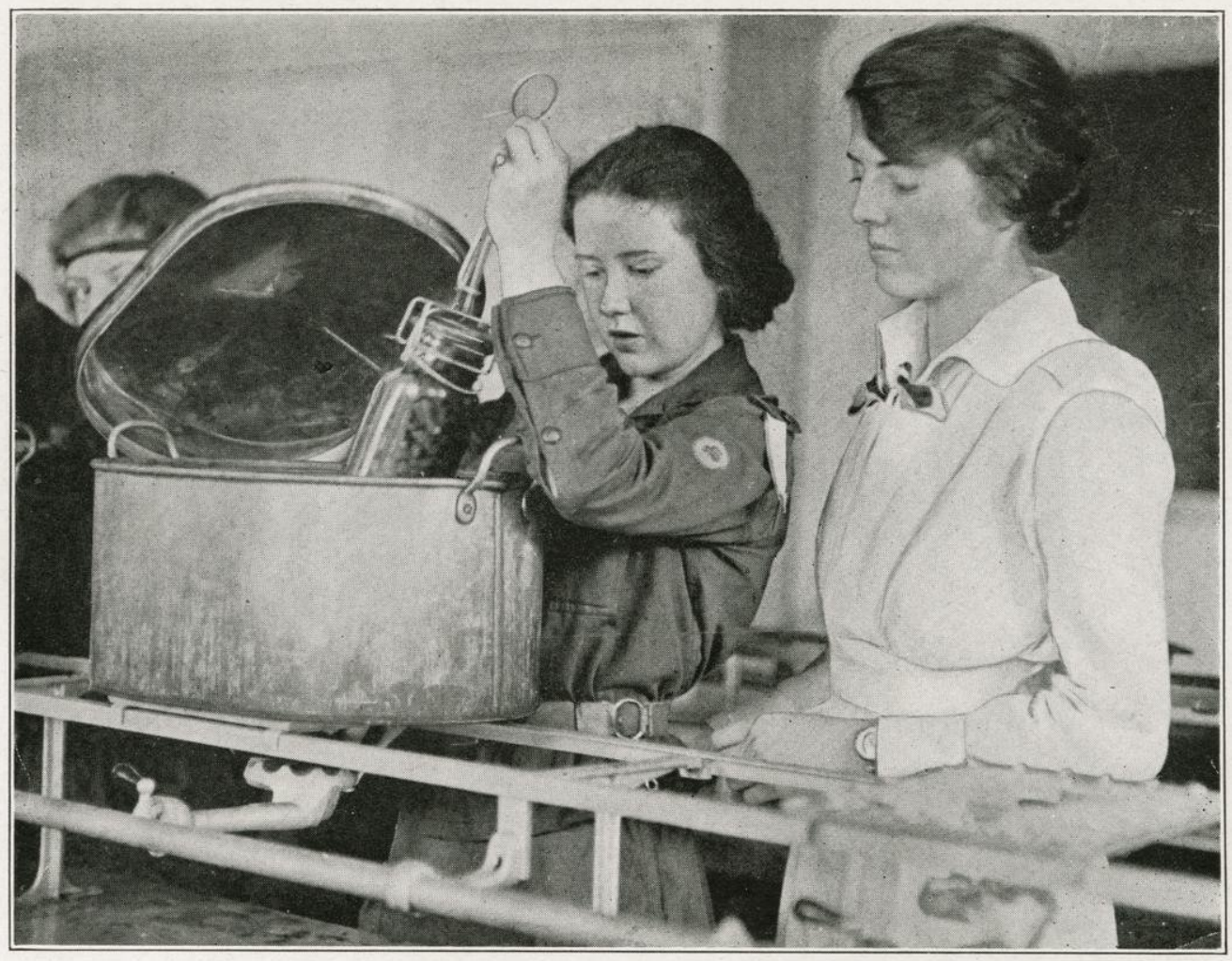

GIRL SCOUTS CAN CAN, TOO

Evening Ledger Photo.

Girl Scouts of the Radnor High School, Wayne, Pennsylvania, under the direction of Miss Ethel Henderson, receiving instruction in the cold-pack method of canning. This campaign, conducted through the schools of the country, has resulted in a wonderful amount of food saving in this way. 

glad of the opportunity afforded by the community market to secure vegetables that were fresh and choice.

One of the most prosperous and successful of these community markets was at Oakland, California, under the direction of Mrs. James Hamilton, the city director of food production, who showed courage and energy in pushing her project to success. It will be well to let her tell something of her own story. Here is part of what she has to say:

So far this market has been the means of saving hundreds of tons of vegetables and fruits, together with quantities of berries, eggs, chickens, pigeons, rabbits and honey. The greater part, if not all, of the perishables otherwise would have been wasted. This market has taken care of the war-garden supplies of our city since it was opened, together with the supplies of several of our big growers of both fruits and vegetables. It will be a very great means of stimulating production for next year because the grower knows he will be given a place where he can market his supplies advantageously.

In Brookline, Massachusetts, a community market was established in an unused church, placed at the disposal of the market committee by the trustees. Here, on two days of each week, surplus garden products could be brought for sale. As gardening had been stimulated to the maximum there was much to be sold. Those who wished to sell their own products were provided, at nominal rental, with individual tables. Sales were made by the market committee for those not wishing to sell in person. For this service a small per- 
centage of the selling-price was charged. To this market were brought products from the school-gardens, the surplus from back-yard gardens, and the excess from community garden-patches on great estates, where ground had been lent by the owners for the use of persons who had no garden space. Vast as was the amount of produce that poured into the market from all these sources, every particle of it was sold; and ordinarily the market was sold out long before the established hour of closing. Thus, at practically no expense, and merely by utilizing facilities at hand, the people of Brookline saved an enormous quantity of food that otherwise would almost surely have gone to waste.

The women of Roselle, New Jersey, wished to establish a community market, but lacked what would ordinarily be considered adequate facilities, until they secured the use of a vacant lot in the town, and then induced the town council to keep the lot clean. Here, on given days of each week, were brought all the surplus products of home gardens and even the excess of neighboring farms which were sold to those who had no gardens or who wished to buy products that they could not raise in their own yards. Thus the excess of the entire neighborhood was brought together and utilized.

At first glance Roselle, like many another small town, had no place which seemed fitted for a community cannery. It had a schoolhouse, however, and that schoolhouse had a kitchen. Presto! It became a community cannery. At the community market the conservation committee bought from day to day such 


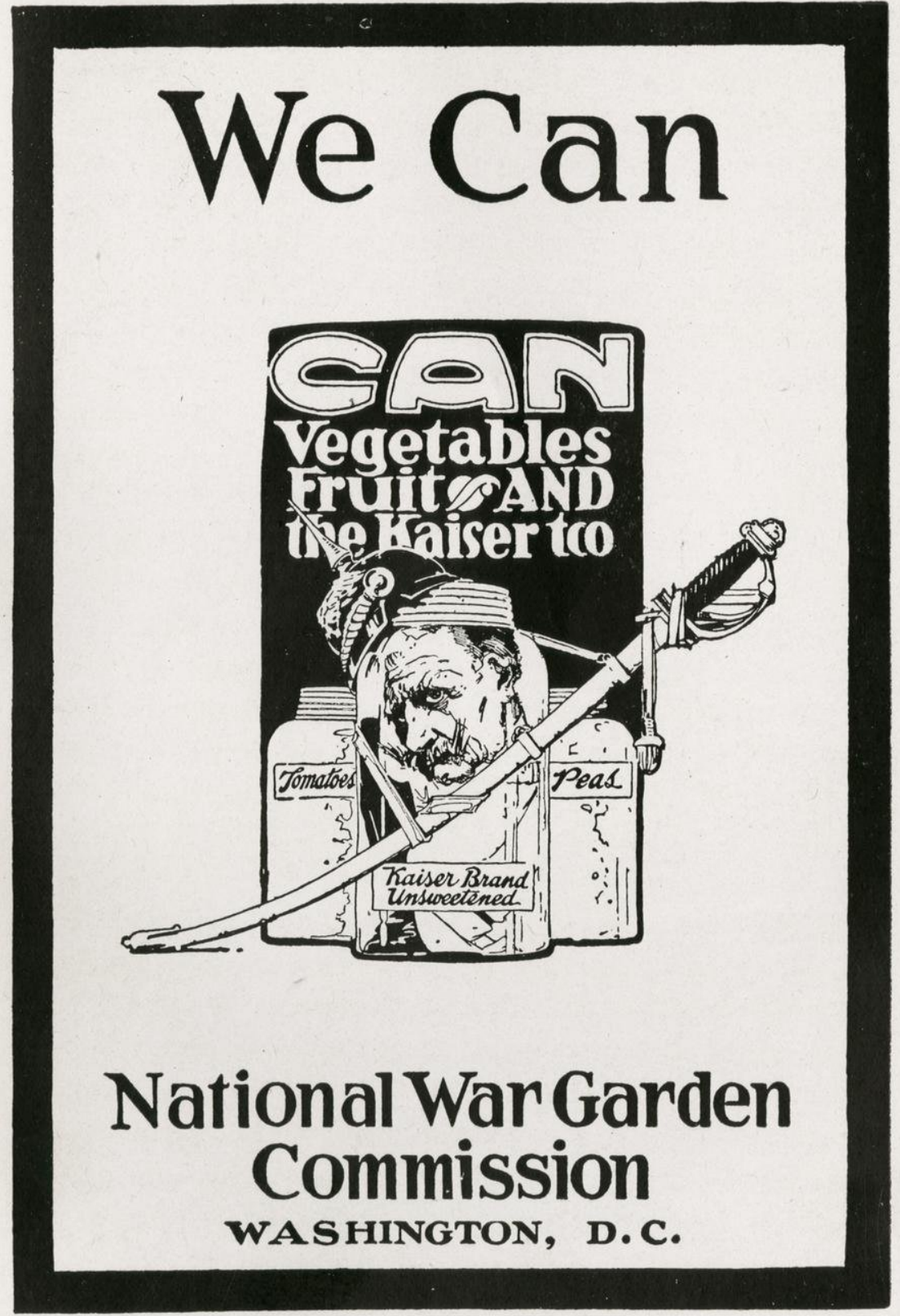

SERVICE FLAG OF THE HOME CANNER

Window hangers like this went broadcast throughout the United States and Canada. Displayed in front windows they carried to all passers-by the message of canning activities within the homes. The eager demand for these hangers showed the pride of the home canners in their work. 

vegetables as it was desired to can, and the transportation committee conveyed these products, in motorcars lent for the purpose, to the schoolhouse cannery, where the women of the town did the canning. Thus Roselle did with its might what its hands found to doand did it with what was available.

In similar spirit of determination the women of Williamsport, Pennsylvania, secured the use of a church kitchen for the summer of 1917 and there began the conservation of community surplus. Under the leadership of Mrs. John G. Reading and Mrs. H. C. McCormick, and with the assistance of Mrs. R. F. Allen and many other able women, this task so humbly begun grew in size and importance until the canning system embraced the entire county. In 1918 adequate quarters were secured in the business district. Here canning outfits were installed, and the women of the city came day after day to put up the surplus from the market and the excess products brought in by farmers. A substantial fund had been voted by the local Committee of Safety to finance this work. Thus the women were able to buy whatever products were brought in. In seven other districts in the county similar work was going on. All the canning centers were run on identical lines and all were affiliated with the central cannery at Williamsport. In this way scores of women throughout the entire county were drawn into the work. Beyond any question this conservation movement had much to do with the remarkable community spirit exhibited throughout the county. 
Another interesting example of a community cannery was to be found in Salt Lake City. Recognizing the need for food conservation, the city's women first brought about the creation of a community market and later established a community canning kitchen that was run in connection with that market. The work was carried on under the chairmanship of Mrs. C. H. McMahon.

The cannery itself consisted of one of the large market stalls, temporarily enclosed for the purpose and equipped with a complete canning outfit. Mrs. W.F. Adams, president of the city's federated women's clubs, was executive head of the organization. She was on duty daily, arriving at the cannery by 7:30 o'clock in the morning. Each morning the market-master purchased in the market such products as Mrs. Adams desired. Sometimes he secured these products direct from the neighboring farms. Occasionally fruit or vegetables were offered to the cannery free on condition that they be picked and taken away. In such cases troops of Boy Scouts were utilized to do the harvesting and motor-cars, offered for the purpose, were used to bring the food to the cannery. In order that there might be a constant force of women at work, that the labor should not become irksome to any, and that the interest be as widespread as possible, Mrs. Adams appointed six lieutenants to look after the labor supply. Each lieutenant was responsible for supplying a given number of hands on one day of each week and each lieutenant procured a certain number of women to pledge them- 


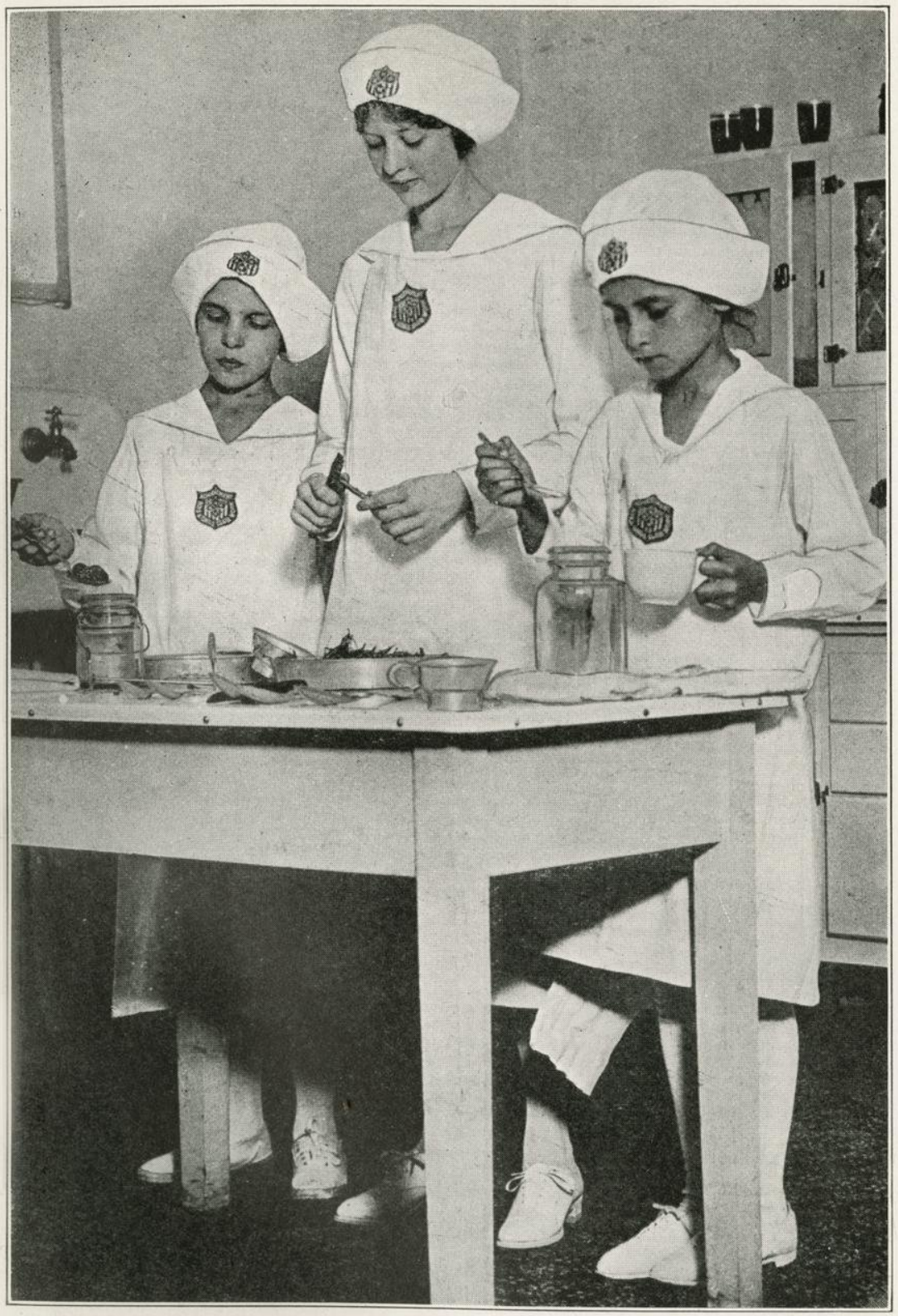

ACHIEVEMENT CLUB GIRLS

Post-Dispatch Photo.

These three young St. Louis girls are members of one of the Achievement Clubs which took an active part in many cities in teaching and spreading the doctrine of proper food preparation and conservation. Canning of surplus vegetables and fruits was one of their most important accomplishments. 

selves to work for her at the cannery on a given day each week. In this way the supply of labor was assured. Usually there was additional help, for all volunteers were welcomed.

In order that the work might be done scientifically, and the pack be uniform from day to day, everything was done under the direction of a paid expert. Visitors were free to come and watch operations, which were thus a continuous demonstration of scientific canning, and thousands of women who had come to market only to buy products also dropped into the cannery and learned the up-to-date methods. The educational value of this effort was beyond computation. The women of the entire city were reached.

One of the most interesting conservation efforts reported to the National War Garden Commission was that of the employés in the shop of the Carolina \& Northwestern Railway Company at Hickory, North Carolina. So great was their enthusiasm that they took the cylinder from an old engine and turned it into a canning plant. They coupled up this cylinder with the shop steam-boiler, put on a steam-gauge and drain-cock, and inside the cylinder placed three shelves of heavy wire to hold the jars of vegetables and fruits. Their community canning plant was then ready for operation.

Reports to the Commission from all parts of the country indicated that in a great number of places arrangements were made to preserve surplus garden products through community canneries, and also 
showed the success that attended this effort. Typical of the spirit that animated many of these reports is a statement in a communication from J. D. Parnell, secretary of the Chamber of Commerce, Vernon, Texas. Mr. Parnell wrote:

We have a community canner and are preserving everything that we grow. We are also going outside of our county into the communities where they are not equipped to preserve perishable stuff and buying surplus. We can it and sell it to those who have no gardens.

Home demonstration agents of the United States Department of Agriculture, women's clubs, representatives of manufacturing concerns, gas and electric companies, and numerous individuals coöperated in this community canning. "The Federation of Women's Clubs and myself coöperating will supervise the marketing and the canning of the surplus products of the gardens," was the report to the Commission from Miss Anna Allen, emergency home demonstration agent at Independence, Kansas. Similar work was performed in hundreds of places.

The success of these community canneries is indicated by many reports such as one from Dallas, Texas, which boasted of 20,000 war gardens in 1918 , with 17,500 cans of vegetables preserved after the plant had been in operation only a few weeks. This same Texas report told of community canneries at Austin, Beaumont, Marshall, and Corsicana. The last named was in the Odd Fellows Hall and was operated by the children. During the first week of its existence the community 


\section{THE WAR GARDEN VICTORIOUS}

cannery at Temple, where there were 5,000 war gardens, took care of one ton of black-eyed peas. The cannery at Beaumont had a capacity of 500 cans daily.

Thus, in hundreds of community canneries the country over, thousands of women were saving the excess food upon which the fate of democracy rested, and practicing, as they canned, democracy itself. 


\section{CHAPTER XVI \\ CONSERVATION BY DRYING}

How American Housewives Made It Hot for the Kaiser

$\mathbf{M}$

ARIE ANTOINETTE'S milliner once remarked that there is nothing new except what is forgotten. One of the "new" methods of food conservation practiced by the women of America during the war was that of drying food. To most of them the process was an absolute novelty, yet it is as old as civilization itself. It is merely one of those practices so long out of use as to be forgotten.

Most of us are familiar with dried apples and the evaporated fruits of California, but there our knowledge ends. To most of us it comes as a distinct surprise, almost as a shock, to learn that practically all vegetables and fruits can be preserved for future use by drying. Certainly it was a great surprise to most of the housewives of America when they were asked to conserve food, not only by canning, with even which process many were only slightly acquainted, but also by drying, a method practically unheard of.

Drying is both economical and simple as a method of preserving food. It requires no elaborate or costly apparatus. The finished product can be kept in any sort of containers that are clean; whereas in canning expensive glass receptacles must be purchased. Dried foods are compact, thus saving space in storing and 


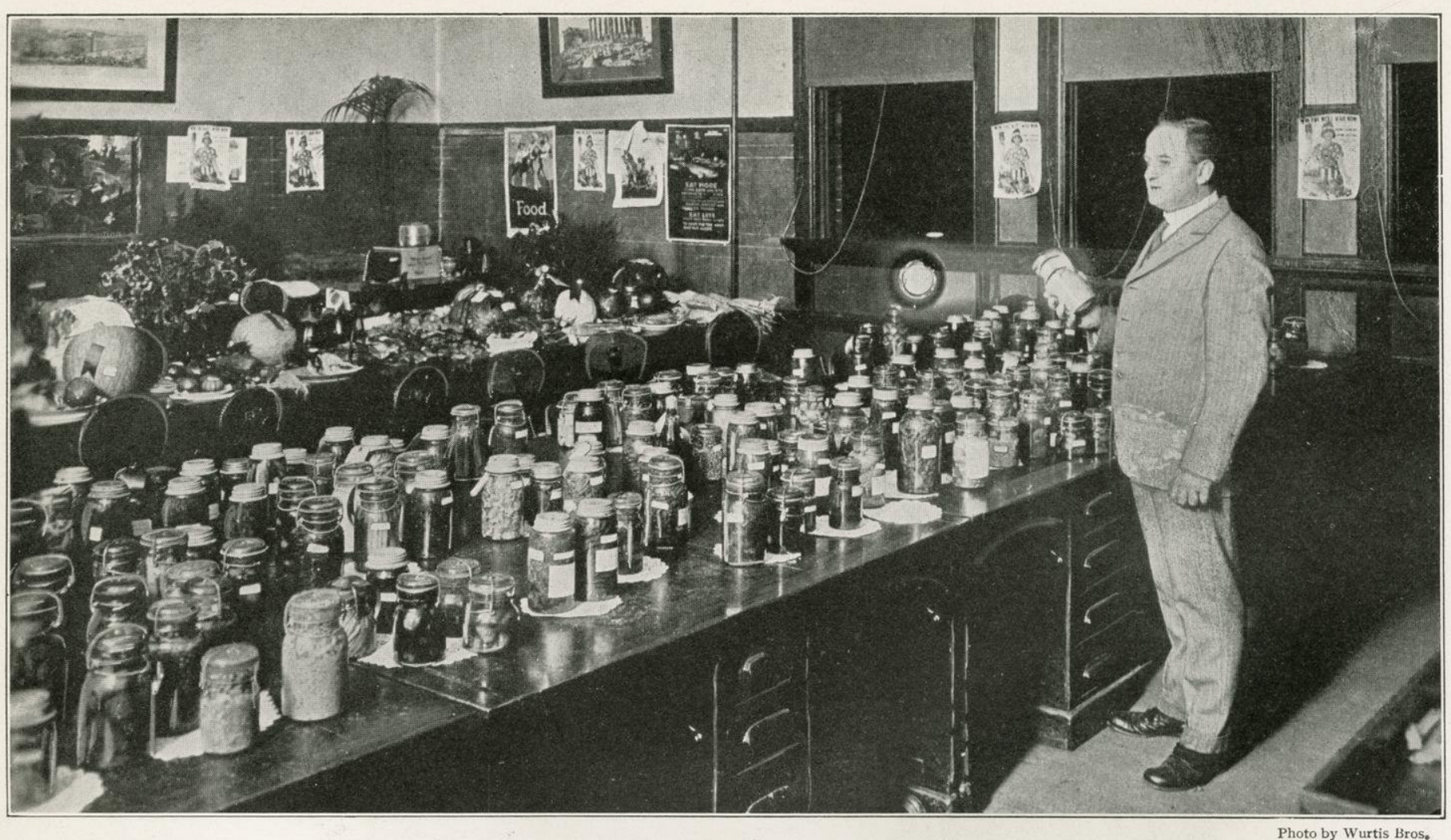

HE IS NOT LECTURING, HE WON THE CANNING CONTEST

The women of Elmhurst, New York, were not jealous but applauded when the announcement was made on the evening of their war-garden contest that the first prize for canned vegetables, carrying with it the National Capitol Prize Certificate, had been awarded by the judges to Mr. Charles A. Rundquist. He did his garden and canning work in the late afternoons and evenings. 

shipping. The original quality and flavor of the dried product is largely retained; and when dried foods are restored by proper soaking, they can hardly be distinguished from fresh vegetables and fruits.

Specifically, dried food products are products free from moisture. The words "dried" and "drying" are applied in general to foods preserved in a comparatively water-free state, without regard to the method of drying employed. Technically, the term "dried" as applied to food products means products that are dried by exposure to the heat of the sun; "evaporating" is drying by artificial heat; "dehydrating" is drying by artificial air blast, the process often including the application of artificial heat as well.

The duration of the drying process varies with the method chosen, the size and degree of compactness of the material to be dried, the variety of the product, the range of temperature, and the humidity of the atmosphere. Two hours is sufficient time to dry some products by evaporation or dehydration. Other products may require from one to several days for sundrying.

Practically all fruits and vegetables, it was early found, can be dried successfully so far as the "keeping" quality is concerned. It was discovered, however, that many dried vegetables were unpalatable when eventually cooked and served. Enzymic action in the raw products, as well as bacterial action, caused chemical changes which not only affected the flavor of dried food but to some extent also affected its wholesomeness. 
The problem thus arose as to how this disadvantage could be overcome.

Cooking was tried. Complete cooking, parboiling, and even partial cooking were employed with various vegetables, until it was found that a certain minimum period of boiling water treatment was favorable to both the wholesomeness and the flavor of dried products.

This treatment, which varies in time for different products, has been accepted as an essential part of the proper drying of vegetables. It is called "blanching." By it the protoplasm is killed and enzymic action stopped. There is a thorough cleansing and a destruction of many bacteria. Furthermore the flow of coloring matter is started, and the color of the product thus accentuated. The fibers are loosened and softened and a condition created which facilitates the giving-off of moisture in the drying process.

In "cooking" food, heat is usually applied long enough to alter the nature of certain materials, such as starch, rendering them digestible. Blanching should not be confused with cooking as it differs both in purpose and effect. It is a preparatory process by which the wholesomeness and flavor of a sound product are retained through the temporary stoppage of chemical changes due to agencies present and to bacterial action when raw flesh is exposed to the air. The drying process should follow at once, and be done as rapidly as possible, with due attention to the proper temperatures, which range from $115^{\circ}$ to $175^{\circ} \mathrm{F}$. according to the products handled. 


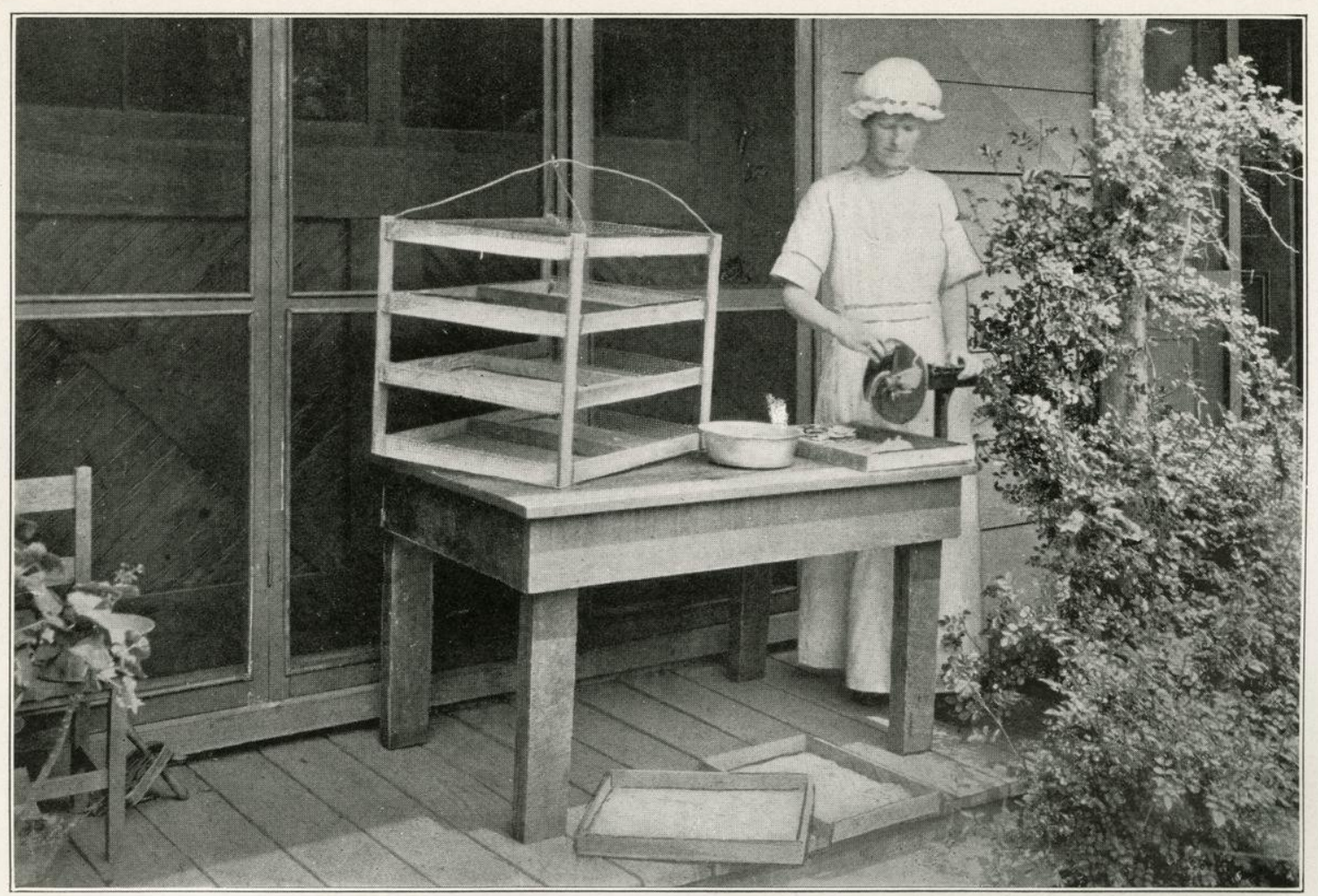

PREPARING TO DRY VEGETABLES

Dehydration except in the case of a few fruits is comparatively a new art in this country, and yet the process is simple. Practically all vegetables can be dried successfully. An effective drier to hang over a stove is simply made. The trays are of galvanized wire screen of small mesh tacked to the frame. A rotary slicer cuts the vegetables into uniform slices and secures regularity in drying. 

If products are not dried sufficiently, the moisture retained makes a medium for the development of bacteria and mold, and spoilage occurs. How much water to extract becomes therefore, an important consideration. The abundant sugar present in most fruits acts as a preservative and therefore it is not necessary that they be so dry as vegetables. A rational method of determining the right degree of drying for the finished stage is by the texture of the products. Most vegetables should be rather brittle when taken from the drier, and fruits should be leathery and pliable. One method of determining whether fruit is dry enough is to squeeze a handful, and if the fruit separates when the hand is opened, it is dry enough. Another way is to squeeze a single piece; if no moisture comes to the surface the piece is sufficiently dry. Berries are dry enough if they stick to the hand but do not crush when pressed.

There is considerable shrinkage in bulk and weight when products are dried. The reduction in weight is in direct proportion to the amount of moisture lost, but the reduction in bulk varies with both the structure of the product and the amount of water removed. In general terms it may be said that foods, in drying, are reduced to a bulk ranging from one-third to one-fifth of their original volume and to a weight from one-sixth to onetwelfth of the weight of the fresh material.

After the Boer War, considerable surplus dried vegetable material, no longer needed for the English army, was put into barrels and stored away. The barrels were opened during the European war and the contents 
satisfactorily used for army rations. Products thus kept unchanged in quality and flavor for eighteen years might reasonably be supposed to keep well almost indefinitely.

Naturally enough, most of the conservation of food so far accomplished through drying has been done by housewives in their homes.

Home drying is profitable both to the household and the nation; but if a neighborhood or community pools its expenditures for equipment and works as a unit, a larger amount of material may be dried with greater convenience and a considerable saving of labor, time, and fuel. A bigger drier than could be put into a home kitchen can be set up in a schoolhouse, parish house, clubhouse, or other accessible place for common use in drying; and definite hours of duty can be assigned to different persons. Such, in general, is the plan of neighborhood or community drying. Details as to how much material each person may bring at one time, just when such material shall be brought, and who shall be on duty to regulate the drier, should be worked out by a small committee, preferably of three persons.

Each woman should prepare her own products and leave in good order the utensils she has used. When people arenovices at drying it is advisable to hire a paid expert for a short time, and if the arrangement for a common drier is to cover the entire community, the continuous services of at least one salaried person are necessary. Some one is also required to do regular cleaning in the quarters used. This may require an 


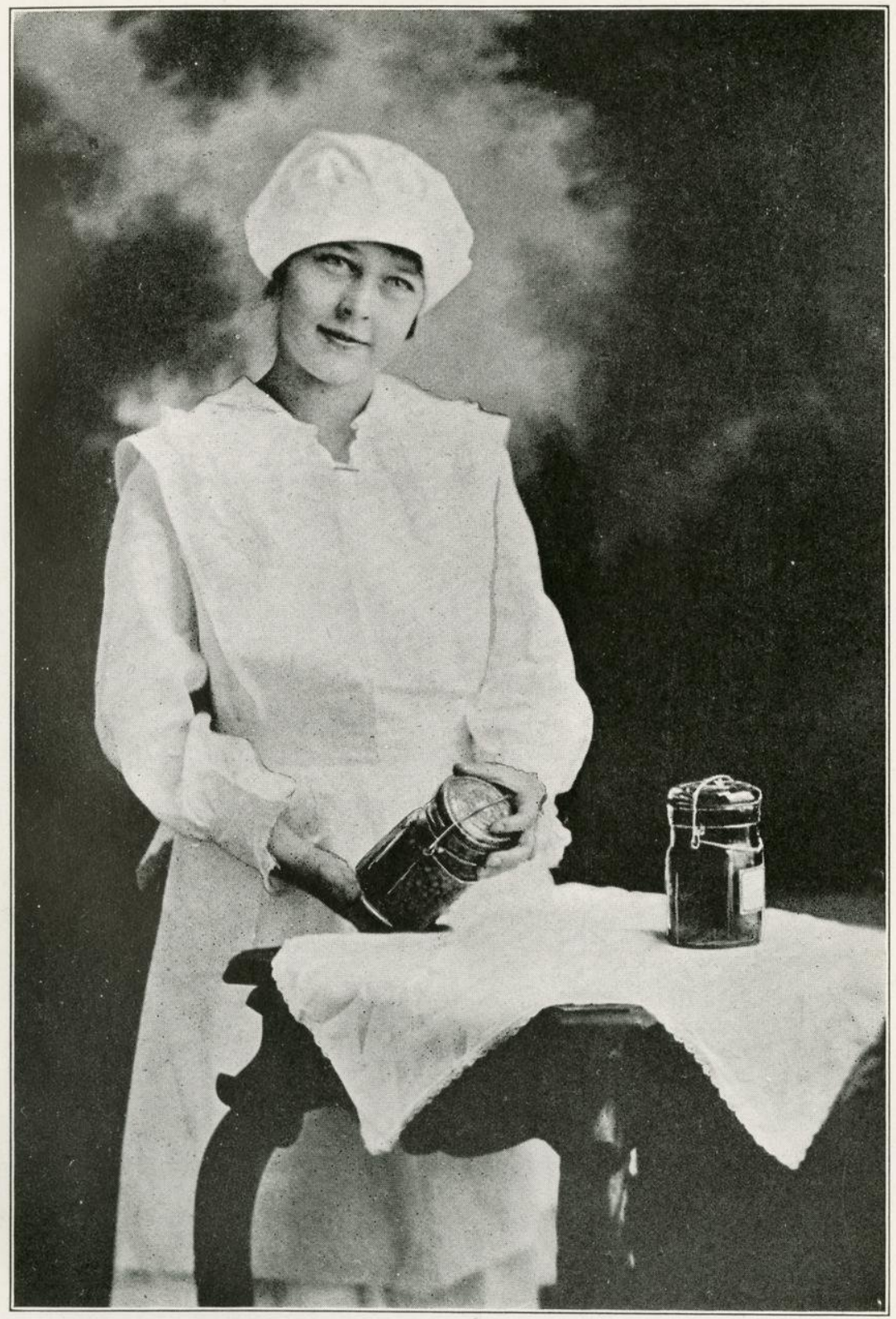

A MONTANA PRIZE CANNER

Although she had never done any gardening or canning before, Irene McMahon, a twelve-yearold girl of Missoula, Montana, won the first award for the products she conserved and exhibited. She received a National Capitol Prize Certificate from the National War Garden Commission. 

hour a day, once or twice a week, or all day every day, according to the needs.

Our country is calling upon the women of America to do their utmost to preserve for winter use all garden, orchard and market surplus. In millions of homes prompt action has been taken for home canning and drying. There remains, in addition, an enormous surplus still uncared for. The solution of the problem is to be found in community drying, which is simply organized drying, not for commercial profit, but for mutual aid and facility in the conservation of vegetables and fruit for home use.

How can a community drier best be started? If three to six or eight families are to benefit, it will be necessary to secure a room with running water in or near it. A space is necessary for conditioning, and, provided it is not damp, the same room or one near by may be used. Space and facilities for blanching vegetables are essential, so that chimney, gas or electric connection is also needed. Such a place can doubtless be found in the home of one of the members.

An evaporator can be purchased for from $\$ 25.00$ to $\$ 50.00$. A stove to supply heat to the evaporator is needed and very probably would not have to be bought. A home-made dehydrator can be readily devised and is practical where rates for electricity are low. A motorfan running on kerosene or aclohol is also on the market. Hot air combined with the fan makes the drying more rapid. Drying by air blast without heat is satisfactory in dry climates. Where the atmosphere is humid, the 


\section{I40 THE WAR GARDEN VICTORIOUS}

process takes a long time and the addition of heat is desirable.

A slicer for vegetables costs $\$ 1.50$ or more, according to size. Tables and other utensils may be collected from the different households. White oilcloth for tables, cheese-cloth for use in protecting material from insects and dust, and pasteboard cartons for containers of dried products would make necessary slight extra purchases. Butter containers are useful for holding dried products, as are also baking-powder cans and similar covered tins.

If an entire community is to be organized, it will be necessary to ascertain how many families will use the community plant and approximately how much material will be dried daily. These things determined, a drier can be chosen intelligently. Because of its usual hot-air blast, which dries products more quickly than they can be dried by the evaporating process, a dehydrator is often preferable. The cost of a satisfactory dehydrator may be put at $\$ 1,000$ to $\$ 2,500$. A homemade outfit may be constructed at considerably less expense. Carpenters and men installing heating apparatus will usually be glad to furnish estimates of cost, if supplied with a description of the apparatus desired.

Mr. C. W. Pugsley* devised a successful community plant, which was first used at Lincoln, Nebraska. His method is dehydration minus heat, which system is

* For dimensions and detailed directions, see "A Successful Community Drying Plant," by C. W. Pugsley, Farmers' Bulletin 916, United States Department of Agriculture. 


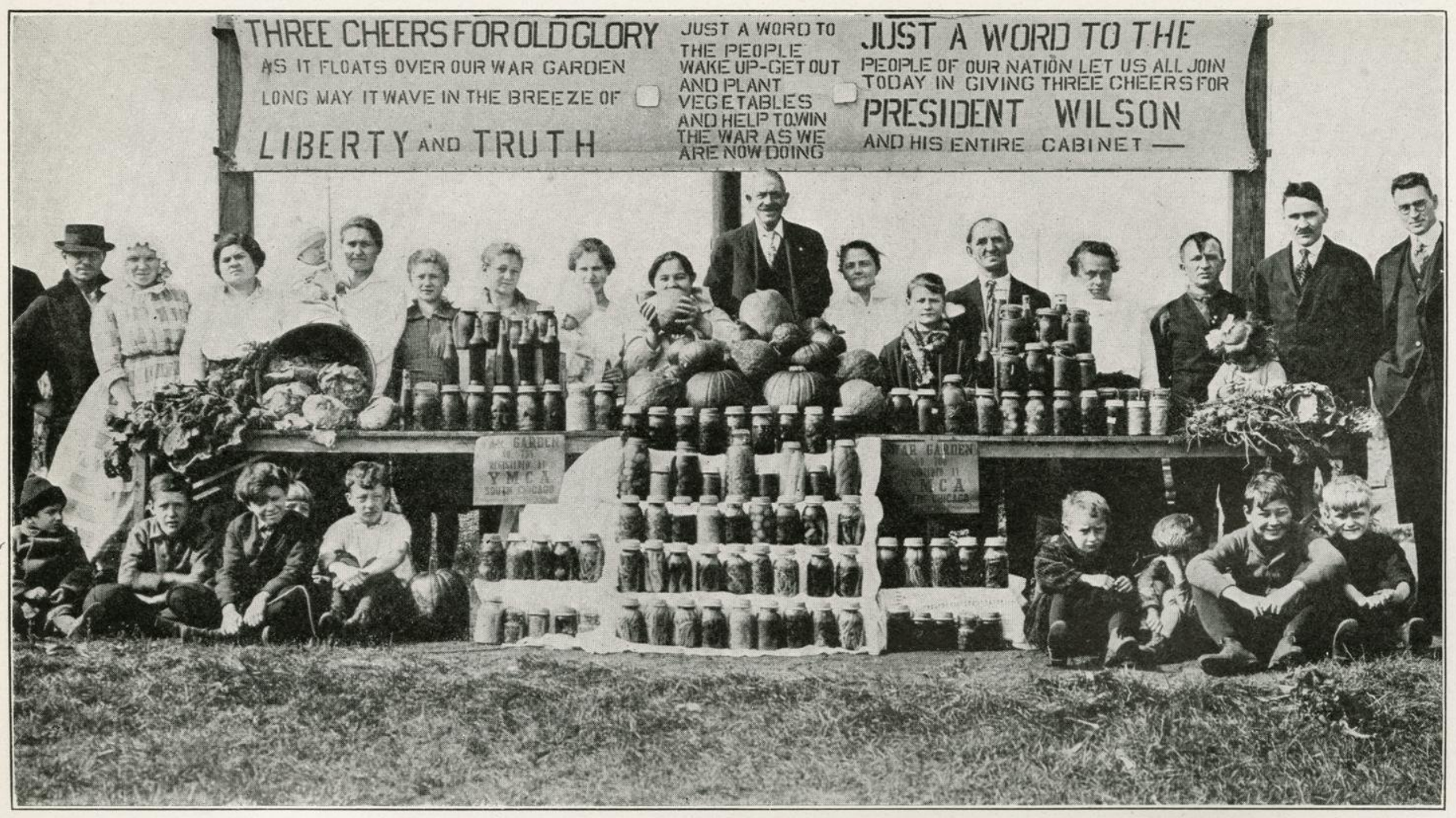

THEY HELPED TO CAN THE KAISER

The Inland Steel Company's plant, at South Chicago, Illinois, was blessed with patriotic employes. Their war gardens supplied vegetables regularly to the South Chicago Day Nursery and to many needy families. The picture shows patriotism expressed in both slogans and canned vegetables. 

serviceable in dry climates. The cost of an outfit like this would be $\$ 250$ or more according to the local cost of materials and labor. Twelve of these driers have been in successful operation. Instead of air being forced over the products, suction is used, the theory being that the drying is quickened by this reversal of the air blast.

Illustrations, descriptions, and prices of several standard ready-made evaporators and dehydrators should be obtained from dealers or manufacturers. From technical training institutions information can be obtained as to the cost of procuring persons for instruction and management to take charge of a drying plant. In making an estimate of funds needed there should be included also service for cleaning, cost of operation of stove, fan, or both, and $\$ 25.00$ to $\$ 30.00$ for accessory equipment. It should be clear to all concerned that a major part of the expenditure would represent investment for an indefinite number of seasons, and should not be considered in terms of one season.

The committee or individual promoter, with the estimate in hand, may then consider how best to finance the matter. The local Chamber of Commerce or a leading women's club is a suitable organization to back a movement for organized food conservation. Such emergency activities should be as far as possible conducted by committees of established central bodies. The unnecessary multiplication of associations is a handicap to a community.

Adequate organization, as well as backing is necessary. It is as essential to have the right executive 
machinery as to have the proper material facilities. There should be an equipment committee, a publicity committee, a workers' committee, a food supplies committee, and an executive committee composed of the chairman of these. All committees should meet at least once a month. In charge of the drying plant there should be a man or a woman of technical training and experience. There should be a checker to keep account of products, and a book-keeper. Volunteer service is usually obtainable for these duties. Women who help to prepare and dry extra products which are sent in as general surplus should be paid by the hour. Such payment should be in products rather than in money, and the value of the products should be based upon market prices of fresh products plus the cost of drying, including labor.

The location is important. It should be central and suitable. School kitchens are usually available, are fitted with various conveniences, and are rarely used during the summer. Church kitchens are sometimes offered, but their use sometimes interferes with other activities on the social side of church work which it may not be wise to interrupt. Empty stores or space in a gas or electric company's quarters are good possibilities.

The schoolhouse is usually the most economic choice. In fact, parts of the house itself may frequently be converted into dehydrators. When viewed merely from a local standpoint, it may seem advisable simply to buy a ready-made dehydrator; but considering the number of communities in the whole country, and the 


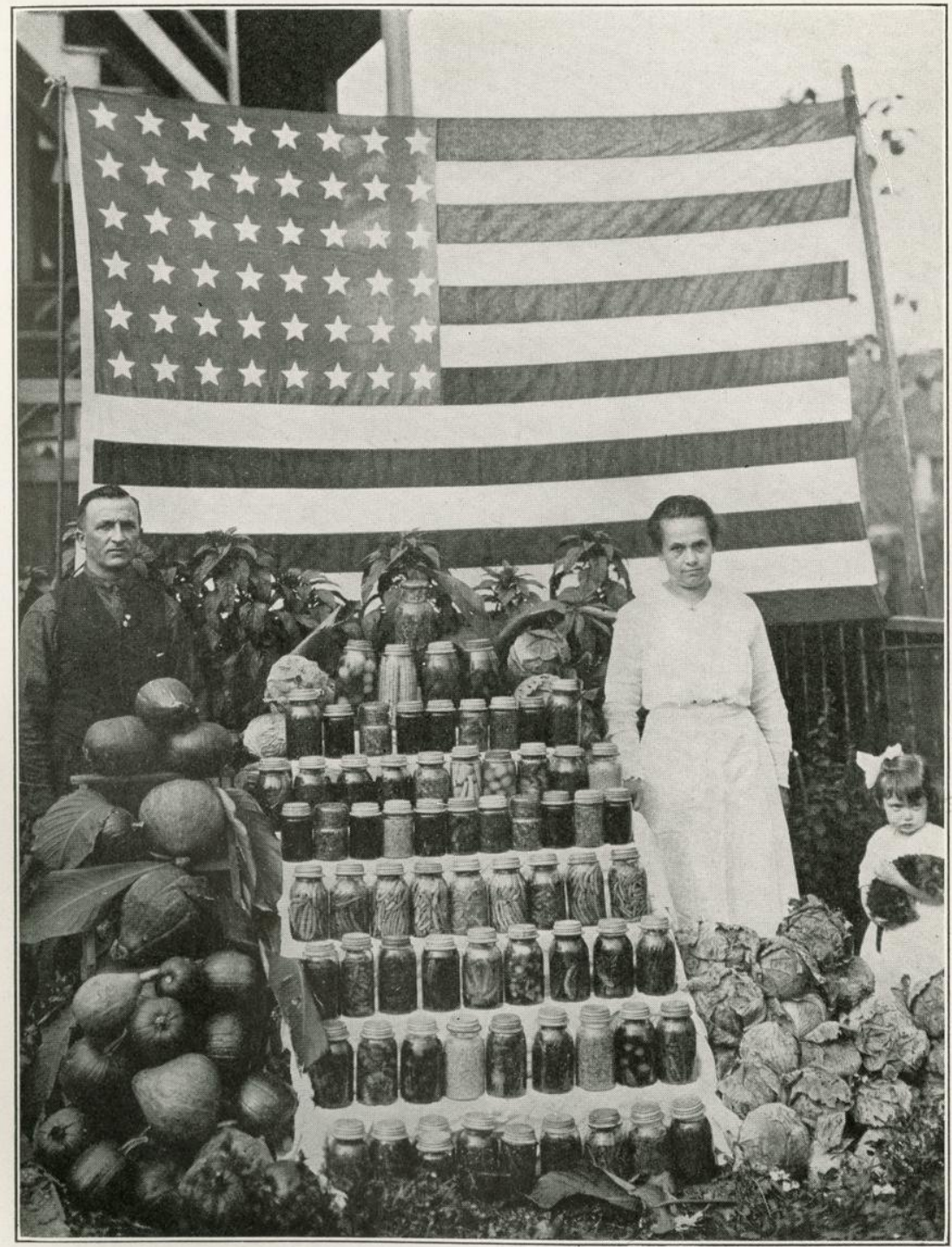

FOOD GOES WITH THE FLAG

The American flag has meant food to Belgium and other countries. In this picture is shown Walter Wolski, an employe of the Inland Steel Company, of South Chicago, who had the prize garden among the employes at the plant. He raised produce worth close to $\$ 200$ and his wife put up more than 200 cans of vegetables. 

need for drying operations in each one, it is uneconomic to buy. There are not enough dehydrators made to dry the surplus home products of the country; shortage of man-power renders an adequate development of their manufacture difficult, not to say impossible.

Mr. W. L. Feisher writes in the Journal of American Society of Heating and Ventilating Engineers, April, 19r8:

I claim that in our newer schools and in our public buildings throughout the country, those things that are required for the drying of food products are already at hand, and that the walls of the rooms, or the corridors in these buildings, eliminate the necessity of a great part of the kilns themselves, and that with very little ingenuity, the heating and ventilating systems in our schools and public buildings can be turned into dehydrating plants in quick order. As to the actual application of my idea, in most of our schools the blowers are located in the basements and the main ducts leading from these blowers are run through the corridors of the basements in the various uptakes. It is my idea that these basement corridors can be turned into tunnel driers by means of wooden partitions, or where the corridors are narrow enough, only cut-offs and divisions are essential. The heated air can then be blown into one end of the corridors and the duct blanked off with a damper beyond this outlet. At the far end of the corridor or tunnel, another damper can be placed and an inlet located at this point, with a connection taken from a point beyond the first damper back into the fan so that recirculation from the fan end of the tunnel can be obtained. In this way, we can create a very fair tunnel drier, which according to commercial practice, is the very best and most economical drier built. 


\section{I44 THE WAR GARDEN VICTORIOUS}

It has ever been true that distance lends enchantment to view. Only the near at hand and the familiar seem mean and commonplace. To use what we already possess often seems both foolish and useless. Yet it was by using the five loaves and two fishes from their own pouches that the disciples fed the multitude, and many another miracle has been performed by utilizing what is already at hand. In organizing community driers it will usually be found that all the facilities needed already exist if only we have the vision to see them. Existing organizations, existing buildings, existing apparatus, and the advice and assistance of local carpenters, plumbers and other workmen will provide the essentials for a successful community drier in almost any city or town. "Use what you have" is a good motto for those about to organize a community drier. 


\section{CHAPTER XVII}

\section{WHY WE SHOULD USE DRIED FOODS}

The War-Time Need of "Multum in Parvo"

$\mathrm{N}$

TECESSITY is said to be the mother of invention; and one of the children to whom Necessity has had to give birth during the American industrial development of the last half-century, and the rapid growth of our cities, was an adequate system of storing up food for winter use and of distributing the food so preserved. It is only within recent years that fresh, succulent vegetables have been obtainable in winter time; and for most people the cost of these is absolutely prohibitive. At first the canning of food products met the needs of the situation, and the last score or two of years have witnessed an incredible development of commercial canning and distribution of food products.

The continued development of our cities with their teeming populations, and particularly the necessities of war time, with their demands for multum in parvo have made imperative a still further advance in the matter of food conservation and distribution. This is particularly true at this time because ahead of us we can distinctly see the lean years yawn, even as Pharaoh beheld the hungry kine in his dream.

History is said to repeat itself; and assuredly we have witnessed an historic repetition in the creation of a food administrator to watch over our stores, even as 
Joseph was appointed to prepare against the lean years that overtook the dwellers along the Nile. Joseph, representing autocracy, took the task into his own hands. Mr. Hoover, acting for democracy, asked us to do the job ourselves. Both cut the Gordian knot of their perplexity in much the same way. Joseph dried the excess corn and stored it in his granaries. Mr. Hoover asked us to can and dry our garden surplus. In each case food conservation won the day. Indeed, so close is the parallel between events in Joseph's day and ours, that no more accurate description of what is doing in the world to-day can be found than the Scriptural recitation of occurrences along the Nile: "The dearth was in all lands; but in all the land of Egypt there was bread. . . And all countries came into Egypt to Joseph for to buy corn."

Even so all countries are coming to America to secure wheat and meat, and particularly fats. Here occurs the feature that differentiates present-day conditions from those of Joseph's time. Joseph's customers could come to him on dry land; but a mighty ocean, three thousand miles wide, lies between America and her starving customers. Before they can get food they must have ships. Even that mighty tonnage pictured in Lloyd George's phrase, "Ships, ships, and still more ships," can hardly transport the food fast enough to save the starving world from starvation. Dean Swift called for benedictions upon the head of him who made two blades of grass or two ears of corn to grow where only one had grown before. To-day, he might add to his list of 
those who deserve well of mankind those who can transport two tons of food where only one was transported before. In effect that is what is made possible by the preservation of food through drying, for in drying, foods lose both bulk and weight.

This reduction in weight of dried vegetables and fruits ranges from five-sixths to eleven-twelfths with even greater reduction in some cases. A California operator furnishes these figures for shrinkage: Potatoes, about six to one; cabbage, about twenty to one; tomatoes, about twenty to one; spinach, about eighteen to one; turnips, fourteen to one; carrots, about nine to one. Less than three pounds of dried tomatoes, for instance, are equivalent to sixty pounds of canned tomatoes. Not only are the products much shrunken, when taken from the drier, but they may be still more compressed in packing so that the bulk is further lessened. This reduction in weight also lowers transportation costs. A shipping incident serves to illustrate clearly the economy involved. Fifty pounds of fresh Brussels sprouts were shipped in the winter of I9I7-I 8 by express from California to an eastern point at twelve cents a pound. Adding to this cost of $\$ 6.00$ the cost of shipping with the vegetables one hundred pounds of ice at twelve cents a pound, there was a total transportation charge of $\$ \mathbf{1} 8.00$. The equivalent of these fifty pounds of fresh Brussels sprouts, namely three pounds of dried products, which required no ice, might have been shipped to the same point by parcel post for thirtyfive or thirty-six cents. 
With such an average reduction in bulk, the space required for transportation and storage is far less than that required for either fresh or canned products. In certain instances the reduction is very great. It varies with the percentage of water in fresh products. One carload of dried tomatoes, for example, is equivalent to thirty carloads of canned tomatoes.

Especially are dried products adapted for our military camps, fleets, and overseas fighting force. Army officials estimate that two men are needed daily to prepare potatoes and other vegetables for every one hundred soldiers. Dried vegetables are already prepared and are ready to cook, after soaking in water. In an army of 2,000,000 men their use would release nearly 40,000 men for other tasks. As the original preparation of vegetables for drying is done largely by simple and inexpensive machinery, there is thus a tremendous saving of man-power. The shrinkage in bulk makes dried products acceptable and fitting naval stores, and trans-ocean freight.

Germany's stores of dried vegetables greatly helped her in carrying on the war. During the last year of which the United States government has any official record, Germany dried, in potatoes alone, more than twice the entire quantity raised in this country. She more than doubled the number of her plants after starting the war, and has now more than two thousand. There are in Germany fifty-six firms supplying complete drying apparatus, and thirty-seven other firms which supply auxiliary machines and parts. The drying is 


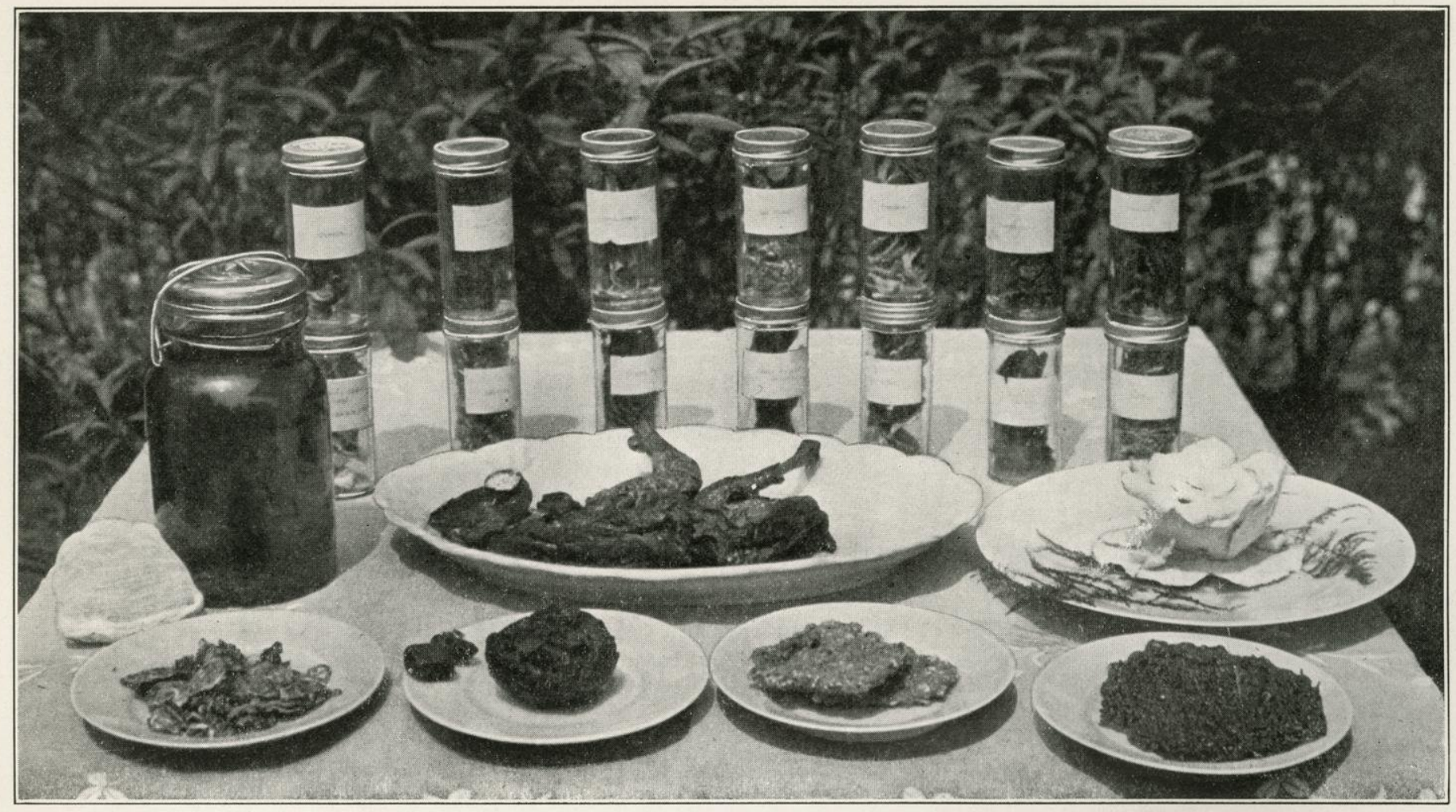

TOOTHSOME VIANDS AT DRIED FOOD LUNCHEON

Copyright 1917 by International Film Service.

When Mrs. Robert Lansing, wife of the Secretary of State, entertained a group of prominent Washington matrons at luncheon, the entire bill of fare was made up of dried foods. The six-course meal included bouillon from dried vegetabies, dried chicken, a Neapolitan salad made of dried peas, dried lima beans and dried tomatoes with cream cheese filling. All the foods were restored to their original volume by steaming and soaking before they were served. 

applied to vegetables chiefly, only about twenty-two plants being for milk-drying.

Despite all these facts one finds practically no dried vegetables for sale at retail in America, and only a limited amount of dried fruit. Outside of government contracts there has been and is little or no market for dried products. The National War Garden Commission has inquired carefully into the matter, and has corresponded with most of the commercial drying concerns in the country. One and all report that, aside from contracts with the War Department, they have practically no market for their products.

It is highly desirable that markets for dried foods be created and speedily. The food situation in the world is to-day more critical than it was at any time during the war. The task of feeding themselves has taxed to the utmost the United States and her co-belligerents. Now peace imposes upon these defenders of civilization a task that is simply appalling. German submarine warfare reduced to actual starvation the $180,000,000$ people in the neutral nations of Europe. Beyond question we must rescue these unfortunates from starvation, by sharing with them. It is apparent, too, that our responsibility does not end there. Austria and the new nations which were formerly a part of that country together with Bulgaria, Turkey, and Russia, are also starving. If we are to have lasting peace in the world, if we are to have stable governments and the settled conditions of existence, which alone make progress possible-in short, if we are to make safe that condition 
of democracy for which we have fought, these people must be fed.

"Hunger," said Robinson Crusoe," knows no friend, no relation, no justice, no right, and therefore is remorseless and capable of no compassion." Hunger will endanger the peace of any community or nation. However we may feel toward our former enemies, the best good of the world, including America, demands that they have enough to eat. Otherwise there can be no settled peace, no progress, no reconstruction. Fate has placed largely upon American shoulders the burden of helping the world's hunger over the critical years that lie immediately before us.

This being the case, we must have conservation, conservation, and still more conservation. We must produce more food than ever before and conserve every ounce produced. As much as possible of this excess should be conserved in the form which best meets the needs of the situation. For use in our homes canned foods are highly desirable, but for shipment abroad, dehydrated products will be particularly needed. France needs steel and wood and cement and a thousand other kinds of material for the rebuilding of those vast ruins which once were French cities. All Europe needs cattle, millions of cattle, to make good the present shortages and needs cattle-feed by the trainload. Ships will be needed to carry our own soldiers back home. The demands on shipping space will be almost beyond conception. Whatever saves space, therefore, is a prime requisite in the upbuilding of a ruined world. Since 
food is the first of all requirements, we should by all means adopt and develop that method of food shipment which calls for least space. This means that we should greatly increase the use of dried foods.

One thing alone stands in the way of a large development of the commercial drying industry. Aside from government contracts, the food driers have at present practically no market for their products. Manufacturer after manufacturer has so reported to the National War Garden Commission, and practically all report that it is difficult to create a market. The period of government contracts is limited. Armyconsumption will decrease rapidly. Faced with this situation, food driers naturally do not care greatly to enlarge their plants.

Something must therefore be done to create a market for dried foods. For one thing, an educational advertising campaign on the part of the operators is to be strongly urged. A western company writes of the astonishment of visitors "at the simple and sanitary method of handling the fruits or vegetables," and their interest "because of the very apparent economy of the method." With this as a premise an intelligent advertising campaign should quickly create a market. The establishment of government-controlled plants and government advertising would more quickly and thoroughly create markets, however, than the usual procedure of private companies. Dried foods are practically "new" foods, and the acquisition of a new food habit by a whole people is exceedingly slow, unless the government systematically undertakes its establishment. 
The policy of the Department of Agriculture in regard to the use of the drying fund of $\$ 250,000$ appropriated by Congress, will be of great economic significance. Such a fund has been strongly needed, and makes possible enlarged and nation-wide help in the urgent matter of drying vegetables and fruits, and placing them in the homes of the people.

The appropriation will be used in conducting further experiments with dehydration of food products and carrying this knowledge to the American people. The Secretary of Agriculture has appointed Major S. C. Prescott, who was in the food division of the surgeon general's office, United States army, and Mr. Lou D. Sweet, of the United States Food Administration, as a committee to carry out the purposes of the appropriation. Major Prescott was professor of micro-biology at the Massachusetts Institute of Technology before he was called into war service.

When the appropriation became available, plans were promptly made for beginning the dehydration experiments. Able construction engineers and other experts whose services could be helpful were called in to aid in this work which Mr. Sweet characterizes as "one of the biggest benefits that has come to the American people as a result of the war." Soon after the committee was organized plans were under way looking to the construction of several dehydration plants with a capacity each of from 60,000 to 100,000 pounds daily of raw product.

These plants are not to be built by the government but by private corporations with which the government 


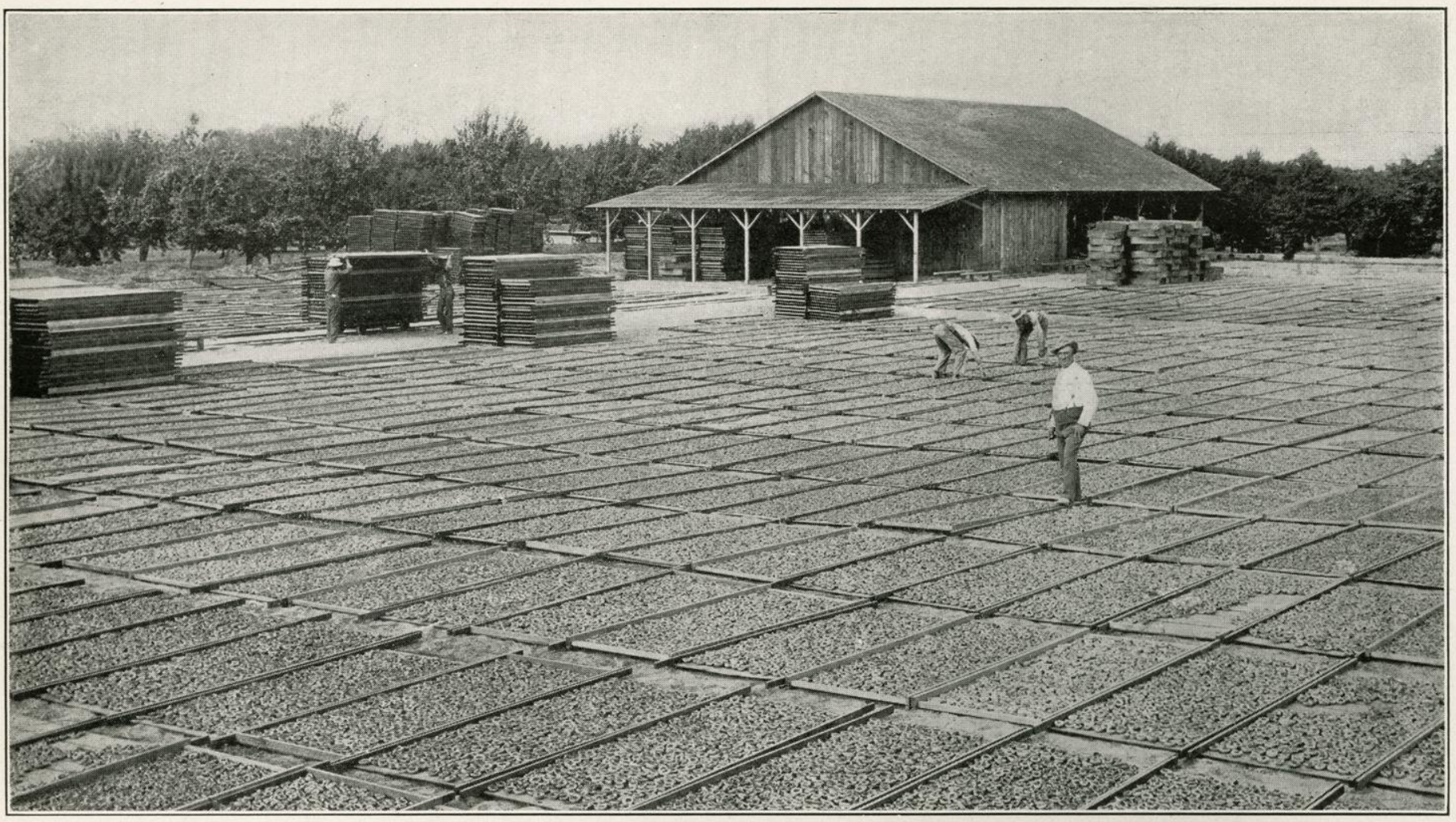

DRYING PEACHES IN CALIFORNIA

Photo. from American Forestry Magazine.

This shows fruit drying on a large scale. The structure of trays and arrangement of fruit are of interest. The shed in the background is used for the preparation of the fruit. Stacks of trays and lug boxes are also pictured. 

will coöperate in making an economic and commercial success of the process so as to help establish a permanent market with the American people for dried foods. In order to do this it is necessary, first to educate the people of this country to the value and the use of such products, and, second, to have the dehydrated foods of such attractive appearance and palatability and of a price so comparable with the average price of the products in their undried form, that they may be marketed in paying quantities.

The federal government and the states, by conducting propaganda directed toward a general use of dried fruits and vegetables, would be performing a needed service toward the preservation of health, with increased economy to all concerned. Advertising on the part of private operators, can be done only in so far as it pays them, and it would take several years and millions of dollars to establish a general retail sale of dried food articles.

Furthermore it is necessary to establish standards. It would be a serious error to allow an inferior class of products to be put forward at this time. The movement would receive a decided check. Commercially dried vegetables should contain a given percentage of moisture, scientifically correct; they should be packed in proper containers, and stored in cool places. So prepared and handled, dried foods will be roo per cent. free from spoilage. Again, blanching is expensive in commercial drying, and its omission necessitates very thorough drying of products to insure their preserva- 


\section{I54 THE WAR GARDEN VICTORIOUS}

tion. Some products, however, such as Irish potatoes, require blanching before drying in order that the dried product may be satisfactorily utilized. These do not "come back" well if dried without blanching. In getting these new foods on the market, therefore, it is desirable that the government draw up strict regulations, just as it has done for other foods through the national pure food laws. 


\section{CHAPTER XVIII}

\section{THE FUTURE OF DEHYDRATION}

\section{Tall OAKs From Little Acorns Grow}

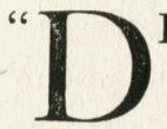

EHYDRATION has come to stay in this country and, while it may still be regarded as in the experimental stage, those who are most familiar with the problems of food production and conservation are firm in the opinion that we are seeing only the beginning of what is sure to expand into an enormous and most important industry." This is the statement of an international food expert, a man who probably knows more on the subject of dried foods than any other authority in the United States. It was made in a recent letter to the National War Garden Commission, by Lou D. Sweet, president of the Potato Association of America, popularly known as the "Potato King." Mr. Sweet was selected by Mr. Hoover as head of the dehydration section of the United States Food Administration, and has more recently, in association with Major S. C. Prescott, U. S. A., been enlisted in the government development of dehydration.

While the drying of food, like some of the other lost arts, is almost as old as the human race itself, still its value and its importance have been brought to the fore by the European war. Necessity has meant the development of an industry which was well-nigh extinct. War gardening and the home production of food have 
called the attention of the country and its people to the merit of drying as a form of vegetable and fruit conservation. The spread of the drying idea made satisfactory progress during the second season of war gardening in the United States. While there was no general practice of the method, nevertheless a fair beginning was made which is bound to lead to widespread and more rapid growth along this line in the future. The seed has been sown; the home food producers of the United States have seen the advantages offered by this means of saving food, and more and more of them are certain topractice it.

The process is really very old, and has been used at times by almost every people in the world. The skill of the squaw in drying corn and the few fruits and vegetables which the American aborigine possessed was all that stood between the Indian family and starvation in the long, cold winters when game was scarce. Our grandmothers made toothsome pumpkin pies from the dried product, while they decorated the attic and the kitchen with long rows of dried apples and peaches. From the Indians they learned also to dry berries and other small fruits. They possessed no glass jars and few of the conveniences which every modern housewife thinks essential; but they managed to vary the monotony of the winter diet with those dried products which cost them nothing but their work. The world has progressed rapidly in many respects during the past few generations. Science and industry have provided many household helps which could not be enjoyed fifty or a hundred years ago. It is obvious, however, that some 


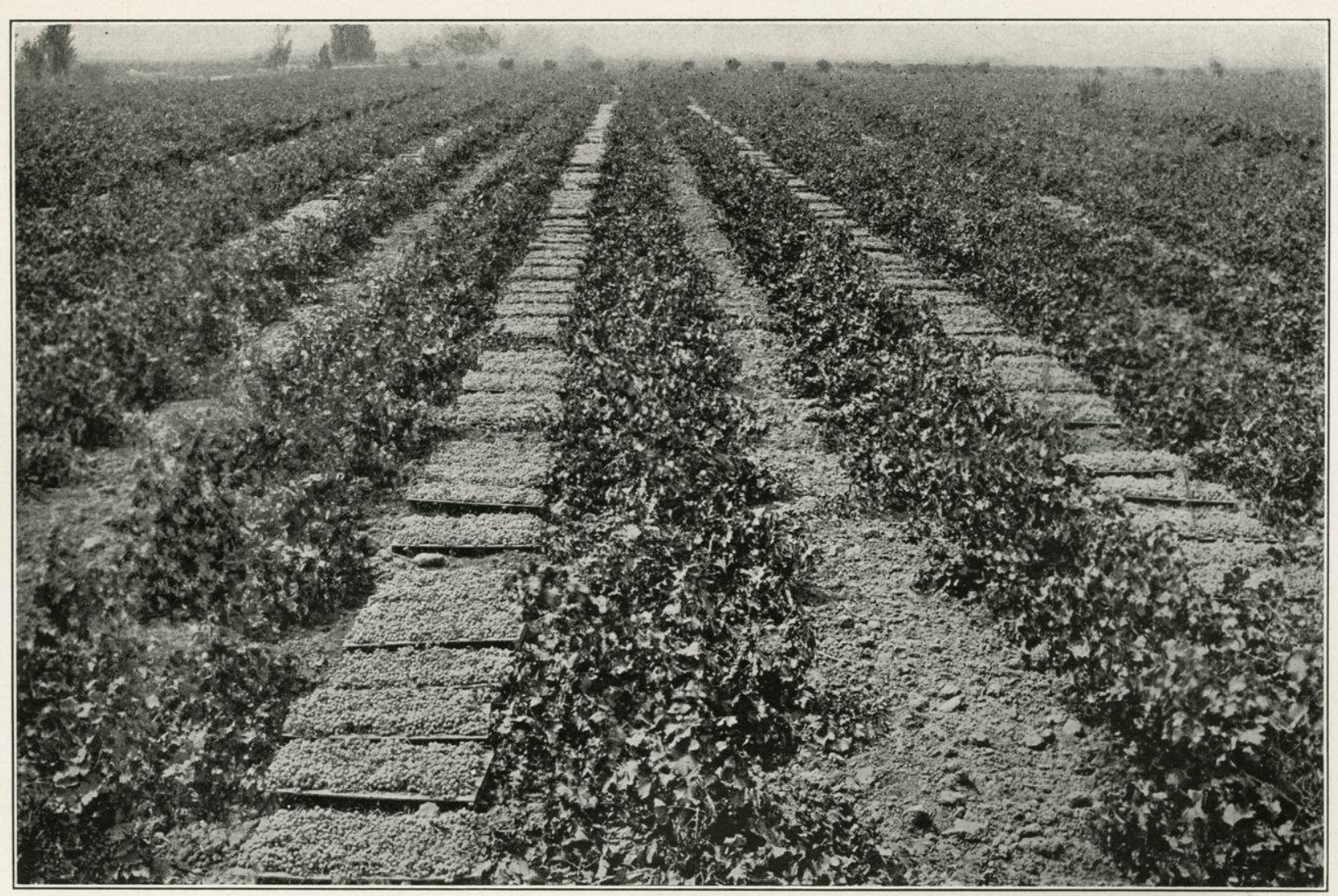

PREPARING RAISINS FOR THE MARKET

Photo, from American Forestry Magazine.

Raisin drying forms an important industry in California. In this picture the operation is shown in a large vineyard. The trays are raised slightly from the ground and supported on timbers. 

of the habits and customs which were in vogue in the earlier days may now be taken up again with profit. Among these is the drying of vegetables and fruits. Thanks to the careful study and research which have been given to this subject, the work can now be performed with greater ease and with more certainty of success than was possible in the past.

Canning is the method which the average American housewife uses in laying by a store of garden products for winter consumption. A great impetus was given to this process by the Civil War; and now it seems as if another war were to be responsible for the introduction to the world, on a large scale, of another food conservation process, namely that of drying. As the possibilities, advantages and details of operation of this process become better known, it will take a larger and larger place both in the home and as a commercial proposition.

Important factors to be taken into consideration by the victory gardener in connection with food drying, are the saving in containers and in pantry-space. Almost any sort of a receptacle can be employed for the storage of dried food. Baking-powder cans and similar covered tins, pasteboard boxes having tight-fitting covers, strong paper bags, and patented paraffin-paper boxes which may be bought in quantities at slight expense, make excellent containers for this class of preserved food. They are not heavy and so do not require especially strong shelves. Besides they do not occupy much space-a thing which in many homes is at a premium. 
Scientists have pointed the way and by their careful research have discovered methods by which potatoes and other vegetables can be dried so that they will retain all their original flavor and food value over long periods of time and under all conditions of weather and temperature. In going into the work on a commercial scale and in preparing such food for large bodies of people such as an army, where some of the products may not be consumed for many months and where they are likely to undergo many changes of temperature in being transported from place to place, it is necessary, of course, to observe scientific precision in the preparation and packing of the goods. For home consumption no such elaborate processes need be followed. This is why any household may prepare with ease its own supplies of this sort. As practiced in the home, vegetable and fruit drying is largely a matter of following with reasonable care a few simple rules. During the season of I9I 8 the National War Garden Commission distributed throughout the United States almost two million copies of its canning and drying book which gave all needed instructions. Thousands of war gardeners, both as individuals and through community effort, added a considerable amount to their winter store by vegetable and fruit drying.

It was during the Boer War that dried foods were used for the first time to any extent in the provisioning of an army. Large quantities of these goods were shipped from Canada to South Africa by the British War Office, and the experiment proved a complete success. 
Some of the unused product was on hand at the beginning of the European war, and when opened, was found to be in a perfect state of preservation. The British soldiers in South Africa could not distinguish between the dried vegetables they were eating and the food to which they were accustomed, and they throve exceedingly well on it. John Hays Hammond, the internationally renowned mining engineer who took such a prominent part in the development of the South African territory and who is a member of the National War Garden Commission, is familiar with this matter. In discussing it he said:

The supplies of dried vegetables which were shipped from Canada to South Africa during the Boer War were found to be just as palatable, just as nutritious, as any of the other rations. I doubt if a single one of the men could have told the difference between this part of their mess and the other edibles that were furnished them. Certainly this is borne out by what a close friend of mine, Dr. Charles L. Lindley, of Lakewood, New Jersey, himself born in South Africa and an army surgeon during Lord Robert's campaign there, recently told me of the experiment. His experience with dried vegetables confirms every claim that can be made for them as a valuable part of a soldier's rations.

It was largely due to the successful results obtained during the Boer War that the British War Office was led to adopt dried vegetables as part of the soldier's supply during the recent war. Since the outbreak of the European struggle the British and French governments have purchased no less than $50,000,000$ pounds of dried foods 
from Canada alone. Following their example the Quartermaster-General's Office of the United States War Department prepared to make similar use of this kind of food. In the spring of 1918 the army used $14,000,000$ pounds of dehydrated goods, and later an order was placed with American and Canadian food driers for more than $40,000,000$ pounds to be delivered before July I, I9I9.

The use of food that is recognized as a valuable army ration and as a war-time economy, is to be encouraged in normal times. The same reasons which made it practical and economical during the war will be arguments in favor of its continued and increased use. Certainly for many years to come, just how many nobody can say, food will be a world problem. In the solution of this problem dried food can and should play a constantly growing part.

The expert testimony in favor of dehydration is well summed up in a statement by David Fairchild, agricultural explorer in charge of the Office of Foreign Plant Introduction, United States Department of Agriculture. $\mathrm{He}$ has made this statement:

I believe the American public should learn to use dried vegetables, because in so doing great economies can be brought about in this country as they have been in Germany and Austria. The dehydrated vegetable saves transportation of both bulky fresh vegetables and bulky canned vegetables, not only those portions which are actually consumed but the waste which forms so large a part of the garbage of our cities. The dehydrated 


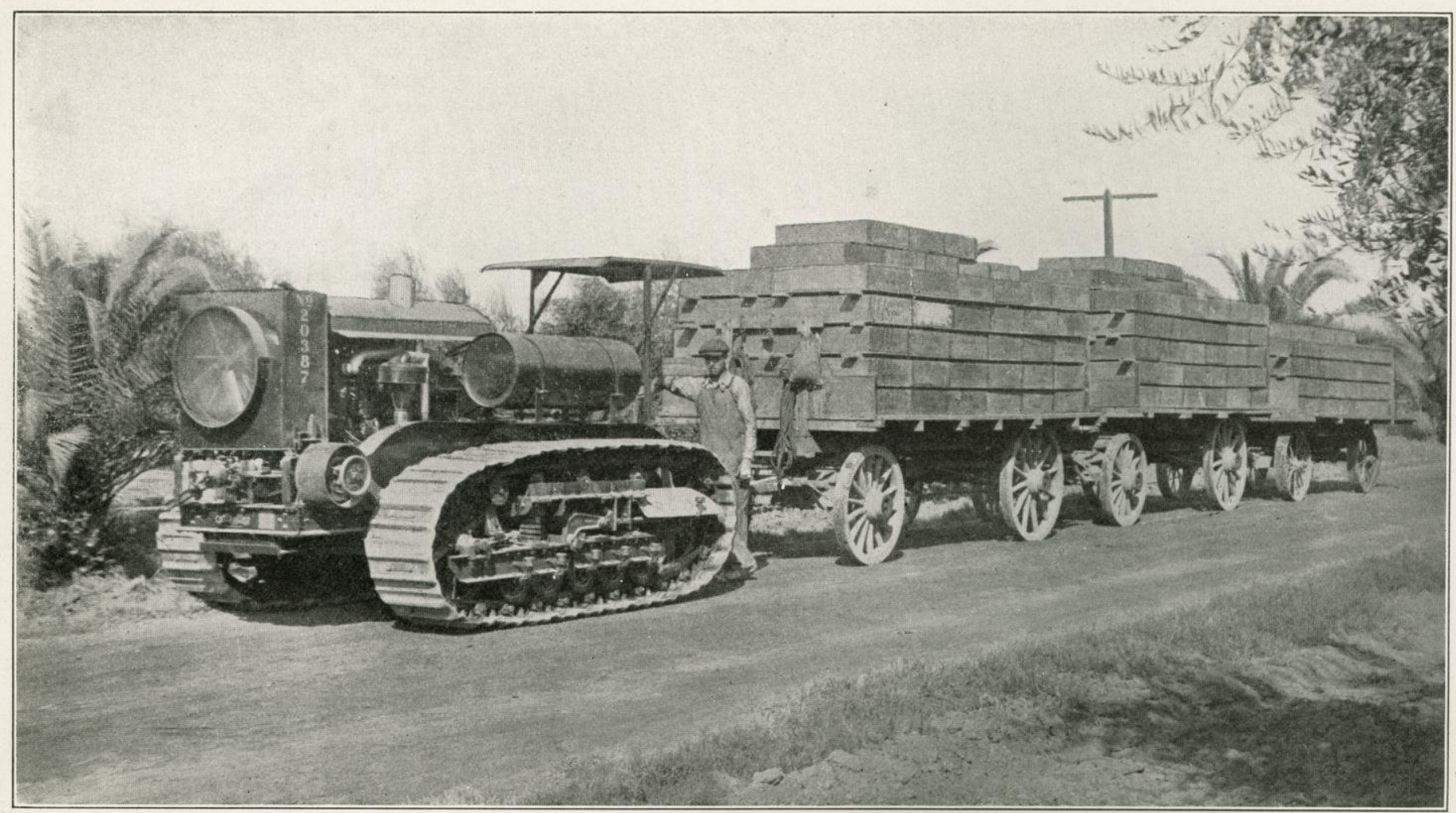

BOXES FOR DRYING RAISINS

A load of 190 "sweat boxes" for curing raisins being hauled by caterpillar tractor to a big vineyard at Dinuba, California, where many tons of this fruit are dried and prepared for the market every year. Practically every kind of garden vegetable can be conserved by drying, as well as the few well-known fruits to which the American people are accustomed. 

vegetable saves tin, since it can be put up in paper containers. It saves labor in the small home where the convenience of its use is apparent. It saves in wastage at the point of production and in the home. We little appreciate how gigantic the wastage of fresh vegetables is, and this wastage is largely because the vegetables are too cheap on the market in the height of the season to warrant a grower to ship them to it, and it is here that dehydration should play an important part.

There is nothing in the vegetable situation which confronts us to-day to assure us of cheaper vegetables in the future. We must not forget the small proportion of women gardeners in this country as compared with the women field-workers of France and Germany and even England, and vegetables require a large amount of hand labor to produce. Where is the labor coming from?

Possessing as we do such remarkable food as Indian corn, and having learned, as we have, to like it, there would seem to be a danger that we depend too fully upon it and, with the increasing price of vegetables, fail to realize that as we increase our corn consumption we require greater quantities of butter, milk, meat, fats, or vegetables to supply the food essentials lacking in corn. As the fresh vegetables become scarcer on the markets, it would become more and more difficult to do this, and the result predicted by dietitians is malnutrition among those who think they cannot afford to buy the vegetables. We should learn to use these dried vegetables to supplement the grain ration.

It is easy to see a hundred reasons why we should not eat dried vegetables, but it is unscientific and unpatriotic to shut our eyes to their possibilities. As a people we should move ahead into the field of dehydrated vegetables, develop it, discard what is not good, 
hold what is good, and make it a means to stabilize those vegetables the price of which fluctuates now in a most unsatisfactory and dangerous way.

While I believe that we should consider first our own attitude toward dried vegetables and work out the best methods of using them for ourselves, we are warranted in believing, as conditions are at present in Europe, that there will be need of large quantities of all kinds of foods, including these dried vegetables, in those countries which are now famine-stricken. Although it is undoubtedly true that the German troops are using enormous quantities of dried vegetables, it is not demonstrated to what extent they will be employed in the feeding of our own boys. No civilian will take the attitude that the boys should be fed on food which he himself refuses to eat. If we learn to use them extensively, it is a practical certainty that our own armies will employ them extensively, as have the armies of Great Britain, France, and Germany.

Inspired, therefore, as an emergency measure to meet war's demand for more complete utilization of the nation's food supply, the drying of garden products must continue. It must save summer crops for winter use and help to care for the needs of the nations which have boen starving. It must take its place as a regulator in the world's problem of food supply and demand.

"There seems to be no reason," says Mr. Sweet, of the United States Food Administration, in his communication to the National War Garden Commission, "why the abundance of one season or locality should not be made available by this means for periods of scarcity or for regions where fresh fruits and vegetables 
cannot be obtained. Every encouragement, therefore, should be given to home drying, in order that the people may become familiar with the excellence of the products which may be prepared by this method, and to save the vast quantities of excellent food which now go to waste for lack of adequate methods of conservation."

The simple form of drying by artificial heat and by heat of the sun in thousands of American homes and in no less degree the science of dehydration as developed on a commercial scale, has shown its economic worth. The art as practiced to-day owes much to scientific research. This does not mean that the methods are complicated. Science has simplified them and given greater assurance of successful results. It has been estimated that the United States could save $\$ \mathbf{1 9}, 000,000$ annually in its transportation bills by the drying of its garden products. The saving of only a portion of this large sum would be worth while, and it would be not alone in the saving of money but in the release of much valuable freight-car space for other purposes that the nation would probably receive important benefit.

Every victory gardener or home food producer in the United States can help to save part of this money and freight-space. It might not be just to ask them to do this if elaborate preparations and large outlay of money were necessary. As these are not required every person who has a vegetable plot should conserve some of the surplus product if it would otherwise go to waste. Practically all vegetables and fruits can be dried. The process is simple. The cost is slight. In every home 


\section{I64 THE WAR GARDEN VICTORIOUS}

the necessary outfit in its simplest form is already at hand. Effective drying may be done on plates or dishes placed in the oven, with the oven door partly open. It may be done on the back of the kitchen stove with these same utensils while the oven is being used for baking. It may also be done on sheets of paper or lengths of muslin spread in the sun and protected from insects and dust.

The earth lives by the light and the heat of the sun. This beneficent power should be put to work by the victory gardeners of the United States, and thus will this country gain a rightful and legitimate "place in the sun." Luther Burbank, a member of the National War Garden Commission, says:

How few people are aware of the scientific fact that all food and all clothing without any exception are first produced by the action of sunlight on the foliage of plants, and that but for the wonderful chemical engines installed in the foliage of plants no life could exist upon the earth; and only by the improvements which have been made in plants and animals which subsist on the productions of plants has our present civilization been made possible.

This gift from Heaven which makes the plants to grow and without which there could be no production, should be utilized also in the conservation of food. 


\section{CHAPTER XIX \\ COÖPERATION OF THE PRESS}

Vital Help Given ay the Newspapers and Periodicals of Amgrica

$7 \mathrm{HE}$ printed word, the most powerful force known to civilization, made war gardens possible. In no other way could they have been made to multiply so rapidly in all parts of the land. From printer's ink to parsnips and parsley is a long jump; but the newspapers and magazines made that jump along with the others which they made for Liberty Loans, the Red Cross, and various other war-work campaigns. When the shadow of war fell across America, and before the actual declaration of war, the National War Garden Commission sent out the first rallying call to the home food producers. The newspapers and magazines spread the call freely. General

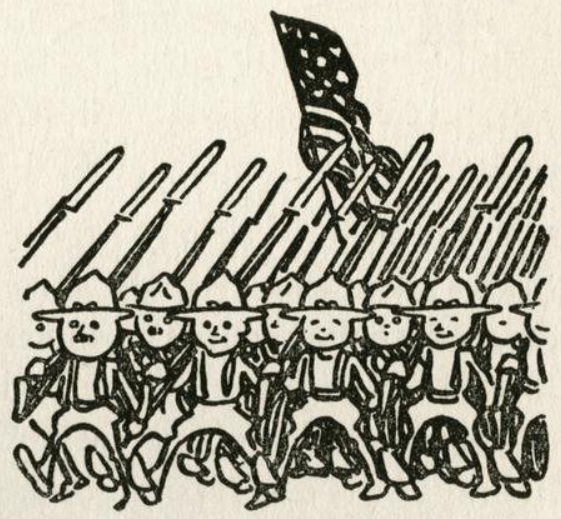
Pershing later said, "Keep the Food Coming"; and the publications heard that call, too, and relayed it to their readers.

The "Soldiers of the Soil" wanted instruction and they wanted it quickly. Prompt action was necessary that 
their service in the "garden trenches" might be effective. There was only one way in which the message of the war garden and the necessary instructions could be carried to all the people with the speed demanded. This was through the press of the country and the printed page. Any other plan of distributing the appeal and the instructions would have been far too slow to

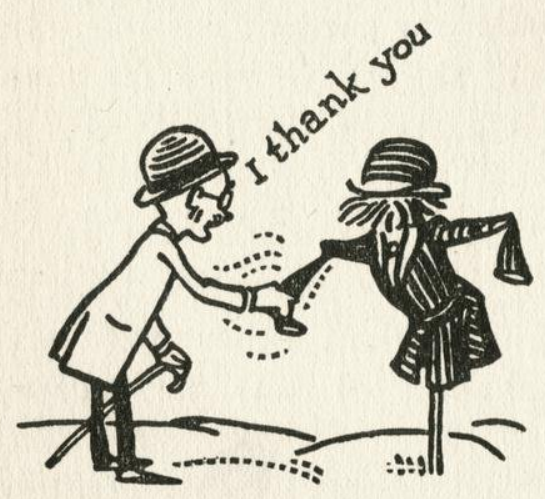

be effective and furthermore would have involved prohibitive expense, if it could have been done at all.

How much of a debt of gratitude the nation owes to its patriotic editors it probably will never be able to realize fully, but it does know that without their wholehearted support and their loyal assistance it would never have been able to arouse the people of the United States as a whole to the strenuous efforts which they exerted to back up the government and the fighting forces. No note of appreciation to the editors of the country could be over-generous in its praise or too liberal in its expression of heartfelt thanks for their substantial aid.

When the Commission began its campaign it realized that it must depend largely upon the support of the newspapers and the magazines. Well-planned and well-directed publicity was necessary to get its message 


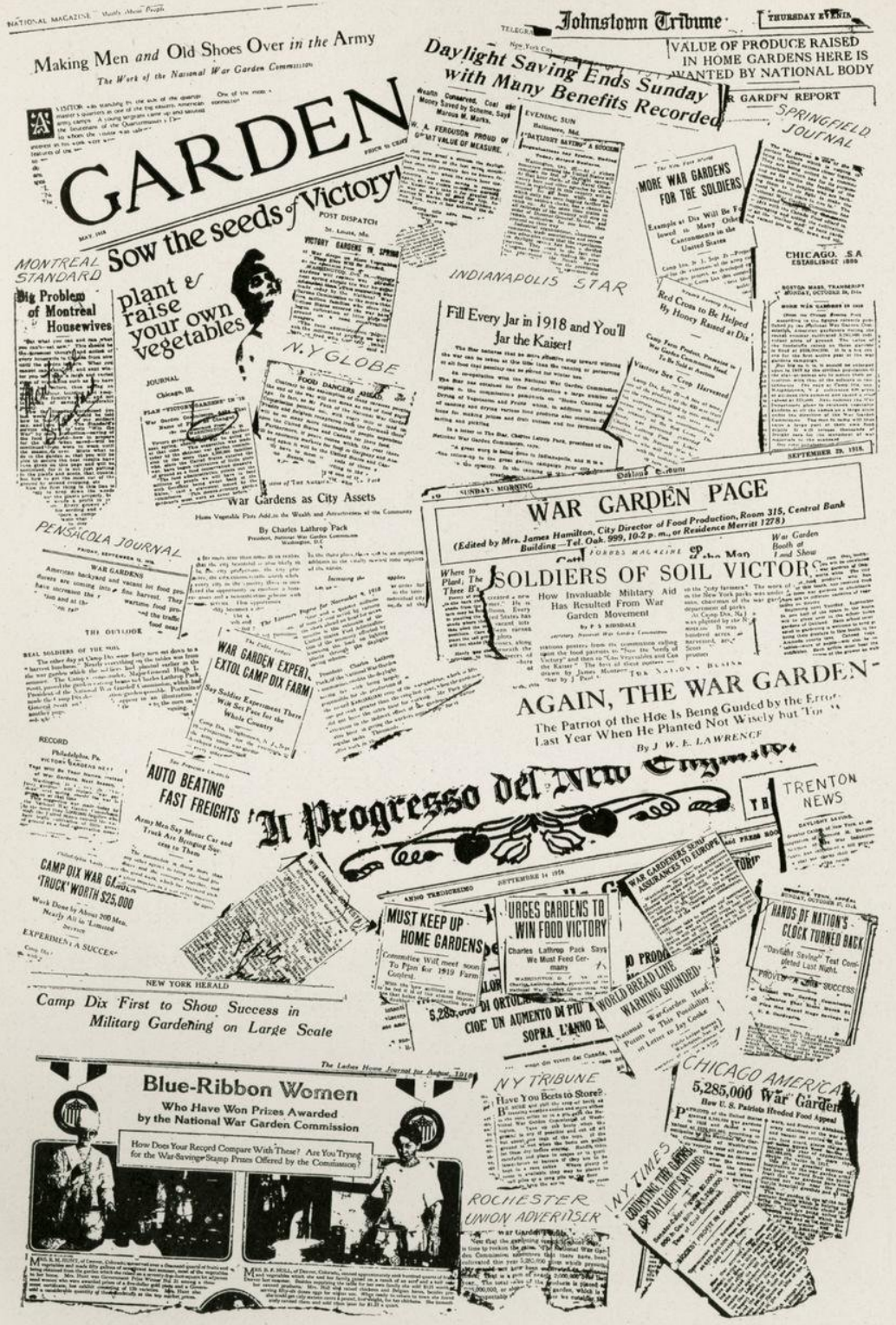

THE KNIGHTS OF PRINTERS INK HEARD THE CALL FOR FOOD

Throughout the land every sort of publication coöperated with the National War Garden Commission in the drive for home food production. Here are but a few of the headlin that show how the press patriotically responded to the call. 

to the people of the United States, and the promptness of the editors in recognizing the vital importance of home food production and their patriotic readiness in conveying the appeal to their millions of readers should be recorded in letters of gold among the nation's permanent records. The Commission has expressed its appreciation to many of them individually and it takes this further and more

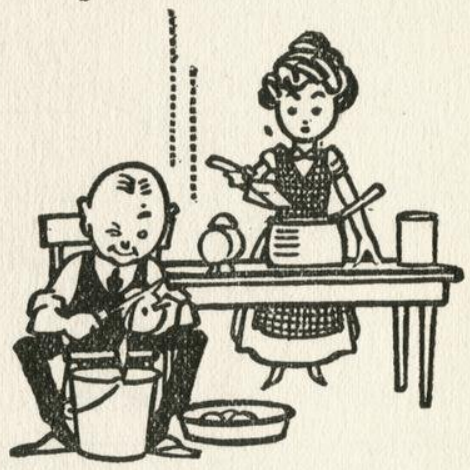
lasting means of acknowledging its thanks, and the thanks of the nation, for their enthusiastic service.

While space became more and more at a premium as the war progressed, the newspapers and magazines

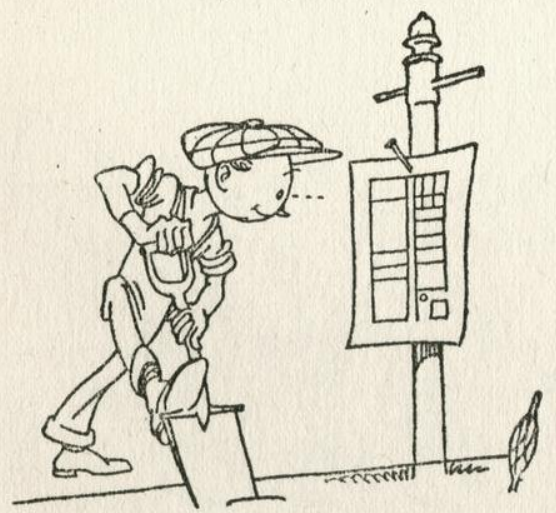

START YOUR GARDEN WITH A PLAN continued to contribute as liberally as they could of their columns to the cause of food production "F. O. B. the Kitchen Door." They stimulated and encouraged the "city farmer" to plant for freedom and they furnished him with the necessary data and instruction, provided by the Commission. The great majority of those who were eager to raise food and help feed the army were amateurs at 
the business. They had to be shown how. They were willing but they needed guidance. The number of competent instructors was limited, and it became nec-

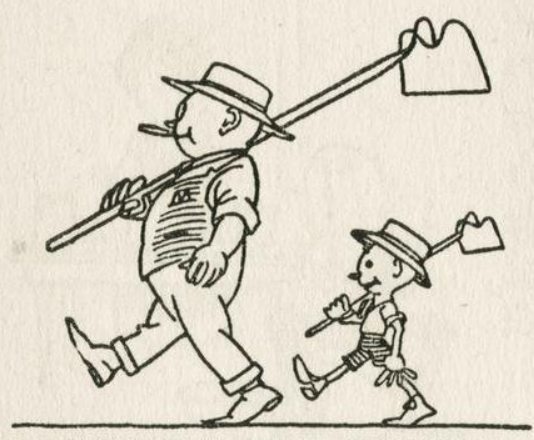

WOE FOR THE GARDEN essary for the war gardener to look to the daily press for information telling him what to do. In this the press did not fail him. Almost unanimously, from one end of the country to the other, the newspapers daily published material furnished by the Commission. If this could be totaled it would run into tens of thousands of columns.

After calling the attention of the country to the vital need of war gardening, the Commission prepared a series of short garden lessons telling the home food growers what, when, and how to plant. These lessons were brief and shorn of technicalities

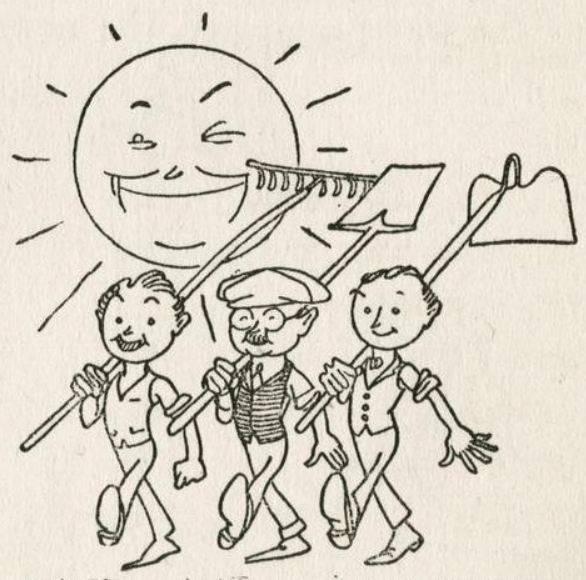

DAYLIGHT SAVED - A GARDEN MADE but authentic, and gave the gardener all he needed to know. They were sent to the newspapers on news-clip sheets, a dozen or more lessons on each sheet, while a 
few short general stories on war gardening were also included on the sheet. This method of sending out the material was economical from every standpoint and effected a great saving of paper. It was highly approved by the War Industries Board

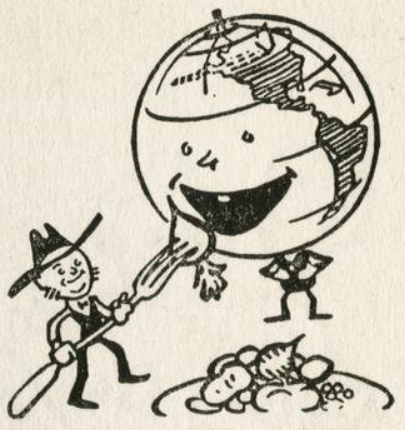
as a valuable conservation scheme in paper economy. As occasion demanded news stories which were of

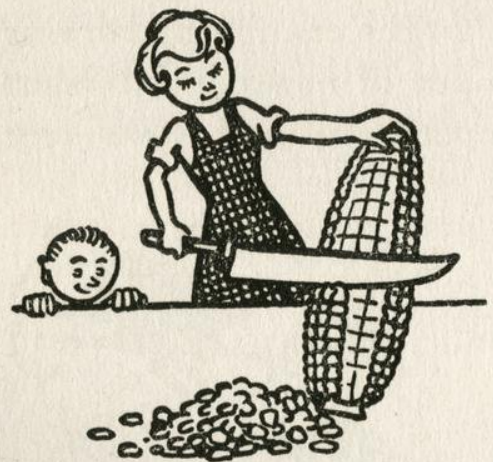
interest only to a particular city, locality, or state were sent out to the papers of that section but not duplicated throughout the country. Thus New York did not receive material in which none but Illinois or California readers would be interested.

In similar manner short lessons telling how to can and dry vegetables and fruits, and items of news value calling attention to the urgent need for this form of food conservation, were sent to the newspapers of the country; and they met with the same generous response from the editors. One

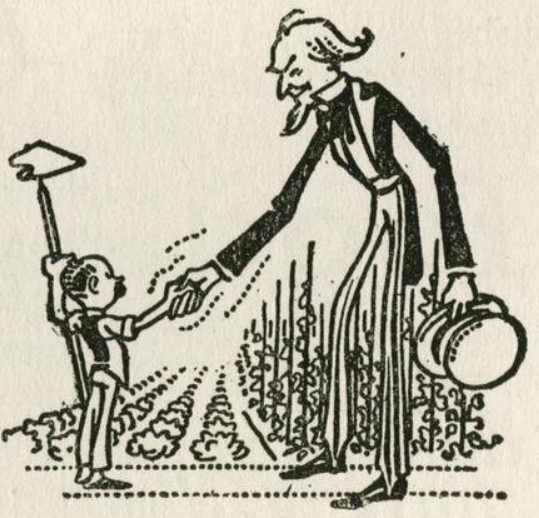


of the most helpful features of the newspapers was the coupon box which hundreds of them ran during the en-

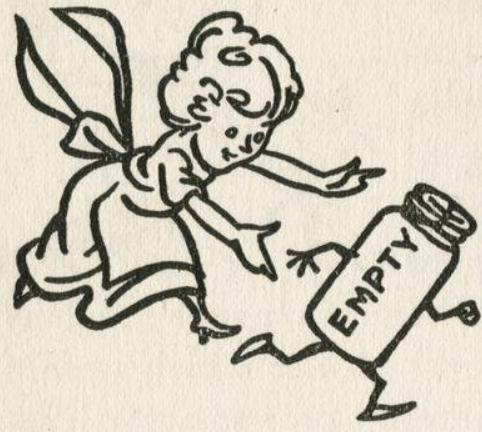
tire garden and canning season, in which the readers were informed that by filling out the coupons and mailing them to the Commission they would receive free copies of the war vegetable gardening or the canning and drying books. Hundreds of thousands of newspaper readers took advantage of this opportunity and were sent copies of the instruction books.

In addition to printing the short garden and canning lessons and numerous items of news value, the papers published Sunday feature stories. The Commission

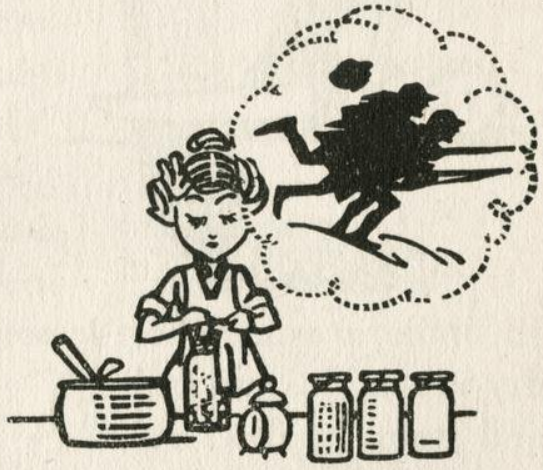
furnished pictures and data for these articles, with photo-

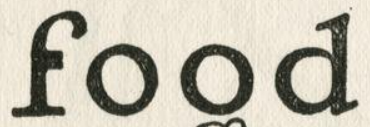
graphs showing types of gardens and how the war gardeners were getting to work in various parts of the country. Soon after the Commission was organized it began to don'stop receive requests from feature and shavingit! magazine writers and editors 


\section{KEEP THE FOOD COMING---Pershing.}

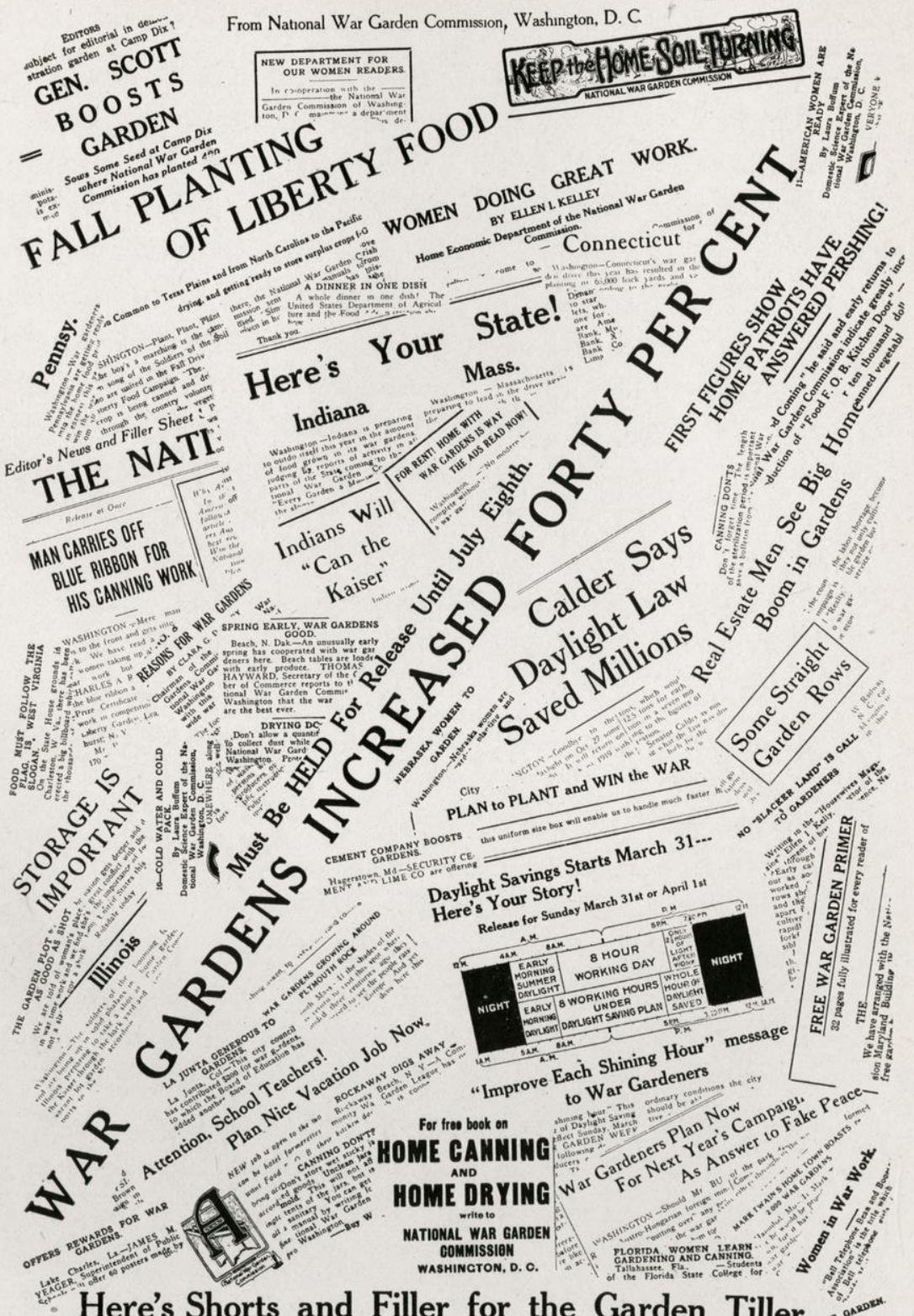

Here's Shorts and Filler for the Garden Tiller

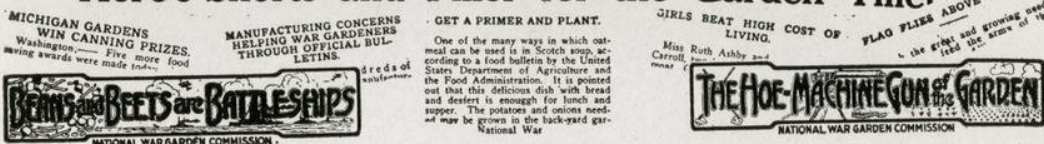



throughout the United States for illustrations and material which could be used in stimulating the home foodgrowing enterprise throughout the territory in which their publications circulated. These requests were promptly met. The Commission was able to do this because it gathered in a short time and had on file in the Washington office a large collection of interest-

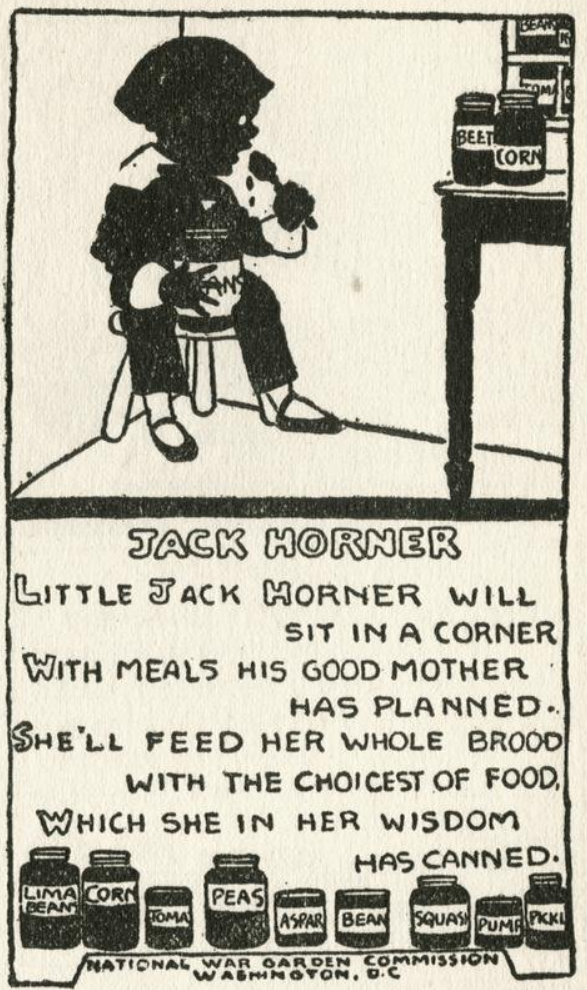
ing photographs as well as much data about war gardens, showing what they could do and were doing. Many of

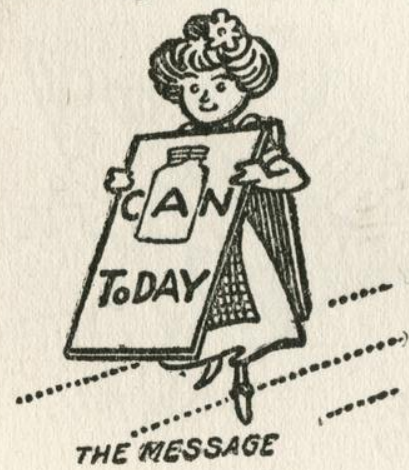
the magazine writers called personally at the headquarters and were delighted and surprised at the readiness with which their needs were filled. They went away with envelopes filled with pictures and materials for their stories.

Some of the publicity matter 


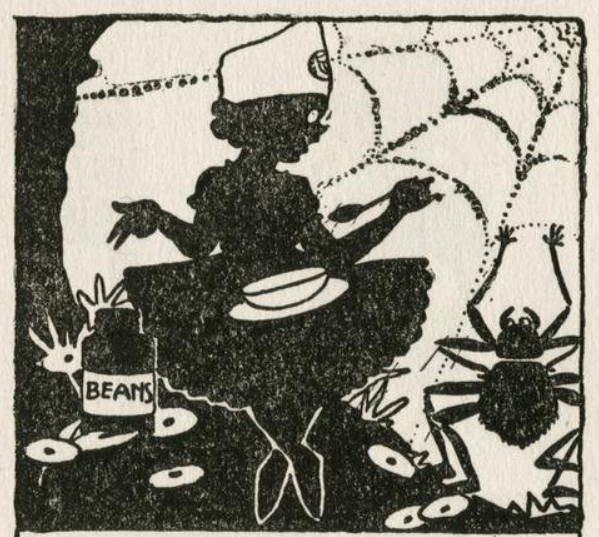

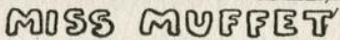

BITTLE MISS MUUFFT WILK SIT ON HER TUFFET AND GIGGLE IM MERRIEST'GLEE FOR SHE'LL NOT BE NEEDING TO BUY STUFF FOR FEEDING OLl CAN IT THIS SUMMER, SAYS SHE

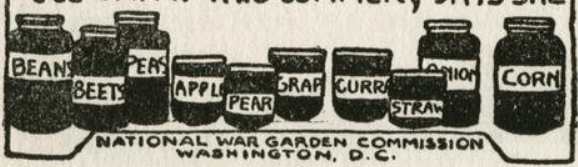

went out to the newspapers in "mat" or matrix form, so that it was necessary for the paper to make only the stereotype from which the printing was to be done. The material which the Commission sent out in this way included reproductions of its several posters, little comics on gardening and canning, a step-by-step series of illustrations explaining in detail the cold-pack process of canning vegetables and fruits; initials to be used in dressing up the garden page; and a number of prose poems with small illustrations inserted. All this material was used very widely.

The news-service organizations and illustrated-feature syndicates used many stories on war-garden work. In this way thousands

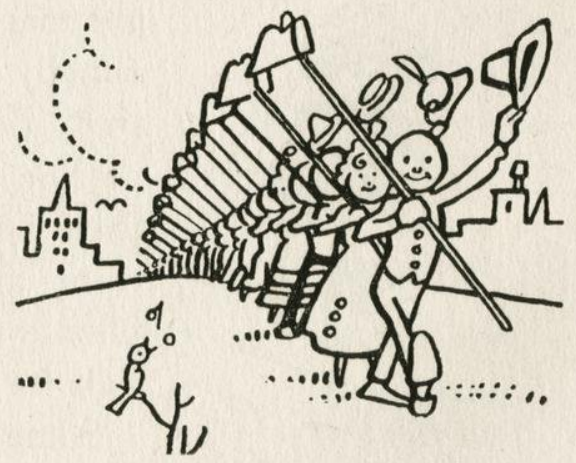




\section{HERES WHERE FALL GARDENERS RALLY! KEEP IT SHORT and CAN the KAISER}
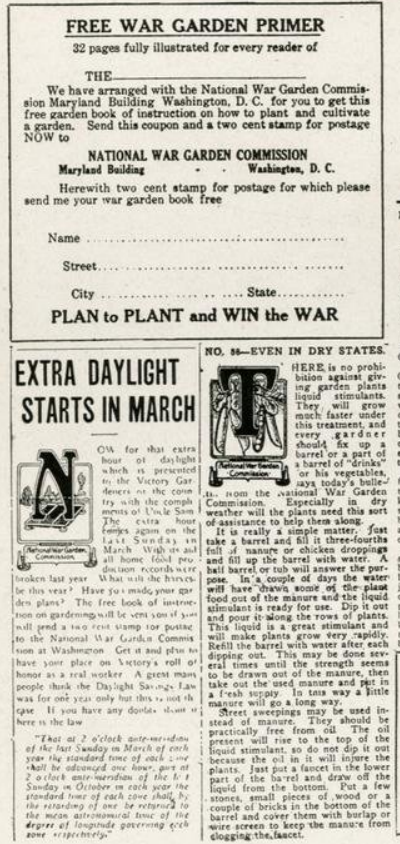

From National War Garden Commission, Washington, D. C
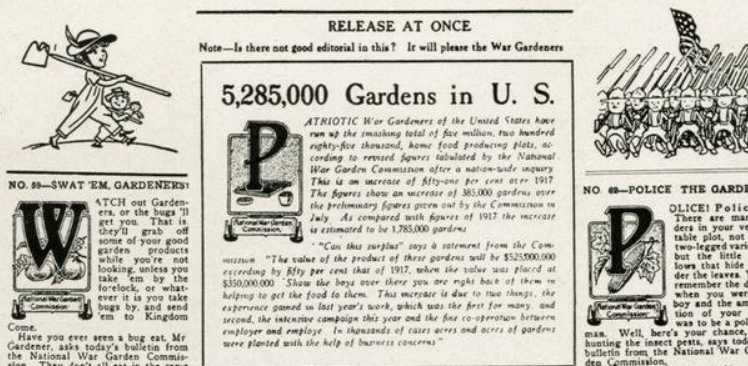

U. S. MINISTERS HOPE CANNING CAMPAIGN WILL BEAR FRUIT!!

They have Sons with the colors and are working hard at home to keep flocks informed. Some do their own canning.

\section{SUNDAY SCHOOLS IN CAMPAIGN}

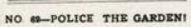

TF ARIOUS church organizations sre out to "Can the Kaiser" and arrangemen's have
juat been $\mathrm{m}$.de by the National War whereby its canning books will be distai buted by the American Sunday School Union of Philadelphia; Brotherhood of ade'phia; the United Christian Endenvor Society with headquarters in Boton; the Epworth League, Chicago. The campaign has been planned with William $\mathrm{H}$. Hirst, recording secretary of the Sunday School Union at Philadelptia; Reving of
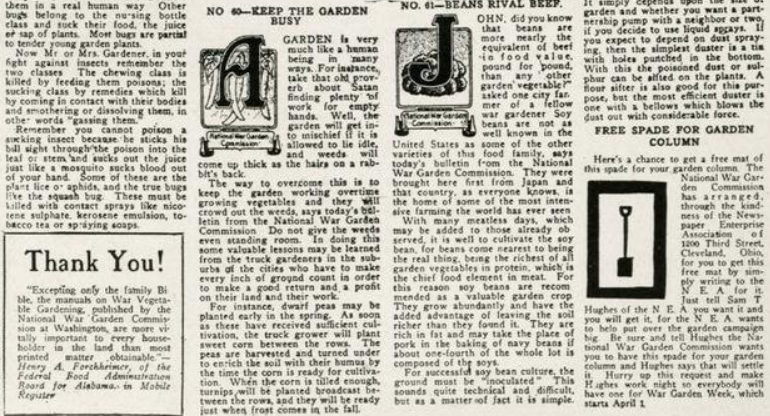
League, 740 Rush Street, Chicago, E. H. Bonsal, Phila.

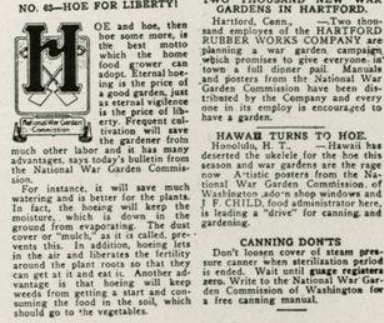



of papers were served by the Associated Press, the United Press, the International News Service, the Western Newspaper Union, the Newspaper Enterprise Association, the News Feature Service, the International Syndicate, and

(ren and another w little farm would n't do us any harm

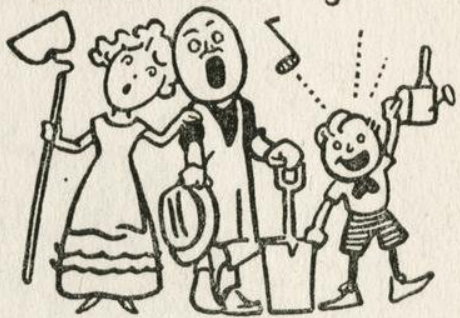
other important agencies. The Washington correspond-

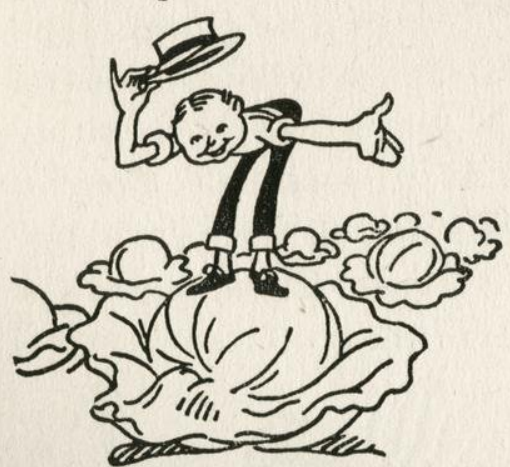

ents of the leading dailies of the country sent to their home papers, by wire and mail, items of national or local interest telling of the activities of the war gardeners. The value of this patriotic service in furthering home food production cannot be over-estimated. Some of the largest and most influential newspapers in the country gave most prominent place on many occasions to the Commission's call to the home food producers and conservers of America. The Philadelphia North American, for instance, reproduced the

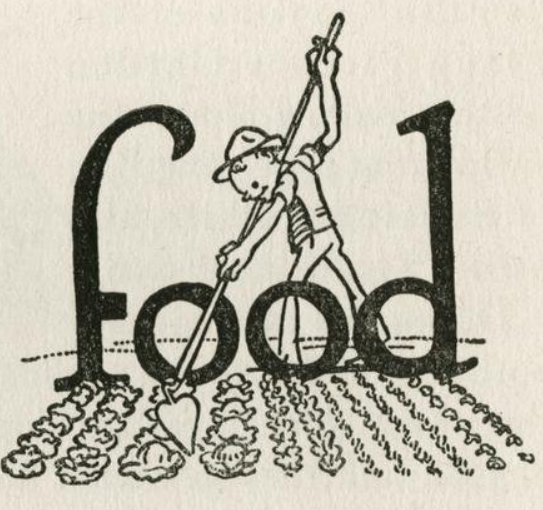


"Can the Kaiser" poster on the front page in a space covering nearly one-quarter of the entire page. The Boston Post used both this and the "Sow the Seeds of

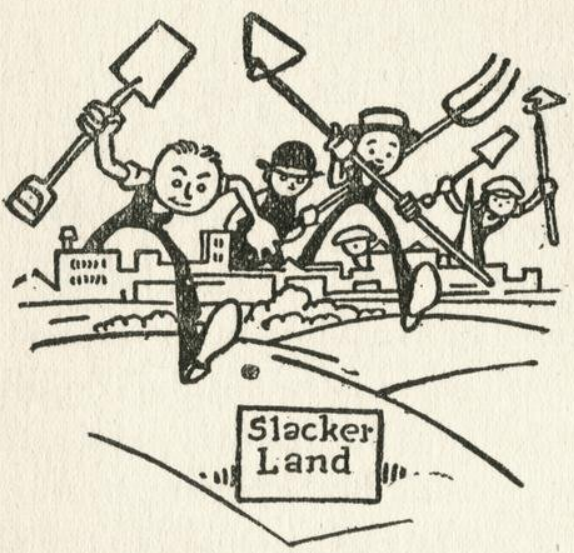
Victory" poster on one page, devoting a large part of the space to these striking designs. The Garden Magazine u s e d reproductions of the posters as cover illustrations on two of its monthly issues. The Forecast

also made use of the Verrees poster as a cover design. The Diario de la Marina, of Havana, Cuba, one of the foreign papers to which copies of the posters and several articles on war gardening in the United States had been sent, published a "smash" layout of the Flagg Victory Garden poster covering almost the entire front page. Zig-Zag, of Santiago, Chile, also used it as a cover design.

During the campaigns of

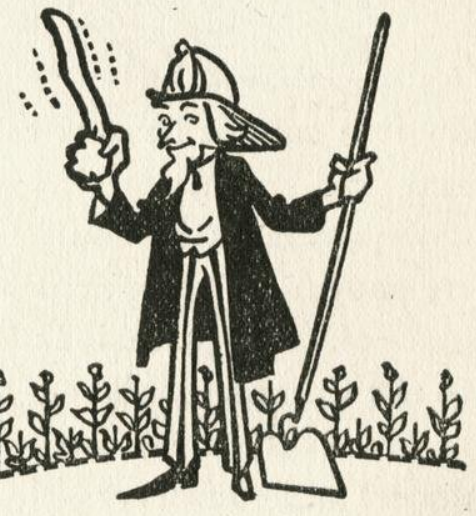
both 1917 and 1918 the newspapers of this country gave the Commission loyal backing. They knew the need of food and they saw what an asset the "city farmer" could be in this direction. 
The most remarkable coöperation was given in New York City when virtually every one of the big metropolitan dailies was running the Commission's garden hints and suggestions simultaneously. The papers thus helping included the Evening World, the Globe, the Evening Post, the Journal, the Evening Telegram, and the Brooklyn Eagle. On Sundays some of the papers regu-

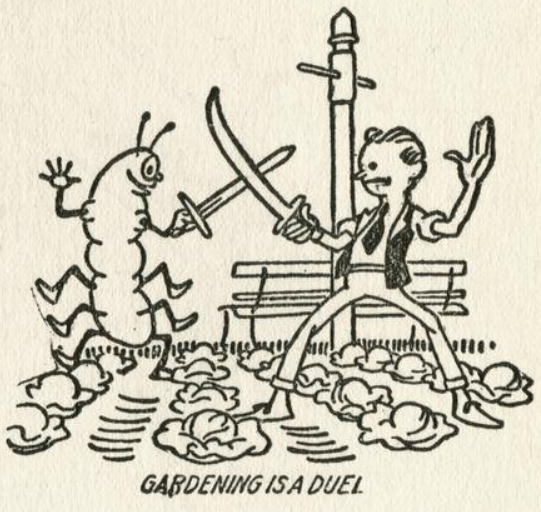
larly ran an entire page or two of war-garden material.

In the United States a large number of the foreignlanguage newspapers, Italian, French and others, told

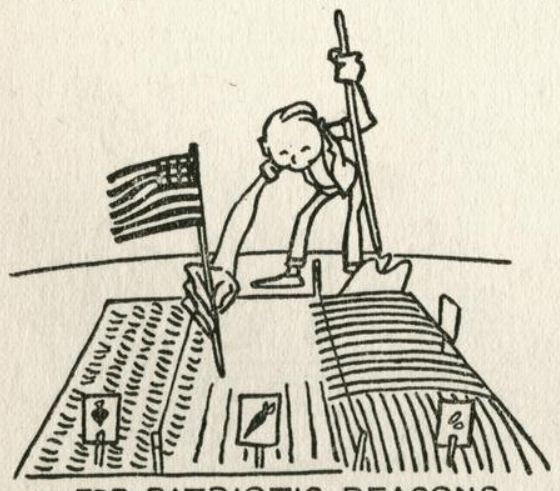

FOR PATRIOTIC REASONS their readers of the service they could perform through war-gardening and the conservation of the surplus products thus grown. Several summaries of the war ${ }^{2}$ garden movement in the United States were translated into French, Spanish, Italian, and Portugese and sent by the Commission to leading publications throughout Latin America, Canada, Australia, Europe, and the Orient. They appeared, for instance, in such widely separated papers as 
the Alexandria (Egypt) Gazette, and Le Messager de São Paulo, Brazil; and were published from Calcutta, India, and Tokio, Japan, to Montreal, Canada. The Asahi

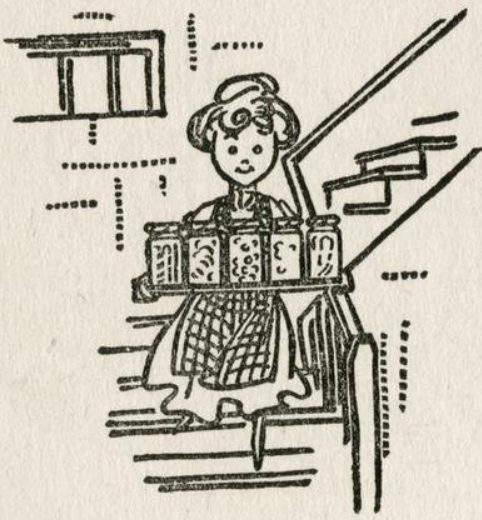

News, a Japanese newspaper of Seattle, gave hearty support to the Commission and published much of its advice and instruction to gardeners and home canners.

Magazines of general interest and many houseorgans coöperated in the campaign and published articles dealing with various phases of war gardening. This applied to conservation as well as to the productive phase of the work. As an illustration, the Ladies' Home Journal published an entire page of pictures of women who had been blue-ribbon winners and had received the Commission's National Capitol Prize Certificates for excellence in canning garden products. The

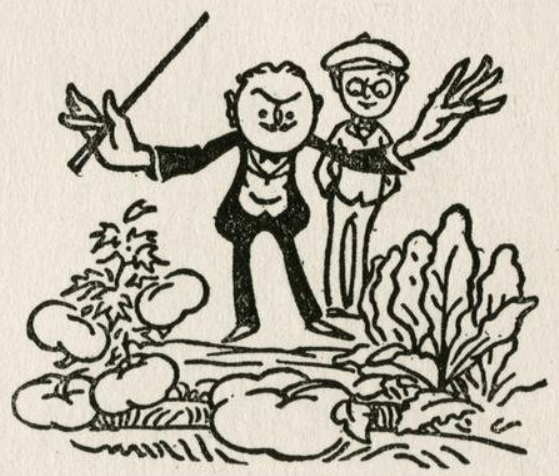
Outlook printed from time to time a number of appreciations of the value of home food growing. The Garden Magazine, of Garden City, Long Island, used a number of stories on the subject and printed a monthly 


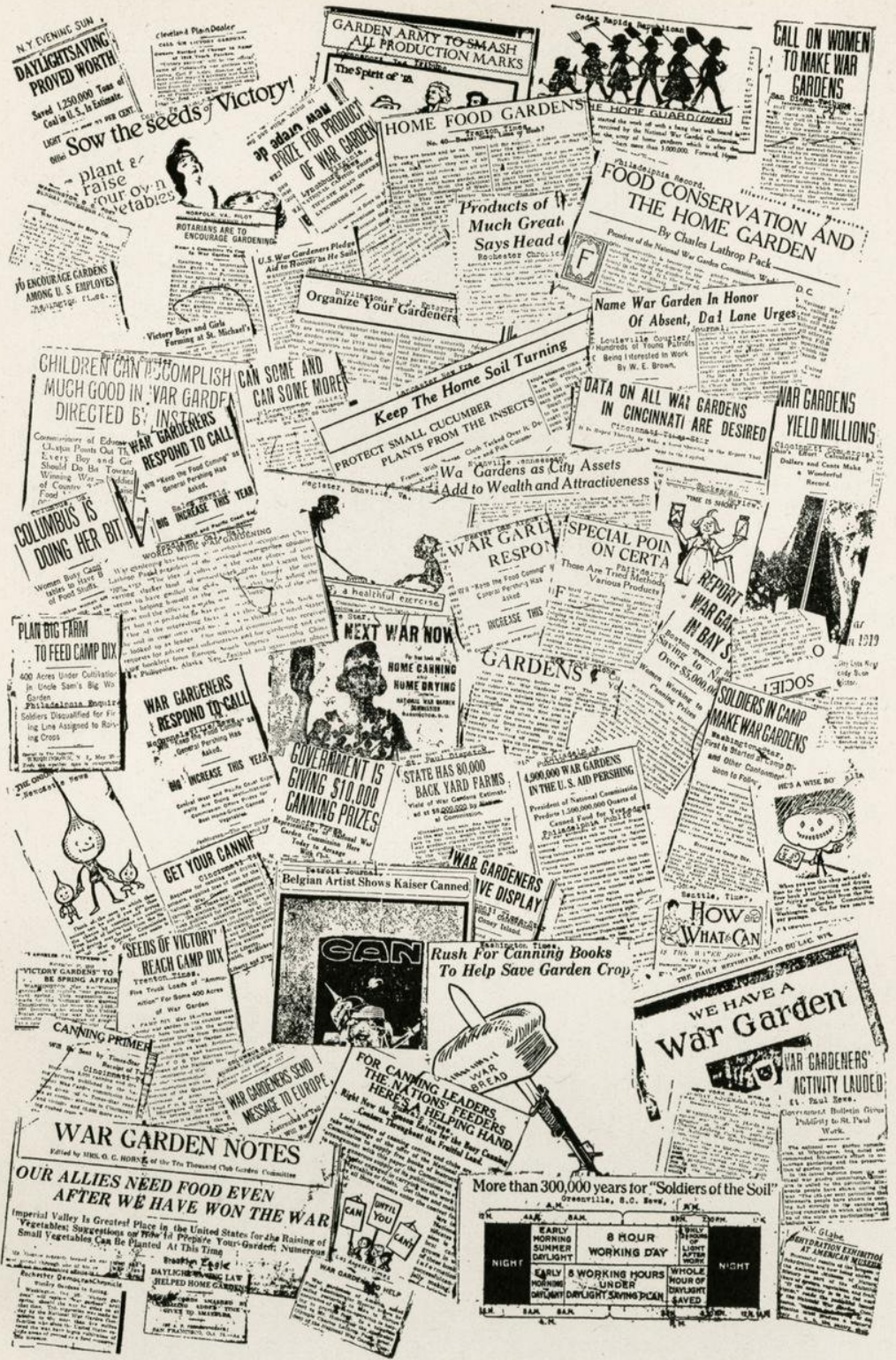

WITH PICTURE AND TYPE THE PRESS URGED GARDENING

The coöperation of the newspapers and magazines in national service was one of the greatest patriotic demonstrations of the world war. This reproduction of clippings shows how data from the National War Garden Commission was printed. 

page summarizing important and inspiring war-garden activities throughout the United States. The Country Gentleman, in addition to regular garden lessons, published several articles commending highly the work of the Commission. Similar helpfulness was extended by the Nation's Business, official publication of the Chamber of Commerce of the United States; the Manufacturers' Record, Baltimore; the American City, New York; the

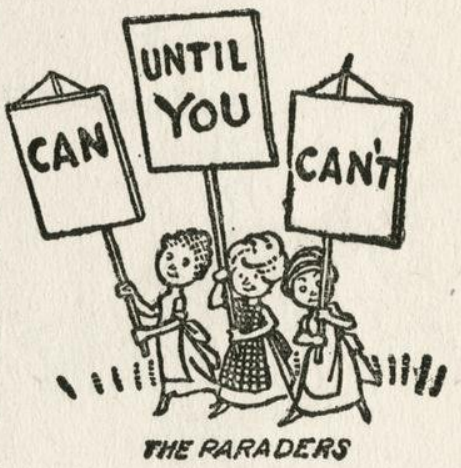
Journal of the American Bankers' Association; the Missouri, Kansas छ๐ Texas Railway, Employés' Magazine; American Industries, and many other trade and

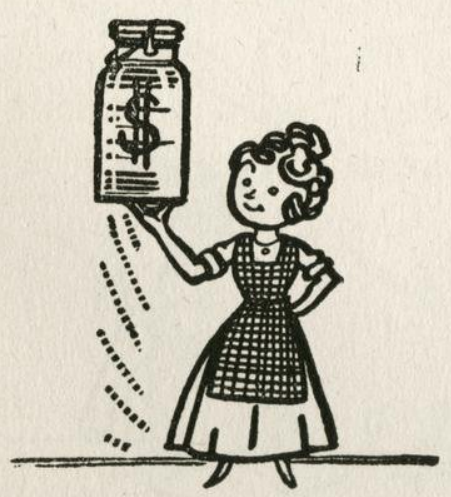
business papers. House and Garden, Vogue, and the Touchstone were among other high-class magazines which printed illustrated war-garden stories supplied by the Commission. The World Court Magazine is another example of this editorial coöperation. The Century, Good Housekeeping, the National Magazine, the Survey, the Illustrated World, the People's Popular Monthly, the Illustrated Sunday Magazine, the Woman'sWorld, the Rotarian, the Lone Scout, Forbes' Magazine, American Forestry, the Southern 
Lumberman, the Christian Endeavor World, the Forecast, and the People's Home Journal, and many others were among the publications that carried war-garden stories.

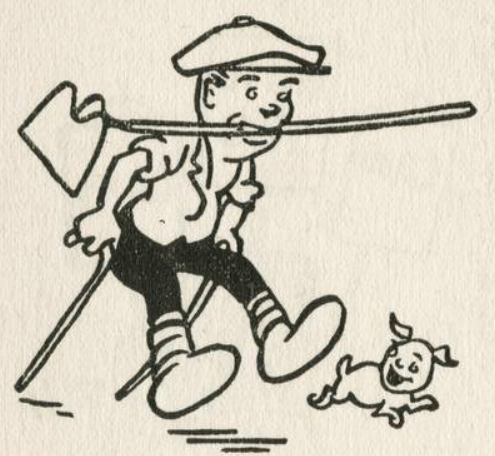

The Literary Digest printed a summary of the work accomplished and showed what Daylight Saving had done to further the efforts of the war gardener.

The manufacturer of plows or soda fountains, as well as the editor of a generalinterest magazine, realized the value of home food production to his employés; and through their houseorgans the heads of many industrial and business concerns spread the gospel of "Food F. O. B. the Kitchen Door." Trade publications of all kinds throughout the country carried garden lessons and inspirational articles urging their workers to produce food and thus help themselves and their country at the same time.

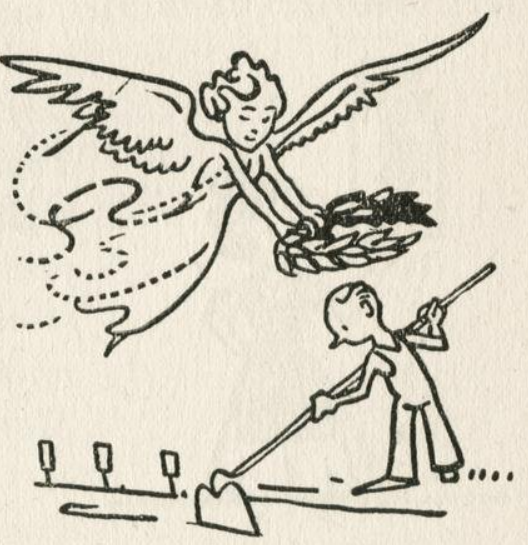
Some of them reproduced the Commission's posters in their magazines and used other material furnished them.

The work of coöperation with newspapers and periodicals was conducted by Russell T. Edwards, under the direction of Secretary Ridsdale. 


\section{THE WAR GARDEN VICTORIOUS}

Thus the magazines and the newspapers of the United States coöperated in making a success of the wargarden movement. Without their help this could not have been accomplished. What was brought about with their aid shows the power of the printed page. It spread the message of the war garden to the millions. It made possible the enlistment of a vast army of war gardeners and of home canners and dryers. It brought into action the patriotic will of the American people to do full share

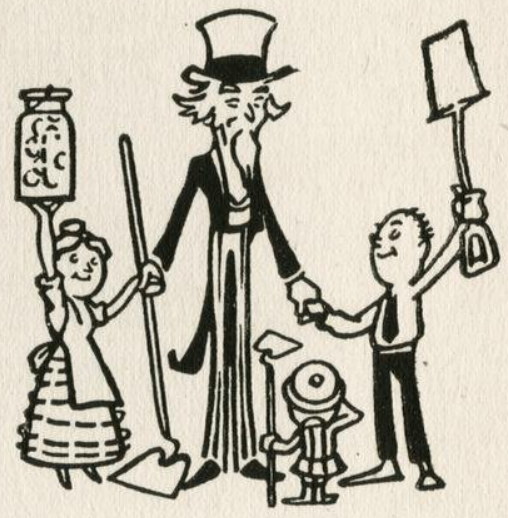
in the battle for international freedom and world-wide democracy. In short it was through the printed page that the war garden and home conservation were given their proper place among war-time activities. 



\section{Appendix}

TWO OF THE VICTORY BOOKS ISSUED BY THE COMMISSION

“WAR GARDENING," VICTORY EDITION, I9I9

"HOME CANNING AND DRYING," VICTORY EDITION, I9I9 



\section{Victory Edition 1919}

WAR GARDENING and Home Storage of Vegetables

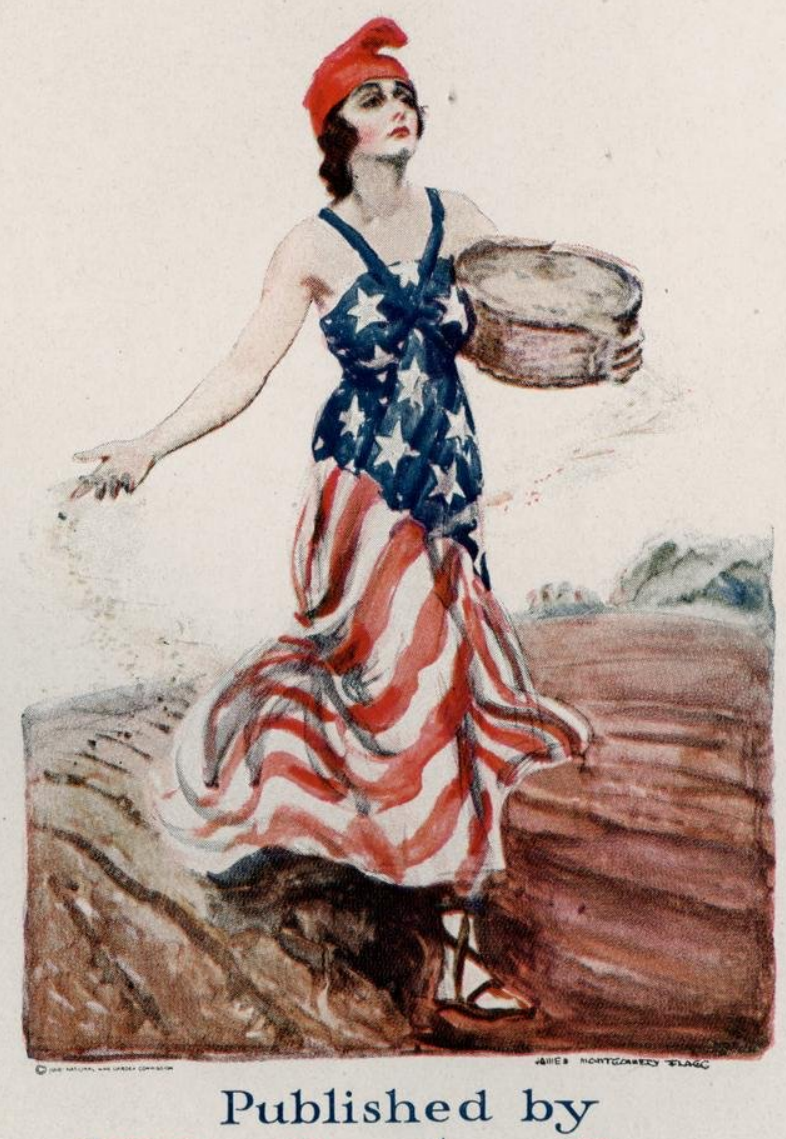

National War Garden Commission Washington, D.C. 


\title{
WAR DEPARTMENT
}

\author{
WASHINGTON
}

June 7, 1918.

\section{NATIONAL WAR GARDEN COMMISSION, WASHINGTON, D. C.}

\section{Dear Sirs:}

The War Department finds much satisfaction in the creation of War Gardens at various army camps by the Conservation and Reclamation Division of the Quartermaster General's office. Food production at these camps has been the subject of some concern with the department. The large areas of tillable land within many of the military reservations have been regarded as offering potential food production on a large scale, and I feel that the army is to be congratulated. that the utilization of this space has now taken concrete form.

Camp War Gardens will serve more than one useful purpose. The production of food at the mess door is of great importance in that it not only lessens the army's demand on the usual sources of supply but eliminates transportation as well.

To the National War Garden Commission I extend the thanks of the Department for its quick response to the appeal of the Quartermaster General's office for co-operation. Not confining itself to mere compliance with the letter of the request, the Commission entered fully into its spirit. At a time when funds were not available through Government channels the Commission voluntarily provided seed, fertilizers and equipment which made possible the establishment of a War Garden of 300 acres or more at Camp Dix. For this generous contribution and for swift action to overcome the handicap of a late start I take pleasure in making this acknowledgment and in expressing the hope that the Camp Dix War Garden of the National War Garden Commission will prove an unqualified success.

Cordially yours,

\section{(Signed) NEWTON D. BAKER,}

Secretary of War.

\section{UNITED STATES FOOD ADMINISTRATION}

\author{
NATIONAL WAR GARDEN COMMISSION, \\ Maryland Building, \\ WASHINGTON, D. C.
}

Baltimore, Maryland. September 14, 1918.

\section{Gentlemen:}

We wish to express to you our appreciation of your helpfulness in our war garden, canning and drying work in Maryland during the season of 1918 . Your book on canning and drying has been of great value, while the canning outfits which you so kindly gave us made it possible for us to establish canning centers throughout the State, with results of far-reaching importance which could not have been otherwise accomplished. We are equally appreciative of your prompt and willing response to our request for the services of one of your trained investigators to assist in our war garden work. Your spirit of prompt and willing service is cordially appreciated.

$$
\text { Yours truly, }
$$

(Signed) EDWIN G. BAETJER,

Federal Food Administrator for Maryland. 
PLAN OF GARDEN 50 by 75 feet, in which careful attention has been paid to proper relation of the season's crops and to a continuous supply of the more important vegetables.

Hot Bed

Cold Frame

Asparagus

Rhubarb

\section{ARRANGEMENT OF SEASON'S CROPS}

Peas, followed by late Tomatoes

Peas, followed by Celery

Onion Sets, followed by Turnips

Corn, followed by Spinach

Beans (bush), followed by Beets

Beets, $1 / 2$ row; Carrots, $1 / 2$ row, followed by Corn

Turnips, followed by Bush Beans

Potatoes, followed by Spinach

Spinach, followed by Potatoes

Cabbage, with Lettuce and Radishes between, followed by Carrots

Beans, Bush Lima

Chard, $3 / 4$ row; Parsley, $1 / 4$ row

Parsnips, $3 / 4$ row (radishes to mark row); Salsify, $1 / 4$ row

Corn, followed by Kohlrabi, $1 / 2$ row; Cauliflower, $1 / 2$ row

Peas, followed by Corn

Beans, Bush Lima

Early Potatoes, followed by late Cabbage

Early Tomatoes

Peppers, $1 / 2$ row; Potatoes, Okra or Eggplant, $1 / 2$ row

Potatoes

Potatoes

Pole Lima Beans

Pole Beans

Gorn

Corn

Corn

\begin{tabular}{|c|c|c|c|}
\hline \multirow[t]{3}{*}{ Cucumbers } & Squash & Squash & Musk- \\
\hline & (bush & (winter) & melon \\
\hline & crook neck) & & \\
\hline
\end{tabular}

Rows are 30 inches apart. If soil is very fertile rows may be closer.

Planting was begun at hotbed end of garden and plantings were made a few days apart to insure a constant supply of vegetables. Planting table on page 23 . 


\title{
MAKE YOUR WAR GARDEN A GARDEN OF VICTORY
}

\author{
By CHARLES LATHROP PACK, President \\ National War Garden Commission
}

\section{$\mathbf{A}^{\mathrm{M}}$}

MERICA'S responsibility for the world's food supply did of the war. In peace, as in conflict, this country must carry the burden of Europe's food problems. With the advent of peace these problems have become intensified. America is now expected to furnish the solution and this can be done only through the continued application of high pressure food production and unwavering food conservation.

For two years of war the War Gardens of America produced foodstuffs which helped establish the balance of power between starvation and abundance. In the spring of I9I8, General Haig declared, "We stand with our backs to the wall." Of that call to the civilized world no phase was more vital than its interpretation and answer in terms of food. During that year the answer was given by the American people with true American spirit. The war gardeners of the United States responded with a vigor which carried the War Gardens over the top to victory. By the addition of more than five hundred million dollars of crop value to this country's food production they made it easier for America to feed her own people and the people of France and Belgium.
The Victory Garden is now as vital as the War Garden. Peace brings new food needs. In reclaiming territory from the enemy France and Belgium have greatly increased the number of their people who must be fed. By restoring these former expatriates to citizenship these countries have also assumed the burden of feeding them. This will mean a vast increase in the demands on America as the source of Europe's food supply in 1919. Europe cannot feed herself during the first year of reconstruction; Russia faced famine conditions in the winter of 1918 I9I9, and Mr. Hoover says that the world's food shortage will last for another seven years.

The war gardener's responsibility, therefore, did not end with the coming of peace. His War Garden must now be made a Victory Garden in the full sense of the words. It must help solve the problem of feeding people rendered helpless by years of ruthless and terrible war.

The garden crop of 1919 must be even greater than that of 1918 , and there must be more canning and drying for winter use. The people of America have a real duty to perform in this respect and the nation counts confidently on full measure of individual response. 


\section{PART I}

\section{WAR GARDENING MANUAL}

As a result of emergency created by war the home garden of America has become an institution of world-wide importance. The planting and growing season of 1918 demonstrated that the products thus raised are essential to the feeding of the people of the United States and the Allied Nations. Under the impetus given by the National War Garden Commission the people of this country last year produced a crop valued at $\$ 520,000,000$ in gardens cultivated in backyards, on vacant lots and on other land previously untilled-the patriotic gift of the war gardens to the nation.

Peace can in no wise diminish America's responsibility for feeding Europe. The recovery of vast areas of devastated country in France and Belgium greatly increases the number of people to be fed and adds heavily to the food burden of America. Because of this the Victory Garden is no less necessary than the War Garden.

\section{WAR GARDENS HELP SOLVE TRAFFIC PROBLEM}

War-time brought the most serious traffic congestion the United States has ever seen. This condition has no meaning more significant than that the gardens of this year must do even more than those of 1918 in freeing the overburdened railroads from the need for transporting food products. With food shortage threatening the Allied Nations and with railroad congestion as an added factor, the war garden results of the coming season must be considerably greater even than the vast yield of last year.

\section{COMMUNITY GARDENING}

Excellent results are obtained through cooperative gardening work. If several families join forces they can reduce the cost of gardening in time, labor and money. Families having adjoining or neighboring garden plots may use one set of tools. To prevent clash of convenience it is well to have an understanding in advance as to the time when each gardener is to have the use of particular tools. By this arrangement it is possible to have complete equipment at expense much less than if each gardener bought his own. Money can also be saved in buying seeds, fertilizers and spraying materials by clubbing together and gaining advantage of the lower prices for large lots.

One of the advantages of doing community work is that it is possible for the gardeners interested in the project to employ a man and a team to prepare their gardens by plowing and harrowing. In this way the man and team can be kept busy throughout the day and the expense to each gardener will be slight.

On a larger scale this principle should be applied to garden plots on tracts of vacant land allotted to individuals in or near cities or towns. Each plot in such a tract is a separate garden, belonging to the individual or family to whom allotted. In many instances the municipal authorities, the mayor's war garden committee or some similar local organization, will provide an expert to supervise work on community gardens of this character. This expert will give advice and instructions as to preparation, planting and cultivation and on other technical subjects.

If an expert is not provided in this way it is wise for the gardeners to club together and arrange for one at their own expense, if the project is large enough to make this possible without too great individual cost. The help of an expert is of great value.

School children and parents may work together to good advantage on these garden plots. In some communities school authorities allow the children to spend a portion of the school hours, on stated days, in their garden work. Through co-operation with street cleaning departments a municipal government may arrange to deliver manure to war gardeners at nominal cost. In at least one important city this is done at a charge of $\$ 2$ per load.

It is a good plan for municipal governments to arrange for lectures at school houses or other places on practical problems in gardening. This increases efficiency. 


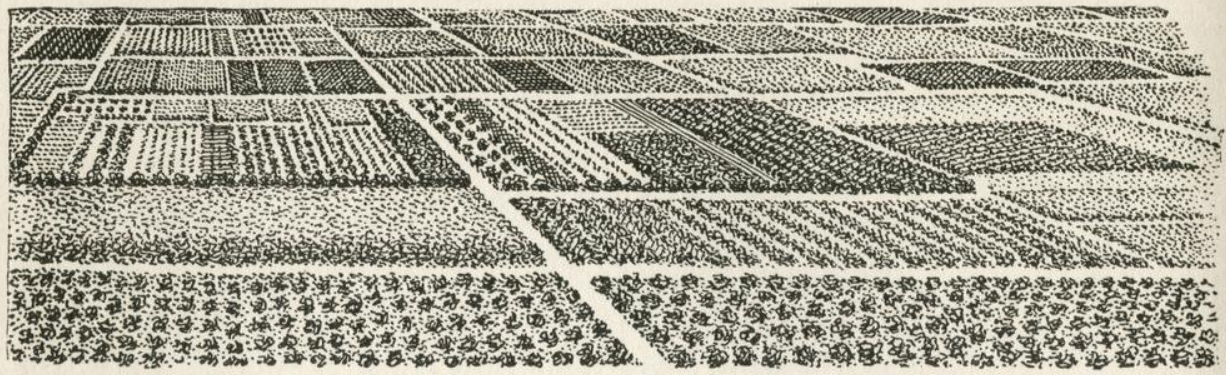

Fig. 1-A community garden which produced excellent results. The ground was provided by a manufacturing concern for its employes and the plowing and harrowing were done by the company. Expert supervisors directed the work. This supervision is an important help to successful gardening.

\section{CORPORATION GARDENS}

Manufacturing concerns, and other enterprises which employ labor on a large scale, may make valuable contribution to the national food supply by encouraging their employees to cultivate war gardens. Many concerns furnish large tracts of land, which are divided into individual garden plots. These plots are allotted to such employes as are willing to cultivate them. Each plot and everything it produces are recognized as the individual property of its cultivator. The company bears the expense of plowing and fertilizing these plots and employs an expert to have charge.

\section{HOW TO HAVE A GOOD GARDEN}

\section{Garden Plan}

Have a plan for your garden-drawn to scale on paper-before you start, to give proper order in planting and enable you to buy the right amount of seeds in advance while the selection is good.

Put in one general group small plants like beets, onions, lettuce, carrots, radishes and parsnips. In another general group put larger plants like corn, tomatoes and potatoes. Spreading ground vines, like melons and cucumbers, which need wider spacing, should be put in another general group. The reason for this grouping is that the various plants in a group need similar general treatment as well as spacing.

In making a plan provide space in which to enter costs and yield of the various crops. This will give you a complete record which will be useful another year. Another helpful use of the plan is that it will guide you in the rotation of next year's crops. For this purpose save your plan for next season.

In planning your garden formulate some definite plan as to what you will do with surplus vegetables. Detailed instructions for home storage of vegetables for winter use are given in Part II of this booklet. Detailed instructions for canning, drying, pickling and other forms of conservation are given in the Home Manual on these subjects issued by this Commission.

\section{Sunshine}

In the location of a garden it is not always possible to choose conditions as to sunlight. It is important, therefore, that in the arrangement of the various varieties of vegetables which are to be planted, due care should be given to providing the greatest exposure to the sun for those crops which need it most. Those plants which must ripen their fruits, such as tomatoes and eggplant, require the greatest amount of sunshine, while lettuce, spinach, kale and other leaf crops require relatively less. Foliage crops must have at least 3 hours of sunlight a day and plants which ripen fruits at least 5 hours a day. This is important.

\section{Vary from Last Year's Plan}

It is important to remember that plant diseases and insects are apt to thrive in a spot in which they have become established. For this reason those who make gardens this year should take care not to place the individual crops in the spot in which the same crops grew last year. Varying the arrangement of the garden in this way will reduce the danger from disease and insects. The same vegetables in the same place each year exhaust certain food elements, and reduced yields are sure to result.

\section{SURPLUS PRODUCTS}

At times, even with the best of planning, a gardener will find that his garden has matured more of some varieties of vegetables than can be used immediately. None of this excess should be wasted and there is no occasion for waste. If there is no ready market for the surplus it should be prepared for winter by either canning or drying. By modern methods either canning or drying may be done with little expense of time, trouble or financial outlay. By using the 
cold-pack method as small a quantity as a single can or jar may be put up in a short time. With proper instructions it is possible for the housewife to dry a handful of peas or beans, sweet corn, a few sweet potatoes or turnips, or small quantities of many other vegetables with practically no expenditure of her time. Explicit and simple directions for canning and drying are given in the Manual issued by the National War Garden Commission.

\section{THE SOIL AND MANURES}

The back yard gardener must use the soil he has, but he can improve it if is poor, and he must do this as far as possible. Stable manure will help even the richest soil, and you are not likely to use too much of it. During a single season professional gardeners apply as much as six inches of it. From 400 to 600 pounds can be used to advantage on a plot 20 by 20 feet. Coarse manure should be applied and thoroughly plowed or spaded under in the fall. In the spring, fine, rotted manure is applied, just before plowing or spading, preceding the planting of any crop. If the ground is fairly rich, and well-rotted manure is scarce, the manure may be scattered in the row only, and should be mixed into the soil before the planting of seed.

Loam is the best garden soil. Sand, with manure, gives good results. Clay is hardest to work, but is greatly improved by wellrotted manure and vegetable matter-called humus. These should be well worked in with hoe and rake. Sifted coal ashes, entirely free from clinkers, will help loosen up clay when mixed into it, but will not remove an acid condition nor increase fertility.

\section{Commercial Fertilizer}

Many gardeners experience difficulty in obtaining supplies of well-rotted manure. In such cases commercial fertilizers should be used. Even where stable manure has been secured and worked into the soil it is well to supplement with moderate quantities of quick-acting fertilizer in order to give plants an early start and hasten maturity.

It is safest to rely upon the ready-mixed fertilizers usually obtainable at seed and hardware stores. Several specially prepared mixtures in convenient packages are now on the market. For large areas, 100 to 200pound bags may be obtained. A mixture containing 3 to 4 per cent nitrogen and 8 to 10 per cent phosphoric acid is about right for the average garden. Your dealer will inform you on this point. If the fertilizer also contains potash, so much the better, but this year potash is scarce and high in price.

Where no manure is used the fertilizer should be spread over the surface of the finely prepared seed-bed at the rate of 5 pounds for a plot 10 feet square, just before planting. The surface soil should then be thoroughly raked so as to mix the fertilizer evenly to a depth of 2 inches. Never place seed or transplanted plants in direct contact with fertilizer. Thorough mixing of the fertilizer with the soil is essential to prevent injury of seed or roots. 
garden next spring. Destroy all plants which are diseased. The compost pile should be built up in alternate layers of vegetable refuse a foot thick and earth an inch or more thick. The earth helps to rot the vegetable matter when mixed with it. The top of the pile should be left flat that the rain may enter and help in the process of decay.

If the pile can be forked over once a month when not frozen and the contents well mixed together, they will decay quite rapidly and be in good usable condition in the spring. The compost may be either spread over the garden and plowed under or it may be scattered in the rows before the seed are sown. This is, of course, not as rich as stable manure, but it is a good substitute.

Compost is also used as a top dressing during the growing season for hastening growth.

In the cities and towns tons of leaves are burned every fall. This is a loss which ought to be prevented. These leaves properly composted with other vegetable waste and earth would be worth hundreds of dollars to the gardens next spring.

In planning a permanent garden, a space should be reserved near the hotbed or seed bed, and in this space should be piled, as soon as pulled, all plants which are free from diseases and insects. This applies to all vegetables and especially to peas and beans, as these belong to a group of plants which take nitrogen from the air, during growth, and store it in their roots. When these plants are decayed they will return to the soil not only much of the plant food taken from it during their growth but additional nitrogen as well. Nitrogen in the soil is necessary for satisfactory leaf growth. The material so composted should be allowed to decay throughout the winter, and when needed should be used according to the instructions given for using compost. The sweepings of pigeon lofts or chicken coops make valuable fertilizer. When cleaning roosts from day to day add $1 / 4$ as much acid phosphate as sweepings. When needed apply 1 pound of this mixture to every 5 square feet of ground, mixing it thoroughly into the soil.
Prepared sheep manure, where procurable at a reasonable price, is possibly the safest concentrated fertilizer. It should be used in small quantities rather than spread broadcast. Scatter it along the row before seed is sown or apply by mixing it with water in a pail, stirring the mixture to the consistency of thin mush, and pouring it along the rows of the plants.

\section{Green Manure}

Green manure is useful as a fertilizer. It consists of green plants turned under by plowing or spading. Rye is the most satisfactory for this purpose. If planted in July or August the crop may be turned under in the fall if early spring planting is desired. If planted later, it is usually turned under in the spring. When not turned under until spring, the growth will prevent the leaching of soluble plant food or the washing away of rich soil.

In sowing rye for this purpose, use at the rate of 1 pound of seed to a strip of ground 50 feet long and 10 feet wide. If the ground is rough or hard it should be cultivated just before the seed is sown, and then cultivated again to cover the seed. Sow the seed between the rows of crops not yet gathered. Rye is very hardy and will sprout even though there is frost nearly every night. At a cost of about 5 cents for a pound of seed a garden of 10 by 50 feet can thus be treated to an application of green manure. The green rye plants soon decay when turned under and answer the same purpose as a light dressing of manure.

Green manure, however, should not be relied upon to do the work of stable manure, as it does not provide phosphorus or potassium.

\section{Lime}

Land which has long been unused, or land in lawns, is apt to be sour. To remedy this condition apply evenly 1 pound of air-slaked lime or 2 pounds of ground limestone to every 30 square feet. The lime should be applied and raked in to a depth of 2 inches when the seed bed is being prepared in the spring. Instead of lime 2 pounds of unleached

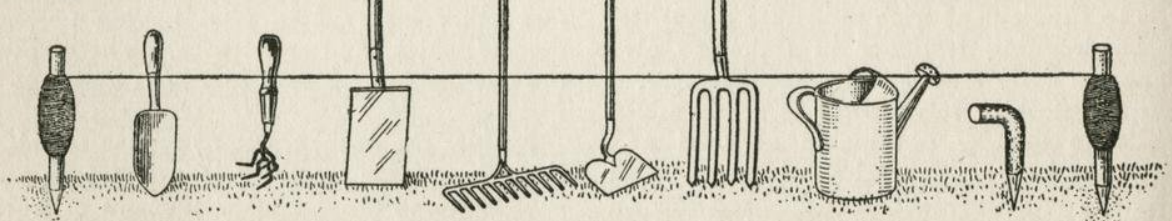

Fig. 3-Tools most commonly needed in a small garden. From left to right, between the balls of cord, they are: Trowel, weeder, spade, steel toothed rake, hoe, garden fork, watering pot and dibble. 
wood ashes may be used. Do not apply lime at the same time as manure or mixed fertilizers, as it will cause loss of nitrogen.

As an addition to soil lime is of considerable value. Besides correcting acidity it changes the physical structure of the soil. One of the elements of lime is calcium, which is required for plant growth.

\section{OUTDOOR HOTBEDS}

For early planting a hotbed may be made, located in a sheltered spot with southern exposure, where it will receive a generous supply of sun. A width of 6 feet is desirable, and the length should be such as will enable the use of standard 3 by 6 foot hotbed sash. A simple, boxlike frame, 12 inches high in the rear and 8 inches high in front, will hold the sash and give a better angle for the rays of the sun.

Dig a pit $11 / 2$ to 2 feet deep, the size of the sash frame to be used. Line the sides of this with boards or planks, brick or concrete, and make a tile drain, or place stones on the bottom of the pit, to carry off surplus water. This pit is to be filled with fresh horse manure. The manure will require special treatment before being placed in the pit. It should be thrown into a pile and allowed to heat. When it has heated and is steaming fork it over into a new pile, throwing the outside material into the center. When the new pile has become well heated fork the material once more into a new pile. This will require from ten days to two weeks and is important in that it gets rid of excessive heat. After this process fill the pit with the manure, packed down firmly and evenly, level with the surface of the surrounding earth. On top of this manure make a covering of good garden loam 3 or 4 inches deep.

When the sash has been put in place the manure will generate heat, in addition to the heat that will be derived from the sun. After this heat has reached its highest point and dropped back to between 80 and 90 degrees F. the seed should be planted. Use the best seed obtainable. Until the seed germinate the hotbed should be kept shaded to hold moisture. This can be done by spreading over the sash strips of old carpet, heavy cloth or newspapers. After germination strong light will be needed. The plants must be watered each morning on clear days, and the sash left partially open for ventilation, as it is necessary to dry the foliage to prevent mildew.

Proper ventilation is essential to the production of strong, healthy plants. The sash should be raised during the warmest part of the day on the side opposite the direction from which the wind is blowing. By opening it in this way instead of facing the wind, the hotbed receives fresh air without receiving direct draft. On cold days raise the sash slightly three or four times a day for a few minutes only. In severe weather cover the beds with mats, straw or manure to keep in as much heat as possible. About two weeks before transplanting time the sash should be removed during the day to "harden" the plants. While in the hotbed the plants should be thoroughly watered, but the water should not reach the manure underneath. Early morning is the best time for watering, so that the plants will be dried before night.

An outdoor hotbed of this character should be started in the early spring-February or March.

\section{THE COLD FRAME}

A cold frame is useful for hardening piants which have been started in the hotbed. It is built like a hotbed, but without the pit or manure. It is built on the surface of the ground. Good, rich soil should be used and the soil kept slightly moist. In mild climates the cold frame may be used instead of a hotbed for starting plants. It is also used in the fall and early winter for growing lettuce, radishes, carrots, parsley, etc.

\section{TOOLS}

Not many implements are required for home gardening. The essentials are a spade or a garden fork, a hoe, a rake with steel teeth, a trowel, a dibble or pointed stick, and a line such as is used by masons, or a piece of common string or cord, to stretch between two stakes for marking off rows. In the case of hard packed earth a pick is useful for digging. For watering, a rubber hose is needed where pipe connections are available. Lacking this equipment a watering pot should be provided. A hand cultivator or wheel hoe is useful, especially in a large garden, and saves much time and labor in turning small furrows. With simple attachments it is used for stirring the soil and the removal of weeds.

\section{PREPARATION OF SOIL}

After the frost goes out test the ground by squeezing a handful of it. If it crumbles the soil is ready for spading. If it packs into a mud ball, the ground is still too wet and should not be worked.

Spade deeply, 8 to 15 inches, unless this latter depth turns up poor soil and buries the richer soil of the top. Pulverize the dirt deeply with hoe, spade and rake, breaking all clods on the surface. If a lawn roller is available it is useful for crushing clods. All vegetable growth on the surface, such as grass 
or weeds, should be turned under, to rot and enrich the soil. This is especially important with ground that has had a growth of turf.

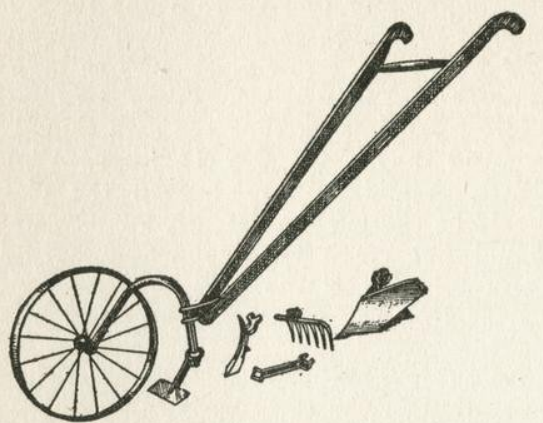

Fig. 4-Wheel hoe and hand cultivator, to be had with attachments such as plow, cultivator teeth, shovels and rake. A simple form may be made at home.

\section{SELECTION OF CROPS}

The home garden campaign for 1919 should be planned with a view to the production of the largest possible amount of food with the smallest possible outlay of seed and fertilizer. Authorities agree that the seed shortage is the worst the country has ever seen. The supply of fertilizers and natural manures is far below the normal. The demand for these materials is exceedingly great and war-time efficiency makes it vital that war-time conservation be practised in the use of them. To this end gardens should be devoted as far as possible to those crops which are most useful for food and in which the chances of failure are least to be feared.

In the selection of vegetables for the home garden preference should be given to the staple crops such as potatoes, beans, tomatoes, corn, onions, and cabbage. Crops of next importance, such as peas, carrots, parsnips, beets, squash, greens, turnips, cauliflower, radishes and celery, should be grown if space in the garden permits.

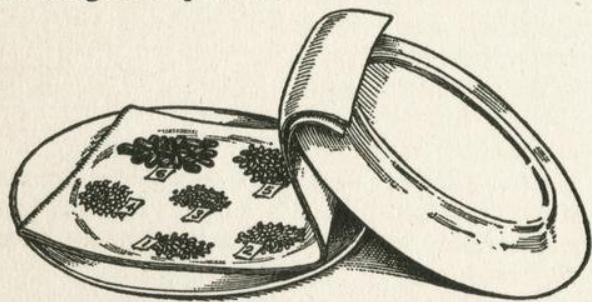

Fig. 5-Simple seed test, using plates and moist blotting paper or cloth. This is extremely useful.

Cauliflower, muskmelons, watermelons, onions from seed, asparagus and cucumbers are some of the plants that are most difficult to raise and these are not recommended to the amateur gardener.
Soils vary so much that serious attention should be given to the crops suited to the individual garden. This is a local question. Consult your local war garden committee's experts as to the best crops for your particular soil. Expert advice will prevent mistakes.

In many communities, last year witnessed an over-production of some vegetables that had to be used during the growing season. Many gardeners had larger crops of these than they could possibly use. Much waste resulted. To prevent this loss in seed, fertilizer, garden space, labor and foodstuffs every gardener should give especial attention to the selection of crops. Plant sparingly of those things which must be used as they mature and plant liberally of those things which may be saved for winter use by canning, drying or storing.

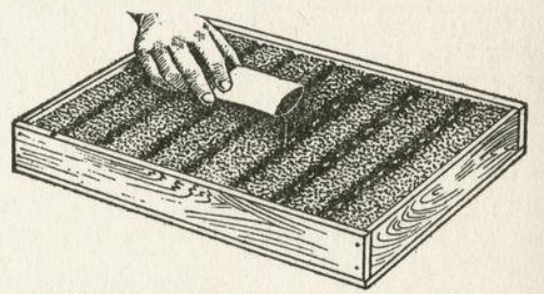

Fig. 6-Use an envelope for sowing seed. The picture shows seed already sown in some of the rows.

\section{PROCURE SEED EARLY}

Seed shortage was a handicap to many gardeners last year. In 1919 the planting of gardens will be increased and the demand for seed even greater than in 1918. It is important, therefore, that the home gardener should procure his supply of seed earlywell in advance of planting time. Be sure to patronize a reliable dealer, as quality is vital.

\section{Use Seed Sparingly}

Home gardeners often plant seed thickly to make sure of a good stand. This is a wasteful method, excepting with such vegetables as will produce young plants which may be used as greens. The better way is to plant according to the directions given in the planting table.

The pronounced seed shortage this year makes it imperative that no seed be wasted.

\section{Testing Seed}

A simple test will give useful advance information of the germinating value of seed. This test is useful as enabling the gardener to determine whether or not seed have been properly cured and are otherwise in good condition. Seed which are too old or have been kept under unfavorable conditions are unsatisfactory. 
should be used to produce plants for a hill of cucumbers, squash, melons or other "vining" plants which are started indoors, as these do not stand transplanting if the roots are disturbed. The pot or other holder may be set into the ground without disturbing the roots. Tomatoes, eggplants and beans may also be started in this way.

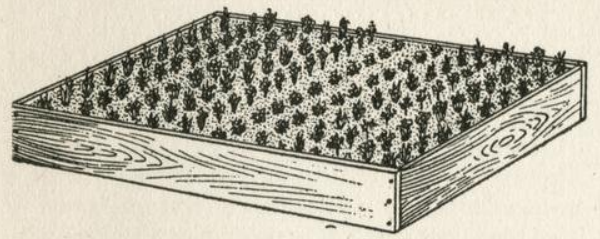

Fig. 9-Seed box for starting plants indoors.

\section{WHEN TO PLANT}

When heavy frosts are over, plant early peas, onion sets and seed, early potatoes, kale, lettuce and spinach. All of these will stand light freezing except potato plants, which should be covered with dirt when frost threatens.

When frosts are about over plant radishes, parsnips, carrots, beets, late peas and early sweet corn, and set out cabbage and cauliflower plants. (An old and useful rule is to "plant corn when the oak leaves are the size of a squirrel's ear").

When all frosts are over and apple trees are in bud, plant string beans and late sweet corn, and set out a few early tommato plants from the indoor boxes.

When apple trees have finished blossoming plant cucumbers, melons, squashes, lima beans and set out the rest of the indoor plants.

\section{SEED BEDS}

Plants for second crops may be raised in an outdoor seed bed occupying small space. These plants may be grown while the space allotted to them in the garden plan is still in use for earlier crops. The rows of seed are not spaced so closely as in boxes used inside the house. If the plants crowd each other too much some of them may be removed and transplanted to another part of the garden. The seed bed plan is useful for such crops as cauliflower, Brussels sprouts, late cabbage and the like.

\section{FALL PLANTING}

It is well to plant a fall garden of some crops, for in spite of the risk of injury by early frost the chances are in favor of satis- factory results. There can be no absolute rule as to the time of planting. The probable time of the first frost in each locality must be taken as a general guide. For planting in August, and possibly even in early September, the following vegetables may be grown:

When first frost may be expected between September 15 and September 25:

Lettuce, Spinach, Turnips, Parsley, Multiplier Onions and Turnips. (Kale and Radishes may be risked.)

When first frost may be expected between September 20 and October 5:

Kale, Lettuce, Parsley, Multiplier Onions, Radishes, Spinach and Turnips. Beets and Chard for greens.

When first frost may be expected between October 5 and October 15:

Beets for canning, Carrots, Kale, Multiplier Onions, Spinach, Chard, Endive, Lettuce, Radishes and Turnips.

When first frost may be expected between October 15 and October 25:

Any of the vegetables mentioned in the preceding lists. (String beans may be risked.)

\section{LAYING OFF ROWS}

Straight rows add to the garden's beauty and make cultivation easier. To make the rows straight stretch a stout string between stakes and follow it with the point of a hoe, with a wheel hoe, or with the end of the handle of the rake or hoe, to open up the row. The plan is suggested in Fig. 10.

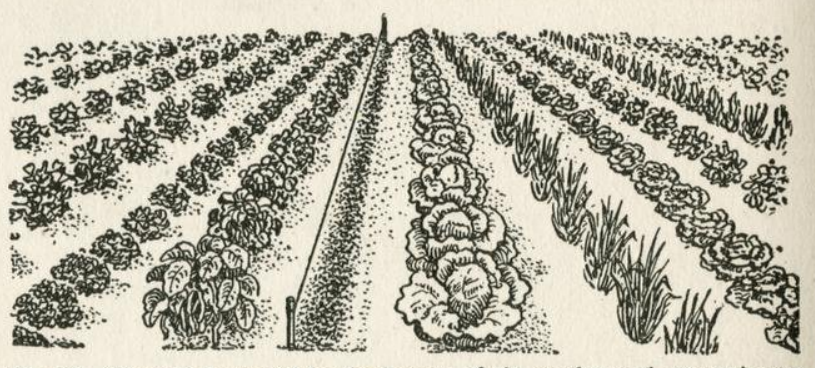

Fig. 10-Straight rows add to the beauty of the garden and are easier to cultivate. The simplest way to lay them off is to stretch a line between two stakes and mark row with a hoe, hoe handle or stick.

\section{SUCGESSION OF GROPS}

Nature generously provides for more than one crop on the same soil. Vegetables which reach maturity early in the season should be followed by later crops of the same vegetable or by rotation of other kinds. Onions to be used green may be grown in rows which are to be occupied by late tomato plants, as a few of the onions may be removed to plant the tomatoes. Radishes mature early and as they are harvested the space may be used for cabbage, lettuce, cauliflower, Brussels sprouts 
and other plants. Many combinations of this kind may be made to good advantage.

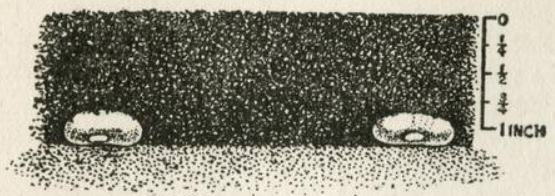

Fig. 11-Beans planted at proper depth.

\section{FOR CONTINUOUS CROPS}

With some of the important vegetables a series of plantings is desirable. Of string beans, lettuce, radishes, spinach, sweet corn, peas, beets and carrots there should be several successive plantings, two or three weeks apart, to provide a fresh and continuous supply all season.

\section{DEPTH OF PLANTING}

Do not plant too deeply. The old rule is to plant to a depth of 5 times the thickness of the seed. This, however, is not an absolute rule and is not safe in all cases. Consult planting table on page 23 for depth.

\section{HOEING}

When the green rows appear it is time to start hoeing or cultivating. Never hoe or cultivate deeply - an inch or two is deep enoughbut stir the ground frequent$1 y$, and always after rain or watering, as soon as it is dry enough. The hoeing must not be done after rain or watering when the ground is still so wet as to cause the muddy earth to pack like cement, as this causes the earth to cake and dry out

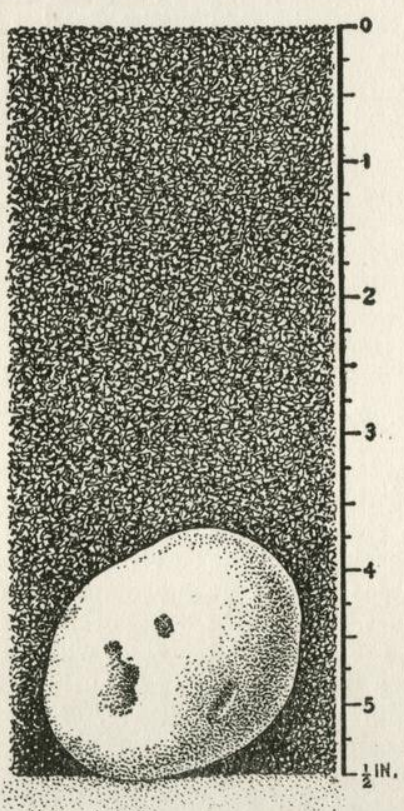

Fig. 13-A small potato planted whole. The depth of planting here shown is approximately $41 / 2$ inches to the center of the potato. This is the depth for late potatoes. Early potatoes are planted 2 inches nearer surface of ground. once a week than to sprinkle every day. Late afternoon is the best time to sprinkle.

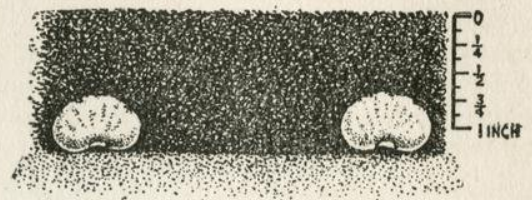

Fig. 12-Lima beans, planted properly, with eyes down.

To moisten the surface is not enough. There must be a thorough wetting. If pipe connections are available a garden hose is the best means of watering. One of the most satisfactory methods is to open small furrows between rows and allow water to run into these trenches, raking the earth back into place several hours later and making a mulch, after the water has thoroughly soaked in. The sprinkling pot will serve if hose is not available, but it is more laborious. Overhead sprinklers are very satisfactory. They consist of pipes mounted on supports extending the length of the area to be watered. Holes are drilled at intervals of 3 to 4 feet and small nozzles are inserted which yield a spray-like misty rain when the water is turned on. By turning the pipes and also changing the position of them it is possible to water an area of any size.

In home gardens proper drainage is often disregarded. Drainage improves the soil by allowing air to enter; by raising the temperature of the soil; by rendering the soil more porous and granular; by enabling the roots of plants to grow deeply into the soil and by allowing earlier cultivation in the spring.

Blind ditches, partly filled with stones or other material covered with soil, or open ditches, will be found satisfactory for the home garden. They should be along the lowest level of the garden, and have suitable outlet. Lacking an outlet, lay tile 12 inches below surface of garden, slanting toward a hole 10 feet deep and 5 feet across, in center of garden. Fill this, two thirds to top, with stones, covering stones with clay and covering the clay with loam.
A plentiful supply of moisture is essential. If there is not sufficient rainfall the moisture should be provided by watering the garden. In doing this it is better to soak the ground 


\section{DIRECTIONS FOR VEGETABLE GROWING}

\section{POTATOES}

As one of the staple needs of the household Potatoes are entitled to special attention in Home Gardening and Community Gardening. In selecting for seed it is desirable to choose medium to large, smooth, shallow-eyed potatoes. The best seed will produce the best crop. Potatoes grow best in sandy loam or in a gravel loam. Heavy, sticky clay or loose sand is not desirable soil. Potatoes should not be grown in the same place in the garden in which they were grown the previous year. A rotation of three or four years is desirable.

Preparation of the soil should be done with care. The ground should be worked with plow, spade and hoe, to a depth of 8 or 10 inches, and should be thoroughly broken up or pulverized, then thoroughly worked with a steel-toothed rake. This preparation is of great importance and should not be slighted. Attention to details is necessary to success.

\section{Treat Seed for Scab}

One of the most common diseases affecting seed potatoes is scab. This attacks the skin of the potato, causing it to thicken, and giving it a scabby appearance. It is carried through the winter, in soil, in manure and on the po-
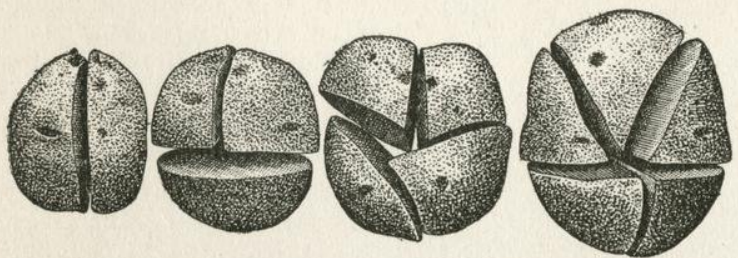

Fig. 14-Properly cut seed potatoes. Each"piece has two good eyes and is about the size of a hen's egg.

tatoes themselves. To control this affection it is important that potatoes should be rotated with other crops as to location, and the same soil not used for potatoes except at intervals of three or four years. A simple remedy, easily applied, is to soak the seed potatoes before planting, in a solution of Formalin and water. This solution is made of 1 ounce of Formalin ( 40 per cent formaldehyde), mixed in 2 gallons of water. In this mixture soak the uncut potatoes for two hours, and spread them out to dry. The solution can be used on as many lots of potatoes as desired.

Seed potatoes should be spread out in a room in which they will be exposed to strong light for two weeks before cutting, to start sprouts and detect poor seed. If large potatoes are used cut them into pieces weighing from 1 to 2 ounces, each piece having at least two eyes. If potatoes are scarce and expensive the pieces may be cut to a single eye. Do not cut the seed until it is to be planted.

\section{Planting}

For planting, prepare trenches or furrows from 3 to 5 inches deep and from 24 to 36 inches apart. Plant seed pieces 3 inches deep for early potatoes and 5 inches for late varieties. The seed pieces should be 14 to 18 inches apart in rows, the smaller the pieces the closer the planting. Fill the trench with dirt, firming it in order that the moisture may be brought in contact with the seed pieces to assist in the process of germination.

Usually potatoes should not be planted as late as the first week in July very far north of the Mason and Dixon line except in sections where it is known that they will mature before freezing weather arrives.

\section{Cultivation}

As soon as the potato plants come up begin cultivating them. The cultivation should begin before they come up if a crust forms. Cultivate or hoe every week during the season, to keep the surface in good condition. When the plants are young work the soil up around them to support the plants.

Potatoes are subject to diseases and insects which are scheduled on page 21 . Take precautions to keep these from getting a start. Follow instructions as to spraying

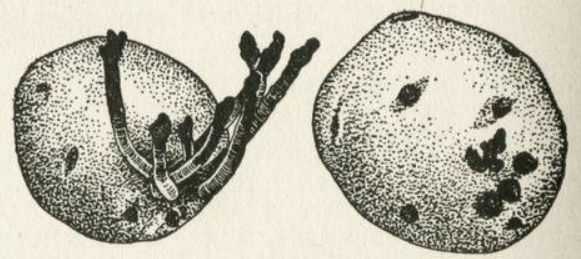

Fig. 15-On the left is shown tuber sprouted in warm, dark storage place. Such spouts sap vitality and decrease yield. On the right is green sprouted tuber. By this latter method the tuber retains its vitality and a good yield is insured.

and keep at it during the season. It is better to spray before trouble appears than to take chances.

Dig early potatoes when they are of the size desired. Late potatoes, for storing, should not be dug until the leaves and stems are dead, or until the skin is so firm that it may not easily be rubbed off. 


\section{SWEET POTATOES}

Sweet potatoes are grown mostly in the Southern States or where there is warm, sandy soil, and are not especially recommended for the home garden. If space permits a few plants may be grown.

If you wish to grow your own plants start a hotbed about six weeks before appleblossom time. Place 5 or 6 inches of sand over the manure in the hotbed and lay down small, healthy sweet potatoes, close together but not touching. Cover them with one or two inches of sand; water occasionally to keep slightly moist. Sprouts will soon begin to grow and immediately send out roots into the sand. When these sprouts are four or more inches long they may be pulled from the potatoes and are rooted and ready to be planted. They need not be pulled, however, until time to plant them in the garden, when all danger of frost is past. They should be set 14 inches apart in rows 36 to 60 inches apart. If only a few plants are wanted they should be purchased from a seedsman, as the trouble involved in growing them in small quantities is too great to make it worth while.

On land which is not thorougly drained the plants should be set on ridges and these should be made broad, as narrow ridges will dry out too rapidly. The ridges should be maintained during the entire growing season.

Sweet potatoes should be dug when the soil is dry and the weather bright, before there is danger of hard frosts. A spading fork may be used in digging them. Guard against bruising or injuring them in digging and handling. Let the roots lie out to dry for two or three hours after digging.

\section{Asparagus}

Use strong plants two years old, which may be purchased from seedsmen. Set them 18 inches apart, in rows 3 feet apart. The rows should be 8 to 10 inches deep, with width of 6 to 8 inches at bottom. After spreading out roots cover crowns with 2 inches of soil. With the growth of the shoots gradually fill in with earth until level with surface. Careful cultivation is required during the season. A small bed heavily manured will furnish plants for 2 or 3 persons.

\section{Beans}

Beans form a staple crop which may be raised in almost every climate. They need a rich soil which holds moisture, but is well drained. Frequent shallow cultivation must be given and they must be kept growing with- out a check until harvested. Never cultivate while moisture is on vines.

Beans are susceptible to cold and for sure results they should not be planted until danger of frost is past. So little trouble is involved in bean planting, however, that it is a good plan to take a chance on making the first planting as soon as the ground is reasonably warm. If the first planting should be killed by frost there is a good chance that the second will come up and that it will mature early. In this way a crop will be assured early enough to make it worth while to take the small risk involved in the possible loss of the early planting.

Dry shell beans are planted and treated the same as string beans are planted and treated. The beans are allowed to mature in the pods. They should be thoroughly dried, shelled and stored as directed for storage of seed on page 32 .

String and lima beans are grown alike. There are two sorts of each -low bush vines and bean vines that climb poles. Pole beans are best for small gardens.

Plant beans and bush limas 1 inch deep, 4 to 6 inches apart in rows.

Make successive plantings every ten days until hot weather. In late summer make successive plantings of string beans until eight weeks before the usual time of first frost.

Plant pole beans and pole limas in hills 1 inch deep, 4 seeds to hill, hills 3 feet apart. Thin to 2 plants to the hill. Before planting fix firmly in each hill a pole 5 to 6 feet long. If desired have two rows of hills and slant the poles so that each set of 4 may be tied together at the top like an Indian teepee. This prevents the poles from falling, but reduces the yield of the vines.

Help the vines to start twining around the poles from right to left. Note: Plant lima beans with the "eyes" of the seed downward.

\section{Beets}

Sow seed rather thickly in row, using $1 \mathrm{oz}$. to 50 feet, but thin the young plants by pulling until the survivors are 4 inches apart. The pulled plants make fine greens for cooking or canning.

\section{Brussels Sprouts}

\section{Grown like cabbage.}

\section{Cabbage}

Set plants from indoor seed boxes or pots 15 inches apart in rows, the rows being 30 inches apart. Between these rows 
early lettuce, radishes, and other little crops may be planted. Early cabbage should be gathered as soon as it has formed solid heads. Late cabbage may be stored in trenches and covered with straw and earth.

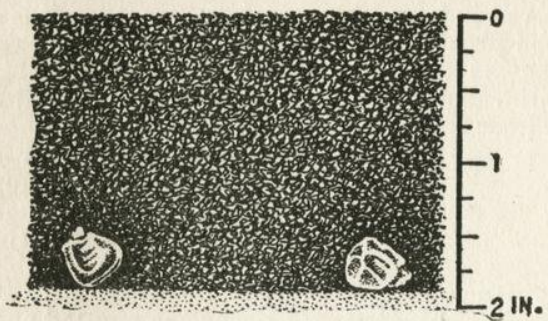

Fig. 17-Corn, planted properly, at depth of 2 inches.

\section{Carrots}

Sow seed $1 / 2$ inch deep, using $1 / 4$ ounce to 25 feet of row. Thin to 2 or 3 inches apart when roots crowd each other.

\section{Cauliflower}

Grown the same as cabbages, except when the heads form, the loose outer leaves should be tied together over the heads to keep out the light and bleach them.

\section{Celery}

Sow seed in seed boxes and set plants in garden in June or July, 6 inches apart, trenches 6 inches deep and 3 feet apart. Make the trenches 6 to 8 inches wide at the bottom so that rains will not wash the earth over the young plants. As the plants grow, cultivate the ground into the trenches. When plants are large heap earth around stalks to whiten them.

\section{Celeriac}

This is a large rooted form of celery. It is grown like celery, except that the plants do not need bleaching. The large root is cooked for use. The plants should be protected in freezing weather by straw or mulch (half-rotted manure and straw), and dug when needed.

\section{Corn, Sweet}

Plant 5 or 6 seed 1 inch deep in hills 3 feet apart. When plants are 4 inches high pull out all but 2 or 3 plants in each hill. Make new plantings every 2 weeks until July or August so as to have corn for use during the entire season.

\section{Cucumbers}

Plant 8 to 10 seed 1 inch deep in hills 4 feet apart. Later thin to 2 plants per hill. Do not plant until soil is warm and frosts are over. Hoe or cultivate only until plants start to vine, then pull weeds by hand.

\section{Eggplant}

Little plants from seed boxes are set 2 feet apart in rows 3 feet apart.

\section{Endive}

In midsummer sow seed $1 / 2$ inch deep and later thin plants to 8 inches apart. To blanch hearts raise leaves and tie together over heart.

\section{Kale}

Sow seed $1 / 2$ inch deep in rows 18 to 24 inches apart. Thin the plants until they are from 6 to 8 inches apart in the rows.

\section{Kohlrabi}

Sow seed $1 / 2$ inch deep and later thin plants to 4 or 6 inches.

\section{Lettuce}

Sow seed $1 / 2$ inch deep in rows 1 foot apart and later thin out until plants are 5 to 6 inches apart. There should be successive plantings, but lettuce is not grown in extremely hot weather. Sow seed the last of August and in September to be transplanted to the cold frame in October.

\section{Mint}

Roots may be procured from a seedsman or neighbor. Plant one or two clumps of these roots in a corner of garden in the spring.

\section{Muskmelon}

Grown like cucumbers except hills must be 6 feet apart.

Muskmelons are difficult to raise and are not recommended to gardeners who are not experienced in their culture.

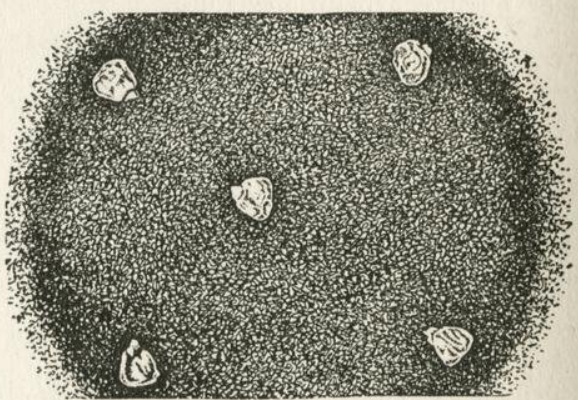

Fig. 18-Corn, planted properly in hill, at a depth of 2 inches and with corner kernels 3 inches apart.

\section{Okra}

Sow seeds when corn and beans are being planted. Sow 1 inch deep a few inches apart in rows 3 to 5 feet apart. Thin plants to 18 or 24 inches apart. Until plants are almost grown cultivate frequently and not very deeply.

Pick young pods every day to keep plant bearing.

\section{Onions}

Onions will grow from seed or from bulbs, called sets. It is better to use sets in home gardens. For early green onions plant sets 
3 inches apart in rows 1 foot or more apart. To grow from seed, plant the seed rather thickly $3 / 4$ of an inch deep in rows and thin them later until plants are 2 to 3 inches apart. If sets for planting next spring are desired, do not thin out any plants, but let them crowd so they will remain small. Seed may be planted in seed box or seed bed and when transplanted placed 3 inches apart.

\section{Parsley}

Sow seed thinly $1 / 8$ inch deep, later thinning plants when they crowd each other.

\section{Parsnips}

Sow seed thinly $3 / 4$ of an inch deep in rows 18 to 24 inches apart and later thin plants to 3 inches apart.

\section{Peas}

An important factor in the successful raising of garden peas is that the smooth-seeded type are not easily damaged by light frost. Because of this they may be planted early in the spring - practically as soon as weather conditions permit preparation of the ground. They may be grown in almost any ordinary soil. The best soil is sandy loam, well drained, and rich with rotted manure. To give continuous supply throughout the growing season make successive plantings from one to two weeks apart. For the earliest crops select the smoothseeded varieties of quick maturity. These varieties require no supports. For later crops select the large, wrinkled varieties.

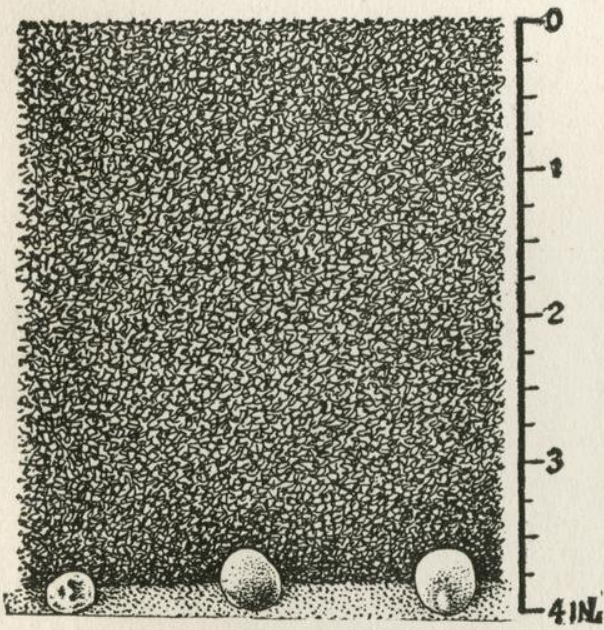

Fig. 19-Peas, planted properly, at depth of 4 inches.

As soon as plants break through the ground, cultivate. Continue to do this three or four times a week until the vines lop over.

Peas should be planted in trenches 4 inchese deep, the seed being covered with 2 to 3 inches of soil. From 1 to 2 pints of seed will plant
100 feet of row. As the plants grow, gradually fill in the trench around them. Let the vines of the tall varieties grow up on brush or poultry wire. The rows of peas should be 3 to 4 feet apart, but if the space is small it is desirable to plant double rows 1 foot apart, placing the brush between these rows.

\section{Peppers}

Set young plants from seed box 18 inches apart in row. Pepper plants are tender and should not be set out until the ground is warm.

\section{Potatoes}

For special instructions on Irish and Sweet Potatoes see pages 12 and 13.

\section{Pumpkin}

Plant in hills 8 to 10 feet apart, using 8 to 10 seed to a hill. Plant seed 1 inch deep. Later thin to 2 or 3 plants to a hill.

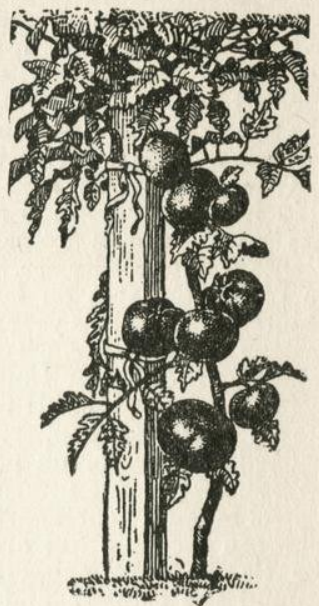

Fig. 20-A tomato plant should be tied with a strip of cloth, at a height of ten inches, again at about 18 inches and again at about 26 inches. The plant here pictured is a good one from which to save seed.

\section{Radishes}

Planted and grown the same as carrots.

\section{Rhubarb}

Procure roots from a neighbor or dealer as seed planting is not advised. Set them 3 to 4 feet apart, in rows or next to fence. Use manure freely.

\section{Salsify or Oyster Plant}

Also called vegetable oyster. Grown like carrots. Plants must be thinned to 3 inches apart.

\section{Spinach}

Sow seed thickly 1 inch deep in rows 12 to 18 inches apart, for both early spring and fall crops.

\section{Squash}

Grown the same as cucumbers or muskmelon, except that the hills of Hubbard squash should be 7 to 9 feet apart.

\section{Swiss Chard}

Sow seed $1 / 2$ inch deep. Thin out when necessary.

\section{Tomatoes}

Tomatoes form one of the favorite crops of the home garden, as they will grow in all types of soil. Sandy loam, with plenty of humus, is ideal for growing tomatoes. 
If plants are grown in seed flats, hotbeds or cold frames, follow the directions for transplanting given on pages 9 and 10 . Plants suitable for setting out should be 4-6 inches high, having a thick stem and dark green leaves. Begin cultivation as soon as the plants are set. Cultivate deeply and close to plants at first but later cultivation should be more shallow to prevent injury to roots. Cultivate frequently to keep the soil loose over the surface, so preventing evaporation. Always cultivate after a rain.

When preparing seed flats, hotbeds, or cold frames for tomato seed, use soil which has never grown tomatoes. This insures plants free from disease. It is not advisable to plant tomatoes on land which has been planted the previous year with white potatoes, melons or tomatoes. To plant on such soil increases the danger from disease and pests.

It is always advisable to train the plants to stakes or other supports. They may be trained on wires or on poultry wire fastened on posts set about fifteen feet apart in rows. Barrel hoops a foot apart fastened to stakes eighteen inches apart are some times used. To tie plant to support, loop the string around the support and tie it under a leaf stem. Remove all side branches at the axil of the leaves as soon as they appear. Do not remove flower clusters. When the plant has reached a height of 5 feet cut off the top.
When three or four clusters of fruit have formed and some of the fruit is as large as a silver dollar prune the leaves at the base one half. This hastens ripening.

Once a month apply a little commercial fertilizer or compost around each plant. Avoid the use of fresh or unrotted manure as this produces too much leaf growth, the fruit does not set and disease is encouraged.

\section{Turnips}

For early spring, plant $1 / 4$ ounce of seed to 50 feet of row, sowing them $1 / 2$ inch deep, in rows 1 foot or more apart. For fall crop $1 / 4$ ounce of seed to 50 feet of row, $1 / 4$ inch deep, or make the rows 8 to 10 inches wide and scatter seeds thinly in broad rows.

\section{Vegetable Marrow}

Plant 6 or 8 seed to a hill, one inch deep, in hills 8 to 9 feet apart. Thin to 2 plants to hill. Give the same care as for pumpkins. The young and tender vegetable marrow may be baked whole like sweet potatoes or may be sliced and fried like eggplant, or boiled like summer squash.

\section{Watermelon}

Plant 1 inch deep, 8 or 10 seed to each hill, the hills 10 feet apart. Later thin to 2 plants to each hill.

Watermelons require much room and are not recommended for small gardens.

\section{DISEASE AND INSEGT PREVENTION}

Every garden is subject to attack from insects and diseases. Your garden may not be attacked, but it is wise to take advance precautions. Spraying at occasional intervals from the time the plants have made their start until they are harvested is worth while. A hand sprayer should be used to distribute the necessary solutions on the plants. Such sprayers may be bought in various types. Some of them may be bought for a dollar or less and others range up to the neighborhood of $\$ 10$ for the small, compressed air type. The simplest and cheapest type is the small atomizer sprayer with hand pump and with glass receptacle
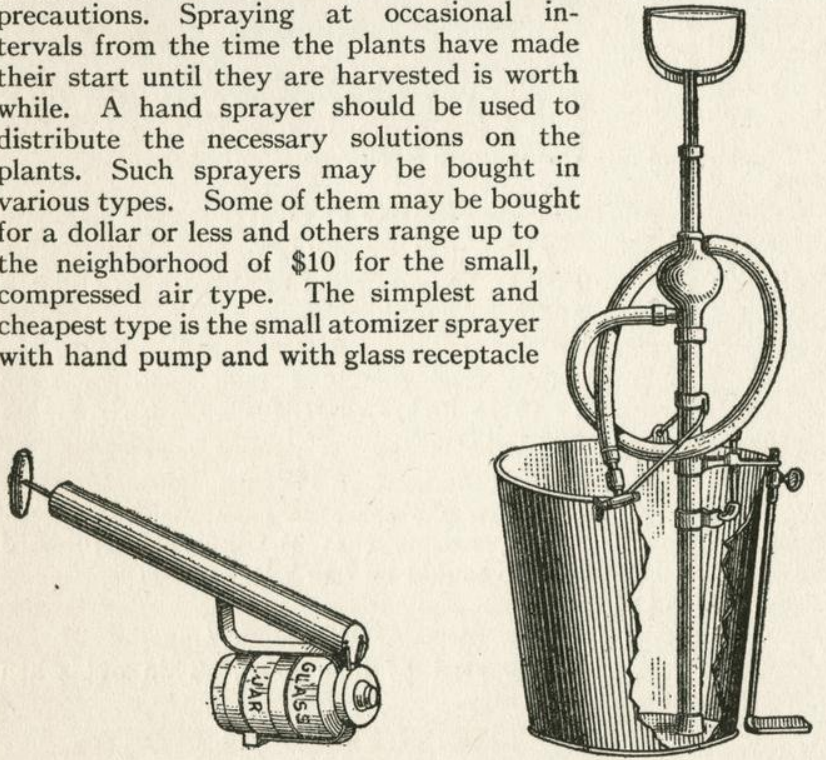

for holding mixture. (Figure 21.) Another type, costing a little more, is the bucket pump. (Figure 21.) If you have no spray pump a

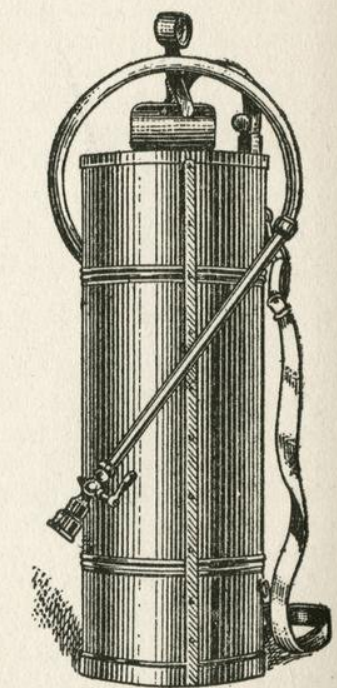

Fig. 21-Some of the best types of sprayer. At the left is a hand sprayer, which is one of the most satisfactory for the small garden. The glass receptacle is better than metal. This sprayer can be bought for from 50 cents to $\$ 2.00$. In the center is a bucket sprayer which costs about $\$ 5.00$. At the right is a compressed air sprayer, which is highly efficient and costs from $\$ 5.00$ to $\$ 10.00$. One sprayer may be used by several families, or by community gardeners, reducing the cost to each user. 
good substitute is the whisk broom, for spattering the spray on plants. After using, wash out pump and hose as some sprays will corrode metal and others will rot hose. The ordinary sprinkling pot may be used to apply mixtures, but this is wasteful.

\section{Buy Spraying Materials Early}

Early purchase of spraying materials is important. The supply will be limited and the demand large. Make a list of the materials you will need, with amounts, and place your order immediately. If you have equipment from last season place your order early for repair parts for pump, hose or nozzle, especially extra couplings and hose splicers for burst hose. If you delay until the spraying season arrives you are likely to fail to procure your supply. By joining with friends or neighbors and buying in quántities you can procure materials at lower prices than if buying alone.

For home mixing the poisons and chemicals required for sprays and other remedies and preventives can be bought at a drug or seed store. The mixtures ready prepared can be bought at a seed store.

\section{Diseases}

The ordinary blights are usually overcome by spraying with Bordeaux mixture, made as indicated in the next paragraph. There are some diseases, however, which cannot be overcome, and when trouble appears that does not yield to treatment the affected plants should be taken up and burned to prevent the spread of the infection to others.

\section{Bordeaux Mixture}

Copper Sulphate, Blue Stone or Blue

Vitriol............................ ounces Lump Lime or Hydrated Lime............. ounces Water...................... $1 / 2$ gallons

To make Bordeaux mixture procure the ingredients at a drug or seed store. If lump lime is used it must be fresh. Instead of lump lime some authorities prefer fresh hydrated lime as being just as good and at the same time much simpler to use, needing only to be stirred into the water. Hydrated lime is lime to which enough water to dryslake it has been added by the manufacturer. It is a powder and does not require slaking.

For making or holding Bordeaux mixture use containers of wood, glass or earthenware. In one container dissolve the copper sul- phate in about one-half gallon of hot water and then dilute with enough cold water to make a total of $11 / 4$ gallons; or wrap the copper sulphate in a small piece of cheesecloth, fill a quart jar with cold water and suspend the copper sulphate into the top of the water; in a couple of hours it will be dissolved. In another vessel slake the lime and dilute it with enough water to make $11 / 4$ gallons. If hydrated lime is used simply mix it with water. Then pour these two solutions together, pouring the solution of copper sulphate slowly into the mixture of lime and water, stirring vigorously while this process is under way. The stirring insures proper mixing of the two.

Bordeaux mixture may be purchased in concentrated form from seedsmen, but the

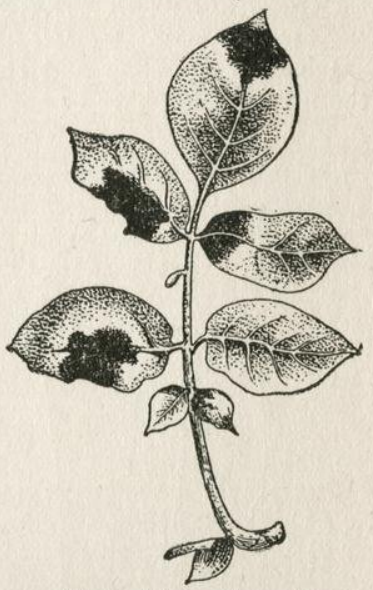
Fig. 22 -Potato blights and their effect. At the left are shown leaves
afflicted with early blight, indicated by brown spots with concentric rings. At the right is shown late blight, with dark brown spots looking
ring

homemade mixture is better and cheaper. Do not make more at one time than will be needed within a short time. The mixture is better and more effective if made fresh for each spraying.

\section{Sulphur}

For the control of mildew, pulverized sulphur or flowers of sulphur, procured at a drug or seed store, is dusted full strength on the diseased plants. A tin can with small holes punched in the bottom makes a good sifter for this purpose, or a cheap flour sifter may be used. The holes in a flour sifter are the proper size for this purpose.

\section{THE SUCKING INSECTS}

For the destruction of insects which suck the sap of plants, such as the true bugs and the plant lice, or aphids, it is necessary to 
use a mixture which kills by contact or substances which smother. Aphids, or plant lice, usually collect on the underside of leaves, causing them to crumple. This crumpling causes the edges of the leaves to turn down, protecting the aphids. Badly crumpled leaves should be picked and burned. In spraying be sure to apply the spray to the underside of the leaves. Otherwise the edges will serve as protection and prevent the spray from reaching the entire plant effectively.

\section{Nicotine Sulphate Solution}

To destroy the sucking insects use nicotine sulphate solution, made as follows:

Nicotine sulphate. ............ 1/2 ounce Laundry or other soap..............

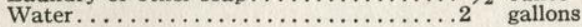

Dissolve the soap and then add this and the nicotine sulphate to the water.
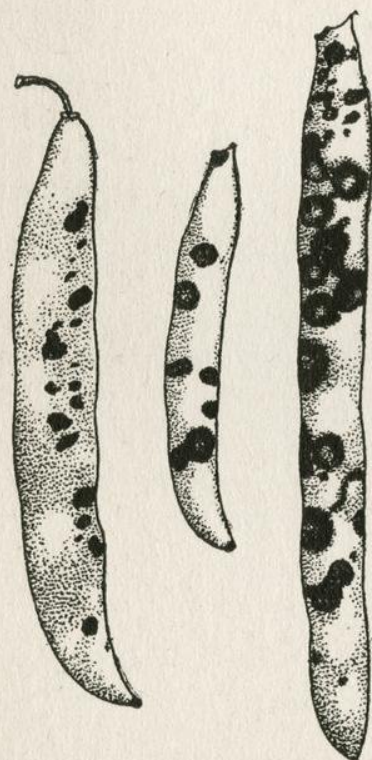

Fig. 23-Bean anthracnose is indicated by dark sunken scab-like spots on pods. There are also spots on leaves.

\section{Bordeaux and Nicotine Sulphate Combination}

A combination spray for plant diseases and sucking insects is made thus:

Bordeaux mixture. . . . $\ldots \ldots \ldots \ldots \ldots 2$ gallons Nicotine sulphate................ $1 / 2$ ounce Laundry or other soap................ $1 / 2$ ounce

\section{THE EATING INSECTS}

The eating insects, or those which eat fruit or foliage, may usually be killed by using a spray of poisonous solution or by dusting poison powders on the plants attacked. Arsenate of lead, procured at a drug or seed store, is a favorite poison for this purpose, and may be used in spray or powder, but it must be handled with care as it is poisonous to human beings. It should never be applied to vegetables that are soon to be used, nor on cabbage or cauliflower after the heads have begun to form. As an added precaution wash carefully all vegetables before using, whether they have been sprayed or not.

\section{Arsenate of Lead Solution}

Arsenate of lead spraying solution is made by mixing 1 ounce of arsenate of lead powder (or 2 ounces of paste) with 6 quarts of water. If the arsenate of lead is used in paste form instead of powder mix 2 ounces with 6 quarts of water. The powder is more easily weighed and handled. Keep the mixture well stirred while spraying, to insure even distribution.

To apply arsenate of lead in dry form mix 1 ounce of the powder with 3 pounds of airslaked lime, dry road dust or ashes finely sifted. Use a sifter for dusting this onto the plants, while the plants are wet with dew or rain.

\section{Bordeaux-Arsenate of Lead Combination}

Spraying with a combination of Bordeaux mixture and arsenate of lead every two weeks is a wise safeguard against both disease and eating insects. To make this combination spray use Bordeaux mixture instead of water when preparing the arsenate of lead. By using a combination spray half the labor of spraying is saved.

In spraying cabbage and cauliflower with Bordeaux and arsenate of lead before the heads form, a little soap mixed with the arsenate of lead will make it stick better. Shave the soap, add a small quantity of water and boil until the soap is dissolved or put it in cold water and stir occasionally until dissolved. Cool and stir into the arsenate of lead solution.

Paris green has long been used for protection, but arsenate of lead is now used much more extensively and is considered better.

\section{Poisoned Bait}

Poisoned bait is useful against cutworms and slugs. Small portions of the bait should be placed around plants subject to attack by them. The pests feed at night and hide under chips or other objects during the day. Bait should be placed beneath these. Poisoned bait may be made at home thus:

Wheat bran ................. pound White arsenic, powdered........... $1 / 2$ ounce

Cheap sirup.................. or 2 ounces Water to make a thick mash of the mixture. 
The bran and the white arsenic should be mixed. Dilute the sirup with a little water and pour this over the bran and white arsenic. Stir well. Add enough water to make a thick mash.

\section{Liquid Poisoned Bait}

Sodium Arsenate. .............. ounce Water.................... $4 \ldots \ldots$ quarts Molasses...................1 pint

Dissolve the sodium arsenate in boiling water and add the molasses. Flavor by adding chopped pieces of vegetable of the kind which is to be sprayed. Apply with a whisk broom.

\section{Removing Insects by Hand}

The larger eating insects may be removed by hand or knocked off into a pan of water on the surface of which a small quantity of kerosene is floating. Insects collected by hand should be destroyed immediately.

For slugs and snails sprinkle any form of lime over plants and around where they occur.

\section{Some Other Forms of Protection}

One form of protection against cutworms is a collar 2 inches wide made of stiff paper, placed around the stem of the plant and with its lower edge inserted in the ground, to prevent the pests from reaching both stem and upper part of root.

Small frames covered with mosquito netting or cheesecloth set over young plants will protect them.

\section{GUARD AGAINST DISEASES AND INSEGTS}

An ounce of prevention is worth a pound of cure in the matter of controlling diseases and insects. Clean garden soil aids in keeping out insects and disease. All plants purchased should be healthy and free from disease. The roots should not be swollen or knotted. Treat Irish potatoes for scab before planting. Do not plant cabbage having clubroot or sweet potatoes affected with black-rot.

Many insects carry disease and spores from one plant to another as well as attacking the crops directly.

Avoid wounding or bruising plants and vegetables when cultivating and harvesting them, to prevent certain insects from gaining access to them.

Have order, neatness and cleanliness in the garden. In the fall turn under promptly, all vegetation so that insects and disease spores may not find winter quarters. Keep down all weeds, as a great many insects feed naturally upon them. All diseased plants which remain at the end of the season should be burned, as should all rubbish which is of such character that it will not decay and is therefore not useful in making compost. This includes trash, sticks and the like. It may seem like a waste of vegetable matter to burn the dead tomato vines, bean vines and other plant tops which have been diseased, but this should be done because to save or compost these for fertilizer would simply be maturing and saving millions of disease spores which would be on hand ready to attack the crops next year. More than this, a clean garden appeals to the eye and to the pride of the owner as a winter landscape.

Corn stalks, cabbage leaves and stumps, beet tops if not canned, and other healthy plants should be saved for mulching or be added to the compost heap.
The remnants of vegetable matter, which are not infected with disease or insects, should be made into compost heaps for the coming year and covered with stable ma-

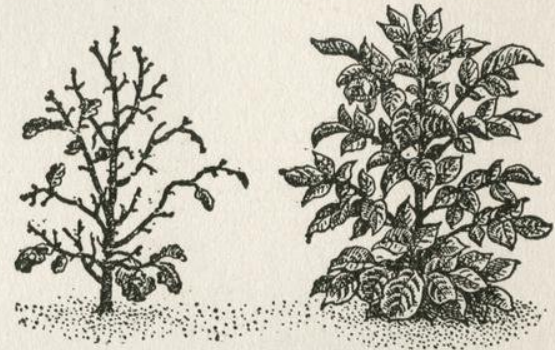

Fig. 24-Emphasizing the importance of spraying. On the left is a potato plant which was not sprayed. The ravages of the potato bug are plainly shown. On the right is a plant which was properly sprayed as a preventive measure.

nure and dirt to hasten decay, as decayed vegetable matter enriches the soil. (Directions for making a compost heap are given on page 5). Plowing or deep spading in the fall is important, as it breaks up the winter homes of underground insect pests. Rotation of crops also lessens the danger of attacks from insects and diseases.

\section{TAKE NO GHANCES}

Too much emphasis cannot be placed on the need for taking precautions against diseases and insects. Familiarize yourself with such diseases and insects as prevail in your neighborhood on the crops you plan to raise. Then provide yourself in advance with remedies and equipment. Watch carefully for first signs of trouble and apply remedies at once. Inspect your garden every two or three days. 


\section{PREVENTIVES AND REMEDIES}

NOTE : It is important that immediate attention be given insects and diseases as soon as they appear. Delay in spraying or removal may prove fatal.

\section{ASPARAGUS}

Rust-(Rusty appearance of leaves and stems).Procure rust resistant variety, such as Reading Giant or Palmetto.

Beetles-(Eat young stems and leaves).

Remedy: On young plants spray with arsenate of lead when pests appear, repeating 10 days later and again 10 days later if necessary. Add an ounce of laundry soap per gallon of spray to make it stick to the foliage. Do not use arsenate of lead on new stems used for food during cutting season. On old plants, spray after cutting season. Nicotine sulphate sprayed on the young insects will kill all it hits.

\section{BEETS}

Leaf spot-(Reddish and purple spots, turning ashy gray).- - Usually not affecting garden beets.

Remedy: Spray with Bordeaux mixture when plants are 3 to 4 inches high, repeating 2 and 4 weeks later.

Web worm-(Eats the leaves).

Remedy: Spray with arsenate of lead when worms appear; repeat when necessary.
Spinach aphis-(Sucks sap from leaves)

Remedy: Spray with hicotine sulphate when pests appear and repeat when necessary. In order to strike the aphids the spray must be directed against the undersides of the leaves.

Beet-root aphis - (Sucks sap from roots).

Remedy: Pour a small amount of nicotine sulphate spray around roots and repeat if necessary.

\section{BUSH BEANS}

Anthracnose-(Dark, sunken spots, scab-like, on pods; spots on leaves).-Pick and burn diseased pods. In saving seed discard those from diseased plants, as seed carry the infection.

Leaf beetles-(Very small, dark or pale stripes; eat leaves).

Remedy: Spray with arsenate of lead when pests appear, repeat in 10 days and later if necessary. Bordeaux mixture repels but does not kill.
Aphids or plant lice-(Suck sap from plant and make leaves crumple).

Remedy: Spray with nicotine sulphate when pests appear, repeating when and as often as necessary. Crumpled leaves protect lice from spray, and should be picked and burned. Apply spray to underside of leaves, to strike aphids.

Bacterial blight-(Water soaked spots on leaves and pods).-No satisfactory remedy. Pull up and burn plants.

Downy Mildew-(thick white growth).-Burn all diseased pods. Spray with Bordeaux mixture, repeating every ten days if necessary.

\section{CABBAGE AND CAULIFLOWER}

Club root-(Root swells and decays).-Pull up and burn plants.

Preventive: In spring apply $1 \mathrm{lb}$. lime to each $8 \mathrm{sq}$. ft. of ground before setting out plants.

Black rot-(Leaves turn yellow, then brown and black and decay. Pull up and burn plants.)

Preventive: Soak seed 15 minutes in solution made of $1 / 4 \mathrm{oz}$. formalin and 3 pints water; rinse in clean water; plant at once.

Yellows-(Leaves turn yellow, then brown, and drop). Pull up and burn plants.

Preventive: Treat seed as for black rot.

Cabbage worms - (Eat leaves)

Remedy: When worms appear spray with arsenate of lead, repeating if necessary before heads form. Add an ounce of laundry soap per gallon of spray to make it stick to the leaves. Do not use arsenate of lead later than 3 weeks before using or marketing cabbage.

Aphids or lice-(Suck sap from leaves).

Remedy: Spray with nicotine sulphate solution when pests appear; repeat if necessary.

Cabbage looper-(Eats leaves).

Remedy: Treat as for cabbage worms.
Cabbage Magots - (Tunnel inside of roots).

Preventive: When plants are set out take a piece of tarred building paper 2 or 3 inches in diameter, cut a slit from one side to center, and 4 or 5 slits at center. Fit this around stem by slipping plant through the long slit, and press paper firmly against ground, to prevent young maggots from reaching root.

Black leg-(Diseased, sunken areas on stem, leaf stem and leaves, plant becoming purplish).There is no remedy. Pull up and burn plants.

Preventive: Disinfect seed for 10 minutes with 1 tablet of corrosive sublimate mixed in 1 pint of water.

Cutworms-(Dark colored, eat young plants off at surface of earth).

Remedy: Spread poisoned bran mash over ground before setting out plants; spread around plants when set. Afterwards spread poisoned bait around plants as necessary to control worms. It is wise to wrap paper around stem from leaves to root just before setting out. Cutworms are especially abundant where sod has grown.

\section{CELERY AND GELERIAG}

Blight or leaf spot-(Gray or brown spots, drooping stems).

Remedy: Spray young seedlings, in seed box or seed bed, with Bordeaux mixture. Spray again as soon as set in garden, repeating 10 to 14 days later. Repeat again if necessary. Spraying in seed bed must not be neglected if disease appears.

\section{SWISS CHARD}

Leaf spot-(Symptoms same as with beets).

Remedy: When disease appears, spray as directed for beets. (Usually no spraying will be found necessary). Wash sprayed leaves well before using.
Damping off-(Small seedlings dying in seed bed). Preventive: Care should be taken to water and partially shade the young seedlings in hot and dry weather. As soon as seed are planted cover bed with thin layer of sand.

\section{SPINACH}

Aphids-(Suck sap from leaves).

Remedy: Spray under side of leaves with nicotine sulphate, when aphids appear. Repeat a second and third time if necessary. 


\section{CORN}

Smut-(Large, black, irregular swellings on ears or tops). The only remedy is to cut off and burn the smut swellings.

Cornear worms-(Bore through husk and eat the young kernels). Kill all worms which are found when husking corn for use.
Cutworms-(A dark worm which cuts plant off at surface of earth when plant is small).

Remedy: Use poisoned bait in the same manner prescribed for cabbage. Repeat if necessary. Being a night worker the cut-worm is usually found in the morning in the ground by cut off plants. Dig out and kill.

Seed Corn Maggot-(Tunnels in seed, sprouts and stems of plants).-Apply liquid poisoned bait with a whisk broom.

\section{CUCUMBERS}

Anthracnose-(Brown spots on leaves).

Remedy: Spray with Bordeaux mixture when plants begin to form vines. Repeat two or three times if necessary, at intervals of 2 weeks.

Downy mildew-(Yellow spots on leaves). Remedy: Treat as for anthracnose.

Wilt-(Leaves droop and wilt quickly).-Pull up and burn plants. Striped beetles act as carriers of this disease and should be controlled carefully.

Stink bug or squash bug-(Sucks sap from leaves and injects an injurious substance).

Remedy: Pick them or shake them into pan of water and kerosene. Destroy egg masses. Place small pieces of boards near hills. The bugs will collect underneath these and may be easily crushed.
Striped beetle or 12-spotted beetle-(Both eat leaves).

Preventive: Cover young plants with protectors of cheesecloth or wire gauze.

Control: Mix arsenate of lead in the Bordeaux mixture which is used for diseases. Another remedy is to cover leaves with tobacco dust. Treatment should be given as soon as beetles appear, or when covers are removed. Repeat 5 days later and again 5 days later, with further repetitions when necessary.

Vine borer-(Worm which bores into vine at surface of earth).

Remedy: Carefully cut the vine lengthwise, remove borer and kill. As plants grow throw earth over vine at every other joint, in order that new roots may form and to keep the vine growing.

\section{EGGPLANT}

Blight or wilt-(Whole plant wilts).-No remedy. Pull up and burn plants.

Flea beetle-(Small jumping beetle which eats leaves).

Remedy: Spray with Bordeaux mixture and arsenate of lead combination.

\section{ONIONS}

Thrips-(Very small sucking insects, which cause leaves to turn a silvery color or whitish, and later to curl and twist).

Remedy: Spray with nicotine sulphate solution when pests appear, repeating once or twice as necessary.

Cutworms-(Dark worms which attack onions as they do corn).

Remedy: Same as with corn.

Onion Magsot-(Eats bulb, inducing decay).Remedy: Apply liquid poisoned bait with a whisk broom.
Anthracnose-(Dark sunken spots in fruit; cracks in leaves).

Remedy: Spray with Bordeaux mixture when plants are set, repeating 10 days later and again 10 days later.

\section{PEAS}

Powdery mildew-(Covers plant with powdery white growth).

Remedy: Use pulverized sulphur or flowers of sulphur, or Bordeaux mixture, by sprinkling on plants when mildew appears, just before bloom appears. Repeat if necessary two weeks later and again 2 weeks later.

Pea Aphis.

Remedy: Same as for bean aphis.

\section{POTATOES}

Early blight-(Brown spots, with concentric rings on leaves. Worst in moist weather.)

Remedy: Spray with Bordeaux mixture when lants are 6 inches high. Repeat two weeks later and again two weeks later.

Late blight-(Dark brown spots on leaves, appearing water soaked and not having concentric rings. The spots become yellow and the leaves die. Worst in hot, sultry weather, August and September. Lives over winter in seed potatoes.)

Remedy: Same as for early blight.

Colorado potato beetle-(The common potato bug, which eats leaves).

Remedy: Spray with arsenate of lead when beetles appear. Repeat when and as often as is necessary. Hand picking is effective, as is also knocking the bugs into a pan of water containing some kerosene.

Blister beetle-(Long black potato bug or old fashioned potato bug. Eats leaves.)

Remedy: Same as for Colorado potato beetle.

Flea beetle-(Small, jumping insect which eats leaves, usually appearing when plant is small).

Remedy: Spray as for Colorado potato beetle.

\section{SWEET POTATOES}

Beetles-(Eat foliage).

Control: Spray with arsenate of lead and lime.

Cutworms-(Worms which cut plants off at the surface of earth).

Control: Use poisoned bait in the same manner as prescribed for cabbage.

\section{PUMPKIN}

This plant is subject to the same diseases and insects as cucumber, and should be treated the same way.
Black Rot-(Black, sunken and nearly circular spots appear on tubers. It begins as small spots on stems and spreads until the stems rot off.)

Control: Use only sound healthy tubers to produce healthy plants.

\section{RUTABAGA}

This plant is subject to the same pests as cabbage and should be treated the same way. 


\section{AVOID WASTE-STORE, GAN OR DRY}

The home gardener must remember that his responsibility does not end with the maturity and harvesting of his crops. Authorities are agreed that after several years of war 1919 will see the world's food shortage more marked than ever before. For this reason the matured crops must be considered as only a beginning. Garden products must be put by for winter use in order that the abundance of the growing season may be made to supply the needs of the months of non-production.

EVERY POUND OF THE SUMMER'S CROP THAT CAN BE SPARED FROM THE SUMMER DIET MUST BE STORED, CANNED OR DRIED IF AMERICA IS TO GIVE THE WORLD THE FULL WORTH OF HER HOME GARDEN PRODUCTION. NOTHING MUST GO TO WASTE.

Vast quantities of foodstuffs must be sent overseas to feed the people of starving Europe. In order that a sufficient volume of exportable food may be available for this purpose it is imperative that the home-grown foodstuffs be made to supply this country's household needs, as far as possible, for the coming winter.

For home storage complete directions are given in Part II of this book.

For home canning and home drying full details are given in a manual issued by the Commission. The book also contains directions for jelly making, the making of fruit butters, pickling, fermentation and salting.

For a copy of the book on canning, drying, etc., write to the National War Garden Commission, Washington, D. C.

\section{RADISH}

Cabbage maggot-(Small worm which tunnels into the radish).

Preventive: Sprinkle tobacco dust along row when seed is planted, or spread sand on which kerosene has been sprinkled along the row when plants are small. Burn all plants that may be infested.

\section{TURNIP}

Subject to the same diseases and insects as cabbage. and should be treated the same way.

\section{RHUBARB}

Flea beetle-(Eats small'holes in the leaves).

Remedy: Same as for flea beetle of potato applied when beetles first appear and repeated when necessary.

\section{SQUASH}

This plant is subject to the same diseases and insects as cucumbers and should be treated the same way.

\section{TOMATOES}

Leaf spot, or blight-(Leaves become spotted, turn yellow and drop; stems dry up and fruits drop).

Remedy: Spraying is not entirely effective but is helpful. Spray with Bordeaux mixture whi'e plants are small in seed box or seed bed. Repeat soon after transplanting to garden and repeat again 3 weeks later and every 3 weeks while disease exists.

Fruit rot-(Decay begins at blossom end of fruit).

Preventive: In the absence of an effective remedy the only safeguard is to cultivate well and be careful to water as the plants need.

Anthracnose-(Sunken, discolored spots in fruit, followed by decay).

Remedy: Same as for leaf spot.
Wilt-(Causes plant to wilt and die).-Pull up and burn plants.

Tomato worms-(Large green naked caterpillar, which eats leaves).

Remedy: Pick by hand and destroy, or spray with lead arsenate solution. (These worms do not often appear in large numbers.)

Cutworms-(Dark worms which cut plants off at the surface of earth).

Remedy: Same as with cabbage.

Flea beetle-(Small jumping beetle which eats small holes in leaves).

Remedy: Same as with potatoes.

\section{WATERMELON}

Anthracnose-(Brown spots on leaves; small sunken spots on fruit).

Remedy: Spray with Bordeaux mixture when melons are half grown. Repeat 10 days later and again if necessary.
Insects-This plant is subject to the same insects as cucumber and should be treated the same way.

\section{YOUR QUESTIONS WILL BE ANSWERED}

This Commission maintains a Department of Household Science which will welcome questions connected with Gardening, Canning, Drying and kindred subjects. Technically trained workers, of practical experience, will give prompt attention to all inquiries. Address Department of Household Science, National War Garden Commission, Washington, D. C. 


\section{PLANTING TABLE}

\begin{tabular}{|c|c|c|c|c|c|c|}
\hline \multirow{2}{*}{ Vegetable } & \multirow{2}{*}{$\begin{array}{c}\text { Quantity } \\
\text { required } \\
\text { for } 100 \\
\text { feet of row }\end{array}$} & \multicolumn{2}{|c|}{$\begin{array}{l}\text { Distance Apart } \\
\text { In Inches }\end{array}$} & \multirow{2}{*}{$\begin{array}{l}\text { Depth of } \\
\text { Planting } \\
\text { Inches }\end{array}$} & \multirow{2}{*}{ Time of Planting } & \multirow{2}{*}{$\begin{array}{l}\text { Mature } \\
\text { (In days, } \\
\text { except as } \\
\text { noted) }\end{array}$} \\
\hline & & Rows & In Row & & & \\
\hline $\begin{array}{l}\text { Asparagus, seed.... } \\
\text { Asparagus, plants... } \\
\text { Beans, snap....... } \\
\text { Beans, pole....... } \\
\text { Beans, Lima, bush.. }\end{array}$ & 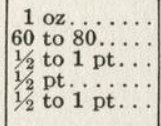 & $\begin{array}{l}12 \text { to } 24 \ldots \\
36 \text { to } 48 \ldots \\
20 \text { to } 24 \ldots \\
36 \text { to } 48 \ldots \\
18 \text { to } 24 \ldots\end{array}$ & $\mid \begin{array}{l}3 \text { to } 5 \ldots \ldots \ldots \\
15 \text { to } 20 \ldots \ldots \ldots \\
4 \text { to } 6 \ldots \ldots \ldots \\
4 \text { ills } 24-36 \ldots \ldots \\
4 \text { to } 6 \ldots \ldots \ldots \ldots\end{array}$ & $\begin{array}{l}1 / 2 \text { to } \\
8 \text { to } \\
1 \ldots \\
1 \ldots \\
1 \ldots\end{array}$ & 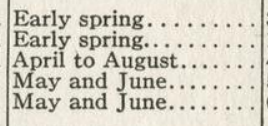 & $\begin{array}{l}3 \text { to } 4 \text { yrs.. } \\
1 \text { to } 3 \text { yrs.. } \\
40 \text { to } 65 \ldots \\
50 \text { to } 80 \ldots \\
60 \text { to } 90 \ldots\end{array}$ \\
\hline $\begin{array}{l}\text { Beans, Lima, pole... } \\
\text { Beets.............. } \\
\text { Brussels sprouts.... } \\
\text { Cabbage, early.... }\end{array}$ & $\begin{array}{l}1 / 2 \mathrm{pt} \\
2 \mathrm{oz} \\
1 / 4 \mathrm{oz} \\
1 / 4 \mathrm{oz}\end{array}$ & $\begin{array}{l}36 \text { to } 48 . . \\
12 \text { to } 18 \ldots \\
24 \text { to } 30 . . \\
24 \text { to } 30 . .\end{array}$ & $\begin{array}{l}\text { Hills } 24 \text { to } 36 \ldots \\
5 \text { or } 6 \text { to } \mathrm{ft} \ldots \ldots \\
16 \text { to } 24 \ldots \ldots \ldots \\
12 \text { to } 18 \ldots \ldots \ldots\end{array}$ & $\begin{array}{l}1 \\
1 \\
1 / 2 \ldots \\
1 / 2 \ldots\end{array}$ & 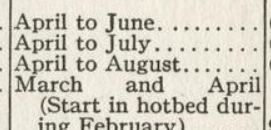 & $\begin{array}{l}60 \text { to } 80 \ldots \\
60 \text { to } 80 \ldots \\
60 \text { to } 80 \ldots\end{array}$ \\
\hline $\begin{array}{l}\text { abbage, late...... } \\
\text { arrot............. } \\
\text { auliflower..... }\end{array}$ & $1 / 4$ oz $\ldots \ldots$ & 24 to 36. & 16 to $24 \ldots \ldots$. & $1 / 2 \ldots$ & druary)...... & $\begin{array}{l}90 \text { to } 130 \ldots \\
90 \text { to } 130 \ldots \\
75 \text { to } 110 \ldots\end{array}$ \\
\hline Celery & 1 packe & 18 to 36 . & 4 to $8 \ldots \ldots$ & $1 / 8$. & $\begin{array}{l}\text { April to June (Start in } \\
\text { hotbed during Feb- } \\
\text { ruary or March)..... } \\
\text { May and June. (Start } \\
\text { in hotbed during }\end{array}$ & 100 to 130 \\
\hline & $1 / 2$ oz $\cdots \cdots \cdots$ & $\begin{array}{l}18 \text { to } 24 \ldots \\
30 \text { to } 36\end{array}$ & & & $\begin{array}{l}\text { March or April) } \\
\text { April to July.... }\end{array}$ & \\
\hline & $\begin{array}{ll}7 / 2 & \mathrm{p} \\
1 / 2 & 0\end{array}$ & 12 to 18 . & & $\begin{array}{l}1 \text { to } \\
1 / 2 \text { to }\end{array}$ & & \\
\hline & & $\begin{array}{l}48 \text { to } 72 . . \\
24 \text { to } 36 . .\end{array}$ & $\mid \begin{array}{l}48 \text { to } 72 \ldots \ldots \\
18 \text { to } 24 \ldots\end{array}$ & & April to July ........... & 60 to $80 \ldots$ \\
\hline $\begin{array}{l}\text { ndive...is.... } \\
\text { Corse-radish........... }\end{array}$ & 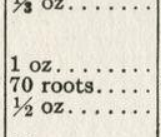 & $\begin{array}{l}18 \ldots \\
24 \text { to } 30 . . \\
18 \text { to } 24 \ldots\end{array}$ & $\begin{array}{l}8 \text { to } 10 \ldots \ldots \ldots \\
4 \text { to } 6 \ldots \ldots \ldots \ldots \\
6 \text { to } 8 \ldots \ldots \ldots \ldots\end{array}$ & $\begin{array}{l}1 / 2 \ldots \ldots \\
3 \text { to } 4 \ldots \\
1 / 2 \ldots \ldots\end{array}$ & 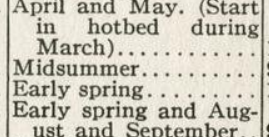 & $\begin{array}{l}100 \text { to } 140 . \\
90 \text { to } 180 . . \\
1 \text { to } 2 \text { yrs.. } \\
90 \text { to } 120\end{array}$ \\
\hline on $\ldots \ldots \ldots \ldots$ & 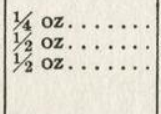 & $\begin{array}{l}18 \text { to } 24 \ldots \\
12 \text { to } 18 \ldots \\
72 \text { to } 96 \ldots\end{array}$ & $\begin{array}{l}4 \text { to } 6 \ldots \ldots \ldots \\
4 \text { to } 6 \ldots \ldots \ldots \\
\text { Hills } 72 \ldots \ldots \ldots\end{array}$ & $\mid \begin{array}{l}1 / 2 \ldots \cdots \cdots \\
1 / 2 \ldots \cdots \cdots \cdots \\
1 \ldots \ldots \cdots\end{array}$ & $\begin{array}{l}\text { ust and September.. } \\
\text { April to August....... } \\
\text { March to September... } \\
\text { April to June. (Start } \\
\text { early plants in hot- }\end{array}$ & $\begin{array}{l}90 \text { to } 120 \ldots \\
60 \text { to } 80 \ldots \\
60 \text { to } 90 \ldots\end{array}$ \\
\hline & 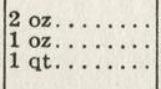 & $\begin{array}{l}36 \text { to } 48 \ldots \\
12 \text { to } 18 \ldots \\
12 \text { to } 18 \ldots\end{array}$ & $\begin{array}{l}24 \text { to } 30 \ldots \ldots \\
5 \text { or } 10 \text { to } \mathrm{ft} \ldots \\
4 \text { or } 5 \text { to } \mathrm{ft} \ldots .\end{array}$ & $\mid \begin{array}{l}1 \text { to } 2 \ldots \ldots \\
1 / 2 \text { to } 1 \ldots \ldots \\
1 \text { to } 2 \ldots \ldots\end{array}$ & $\begin{array}{l}\text { during March).. } \\
\text { and June......... } \\
\text { and May } \\
\text { nn and March to }\end{array}$ & $\begin{array}{l}120 \text { to } 150 . \\
60 \text { to } 90 . \\
130 \text { to } 150 .\end{array}$ \\
\hline$\cdots$ & $1 / 4 \mathrm{oz}$. & 12 to 18. & 3 to 6. & & $\begin{array}{l}\text { May . . . . . . . . } \\
\text { tember }\end{array}$ & 90 tc \\
\hline 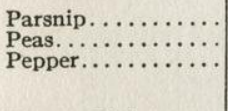 & 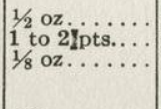 & $\begin{array}{l}18 \text { to } 24 \ldots \\
36 \text { to } 48 \ldots \\
18 \text { to } 24 \ldots\end{array}$ & $\mid \begin{array}{l}4 \text { or } 6 \mathrm{to} f \mathrm{ft} . \ldots \\
15 \text { to } \mathrm{ft} . \ldots \ldots \ldots \\
15 \text { to } 18 \ldots \ldots \ldots\end{array}$ & $\mid \begin{array}{l}1 / 2 \text { to } 1 \ldots \ldots \\
3 \text { to } 4 \ldots \ldots \\
1 / 2 \ldots \ldots \ldots\end{array}$ & $\begin{array}{l}\text { tember } \\
\text { April and May......... } \\
\text { March to June. } \\
\text { May and June. (Start } \\
\text { early plants in hot- }\end{array}$ & $\begin{array}{l}90 \text { to } 120 \ldots \\
125 \text { to } 160 \\
40 \text { to } 80 \ldots\end{array}$ \\
\hline $\begin{array}{l}\ldots \ldots \\
\ldots \ldots \\
\ldots \ldots \\
\ldots \ldots \\
\ldots \ldots \\
\ldots \ldots \\
\ldots \ldots\end{array}$ & $\begin{array}{l}5 \text { lbs } \ldots \ldots \ldots \\
75 \text { slips.... } \\
1 / 2 \text { oz } \ldots \ldots \\
1 \text { oz } \ldots \ldots \ldots \\
33 \ldots \ldots \\
1 / 4 \text { oz } \ldots \ldots \ldots \\
1 / 2 \text { oz } \ldots \ldots \\
1 \mathrm{oz} \ldots \ldots\end{array}$ & $\begin{array}{l}24 \text { to } 36 \ldots \\
36 \text { to } 60 \ldots \\
96 \text { to } 144 . \\
12 \text { to } 18 \ldots \\
36 \text { to } 60 \ldots \\
18 \text { to } 24 \ldots \\
18 \text { to } 24 \ldots \\
12 \text { to } 18 \ldots\end{array}$ & $\begin{array}{l}14 \text { to } 18 \\
14 \ldots \\
96 \text { to } 14 \\
8 \text { or } 12 \text { t } \\
36 \text { to } 48 \\
6 \text { to } 8 \ldots \\
2 \text { to } 4 \ldots \\
7 \text { or } 8 \text { to }\end{array}$ & $\begin{array}{l}3 \text { to } 5 \\
2 \text { to } 3 \\
1 \\
1 \% \cdots \\
* \text { NoT } \\
1 / 2 \text { to } 1 \\
1 / 2 \ldots \cdots \\
1 \text { to } 2\end{array}$ & 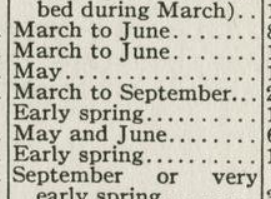 & $\begin{array}{l}100 \text { to } 140 . \\
80 \text { to } 140 \ldots \\
100 \text { to } 130 . \\
100 \text { to } 140 . \\
20 \text { to } 40 \ldots \\
1 \text { to } 3 \text { yrs.. } \\
60 \text { to } 80 \ldots \\
120 \text { to } 180 .\end{array}$ \\
\hline Tomato, plants. & $\begin{array}{ll}1 / 2 & \text { oz } \ldots \\
1 / 2 & \text { oz } \ldots \\
1 / 3 & \text { oz } \\
33 & \text { to } 40\end{array}$ & $\begin{array}{l}36 \text { to } 48 \ldots \\
84 \text { to } 120 . \\
36 \text { to } 48 \ldots \\
36 \text { to } 48 \ldots\end{array}$ & $\begin{array}{l}\text { Hills } 36 \text { to } 48 \\
\mathrm{Hi} \mathrm{l} \text { s } 84 \text { to } 108 . \\
30 \text { to } 36 \ldots \ldots \ldots \\
30 \text { to } 36 \ldots \ldots \ldots\end{array}$ & $\begin{array}{l}1 \ldots \ldots \\
1 \\
1 / 2 \\
\cdots\end{array}$ & 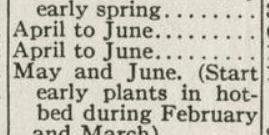 & $\begin{array}{l}30 \text { to } 60 \ldots \\
60 \text { to } 80 \ldots \\
120 \text { to } 160 . \\
100 \text { to } 140 .\end{array}$ \\
\hline $\begin{array}{l}\text { urnip...... } \\
\text { eg. marrow } \\
\text { Vatermelon. }\end{array}$ & $\begin{array}{l}1 / 2 \\
\text { oz } \ldots \\
1 / 2 \\
1 / 2\end{array}$ & $\begin{array}{l}18 \text { to } 24 \ldots \\
96 \text { to } 144 \ldots \\
96 \text { to } 120 \ldots\end{array}$ & $\mid \begin{array}{l}6 \text { or } 7 \text { to } \mathrm{ft} \\
\text { Hills } 96 \text { to } 108 \\
96 \text { to } 120 \ldots \ldots\end{array}$ & $\mid \begin{array}{l}1 / 4 \text { to } 1 / 2 \ldots \\
1 \text { to } 2 \ldots \ldots \\
1 \ldots \ldots \ldots\end{array}$ & 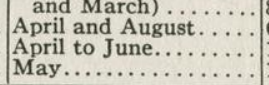 & $\begin{array}{l}80 \text { to } 100 . \\
60 \text { to } 80 . \\
110 \text { to } 140 \\
100 \text { to } 120\end{array}$ \\
\hline
\end{tabular}

* NOTE.-Set rhubarb plants so that growing tips are at surface of ground.

Absolute dates for planting can not be given, because of variations in seasons from year to year and varying climatic conditions in different sections. For general guidance see "When to Plant," on page 10. 


\section{HOME STORAGE MANUAL FOR VEGETABLES AND APPLES}

No form of Food Conservation is more important than the home storage of vegetables for winter use. Canning and drying are essential to the nation's food supply, and should be practised to the fullest possible extent, but they do not take the place of storage. To keep vegetables in their natural state is the simplest form of preparation for winter needs. By taking proper precautions against decay and freezing an abundant supply of certain kinds of fresh vegetables may be kept at minimum expenditure of money and effort.

\section{STORAGE HELPS SOLVE FOOD PROBLEM}

The importance of making provision for winter food needs is even greater this year than it was in 1918. Every pound of foodstuffs that can be spared for export will be needed in Europe for feeding American troops and to prevent the starvation of the domestic and military populations of the Allied nations. Every pound of vegetables stored away for home uses will release exportable food. A nation with a food shortage is a nation in peril. For this reason it is of vital importance that no vegetables of high food value be allowed to go to waste. To save is to be patriotic.

The home gardening campaign conducted by the National War Garden Commission will this year result in the creation of a vast new planting area. The output of these gardens is greatly in excess of immediate needs. Unless proper steps are taken to safeguard the surplus the waste will be prodigious. This Commission will stimulate nation-wide activity in canning and drying. An important purpose of this booklet is to arouse similar interest in the storage of vegetables.

\section{WHAT AND HOW TO STORE}

There are many vegetables which can be stored to good advantage. Included in the list are Potatoes, Beets, Carrots, Parsnips, Onions, Sweet Potatoes, Celery, Salsify, Cabbage, Cauliflower, Brussels Sprouts, Winter Squash, Turnips, Beans and Lima Beans. Good results in storage depend upon:

1 -Ventilation.

2-Regulation of temperature.

3-Sufficient moisture.

4 -Quality of vegetables stored.
For some vegetables satisfactory storage places are afforded by the pantry shelf or attic. For others the cellar is the right place. For others outdoor storage is preferable. This may take the form of pits or banks, or it may be done in hillside caves or cellars.

\section{COMMUNITY STORAGE}

Especially good results may be obtained if several neighboring families will form community clubs to provide storage facilities. In this way very complete provision may be made for handling winter supplies at slight trouble and expense to the individual household.

Community or co-operative storage may be effected in various ways. Several families may join together and construct outdoor cellars or they may join in the use of an available building conveniently located in which vegetables may be stored in large quantities.

\section{CELLAR STORAGE}

Beets
Cabbage
Carrots
Celery

Parsnips
Potatoes
Salsify
Turnips

In a house heated by a cellar furnace vegetables may be stored to good advantage in the cellar. Partition off a small room as far as possible from the heating plant. Two sides of this room should be outside walls. There should be at least one outside window, for temperature regulation and ventilation. The suggested arrangement in Figure 1 shows ventilation afforded by a stove- 


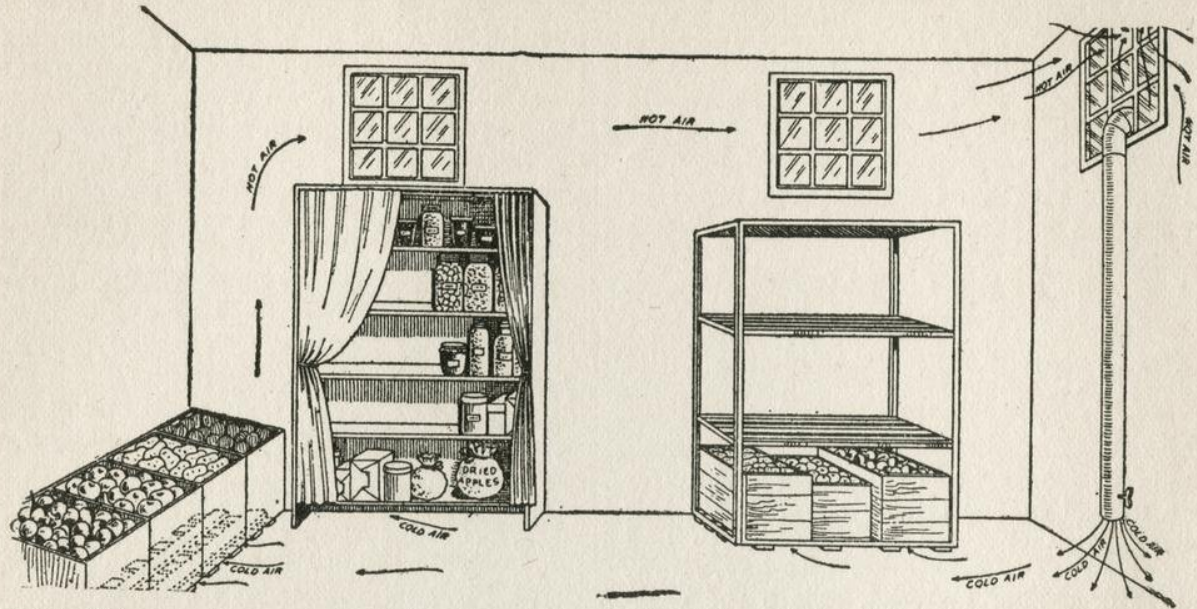

Fig. 1-This suggests an arrangement for storage in a cool cellar. An earth floor is best, as it gives off some mois. ture. If the floor is of concrete it should be covered with 2 or 3 inches of sand and this should be sprinkled with water occasionally. In the drawing a pane in the upper part of one window is shown to be missing. This is to allow the escape of heated air. In severely cold weather close these openings. The stove pipe fitted into the place for one of the lower panes admits cold air. Instead of a stove pipe a wooden flue, made of old boards or parts of boxes, may be used. Bins and boxes should be placed on slats to lift them from the floor and allow circulation. For this same purpose bins and boxes should be at least one or two inches from the wall. Air holes bored in sides and bottom of bins and boxes help circulation. Protect glass jars from light.

pipe inserted through one of the lower panes of the window, to admit cold air and indicates the removal of one of the upper panes of glass to allow the escape of warm air. This affords constant circulation.

An earth floor is desirable, but this is not always possible, as most city and many town and country houses have floors of concrete. In a cellar with a concrete floor the concrete should be covered with two or three inches of sand, which should be sprinkled with water from time to time.

In this room may be stored Beets, Carrots, Cabbage, Celery, Parsnips, Salsify, Turnips and Potatoes. (Special attention is given Potatoes on page 28.) Put them in bins or in boxes, baskets, slat crates or barrels. It is best to use movable containers and small ones. Bins should not hold more than two or three bushels apiece, as the larger bulk brings danger of heating and consequent decay. There should be full protection from mice.

The vegetables should be harvested when the ground is dry, if possible, and should lie outdoors a few hours until any surface moisture on them has evaporated. Remove the tops, leaving an inch or so, from beets, turnips, carrots and salsify. To leave an inch or so of top prevents bleeding and drying out. Sort vegetables according to size and condition. Imperfect or bruised ones should be selected for immediate use and only sound vegetables should be stored.

In cellar storage beets, turnips and carrots may be buried in slightly damp sand to good purpose.
Cabbages may be stored in the cellar in boxes or barrels of earth or sand, or they may be placed in a cool cellar on the floor with roots up.

Celery, to be stored in a cellar, should be allowed to stay in the garden until there is danger of severe freezing. In order to prolong the period of keeping it outdoors the plants should be protected from frost by banking them with earth to within two or three inches of the tops. On cold nights protect the tops with paper, burlap, mats, straw or other covering. The importance of not harvesting at the first appearance of frost arises from the fact that this period is likely to be followed by warm weather, which will cause decay by creating too high a temperature in the place of storage. With the arrival of steady cool weather, which will freeze the plants, dig them, leaving some soil adhering to the roots. For cellar storage place the plants upright, covering the roots with three or four inches of sand or light soil. (Fig. 2.) Earth may be banked around the stalks but this is not necessary. Water the soil occasionally, being sure to keep the leaves and stalks dry to prevent decay.

Celery may also be stored in cellar boxes, following these same directions.

The cellar storage room may also be used for the storage of fresh fruits and for canned goods, preserves and dried vegetables and fruits. Fig. 1 shows a suggested arrangement for shelves for canned and dried articles. If the shelves are not protected from light by doors all canned goods in glass should be wrapped in brown paper, to prevent bleaching 
of the contents as a result of exposure to the light.

Wide fluctuations of temperature should be avoided. The ideal temperature is 40 degrees F. The root cellar should be kept at not less than 32 degrees and not over 50 degrees.

\section{PIT STORAGE}

\section{Beets \\ Carrots \\ Cabbage \\ Celery}

For outdoor storage one of the best forms is a mound shaped pit. To prepare for this remove two or three inches of earth and line this shallow excavation with hay, straw, leaves or similar material. Place the vegetables on this in a conical pile. Cover the vegetables with several inches of the material used in making the lining. Cover this with 3 or 4 inches of earth. As severe weather approaches the outer covering should be increased. An additional layer of hay or similar material may be placed over the layer of earth and on top of this another layer of earth. In extremely cold climates the total thickness of earth layers should be as much as 12 inches. Over the outer layer of earth pile manure or corn stalks for added protection. To give ventilation have the inner layer of straw project through the outer covering and extend to the top of the cone. For protection from rain and snow this opening should be covered. A board laid over the top and weighted with a stone is

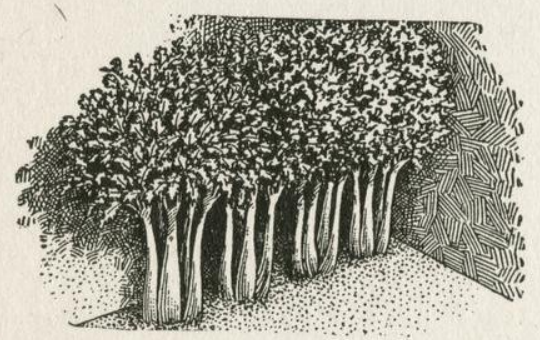

Fig. 2-For storage in cellar without heater celery should be set in two or three inches of sand or light soil and the plants then banked with soil. The soil must not be allowed to become dry.

suitable for this purpose. An idea of the construction is given in Fig. 5 .

It is well to make several small pits rather than one large one, for the reason that when a pit has been once opened the entire contents should be removed. This form of storage is used for potatoes, beets, carrot, turnips, parsnips, cabbage and salsify. It is well to store several varieties of vegetables in one pit so that the opening of a single pit will afford a supply of all of them. In following this plan it is desirable to separate the various crops by the use of straw or leaves.

When a pit has been opened it is impossible to give adequate protection to vegetables therein. For this reason those not required for immediate use should be removed, placed in the basement storage room, or other cool

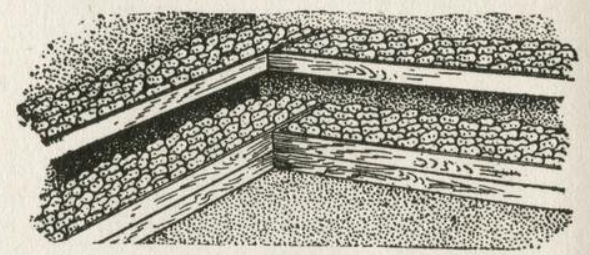

Fig. 3-Shallow bins or shelves with board sides, for storing root crops in cool cellar. The air of the room must not be allowed to become too dry, as this will cause the vegetables to shrivel. Potatoes must be protected from light.

place, and used as needed. This emphasizes the importance of making small pits, each one holding not more than two to six weeks' supply.

Instead of making a dirt pit, barrels may be used in which to place vegetables. (Fig. 8.) Make a slight depression the length of the barrel and put in a thick layer of straw or leaves. On this place the barrel. Cover the barrel with successive layers of straw or leaves, and dirt. As the weather grows colder put on more dirt until there is from 14 to 18 inches of covering. For ease in opening make a door at one end, against which pile earth and manure of sufficient thickness to prevent freezing.

\section{Cabbage}

For late varieties of cabbage the pit should be long and narrow. The cabbages are placed in rows with heads down and covered with dirt. No other covering is needed. The removal of a portion of this supply does not disturb the remainder. (Fig. 6.)

Cabbages may also be stored by placing the whole plants in a trench, roots down and plants close together. The roots should be covered with dirt. A frame should be built around the trench by driving stakes at the corners and placing boards against these to form the enclosure. The construction of such a trench is shown in Fig. 7. The boards are banked with earth and across the top of the trench boards or poles are placed, supported by the frame. These should be covered with straw, hay or corn fodder, for protection of the contents of the trench. Two feet of the straw or similar material will be required in cold climates.

Mature heads of cabbage of long-keeping sorts, such as Danish Ball Head, may be cut 
from the plant and stored une layer deep on shelves in cool, frost-proof cellars.

\section{Celery}

In storing celery in a pit or trench, the plants are set side by side as close as they may be packed and wide boards set up

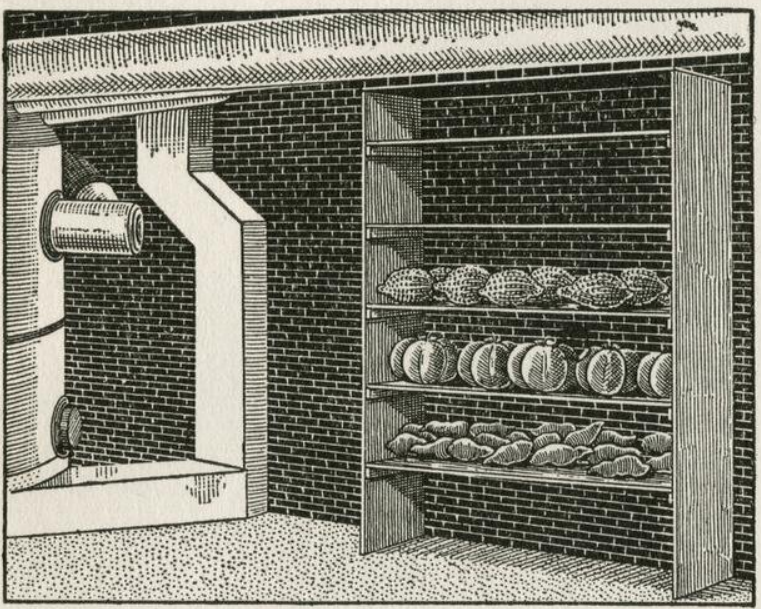

Fig. 4-For squashes, sweet potatoes and pumpkins shelves near furnace afford good storage.

along the outside edges of the pit. Dirt is banked up against these boards and the top covered with corn fodder or similar covering. If celery is kept in the row where grown the earth should be banked around the plants with the approach of cold weather. For freezing weather bring the dirt to the tops of the plants and cover the ridge with coarse manure, straw or fodder, using stakes or boards to hold the covering in place. Only late maturing and late planted celery can be safely stored. (Fig. 9.)

A hotbed, instructions for the making of which are given on page 7 (Fig. 2), in Part I of this booklet, makes an excellent place for outdoor storage for celery. The surplus earth and manure should be removed and a board covering should be substituted for the sash and glass. Store the celery in the same manner as in pit storage. For protection from cold use any covering that will prevent freezing.

Celery should not be stored with turnips or cabbage. It will absorb odors from these vegetables and its flavor will be impaired.

\section{OUTDOOR GELLAR

$\begin{array}{ll}\text { Beets } & \text { Potatoes } \\ \text { Carrots } & \text { Turnips } \\ \text { Parsnips } & \text { Salsify }\end{array}$

An outdoor cellar makes a good storage place. In cold climates this should be par- tially underground. A side-hill location is desirable for ease in handling the vegetables. To make such a cellar dig an excavation and in this erect a frame by setting posts in rows near the dirt walls. Saw these posts off at uniform height and place plates on their tops. On these plates place rafters. Board up completely with the exception of a place for the door. The whole should be covered with dirt and sod, and in cold climates added protection should be given by a layer of straw, fodder or similar material. Ventilate with a flue. A dirt floor is best, as some moisture is desirable. This form of storage is especially good for the joint use of several families.

On a more pretentious scale cellars of this nature may be made of brick, stone or concrete. Such cellars afford practically perfect storage room for potatoes, carrots, cabbages, parsnips, beets, turnips and salsify.

\section{VARIOUS METHODS}

Permanent cold frames, with deep pits, may also be used to advantage in storing vegetables if the drainage is made thorough. After the frames are filled the sash should be covered with boards and the outside banked with soil or manure. As the weather becomes severe a covering of straw or mats is necessary. This covering should be heavy enough to prevent freezing.

Cauliflower and Brussels Sprouts which have not matured may be taken up and

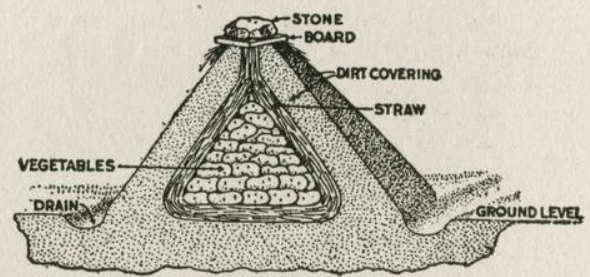

Fig. 5-Irish potatoes in an outdoor mound. This mound must be in a well-drained location. After removing 2 or 3 inches of earth, pile the potatoes on a 2 or 3-inch layer of dry straw, leaves or hay. Cover the vegetables with 2 or 3 inches of straw, leaves or hay, and cover this with 3 or 4 inches of earth. Increase the thickness of the earth layer as severe weather approaches, making it as much as 12 inches in extremely cold climates. Manure or corn stalks should be piled over the mound. The straw, coming to the top, will afford ventilation. The opening should be covered for protection from rain.

planted in shallow boxes of soil in a light place in the cellar. If kept well watered they will mature for winter use. 
Dry beans may be stored in cloth bags in a pantry or in any cool, dry and well ventilated room. The bags should be hung away from the floor to prevent damage by rats and mice.

Onions require a cool, dry place. They should be cured by being exposed to the air for a few days in the shade. The tops should be removed before storing. Keep them in baskets, trays or other holders which let the air circulate. Onions are not damaged by temperatures slightly below freezing, and for storing them the attic is better than the cellar. If stored in the cellar they should be suspended from the ceiling.

Squashes are susceptible to cold and moisture, and for that reason should be stored in a dry place where the temperature will be between 50 and 60 degrees F. Squashes may be kept by placing them in a single layer on a dry floor and covering with rugs or carpets, but care must be taken that the stems are not broken off and that they do not become bruised before storing. Whenever it is found that any of the squashes or pumpkins are showing signs of decay, the sound portions should be canned.

Tomatoes may be saved by pulling up the entire plant before freezing weather. The vines should be suspended by the roots in a cool cellar. The tomatoes will gradually ripen. If these tomatoes, when cooked, are found to be acid, the acidity can be overcome by using baking soda.

Parsley may be saved by transplanting into flower pots late in the fall. These should be kept in windows where they will receive sunshine.

Parsnips and salsify are not injured by remaining in the ground all winter. Enough for immediate needs may be dug in the fall and the others harvested as required.

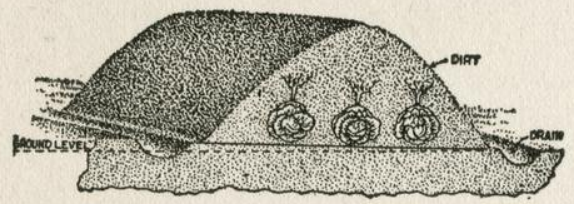

Fig. 6-Cabbage stored, roots up, in a bank of earth. The place must be well drained. The cabbages are covered with earth, but this need not be as thick as for some vegetables, as slight freezing does no harm.

\section{POTATOES}

As one of the staple vegetables, potatoes are entitled to special consideration for winter storage. If you have raised a surplus crop in your own garden save as many as possible for your winter's supply. If you have none of your own raising it is well to buy them early in the fall, at the time of greatest supply and lowest prices, and store them for the winter, making yourself independent of the market during the time of highest prices.

Potatoes may be stored in cellars, pits and outdoor cellars, as already described. Before they are stored they should be allowed to dry. This is done by digging

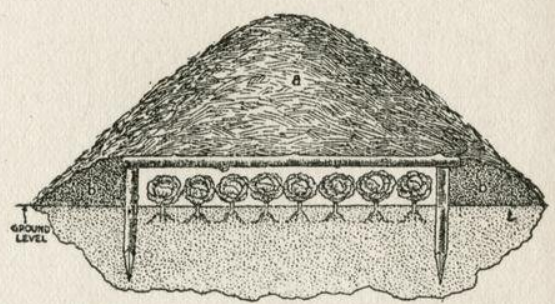

Fig. 7-This shows cabbage, pulled with roots, stored in a shallow trench, with roots down. The roots are covered with earth. The stakes, projecting 2 feet above the surface of the earth, serve as supports for boards or "poles which make an enclosure. This frame should be banked with dirt (b). Across the top place poles or plank and cover with straw, hay or corn fodder (a). Make the trench as long as necessary and any width up to 8 feet.

them on bright days, if possible, and allowing them to lie alongside the rows for a few hours. Before storing sort them carefully as to size and soundness. The smaller potatoes and those which show signs of threatened decay should not be stored, but should be used early.

The success of potato storage depends on the exclusion of light, proper ventilation, the proper amount of moisture, the size of the pile or container and the type of the tubers stored.

In storing potatoes it should be remembered that the purpose is to protect them from great changes of temperature and from light. Even a small amount of light. changes the food value of potatoes. There should be enough moisture to keep the potatoes from wilting, but not enough to cause moisture to gather on the surface.

If potatoes are stored in a place where there is moisture in the air, provision should be made to permit free circulation of air through the containers. Barrels, boxes and bins may be ventilated by boring holes in sides and bottoms. Barrels, boxes and crates should be set on slats to hold them off the floor and allow the air to circulate underneath. If the storage place is light a blanket, several thicknesses of paper, or old sacks should be placed on top of the containers.

If the air of the storage place is dry it should not be allowed to circulate freely through the containers, as dry air will cause withering of the potatoes. In such storage places the potatoes should be put 
in containers made airtight by lining bottom and sides with several thicknesses of newspaper and covering the top snugly in the same manner.

The temperature of a cellar storage room for potatoes should be carefully controlled

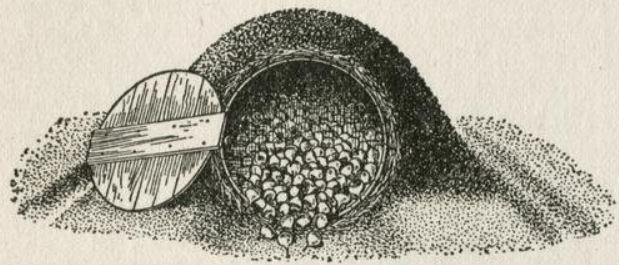

Fig. 8-A barrel can be made into a good storage pit for cabbage, turnips, potatoes etc. Barrel is placed on its side and covered with straw and dirt.

to prevent wide fluctuations. A constant temperature around 40 degrees $\mathrm{F}$. is desirable. It should not be allowed to go below 32 degrees or above 50 degrees.

Potatoes should not be washed before storage. If they begin sprouting in the spring all the shoots should be rubbed off. The bins should be examined occasionally and any rotting potatoes removed to prevent the spread of infection.

\section{Bins}

Do not have one large bin for potatoes, as those in the center will be subjected to too high temperature, which will cause all of them to go through a sweating process. Too large a bin makes good ventilation impossible. Open bins, not more than a foot deep, arranged as a shelf, as shown in Fig. 3 , are excellent for cellar storage. Another good arrangement of shelf storage for certain crops is shown in Fig. 4.

\section{Pits}

A small pit provided with ventilation, as shown in Fig. 5, is the most satisfactory. It is better to have several small pits than one large one, as the entire contents must be removed when a pit is opened. Place not more than two to six weeks' supply in a single pit.

\section{SWEET POTATOES}

In storing sweet potatoes the important points to be kept in mind are that the potatoes must be well matured before they are dug; they must be handled with extreme care; they must be allowed to dry or cure thoroughly before storage, and they must be kept at an even temperature. A test for maturity is to cut or break a sweet potato and expose it to the air for a few minutes. If the surface of the cut or break dries the potato may be considered mature, but if moisture remains on the surface it is not properly ripe. In sections where frosts come early digging should take place about the time the first frost is expected, without regard to maturity. Care in handling is necessary to prevent bruising and subsequent decay. Curing is done by keeping them at an even temperature of 80 to 85 degrees F. for a week or ten days after harvesting, to dry off the moisture. The room in which this is done must be ventilated in order that the moisture-laden air may escape.

For storing sweet potatoes on a large scale a specially constructed house is desirable. For home storage the roots may be kept near the furnace in the cellar or near the furnace chimney in a vacant upstairs room or in the attic. The room should be kept fairly warm. After curing the temperature should be maintained around 55 degrees $\mathrm{F}$.

Care should be taken not to store sweet potatoes which are infested with the sweet potato weevil or root-weevil, one of the most serious pests of the Gulf region. This pest practically confines itself to destruction of the tubers after harvesting. When the tubers are found infested they should be fumigated with carbon disulphid, to be procured at a drug store. Place the tubers in a box or other container which can be tightly closed. The carbon disulphid is a liquid which gives off fumes heavier than air, and one ounce per bushel should be placed in an open dish on top of the roots and the container closed. Do not allow open lights or fire in the presence of this gas as it is highly explosive. All badly affected roots should be burned.

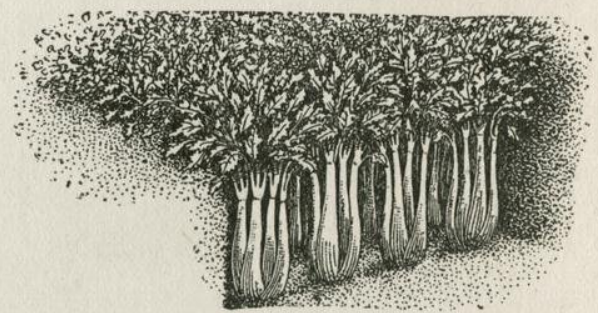

Fig. 9-This shows celery set into an outdoor pit or trench for storage. Boards should be placed along the edges of the pit or trench and dirt banked against these boards. The tops of the celery should be covered with corn fodder, straw or similar covering. The celery may be removed easily at any time.

\section{APPLES}

Apple storage is simple and is desirable not only for those who grow their own apples but also for those who depend on the market for their supply. The one essential is that the fruit be kept in a cool, 
dry place, and so stored as to be in no danger of absorbing odors from vegetables stored nearby.

Families raising no apples, but having a good storage place, meeting the requirements as to temperature, will find it advantageous to buy a winter's supply in the fall, when prices are low. The cost of purchases thus made will be considerably less than if apples are bought as needed during the winter.

To store, sort apples carefully, removing and using at once all fruit which is bruised or shows signs of decay. The best results are secured by wrapping each apple in half a sheet of newspaper and storing in barrels, boxes, crates or bins. The wrapping prevents the apples from touching each other and thus prevents the spread of decay which may start. It also protects the apples from odors if vegetables are stored nearby. Apples absorb odors freely from potatoes, onions, turnips and other vegetables and should never be stored, unwrapped, in the same room with vegetables of any kind. In addition to wrap- ping the individual apples it is desirable to line the barrel or other container with a half inch thickness of newspapers, on the bottom and sides, and then cover the top with newspapers and either nail a cover on or tie the papers securely with strings. This will keep odors out. The lining and covering give full protection and make it possible to store apples in the general cellar storage room.

Remember that the cellar or other place in which they are stored must be cool. A temperature of 32 degrees F. is ideal, and the temperature should not be allowed to go above 40 degrees if it can be held this low.

Apples may be stored unwrapped in barrels, boxes, crates or bins if proper attention is paid to sorting, to providing a cool place for storage and to occasional sorting during the winter, for the removal of possible decayed fruit. If any of the fruit in any container is found to have begun to decay all the apples in all the containers should be sorted at once and decaying fruit removed. Apples stored unwrapped must not be kept in the room with vegetables.

\section{SAVE NEX'T YEAR'S SEED FROM THIS YEAR'S GARDEN}

Owners of gardens will find that the saving of seed from this year's gardens will be of great help for next year's planting. While it is more satisfactory, ordinarily, to purchase seed from reliable dealers the increased planting of home gardens, the poor crop of seed, the decrease of foreign importation, the exporting of certain seed to Europe and the use of certain kinds for food have caused a shortage and, as an emergency measure, each gardener should save as much seed as possible.

Saving of seed is easily done, though it requires care and attention. In saving seed select them from plants of a single variety grown by itself if possible, rather than from plants where more than one variety have been planted. Where there are two or more varieties of the same vegetable growing side by side, cross fertilization takes place and standard seed cannot be obtained. It is well to learn all the features which make up the most desirable type of variety of vegetable from which seed is to be saved. Seed saved where it is grown has two advantages. For one thing more careful selection can be given than is possible for all seed placed on the market. Another advantage is that plants from this seed will succeed best under local conditions.

Select seed plants which are free from disease, which show a vigorous growth, a good yield and quality, and mature early. Mark selected plants with string. Plants selected for seed should be given especially careful cultivation and every effort should be made to promote their full development. When seed is ripe harvest with care.

Seed properly stored, with the exception of parsnip and onion, should retain vitality from 2 to 5 years. Thus enough seed may be saved from a good crop to tide over the poor years.

\section{SEED MATURING IN ONE YEAR}

Some of the seed desirable for saving because they mature in one year are:

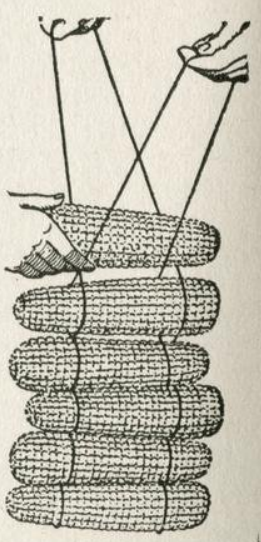

Fig. 11-A good way of hanging seed corn to dry.

BEANs-Select the best plants and let the pods mature. Pull up plants preferably in 
the early morning, to prevent shattering. Place plants in a dry, well aired place until seed are hard. Shell and spread in a layer until dry.

SweEt CorN-Select the ears just at maturity and while on plants, as plant must be considered as well as the ear. The plant should be free from disease and preferably have two or more good ears to the stalk. The distance between joints should be short and the ears set on short, strong shanks. Ears should be nearly cylindrical and should taper

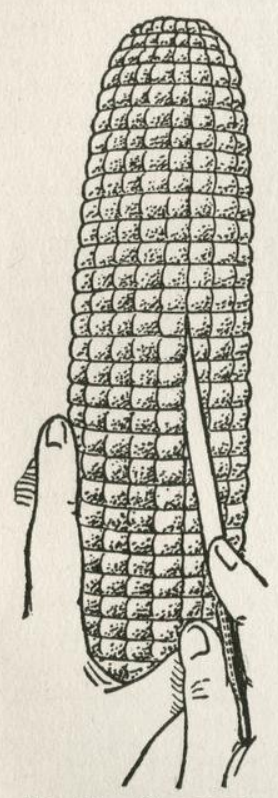

Fig. 12 - To remove kernels when preparing to plant or to test seed, insert knife between rows and pry sideways. but slightly from butts to tips. They should be well filled out, with husks tightly folded over ears. Pick ears from plants maturing at nearly the same time, uniform in size, strong and well rooted. Medium sized ears are best. When fully mature strip down husks and string up 10-15 ears in a dry shady place so as to dry out ears quickly.

CUCUMBERS AND Summer SquashSelect desirable fruits when in the usable stage. Allow them to remain on vines until ripe, as indicated by change of color or hardening of surface. Remove the seed from the ripe fruit and wash free of pulp. Spread in a thin layer in the sunshine to dry, stirring frequently. A quart or less should dry satisfactorily in a day.

EGGPLANT-When fruit is opened for food, select the best formed seed, wash and dry.

LetTuce-Plants for seed should be started early enough so that seed setting and ripening does not occur during the hot weather. With heading varieties it may be necessary to cut across the tops of the heads to allow the seed stalks to push through. When seed heads turn white and open, cut or pull the plants, put heads in paper bags and hang in a dry place until seed are ripened and drop out of leads, or lay the plants on a table in a dry airy place.

Potatoes-Select productive seed hills, as nearly free from disease as possible. Potatoes should be true as to variety, which means that a late variety should not be substituted for early variety if the crop is to be harvested early. Early varieties cannot be substituted for late varieties as they are not as productive. Seed potatoes should be kept dormant in a dark, cool place until planting time. The production of long sprouts, or wilting, will reduce the vigor. Rub off the long sprouts before the potatoes are planted.

RADISHESSelect the finest roots and cut off all but a few central leaves. Put the roots in a moist, airy

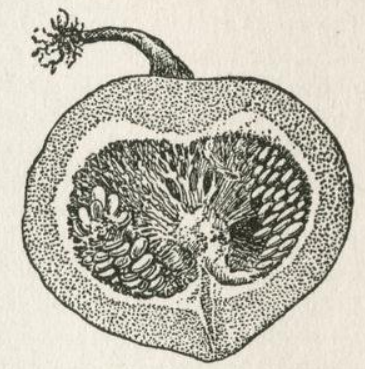

Fig. 13-Hubbard squash. A good type winter squash for seed.

\section{place for a short}

time and then plant them with the crown an inch below the surface. When seed ripen, cut plants and lay on paper exposed in the sun. When the outside covering is dry, then rub out seed, dry and store.

Tomatoes-Gather fruit from selected plants when a little over ripe, but not decayed. The seed may be freed by one of two methods. One of these is to crush the fruit, and force through a sieve, and then put the seed in a coarse cloth and press out pulp under water. Another method is to crush fruit, put in a container and allow to ferment for two or three days, stirring once in a while. The seed settle and the pulp which rises may be poured off. Wash the seed in clear water an dry.

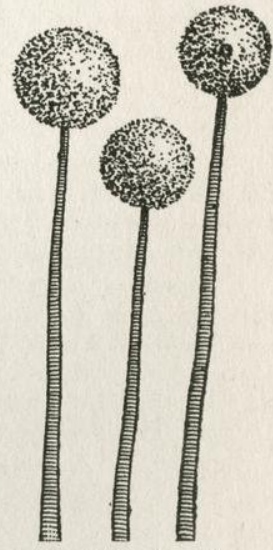

Fig. 14-Seeding som. They should be staked. plants of onion in blos-

\section{Winter Squash, Pumpkin, Muskmelon, Watermelon}

When fruit is opened for food, select the best formed seed, wash and dry.

\section{SEED MATURING IN TWO YEARS}

Such vegetables as beets, carrots, parsnip, salsify, cabbage, etc., which require one season in which to grow will produce seed in the secon 1 year. Seeds of beets, carrots, cauliflower, turnips and late radishes are not often grown satisfactorily in the home garden. 
They must be carefully stored during the winter. Root crops of late planting are most satisfactory for seed. Select those of the best shape, color and size. Cut off all but an inch or two of the leaf stems and store in a frost proof pit or cellar. If a cellar is used protect the roots from withering by putting them in sand, fine soil or sifted coal ashes. They should be kept very slightly moist. Do not store them in a heated cellar.

CaBbage-In the fall select the best heads, pull up entire plants and store them in a trench. Next spring set out two or more plants as one plant alone rarely produces seed. It may be necessary to cut the head across the top to allow the seed stalk to develop. When the seed pods turn yellow cut off the stalk and lay it on paper in a cool shady place to dry; early morning is the best time to gather. Rub out the seed when the pod is dry. Do not grow kale, collards, cabbage or kohlrabi-any two of them-in the same garden, as they will cross-fertilize.

OnIONS - Seed bearing bulbs should be well rooted. In the fall plant them 3 inches deep. As cold weather approaches cover with earth to protect them from freezing. In the spring remove the ridges. The seed stalks should be supported with stakes. When most of the seed is ripe cut out the seed stalks, dry in the sunshine and rub out the seed.
PARSNIPS-These may be left in the ground all winter. In the spring plant selected roots 3 to 5 feet apart in row. When seed are ripe cut seed stalk and dry.

\section{STORAGE OF SEED}

Put heavy seed, such as beans and peas, in cloth bags; smaller seed in paper bags or envelopes. Label each bag carefully, inside and out, as to contents. To protect seed from mice put the bags in perforated tin boxes. A bread box makes an ideal storage place for seed. An upstairs room or attic room, provided it is not warm, is a very good place in which to store seed. The room must be dry and well ventilated to prevent molding.

Stored seed should be occasionally examined for insects. If insects or weevils are present fumigate with carbon bisulphid, a liquid which vaporizes, producing a gas heavier than air. To fumigate, place the seed in an air-tight receptacle and pour the carbon bisulphid over the seed. Open to air in from 24 to 36 hours. Use an ounce of carbon bisulphid to a bushel of seed. Carbon bisulphid is very inflammable and fire or flame must not be taken near the fumigating receptacle. Disregard of this precaution will result in an explosion.

This manual was prepared by the Commission's experts and is based on their own research and experience, supplemented by information procured from the United States Department of Agriculture, Agricultural Colleges, Experiment Stations, and other sources.

The National War Garden Commission, wishing to do all within its power to aid the War Industries Board in the very necessary economy in the use of paper, has limited the edition of this book and asks those who receive it in quantity to make the most careful distribution so that the book may reach the hands of none but those who will use it. IF THE INDIVIDUAL RECIPIENT GAN NOT USE THIS BOOK IT IS URGED THAT IT BE HANDED TO SOME ONE WHO WILL USE IT.

\section{TABLE OF CONTENTS}

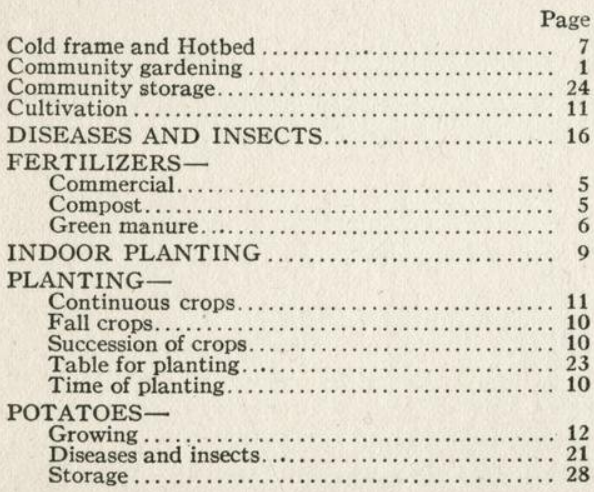

POTATOES, SWEET -

Growing $. . . \ldots \ldots \ldots \ldots \ldots \ldots \ldots \ldots \ldots \ldots \ldots, 13$

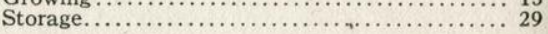

SEED -

Quantity to buy ......................... $9{ }_{30}^{9}$

Testing before planting .......................... 8

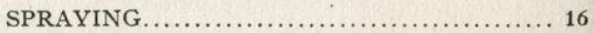

SOIL .................................. 7

STORAGE-

Apples................................. 29

Cellar......................................... 24

Outdoor cellar...................................... 27

Pit............................................... 26

Seed ................................................... 32

Various methods.............................. 27

TOOLS.............................. 7 


\section{UNITED STATES FOOD ADMINISTRATION}

Mobile, Alabama.

MR. P. S. RIDSDALE, Secretary,

September 6th, 1918.

National War Garden Commission,

WASHINGTON, D. C.

\section{Dear Mr. Ridsdale:}

I desire to tender my sincere thanks for the books which you have furnished for distribution and use among the war gardeners of Mobile, and as encouragement and assistance to others to take up this splendid work conducive not only to increased supply of food products, but to the health and happiness of those who wisely give Mother Earth the attention which just at this time she all the more richly deserves.

It is needless for me to assure you that the books have been extremely helpful. I consider them the most complete and serviceable ever produced; and excepting only the family Bible, the foundation of all ethics and morality as well as the common law, these books are of more vital importance to every householder, in fact, good citizens throughout the land, than most printed matter obtainable.

Your books on canning and drying are likewise of inestimable value, and your splendid co-operation in the common cause of increasing and conserving the food supply in our present crisis meets with the heartiest appreciation.

\section{Very sincerely,}

(Signed) HENRY A. FORCHHEIMER,

Federal Food Administration Board.

\section{UNITED STATES FOOD ADMINISTRATION}

MR. P. S. RIDSDALE, Secretary,

Davenport, Iowa.

September 5, 1918.

National War Garden Commission,

WASHINGTON, D. C.

My dear Mr. Ridsdale:

We have found your publications of great value in our work in this State and it gives me pleasure to thank you for your prompt and cordial compliance with all of our requests.

Your book on War Vegetable Gardening and the one devoted to Canning and Drying are filled with information of great value to the gardener and housewife.

It has been a source of great satisfaction to us to be able to distribute your books in every County in Iowa and we have used care to place them in the hands of people who need them and who are constantly calling for just the information contained in them.

We feel that your co-operation has been of great importance.

Faithfully yours,

(Signed) M. L. PARKER,

State Merchant Representative,

Iowa Food Administration. 


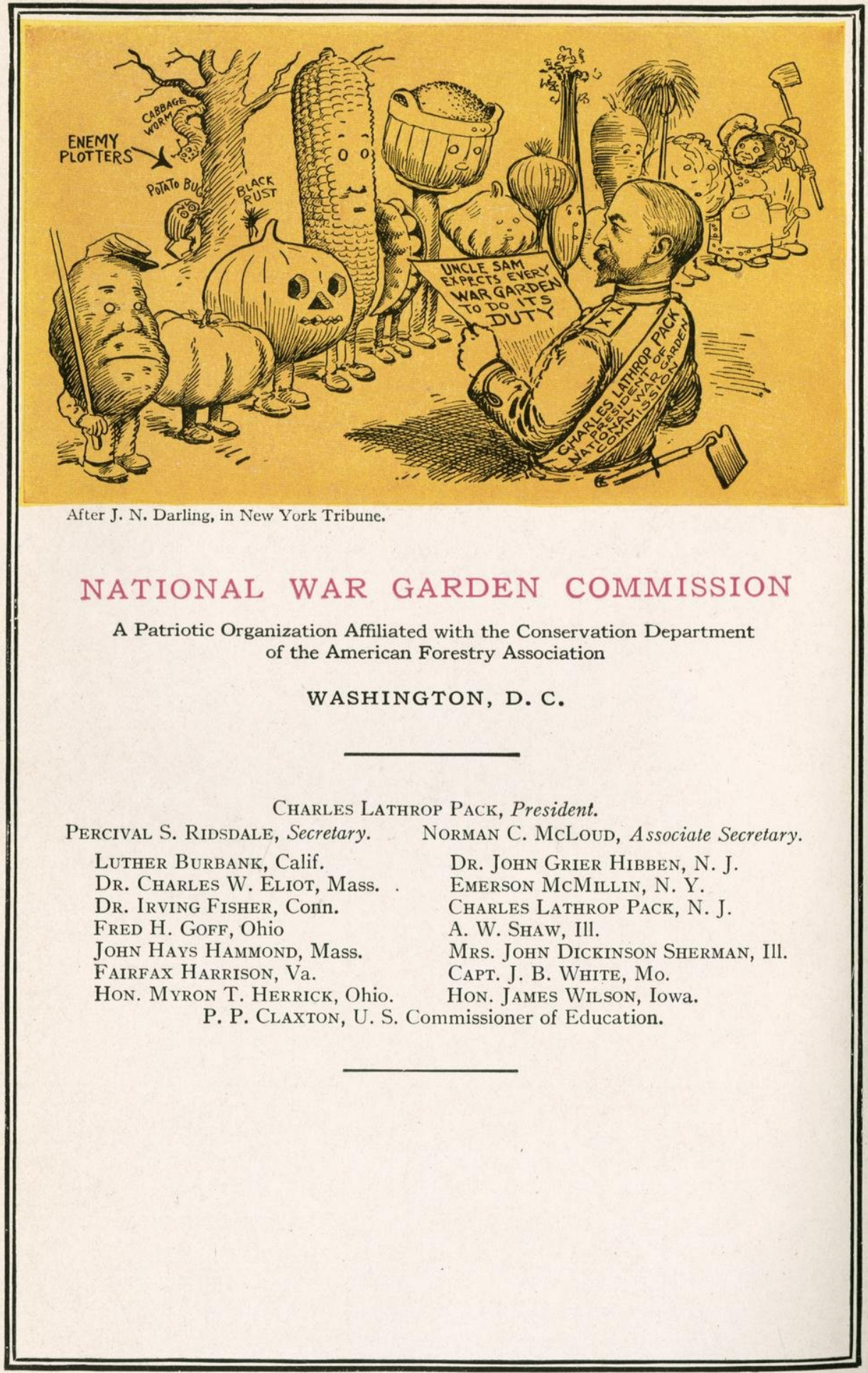




\section{Victory Edition 1919}

\section{HOME}

CANNING \&DRYING

of Vegetables \& Fruits

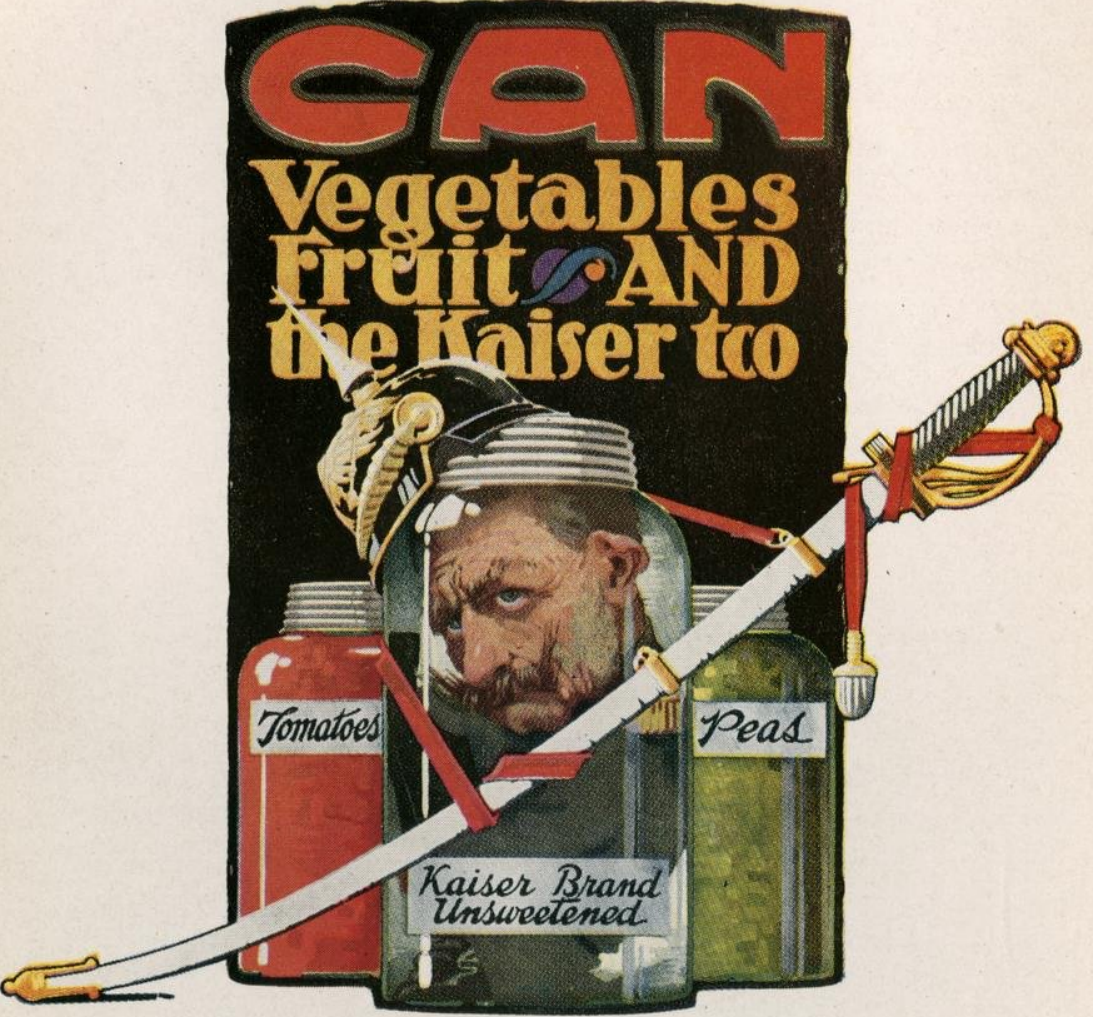

Published by

National War Garden Commission Washington, D.C. 


\title{
WAR DEPARTMENT
}

\author{
WASHINGTON
}

June 7, 1918.

\section{NATIONAL WAR GARDEN COMMISSION, WASHINGTON, D. C.}

\section{Dear Sirs:}

The War Department finds much satisfaction in the creation of War Gardens at various army camps by the Conservation and Reclamation Division of the Quartermaster General's office. Food production at these camps has been the subject of some concern with the department. The large areas of tillable land within many of the military reservations have been regarded as offering potential food production on a large scale, and I feel that the army is to be congratulated. that the utilization of this space has now taken concrete form.

Camp War Gardens will serve more than one useful purpose. The production of food at the mess door is of great importance in that it not only lessens the army's demand on the usual sources of supply but eliminates transportation as well.

To the National War Garden Commission I extend the thanks of the Department for its quick response to the appeal of the Quartermaster General's office for co-operation. Not confining itself to mere compliance with the letter of the request, the Commission entered fully into its spirit. At a time when funds were not available through Government channels the Commission voluntarily provided seed, fertilizers and equipment which made possible the establishment of a War Garden of 300 acres or more at Camp Dix. For this generous contribution and for swift action to overcome the handicap of a late start I take pleasure in making this acknowledgment and in expressing the hope that the Camp Dix War Garden of the National War Garden Commission will prove an unqualified success.

\section{UNITED STATES FOOD ADMINISTRATION}

Baltimore, Maryland.

September 14, 1918.

\section{NATIONAL WAR GARDEN COMMISSION, Maryland Building,} WASHINGTON, D. C.

\section{Gentlemen:}

We wish to express to you our appreciation of your helpfulness in our war garden, canning and drying work in Maryland during the season of 1918. Your book on canning and drying has been of great value, while the canning outfits which you so kindly gave us made it possible for us to establish canning centers throughout the State, with results of far-reaching importance which could not have been otherwise accomplished. We are equally appreciative of your prompt and willing response to our request for the services of one of your trained investigators to assist in our war garden work. Your spirit of prompt and willing service is cordially appreciated.

Yours truly,

(Signed) EDWIN G. BAET JER,

Federal Food Administrator for Maryland. 


\title{
BACK UP THE CANNON BY USE OF THE CANNER
}

\author{
By CHARLES LATHROP PACK, President
}

National War Garden Commission

\section{W}

E stand with our backs to the wall." That call to the civilized world, made by General Haig in the spring of I9I8, has brought and still must bring answer from the women. Only by their cooperation has it been possible for that call to be answered, for no nation can do a great work unless the women of that nation put their influence into the job.

We were forced into a war which was something more than a war to decide policies or mark boundariesa war involving the most sacred questions with which men and women have to deal-the sanctity of womanhood, the sacredness of childhood and the right to live in freedom. We could not yield these rights while we had the strength to defend them.

In the emergency created by this war the question of food goes hand in hand with thrift. Our position has been no less closely involved in the conflict than that of Europe. In proof of this let me call attention to the plan the enemy had for us. I quote from a book called "War," by Klaus Wagner, published in I9I6 in Berlin. On page 165 the author says:

"Not only North America, but the whole of America must become a bulwark of German Kultur, perhaps the strongest fortress of the Germanic races. That is every one's hope who frees himself from his own local European pride and who places race feeling above his love for home."

Mark that well-his race feeling above his love for home; and then let me quote one of the thousands of letters received by the National War
Garden Commission. Here it is, from a boy:

"I have decided to help win the war by having a war garden, and I have just read your notice that any one can have a free garden book. Please send it to me. My father joined the army in 1915 and was killed in I916. - Harvey Cameron, New Glasgow, Nova Scotia."

That boy is typical of the boys and men of many nations who have been fighting against the common enemy. If they could look the job in the face that way, what can we do? Our boys have been giving their lives toward the achievement of victory. Every mile of reclaimed territory in devastated France and Belgium adds hundreds of hungry mouths to be fed. With France and Belgium liberated many more people have become dependent on this country's food supply. In victory we must feed not only more millions abroad but also care for our own people at home and our soldiers until they return. Peace cannot mean an increase of the world's grain supply for another year at least, and it will take several years of bountiful crops to refill the empty bins and granaries of the world.

Victory, therefore, must necessarily bring a large increase in our obligation. We must not only produce food as close to the kitchen door as possible, but we must save a vast volume of this food for winter use. To save it we must can it, dry it, or otherwise prepare to have it in readiness for the months of non-production. Canning and drying, therefore, are as imperative to-day as if the war were just beginning. 


\section{TIME-TABLE FOR BLANCHING AND STERILIZING}

The following time-table shows blanching time for various vegetables and fruits, and also sterilizing time in the hot-water bath outfit, and in equipment for sterilization by the water-seal method, the steam-pressure method and the aluminum steam-cooker method:

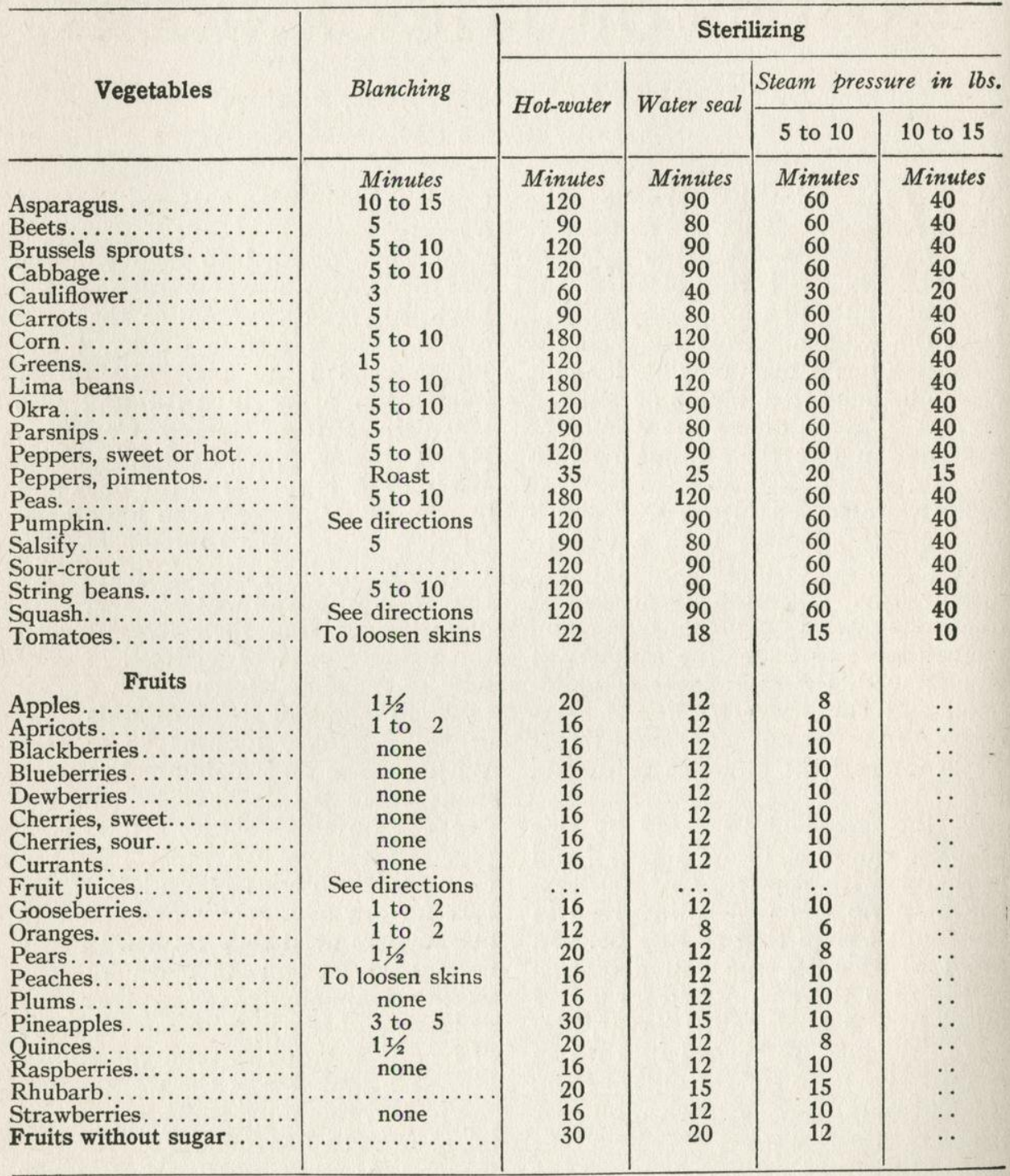

The time given in this table is for quart jars. Add 30 minutes for 2-quart jars and deduct 5 minutes for pint jars.

The time given is for fresh, sound and firm vegetables. Increase the time of sterilization by adding one-fifth for vegetables which have been gathered over 24 hours.

The time given is for altitudes up to 1000 feet above sea level. For higher altitudes increase the time in hot-water bath 10 per cent for each additional 500 feet. For example, if the time is given as 120 minutes in the table and your location is 1500 feet above sea level, the time should be made 132 minutes. Neither home-made nor commercial hot-water bath outfits are entirely satisfactory, however, for canning at very high altitudes, as the temperature of water in them does not reach 212 degrees $F$. In such localities water-seal and steam-pressure outfits are advisable, as they give higher temperatures. 


\section{PART I \\ HOME CANNING MANUAL}

To save vegetables and fruits by canning this year is a patriotic duty. War has made the need for Food Conservation more imperative than at any time in history. America is responsible for the food supply of Europe. The American family can do nothing more helpful in this emergency than to Can All Food That Can be Canned. In this way the abundance of the summer may be made to supply the needs of the winter.

\section{CANNING IS FOOD THRIFT}

The National War Garden Commission's campaign for five million or more War Gardens has brought about the creation of a vast food supply hitherto greatly neglected. To utilize this to the best advantage calls for Canning operations in every household throughout the nation.

The preservation of foodstuffs by Canning is always effective Food Thrift. It enables the individual household to take advantage of summer's low prices for vegetables even if no garden has been planted. It effects the saving of a surplus of foodstuffs that would otherwise be wasted through excess of supply over immediate consumption. It eliminates the cold storage cost that must be added to the prices of commodities bought during the winter. Of vital importance, also, is that it relieves the strain on transportation facilities of the country. This phase has been especially emphasized for this year by the unprecedented traffic situation. All this increases the need for Home Canning and proves that this is a national obligation.

\section{CANNING MADE EASY BY MODERN METHODS}

By the Single Period Cold-Pack method it is as easy to can vegetables as to can fruits, and this year it is more useful. By the use of this method canning may be done in the kitchen or out of doors. It may be done in the individual household or by groups of families. Community canning is important in that it makes possible the use of the best equipment at small individual outlay and induces Food Conservation on a large scale. Community canning by school children, under the direction of competent teachers, is especially valuable.

This Manual presents all necessary instructions for canning vegetables and fruits, in a manner which may be so readily understood that the work is no longer a problem, but is so simple that any adult or child may do it with success.

\section{COMMUNITY WORK}

One of the best methods to follow in canning and drying operations is for several families to club together for the work. The work may be carried on at a schoolhouse, in a vacant storeroom, at the home of one of the members or at some other convenient and central location where heat and water can be made available. By joining in the purchase of equipment each participant will be in position to save money as against individual purchases and at the same time have the advantage of larger and more complete equipment. The cost is slight when thus divided and the benefits very great to all concerned.

For a co-operative enterprise it is well to have a committee of from three to five to take charge of all details. First determine how many people will take part in the work, how much each proposes to can or dry, what vegetables and fruits each will furnish and such other information as will have a bearing on the selection of equipment. After deciding how much money will be needed, 
have each member contribute his or her proportion, determined by the amount of canning or drying he or she proposes to do.

The equipment should be bought as early as possible to prevent disappointment in

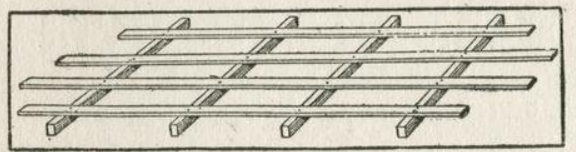

FIG. 1. Home-made rack for wash-boiler.

delivery which is almost certain to follow delay. This equipment may be ordered through a local dealer or direct from the manufacturers. The National War Garden Commission publishes a list of manufacturers which may be had upon application.

The equipment may be used by the individual members on a schedule arranged by the committee, or a working force may be appointed to do all the work, receiving pay in the form of a percentage of the product.

Publicity is important in keeping interest aroused and there should be a committee to arrange with the local papers for the publication of information concerning the enterprise. This serves as an incentive to others.

The National War Garden Commission will send upon application its pamphlet on Community and Neighborhood Canning and Drying, giving details as to organization.

\section{STERILIZATION OF FOOD}

The scientist has proved that food decay is caused by microorganisms, classed as bacteria, yeasts and molds. Success in canning neces-

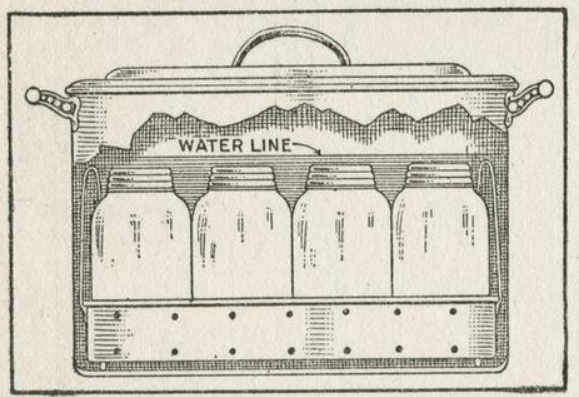

FIG. 2. Wash-boiler with rack for jars.

sitates the destruction of these organisms. A temperature of $160^{\circ}$ to $190^{\circ} \mathrm{F}$. will kill yeasts and molds. Bacteria are destroyed at a temperature of $212^{\circ} \mathrm{F}$. held for the proper length of time. The destruction of these organisms by heat is called sterilization.

\section{METHODS OF CANNING}

There are five principal methods of home canning. These are:

1. Single Period Cold-pack Method.
2. Fractional or Intermittent Sterilization Method.

3. Open Kettle or Hot-pack Method.

4. Cold Water Method.

5. Vacuum Seal Method.

The method recommended for home use is the Single Period Cold-pack method. It is much the best because of its simplicity and effectiveness, and in this book detailed instructions are given for its use.

The outlines of the various methods are:

1. Single Period Cold-pack Method: The prepared vegetables or fruits are blanched in boiling water or live steam, then quickly cold-dipped and packed at once into hot jars, the contents covered with boiling water or syrup, and the jars partially sealed and sterilized in boiling water or by steam pressure. The jars are then sealed tight, tested for leaks and stored. Full details are given on page 7 and the pages following.

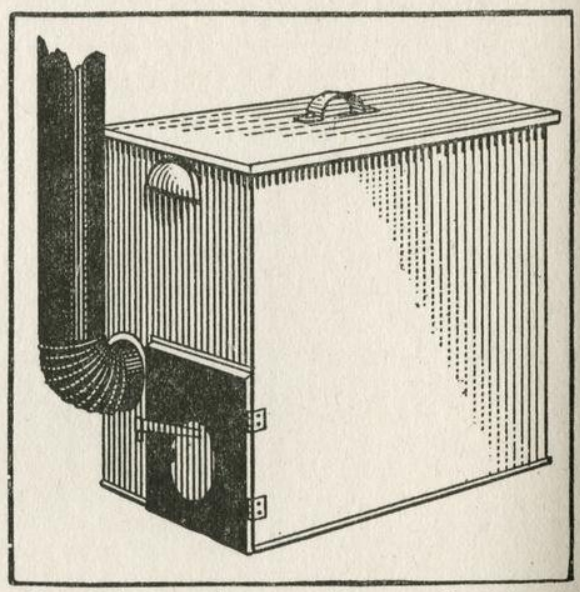

FIG. 3. A type of commercial canner for hot-water bath, using wood, coal, charcoal, chips, cobs, or brush.

2. Fractional or Intermittent Sterilization Method: Vegetables are half sealed in jars and sterilized for 1 hour or more on each of three successive days. This method is expensive as to time, labor and fuel and discourages the home canning of vegetables.

3. Open Kettle or Hot-pack Method: Vegetables or fruits are cooked in an open kettle and packed in jars. There is always danger of spores and bacteria being introduced on spoons or other utensils while the jars are being filled. This method should never be used in canning vegetables. Even with fruits it is not as desirable as the cold-pack.

4. Cold-water Method: Rhubarb, cranberries, gooseberries, and sour cherries, because of their acidity, are often canned by this method. The fruits are washed, put in sterilized jars, cold water is added to overflowing, and the jar is then sealed. This method is not always successful as the acid content varies with ripeness and the locality in which the fruits are grown. 
5. Vacuum Seal Method: Vegetables are washed, blanched, cold-dipped and cooked asfor table use; packed and sealed in especially made vacuum seal jars. The jars must be well made and the work properly done to bring about satisfactory results.

\section{ADVANTAGES OF THE COLD-PACK}

The Single Period Cold-pack method is a simple and sure way of canning. It insures a good color, texture and flavor to the vegetable or fruit canned. In using this method sterilization is completed in a single

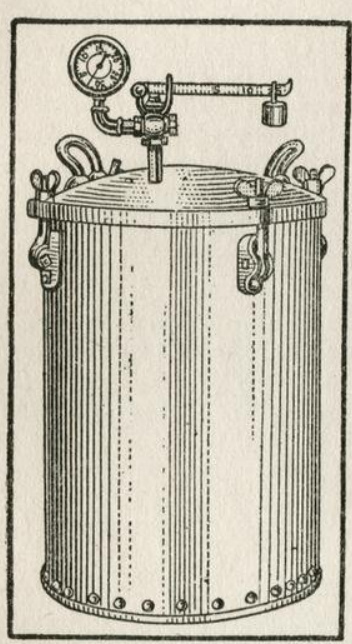

FIG. 4. Steam pressure canner; home and community canning. period, saving time, fuel and labor. The simplicity of the method commends it. Fruits are put up in syrups. Vegetables require only salt for flavoring and water to fill the container.

Another a dvantage is that it is practicable to put up food in small as well as large quantities. The housewife who understands the process will find that it pays to put up even a single container. Thus, when she has a small surplus of some garden crop she should take the time necessary to place this food in a container and store it for future use. This is true household efficiency.

\section{COLD-PACK EQUIPMENT}

1. The Homemade Hot-water Bath Outfit.A serviceable Single Period Cold-pack canning outfit may be made of equipment found in almost any household. Any utensil large and deep enough to allow an inch of water above jars, and a false bottom beneath them, and having a closely fitting cover, may be used for sterilizing. A wash-boiler, large lard can or new garbage pail serves the purpose when canning is to be done in large quantities. Into this utensil should be placed a wire or wooden rack to hold the jars off the bottom and so constructed as to permit circulation of water underneath the jars.

For lifting glass-top jars use two buttonhooks or similar device. For lifting screwtop jars, suitable lifters may be bought for a small sum. A milk carrier makes a good false bottom, and if this is used the jars may be easily lifted out at the end of the sterilization period.
2. Commercial Hot-water Bath Outfits.There are upon the market outfits on the order of the wash-boiler or pail type of homemade canner. These are excellent and are especially desirable if one has considerable quantities of vegetables or fruits to put up. There are also commercial canners conve-

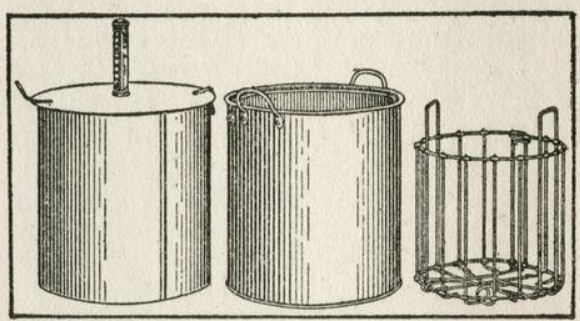

FIG. 5. Water-seal outfit. On the left is shown the cover, with thermometer. In the center is the double walled vat or holder. On the right is a crate for jars.

nient for out-door work, having fire-box and smoke-pipe all in one piece with the sterilizing vat. As with the homemade outfit, containers are immersed in boiling water.

3. Water Seal Outfits. - These are desirable, as the period of sterilization is shorter than in the homemade outfit and less fuel is therefore required. The outfit consists of two containers, one fitting within the other, and a cover which extends into the space between the outer and the inner container. The waterjacket makes it possible for the temperature in the inner container to be raised several degrees above $212^{\circ} \mathrm{F}$.

4. Steam Pressure Outfits.Canning is very rapid when sterilization is done in steam maintained at a pressure. There are several canners of this type. Each is provided with pressure gauge and safety valve and they carry from

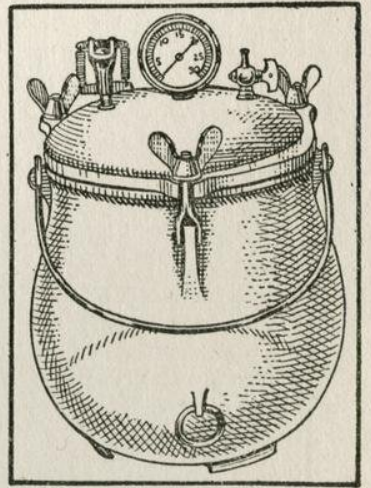

FIG. 6. Aluminum pressure canner. 5 to 30 pounds of steam pressure. This type is suitable for home or community canning.

5. Aluminum Pressure Outfits.-These cookers are satisfactory for canning and for general cooking. They carry from 5 to 30 pounds of steam pressure. Each outfit is provided with a steam pressure gauge and safety valve.

\section{HIGH ALTITUDES}

At high altitudes the boiling point of water is below $212^{\circ} \mathrm{F}$. At moderate elevations satisfactory results may be obtained in the use of the hot-water bath by increasing the time of sterilization 10 per cent for every 
500 feet above 1000 . To insure best results in very high altitudes, however, a steam pressure canner or aluminum pressure cooker

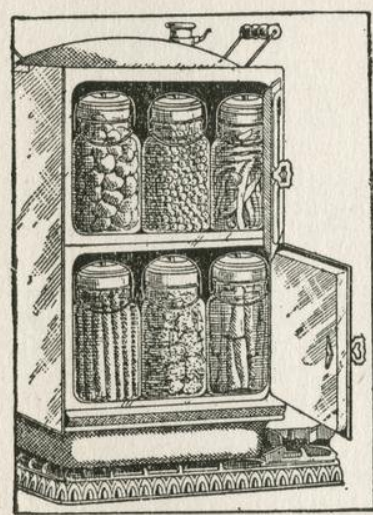

Frg. 7. Home canner and steam cooker holding 14 quart jars. Requires same time as hot-water bath.

\section{OPERATION OF PRESSURE CANNERS AND ALUMINUM COOKERS}

1. Have water in the canner up to the false bottom, but not above it. Keep this water boiling during the time that packed jars are being placed in the canner, and add water occasionally to prevent its boiling dry.

2. To prepare product follow instructions in "Steps in the Single Period Cold-pack Method" on pages 8 and 9. As each jar is packed, set it at once, partially sealed, in the canner. The cover of the canner may be put in position, but not clamped.

3. When all of the filled jars are placed in the canner, put on the cover, and fasten opposite clamps moderately tight; then tighten each pair of clamps fully.

4. The petcock should be left open until live steam escapes from it. The canner should be steam-tight, and no steam should escape except through the open petcock. When live steam escapes, close the petcock completely.

5. Begin to count time when the steam gauge registers the required temperature.

6. Maintain a uniform pressure during the sterilizing period by setting the weight on the arm, when the proper pressure is registered on the steam gauge, so that surplus steam will escape at that desired pressure. A uniform temperature may be maintained also, by turning down the flame or moving the canner to a less hot part of the stove.

7. When the sterilization period is complete, do not allow steam to escape, but allow the canner to cool until the steam gauge registers zero.

8. Open petcock, remove the cover of canner, and take out the jars. As each jar is removed, complete seal at once.

\section{CONTAINERS}

For home use glass jars are more satisfactory for canning than tin. This is especially true this year when there is a shortage of tin cans. Tin cans are used chiefly for canning on a large scale for commercial purposes.

There are many jars of different styles and prices on the market; and provided the seal is not defective, equally good results may be obtained from all. Glass is a popular household choice because one can see through it and thus have some idea as to the condition of the contents. Glass jars may be used for years if properly cared for.

All types of jars which seal readily may be used. Jars having glass tops held in place by bails are especially easy to handle while hot. Screw-top jars are serviceable. Glass caps held in place by separate metal screw bands are now on the market, as well as the one-piece sort of former years. Vacuum seal jars are very easily managed. Tops for Economy jars should be purchased each year. The composition material, which takes the place of rubber, should have a rubber-like texture. If of mealy consistency it is unfit for use and the top will not make a tight seal.

The color and shape of jars are not of first moment, but are to be considered. Containers made of white glass should be used if the product is to be offered for sale, as blue or green glass detracts from the appearance of the contents. Wide-mouthed jars are best for packing wholeproducts

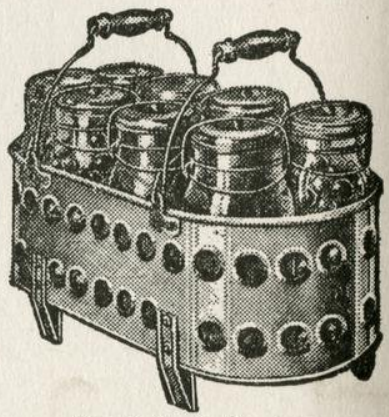

FIG. 8. Rack for jars. and are easiest to clean. Small-necked bottles can be used for fruit juices. Largemouthed bottles can be used for jams, marmalades and jellies.

\section{TESTS FOR JARS}

Jars should be tested before they are used. Some of the important tests are here given:

1. Glass-top Jars.-First examine for cracks. Then run a finger around the edge of necks of jars, and if there are sharp projections, file them off, or scrape them off with an old knife. If left on they may cut rubbers and interfere with perfect sealing. Place a top on a jar. It will slip from side to side, but should not rock, when tapped. Rocking tops will not make a tight seal. Sometimes the fault is with the top and sometimes with the neck. Defective jars and tops when discarded for 
canning purposes may be used as containers for jams, etc. The top-bail should go into position with a light snap. If too loose it should be taken off and bent slightly inward in the center. If too tight bend outward.

2. Screw-top Jars.-Use only enameled, lacquered or vulcanized tops. Screw the top

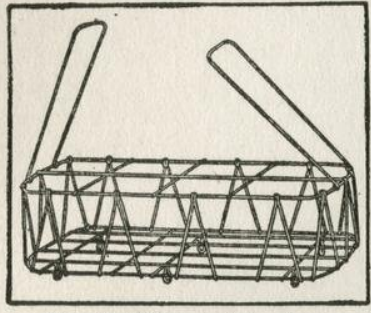

Fig. 9. Wire rack for jars. on tightly without the rubber. If the tip of a knife or finger - nail can be inserted under the rim, the topsshould not be used for cold-pack canning. If the defect is very slight, however, it may be remedied by pressing a knife handle on the lower edge against a hard surface, thus straightening the offending bulge. Another test is made by putting on the rubber, screwing the top on tightly and then pulling the rubber out. If the rubber returns to place, the top does not fit and should not be used on that jar.

3. Vacuum seal jars may be tested in the same way as the glass-top jars. See if the tops rock if tapped, when placed on the jar without fastening.

\section{STANDARDS AND TESTS FOR RINGS}

1. Good Rubber Essential.-Buy new rubbers every year, as rubbers deteriorate from one season to another. A good rubber for

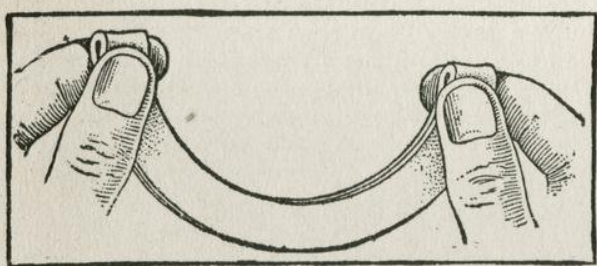

FIg. 10. Simple test for rubbers. A perfect rubber will show no crease or break after being folded tightly several times.

cold-pack canning must be such as to stand four hours of continuous boiling or one hour under 10 pounds of steam pressure. The combination of moist heat plus acids and mineral matter in vegetables and fruits tends to break down the rubbers during sterilization. Rubbers kept in a hot or very warm place, as for example, on a shelf near the kitchen range, will deteriorate in quality. Be very particular about the rubbers used. Spoilage of canned goods has been traced frequently to the use of poor rubbers.

2. Testing Rubbers.-It is always well to test rubbers when buying. A good rubber will return to its original size when stretched. It will not crease when bent double and pinched (Fig. 10). It should fit the neck of the jar snugly. It is cheaper to discard a doubtful rubber than to lose a jar of canned goods.

\section{GRADING}

Vegetables and fruits should be sorted according to color, size and ripeness. This is called grading. It insures the best pack and uniformity of flavor and texture to the canned product, which is always desirable.

\section{BLANCHING AND COLD-DIPPING}

The most important steps in canning are the preliminary steps of blanching, colddipping, packing in hot, clean containers, adding hot water at once, then immediately half sealing jars and putting into the sterilizer. Spoilage of products is nearly always due to carelessness in one of these steps. Blanching is necessary with all vegetables and some fruits. It insures thorough cleansing and removes objectionable odors and flavors and excess acids. It starts the flow of coloring matter. It reduces the bulk of greens and causes shrinkage of fruits, increasing the quantity which may be packed in a container, which saves storage space.

Blanching consists of plunging the vegetables or fruits into boiling water or exposing them to steam for a short time. For blanching in boiling water place them in a wire basket (Fig. 17) or piece of cheesecloth (Fig. 18). The blanching time varies from one to fifteen minutes, as shown in the time-table on page 2 , and the products should be kept under water throughout the period. Begin counting time when the articles are first placed in boiling water or steam.

Spinach and other greens should not be blanched in hot water. They must be blanched in steam to prevent the loss of mineral salts, volatile oils and other valuable substances. To do this place them in a colander and set this into a vessel which has a tightly fitting cover. In this vessel there should be an inch or two of water, but the water must not be allowed to touch the greens (Fig. 12). Another method is to suspend the greens in the closed vessel above an inch or

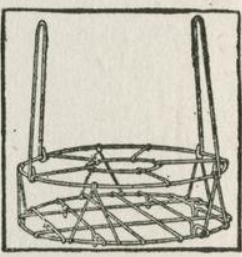

FIG. 11. Wire rack for jars. two of water. This may be done in a wire basket or in cheesecloth. Allow the water to boil in the closed vessel fifteen minutes. Excellent results are obtained, also, by the use of a steam cooker or steam pressure canner.

When the blanching is complete remove the vegetables or fruits from the boiling water or steam and plunge them once or twice 
into cold water-the colder the better. This latter process is the Cold Dip. It hardens the pulp under the skin, so that the products are not injured by peeling. It also sets the coloring matter. Do not allow the products to stand in the cold water.

Always blanch and cold-dip only enough product to fill one or two jars at a time. The blanching and cold-dipping should follow at once when the vegetable or fruit is prepared, and the packing into jars should immediately follow the blanching and cold-dip.

\section{PROCESSING}

Processing is the sterilization treatment to which products are subjected after packing them into jars. As soon as the jar is filled, put the rubber and cap in place and partially seal by adjusting top bail or screwing on top with thumb and little finger. If Economy jars are used the top should be held in place with clamp. The jar should then be put into sterilizer at once.

In using the hot-water bath outfit, count the time of sterilization from the time water

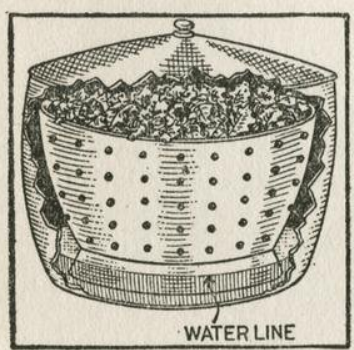

FIg. 12. Use of a colander to blanch greens in steam. The colander is placed in a receptacle with tightly fitting cover. No water should touch the greens.

when the gauge reaches the number of pounds called for in directions.

When the processing is finished, at once remove and seal each jar.

\section{ARRANGING FOR CANNING}

It is important to plan your work so that whatever may be needed will be ready for use. Arrange everything conveniently in advance. Preliminary provisions include:

1. A reliable alarm clock in a convenient place (set to ring when the sterilizing is done).

2 . All the necessary equipment in place before beginning work. See Fig. 14 .

3. Jars, tops and rubbers carefully tested.

4. Fresh, sound fruits and vegetables.

5. Plenty of hot water for sterilizer, blanching, warming the jars and for pouring into packed jars.

6. Salt or syrup at hand.

7. Reliable instructions, carefully followed.

8. Absolute cleanliness.

\section{STEPS IN THE SINGLE PERIOD COLD-} PACK METHOD

In canning by the Single Period Cold-pack method it is important that careful attention be given to each detail. Do not undertake canning until you have familiarized yourself with the various steps, which are as follows:

1. Vegetables should be canned as soon as possible after picking; the same day is best. Early morning is the best time for gathering. Fruits should be as fresh as possible.

2. Before starting work have on the stove the boiler or other holder in which the sterilizing is to be done, a pan of boiling water for use in blanching, a vessel containing water to be used for warming several jars at a time, and a kettle of boiling water for use in filling jars of vegetables; or, if canning fruits, the syrup to be used in filling the jars. Arrange on this working table

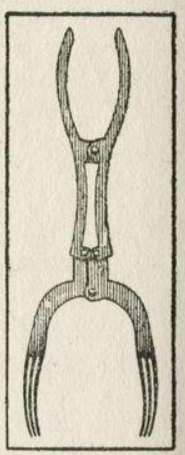

FIG. 13. A jarlifter is useful. all necessary equipment, including instructions. (Fig. 14.)

3. Test jars and tops. All jars, rubbers and tops should be clean and hot, at the moment of using.

4. Wash and grade product according to size and ripeness. (Cauliflower should be soaked 1 hour in salted water, to remove insects if any are present. Put berries into a colander and wash, by allowing cold water to flow over them, to prevent bruising.)

5. Prepare vegetable or fruit. Remove all but an inch of the tops from beets, parsnips and carrots and the strings from green beans. Pare squash, remove seeds and cut into small pieces. Large vegetables should be cut into pieces to make close pack possible. Remove pits from cherries, peaches and apricots.

6. Blanch in boiling water or steam as directed. Begin to count time when the product is immersed.

7. Cold-dip, but do not allow product to stand in cold water at this or any other stage.

8. Pack in hot jars which rest on cloths wrung out in hot water. Fill the jars to within $1 / 4$ to $1 / 2$ inch of tops. (In canning lima beans, squash, corn, peas, pumpkin and sweet potatoes fill the jars to within 1 inch of the top, as these vegetables swell during sterilization. In canning berries, to insure a close pack, put a 2 or 3 inch layer of berries on the bottom of the jar and press down gently with a spoon. Continue in this manner with other layers until jar is filled. Fruits cut in half should be arranged with pit surface down.)

9. Add salt and then boiling water to vegetables to cover them. To fruits add hot syrup or water.

10. Place a new wet rubber on jar and put top in place. 


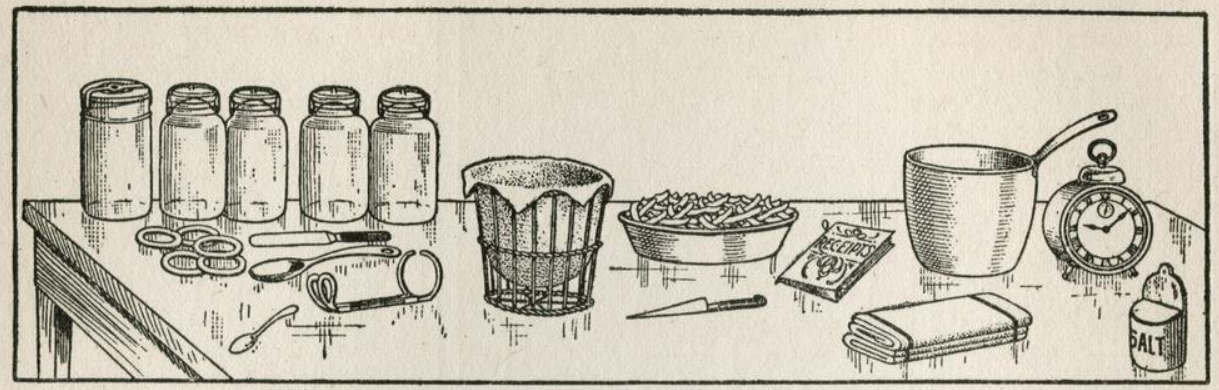

FIG. 14. Table arranged conveniently with various articles needed for canning by the Cold-pack method. The picture shows jars, rubbers, knife for removing air bubbles in containers, spoons, jar lifter, wire basket for blanching, knife for paring and coring, book of directions, towels, pan for cold-dipping, alarm clock and"salt.

11. With bail-top jar adjust top bail only, leaving lower bail or snap free. With screwtop jar screw the top on lightly, using only the thumb and little finger. (This partial sealing makes it possible for steam generated within the jar to escape, and prevents breakage.) On vacuum seal jars adjust spring securely.

12. Place the jars on rack in boiler or other sterilizer. If the homemade or commercial hot-water bath outfit is used, enough water should be in the boiler to come at least one inch above the tops of the jars, and the water, in evaporating, should never be allowed to drop to the level of these tops. In using the hot-water bath outfit, begin to count sterilizing time when the water begins to boil. Water is at the boiling point when it is jumping or rolling all over. Water is not boiling when bubbles merely form on the bottom or when they begin to rise to the top. The water must be kept boiling all of the time during the period of sterilization.

13. Consult time-table on page 2 and at the end of the required sterilizing period remove the jars from the sterilizer. Place them on a wooden rack or on several thicknesses of cloth to prevent breakage. Complete the sealing of jars. With bail-top jars this is done by pushing the snap down (Fig. 15); with screw top jars by screwing cover on tightly.

14. Turn the jars upside down as a test for leakage and leave them in this position till cold. Let them cool rapidly but be sure that no draft reaches them as a draft will cause breakage. (If there is any doubt that a bail-top jar is perfectly sealed a simple test

\section{CAUTION AGAINST FREEZING}

From a number of sources it has been learned that the severe weather of last winter caused considerable loss through the freezing of canned goods. To prevent similar trouble, care should be taken to store canned vegetables and fruits where they will be protected from freezing. If the place of storage is not frostproof the jars should be moved to a warmer place in severe weather. may be made by loosening the top bail and lifting the jar by taking hold of the top with the fingers. (Fig. 28.) The internal suction should hold the top tightly in place when thus lifted. If the top comes off put on a new wet rubber and sterilize 15 minutes longer for vegetables and 5 minutes longer for fruits.) With screw-top jars try the tops while the jars are cooling, or as soon as they have cooled, and, if loose, tighten them by screwing on more closely. Vacuum seal jars should be placed upright while cooling, and

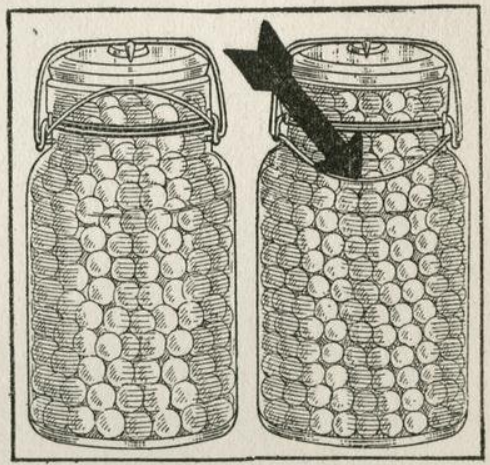

FIG. 15. To the left is a bail-top jar partially sealed and ready for sterilization. The top bail is snapped into place and the lower bail left free. To the right is shown the way to complete the seal.

the clamp removed when the jar is cool. Then lift by the top and turn upside down, as a test for leakage.

15. Wash and dry each jar, label and store. If storage place is exposed to light, wrap each jar in paper, preferably brown, as light will either fade or darken the color of products canned in glass. The boxes in which jars were brought afford good storage. Store in a cool, dark place, preferably dry. Exposure to mold will cause decay of rubber, allowing the leakage of air into jars. Paper wrappings prevent mold.

This Commission publishes a book on "War Gardening and the Home Storage of Vegetables," completely covering both subjects. 


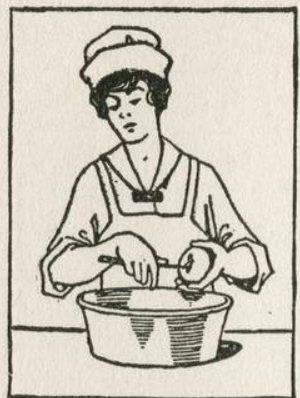

FIG. 16

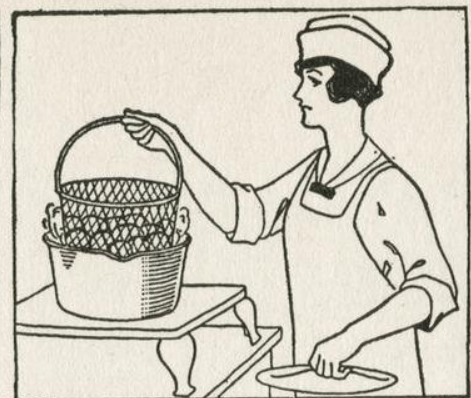

FIG. 17

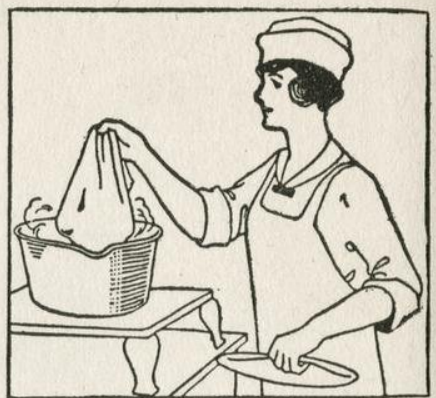

FIG. 18

In the pictures on this and the next page are shown successive steps in canning by the Single Period Coldpack Method. FIG. 16 shows paring and coring with sharp knife. FIG. 17 shows blanching with wire basket. FIG. 18 shows blanching with cheesecloth. (Continued at top of opposite page.)

\section{SPECIAL INSTRUCTIONS FOR CANNING VEGETABLES}

The addition of 1 level teaspoonful of salt to a jar of vegetables is for quart jars. For pint jar use $1 / 2$ teaspoonful. For 2 quart jar use 2 teaspoonfuls.

\section{Asparagus}

Wash, scrape off scales and tough skin. With a string bind together enough for one jar. Blanch tough ends from 5 to $10 \mathrm{~min}$ utes, then turn so that the entire bundle is blanched 5 minutes longer. Cold-dip. Remove string. Pack, with tip ends up. Add 1 level teaspoonful of salt and cover with boiling water. Put on rubber top and adjust top bail or screw top on with thumb and little finger. Sterilize 120 minutes in hot-water bath. Remove jars, complete seal and cool. With Steam Pressure Outfit sterilize $60 \mathrm{~min}$ utes at 5 to 10 pounds pressure.

\section{Beets}

Use only small ones. Wash and cut off all but an inch or two of root and leaves. Blanch 5 minutes, cold-dip and scrape off skin and stems. They may be packed in jar sliced or whole. Add 1 level teaspoonful of salt and cover with boiling water. Put on rubber and top and adjust top bail or screw top on with thumb and little finger. Sterilize 90 minutes in hot-water bath. Remove jars, complete seal and cool.
With Steam Pressure Outfit sterilize 60 minutes at 5 to 10 pounds pressure.

Young, tender beet tops should be canned as greens.

\section{Cabbage and Brussels Sprouts}

The method is the same as for cauliflower, except that the vegetables are not soaked in salted water. Blanch 5 to 10 minutes. Sterilize 120 minutes in hot-water bath.

With Steam Pressure Outfit sterilize 60 minutes at 5 to 10 pounds pressure.

\section{Carrots}

Select small, tender carrots, leave an inch or two of stems, wash, blanch 5 minutes and cold-dip. Remove stems and scrape off skins. Pack whole or in slices, add 1 level teaspoonful of salt and cover with boiling water. Put on rubber and top and adjust top bail or screw top on with thumb and little finger. Sterilize 90 minutes in hot-water bath. Remove jars, complete seal and cool.

With Steam Pressure Outfit sterilize 60 minutes at 5 to 10 pounds pressure.

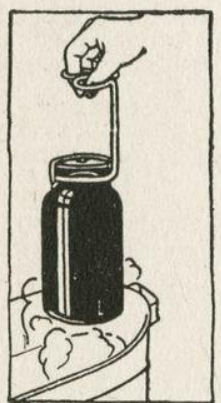

FIG. 22

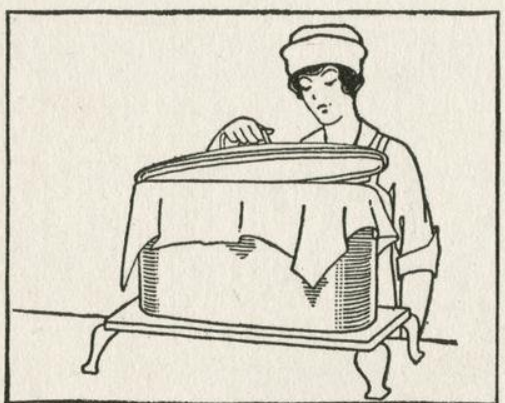

FIG. 23

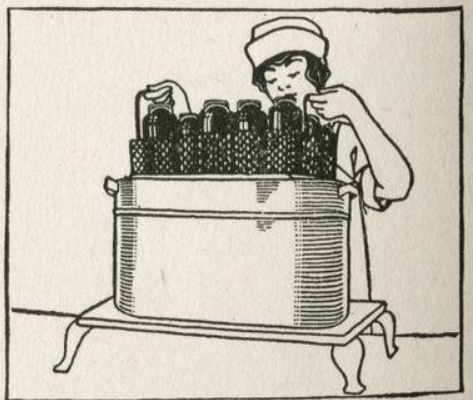

FIG. 24

After partially sealing jars, place them in hot-water bath. FIG. 22 shows jar being placed in ordinary household wash-boiler for sterilizing. FIG. 23 shows the adjustment of cover, with cloth to give tighter fit and make it hold the steam. FIG. 24 shows jars being removed. (Continued at bottom of next page.) 


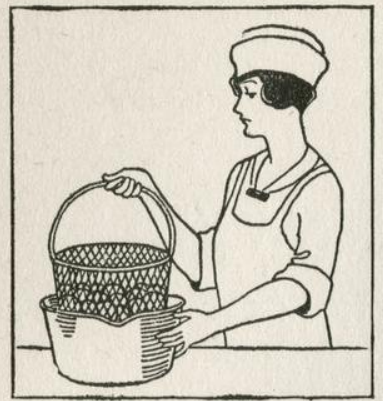

FIG. 19

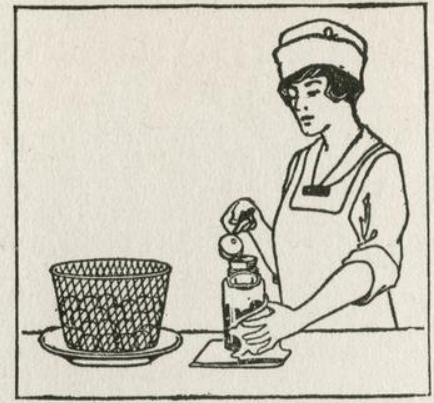

FrG. 20

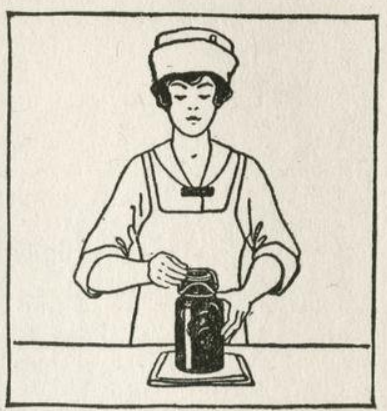

FIG. 21

After blanching, as shown in FIGs. 17 and 18, vegetables and fruits are cold-dipped, as shown in FIG. 19. In FIG. 20 is shown the process of filling jar, by use of funnel. Fig. 21 shows the partial sealing of jar. With bail-top jar adjust top bail only; with screw top jar screw top on lightly. (Continued at bottom of opposite page.)

\section{Cauliflower}

Wash and divide head into small pieces. Soak in salted water 1 hour, which will remove insects if any are present. Blanch 3 minutes, cold-dip and pack in jar. Add 1 level teaspoonful of salt and cover with boiling water. Put on rubber and top and adjust top bail or screw top on with thumb and little finger. Sterilize 60 minutes in hot-water bath. Remove jars, complete seal and cool.

With Steam Pressure Outfit sterilize 30 minutes at 5 to 10 pounds pressure.

\section{Corn}

Canning corn on the cob, except for exhibition purposes, is a waste of space, time and fuel. For home use remove the husks and silk, blanch tender ears 5 minutes, older ears 10 minutes, cold-dip, and cut from cob. Pack lightly to within 1 inch of the top of the jar, as corn swells during sterilization. Add 1 level teaspoonful of salt and cover with boiling water, put on rubber and top, adjust top bail or screw top on with thumb and little finger. Sterilize 180 minutes in hot-water bath. Remove jars, complete seal and cool. (When canned on cob 1 hour longer of sterilization is necessary).

With Steam Pressure Outfit sterilize 90 minutes at 5 to 10 pounds pressure.

\section{Greens}

Wash until no dirt can be felt in the bottom of the pan. Blanch in steam 15 minutes. (Mineral matter is lost if blanched in water.) Cold-dip, cut in small pieces and pack or pack whole. Do not pack too tightly. Add 1 level teaspoonful of salt and cover with boiling water. Put on rubber and top and adjust top bail or screw top on with thumb and little finger. Sterilize 120 minutes in hot-water bath. Remove jars, complete seal and cool.

With Steam Pressure Outfit sterilize 60 minutes at 5 to 10 pounds pressure.

\section{Lima Beans}

Shell. Blanch 5 to 10 minutes. Colddip, pack in jar, add 1 level teaspoonful of salt and cover with boiling water. Put on rubber and top, and adjust top bail or screw top on with thumb and little finger. Sterilize 180 minutes in hot-water bath. Remove jars, complete seal and cool.

With Steam Pressure Outfit sterilize 60 minutes at 5 to 10 pounds pressure.

\section{Okra}

Wash and remove stems. Blanch 5 to 10 minutes, cold-dip and pack in jar. Add 1 level teaspoonful of salt and cover with boiling

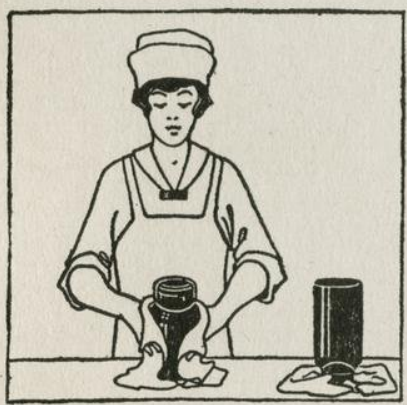

FIG. 25

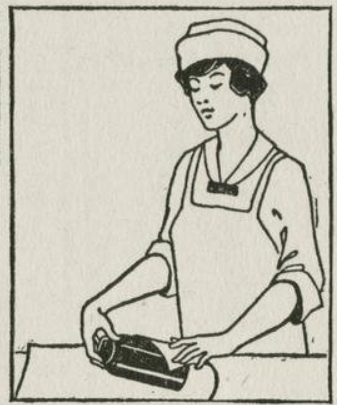

FIG. 26

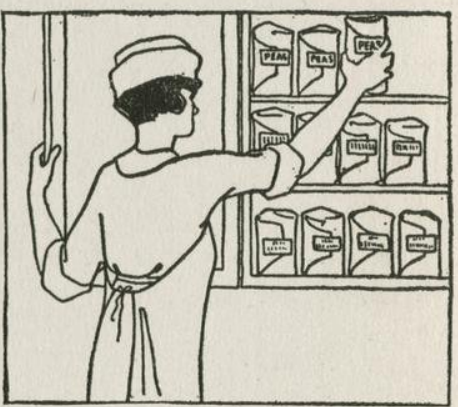

FIG. 27

After remaval from hot-water bath jars are inverted to test for leakage (FIG. 25) and left inverted until cooled. They should be cooled rapidly, but protected from draft. FIG. 26 shows wrapping jar in brown paper to exclude light. FIG. 27 shows storage on shelves. If shelves are exposed to light, do not neglect wrapping. 


\section{A WORD OF CAUTION}

It must not be forgotten that success in canning demands careful attention to every detail. No step should be slighted. Follow one set of instructions closely and do not attempt to combine two, no matter how good both of them may be. To attempt to follow two sets will inevitably cause spoilage.

The experience of the United States Department of Agriculture during the last five years indicates that 75 per cent. of the spoilage has been due to the use of poor rubbers, the use of old tops on screw-top jars, and improper sealing resulting from the use of defective joints, springs and caps. Another fruitful source of trouble is that people sometimes undertake to can stale or wilted vegetables. No amount of sterilizing will overcome staleness. Careless handling is also sure to cause loss. Absolute cleanliness in every step is essential.

In sterilizing care must be exercised to see that the temperature is high enough and maintained for the proper length of time.

IN OTHER WORDS DO NOT BLAME THE METHOD FOR FAILURE. FOLLOW DIRECTIONS CAREFULLY AND PREVENT FAILURE.

water. Put on rubber and top, adjust top bail or screw top on with thumb and little finger. Sterilize 120 minutes in hot-water bath. Remove jars, complete seal and cool.

With Steam Pressure Outfit sterilize 60 minutes at 5 to 10 pounds pressure.

\section{Parsnips}

The method is the same as for carrots.

\section{Peas}

Those which are not fully grown are best for canning. Shell, blanch 5 to 10 minutes and cold-dip. Pack in jar, add 1 teaspoonful of salt and cover with boiling water. If the jar is packed too full some of the peas will break and give a cloudy appearance to the liquid. Put on rubber and top and adjust top bail or screw top on with thumb and little finger. Sterilize 180 minutes in hot-water bath. Remove jars, complete seal and cool.

With Steam Pressure Outfit sterilize 60 minutes at 5 to 10 pounds pressure.

\section{Peppers}

Wash, stem and remove seeds. Blanch 5 to 10 minutes, cold-dip and pack in jar. Add 1 level teaspoonful of salt. Cover with boiling water, put on rubber and top and adjust top bail or screw top on with thumb and little finger. Sterilize 120 minutes in hot-water bath. Remove jars, complete seal and cool.

With Steam Pressure Outfit sterilize 60 minutes at 5 to 10 pounds pressure.

\section{Pimentos}

Place in a hot oven from 6 to 8 minutes. Peel, remove seeds, and pack in flat layers. Do not add any liquid. Sterilize 35 minutes in hot-water bath.

\section{Pumpkin, Winter Squash}

(a) Remove seed. Cut the pumpkin or squash into strips. Peel and remove stringy center. Slice into small pieces and boil until thick. Pack in jar and sterilize 120 minutes in hot-water bath. Remove jars, complete seal and cool.

(b) Another method is to prepare the pieces as in (a), blanch 3 minutes, cold-dip, pack in jars and add 1 level teaspoonful of salt to each quart jar. Cover with boiling water and sterilize as (a).

With Steam Pressure Outfit sterilize 60 minutes at 5 to 10 pounds pressure.

\section{Salsify}

Wash, blanch 5 minutes, cold-dip and scrape off skin. It may be packed whole or in slices. Add 1 teaspoonful of salt, and cover with boiling water. Put on top and rubber and adjust top bail or screw top on with thumb and little finger. Sterilize 90 minutes in hot-water bath. Remove jars, complete seal and cool.

With Steam Pressure Outfit sterilize 60 minutes at 5 to 10 pounds pressure.

\section{String Beans}

Wash and remove ends and strings and cut into small pieces if desired. Blanch from

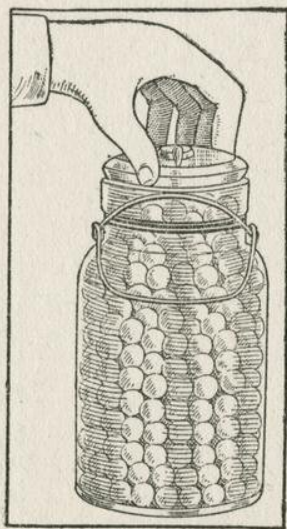

FIG. 28. A simple test for proper sealing of bail-top jars is to loosen top bail and lift jar by taking hold of top with the fingers. See top with the fingers.
Step No. 14, page 9. 5 to 10 minutes, depending on age. Beans which have been properly blanched will bend readily without breaking. Cold-dip, pack immediately in jar, add 1 level teaspoonful salt and cover with boiling water. Put on rubber and top and adjust top bail or screw top on with thumb and little finger. Sterilize 120 minutes in hot-water bath. Remove jars, complete seal and cool.

With Steam Pressure Outfit sterilize 60 minutes at 5 to 10 pounds pressure.

\section{Summer Squash}

Pare, cut in slices or small pieces and blanch 10 minutes. Cold-dip, pack in jars, add 1 level teaspoonful of salt, cover with boiling water, put on rubber and top and adjust top bail or screw top on with thumb and little finger. Sterilize 120 minutes in hot- 
water bath. Remove jars, complete seal and cool.

With Steam Pressure Outfit sterilize 60 minutes at 5 to 10 pounds pressure.

\section{Tomatoes}

Take medium sized tomatoes. Wash them, blanch $11 / 2$ minutes or until skins are loose, cold-dip and remove the skins. Pack whole in jar, filling the spaces with tomato pulp made by cooking large and broken tomatoes until done and then straining and adding 1 level teaspoonful of salt to each quart of the pulp. Put on rubber and top and adjust top bail or screw top on with thumb and little finger. Sterilize 22 minutes in hot-water bath. Remove jars, complete seal and cool.

With Steam Pressure Outfit sterilize 15 minutes at 5 to 10 pounds pressure.

Tomatoes may be cut in pieces, packed closely into jars and sterilized 25 minutes in hot-water bath. If this is done do not add any liquid, as the liquid in the tomatoes will be sufficient.

\section{THE CANNING OF FRUITS}

For fruits, as well as for vegetables, the Single Period Cold-pack method is best. With some exceptions, as shown in the table on page 2, fruits should be blanched before canning. When fruits are intended for table use, syrup should be poured over them to fill the jars. In canning fruits to be used for pie-filling or in cooking, where unsweetened fruits are desirable, boiling water is used instead of syrup, and the sterilization period in hot-water bath is thirty minutes.

\section{SYRUPS}

In the directions given various grades of syrup are mentioned. These syrups are made as follows:

Thin-1 part sugar to 4 parts water.

Medium -1 part sugar to 2 parts water.

Thick-1 part sugar to 1 part water.

\section{SPECIAL INSTRUCTIONS FOR CANNING FRUITS}

\section{Apples}

Wash, pare, quarter or slice and drop into weak salt water. Blanch $11 / 2$ minutes, colddip, pack into jar and cover with water or thin syrup. Put on rubber and top and adjust top bail or screw top on with thumb and little finger. Sterilize for 20 minutes in hot-water bath. Remove jars, complete seal and cool.

With Steam Pressure Outfit sterilize 8 minutes at 5 to 10 pounds pressure.

Apples shrink during sterilization and for this reason economy of space is obtained by canning them in the form of sauce instead of in quarters or slices. In canning sauce fill the jars with the hot sauce and sterilize 12 minutes in hot-water bath.

\section{Apricots}

Use only ripe fruit. Wash, cut in half and remove pit. Blanch 1 to 2 minutes. Pack in jar and cover with medium syrup. Put on rubber and top and adjust top bail or screw top on with thumb and little finger. Sterilize 16 minutes in hot-water bath. Remove jars, complete seal, cool and store.

With Steam Pressure Outfit sterilize 10 minutes at 5 to 10 pounds pressure.

\section{Blackberries}

Wash, pack closely and cover with medium syrup. Put on rubber and top and adjust
Heat the water to boiling, then add the sugar gradually, stirring constantly and keeping the liquid boiling until the sugar is dissolved. Syrup made in this way requires little or no skimming.

Use thin syrup with sweet fruits. Use medium syrup with sour fruits. Thick syrup is used in candying and preserving.

Because of the shortage of sugar it is important to use substitutes wherever possible. A very satisfactory syrup for fruits may be made of one part of light corn syrup or honey to three parts of water or juice of the fruit. Add the honey or corn syrup to the liquid and simmer ten minutes.

Allow two cupfuls of syrup to each quart jar of fruit.

top bail or screw on top with thumb and little finger. Sterilize 16 minutes in hot-water bath. Remove jars, complete seal and cool.

With Steam Pressure Outfit sterilize 10 minutes at 5 to 10 pounds pressure.

\section{Blueberries Loganberries \\ Currants Raspberries}

The method is the same as for blackberries. Sterilize 16 minutes in hot-water bath.

With Steam Pressure Outfit sterilize 10 minutes at 5 to 10 pounds pressure.

\section{Cherries}

Cherries should be pitted before being canned. Pack in jar and cover with medium syrup. Put on rubber and top and adjust top bail or screw on top with thumb and little finger. Sterilize 16 minutes in hot-water bath. Remove jars, complete seal and cool.

With Steam Pressure Outfit sterilize 10 minutes at 5 to 10 pounds pressure.

\section{Fruit Juices \\ See "Winter Jelly Making" on page 17. \\ Pears}

Peel and drop into salt water to prevent discoloration. Blanch $11 / 2$ minutes. Pack in jar, whole or in quarters, and cover with thin syrup. Put on rubber and top and adjust top bail or screw on top with thumb and little 
finger. Sterilize 20 minutes in hot-water bath. Remove jars, complete seal and cool. A slice of lemon may be added to the contents of each jar for flavor.

With Steam Pressure Outfit sterilize 8 minutes at 5 to 10 pounds pressure.

\section{Peaches}

Blanch in boiling water long enough to loosen skins. Some peaches do not peel readily even if dipped in boiling water. In such cases omit dipping in boiling water and pare them. Cold dip and remove skins. Cut in half and remove stones. Pack in jars and cover with thin s rup. Put on rubber and top and adjust top bail or screw on top with thumb and little finger. Sterilize 16 minutes in hot-water bath. Remove jars, complete seal and cool.

With Steam Pressure Outfit sterilize 10 minutes at 5 to 10 pounds pressure.

\section{Plums}

Wash, pack in jar and cover with medium syrup. Put on rubber and top and adjust top bail or screw on top with thumb and little finger. Sterilize 16 minutes in hot-water bath. Remove jars, complete seal and cool.

With Steam Pressure Outfit sterilize 10 minutes at 5 to 10 pounds pressure.

\section{Pineapples}

Pare, remove eyes, shred or cut into slices or small pieces, blanch 3 to 5 minutes, according to size of pieces, and pack in jar. Cover with medium syrup. Put on rubber and top and adjust top bail or screw on top with thumb and little finger. Sterilize 30 minutes in hotwater bath. Remove jars, complete seal and cool.

With Steam Pressure Outfit sterilize 10 minutes at 5 to 10 pounds pressure.

\section{Quinces}

The method is the same as for apples. They may be canned with apples. Sterilize 20 minutes in hot-water bath

With Steam Pressure Outfit sterilize 8 minutes at 5 to 10 pounds pressure.

\section{Rhubarb}

Wash and cut into short lengths. Cover with boiling water or thin syrup. Put on rubber and top and adjust top bail or screw on top with thumb and little finger. Sterilize 20 minutes in hot-water bath. Remove jars, complete seal and cool.

With Steam Pressure Outfit sterilize 15 minutes at 5 to 10 pounds pressure.

\section{Strawberries}

Wash and pack closely in jar. Cover with medium syrup, put on rubber and top and adjust top bail or screw on top with thumb and little finger. Sterilize 16 minutes in hotwater bath. Remove jars, complete seal and cool.

With Steam Pressure Outfit sterilize 10 minutes at 5 to 10 pounds pressure.

\section{CANNING IN TIN}

In sections where there is a large yield of fruits or vegetables canning in tin in the home is practical. This is especially true when the goods are to be sold, as tin cans are more easily transported than glass containers. Tin cans of standard sizes may be purchased in sanitary or cap and hole type. The No. 2 can is most satisfactory for canned vegetables and small fruits. No. 3 is used for peaches, pears, and tomatoes. Enameled tins should be used when canning berries, plums, cherries, beets, pumpkins, and greens.

To can in tin special equipment is needed.
This includes a capping steel, a tipping copper, fire pot for heating tools, flux, sal ammoniac and wire solder. Sanitary cans require a special machine for sealing, which eliminates the use of all other equipment.

Fruits and vegetables are prepared as shown in the directions given for the coldpack method on pages 8 and 9 . The only variation is that after the product is packed the cap is soldered and cans are then put into the sterilizer and exhausted from two to fifteen minutes, depending upon the kind of contents. Exhausting is necessary as it

\section{A WORD AS TO BOTULISM}

Wide-spread attention has been attracted by the statement that vegetables canned by the Single Period Cold-pack Method had caused cases of poisoning technically known as botulism. It has been declared that the bacillus botulinus, which produces botulism, was a menace to all users of vegetables canned by this method. Such statements were obviously circulated by those seeking to discourage American food-thrift. Expert research workers of the National War Garden Commission and the United States Department of Agriculture agree that there is no danger of botulism from eating vegetables which have been canned by carefully following the directions issued by the Commission or the Department. CARE MUST BE TAKEN, HOWEVER, TO FOLLOW DIRECTIONS EXPLICITLY. Cooking canned vegetables for 10 minutes at the boiling point, after opening the jar for use, will remove any possible danger. This applies also to Apricots and Pears. 


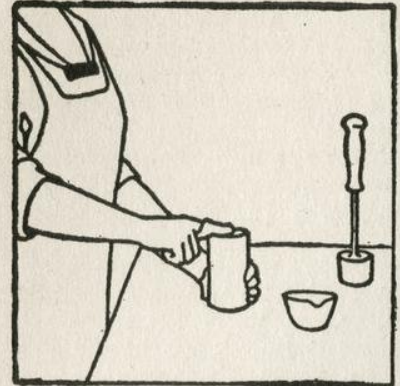

FIG. 29

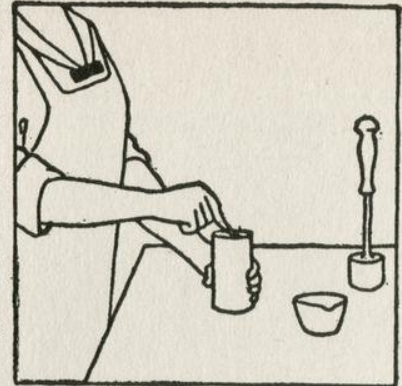

FIG. 30

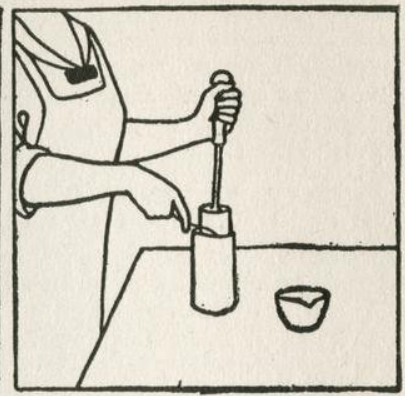

FIG. 31

Canning in TIN. Fig. 29. Wiping juice and syrup from groove. Fig. 30. Applying cap and wiping groove with brush dipped in soldering fluid. FIG. 31. Placing clean hot capping steel on can and melting solder into groove.

drives out the air which will cause the can to bulge, giving it the same appearance as when spoilage has occurred. After exhausting, the cans are removed from the sterilizer and the vent hole is closed. The cans are returned to the sterilizer and sterilized, following the time-table given on page 2 . At the end of the sterilization period remove cans and plunge immediately into cold water. Do not stack cans closely until cold.

After packing, label each can by writing the name of contents on the side. If intended for sale affix a label just before shipping. Do not allow paste to touch the can, as it will cause the tin to rust. The label should be large enough to encircle the can and overlap at the edges. Put the paste on one of the overlapping edges and draw label tightly around can, pasting the two edges together.

To seal, wipe top of can clean and dry and then put the cap in place, applying flux carefully to the groove. Do not allow the flux to enter can, as it is poisonous. Hold the cap in place with the center rod and lower the hot capping iron squarely and firmly on the solder rim of the cap, or melt a little solder in the groove by holding the solder wire against the lower part of the capping steel. Revolve the iron to melt the solder and seal the can. Lift the capping iron with a sudden twist, holding the center rod in place. When solder has hardened remove center rod.

To tip, dry top of can and apply flux to the hole in the center of the cap. Hold the solder in the left hand, brush it with the hot tipping iron so only a bead will drop and close hole.

The steels must be kept clean and well coated with solder. To do this, if capping steel is rusty, clean with a file, brick or emery paper. To tin the capping steel heat and dip in flux, then heat again until red hot and dip in sal ammoniac and solder until well coated. Sal ammoniac is made by mixing equal parts of dry sal ammoniac with solder chips. Coat the tipping copper in same way.

Flux is made as follows: To muriatic acid add strips of zinc until no more will dissolve. Strain through a cloth and when ready to use add an equal quantity of water. Flux which is used for tinning the tools should not be used for soldering.

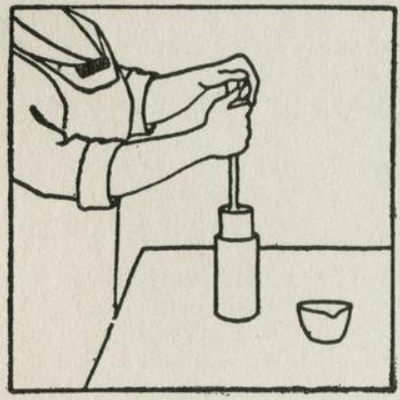

FIG. 32

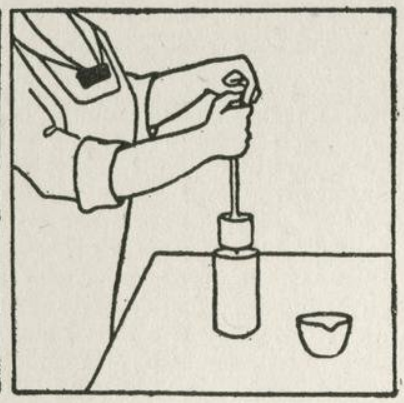

FIG. 33

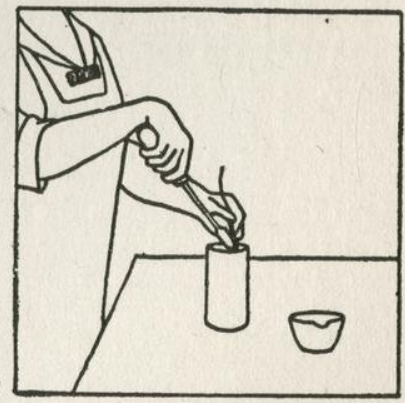

FIG. 34

CANNING IN TIN, continued. Fig. 32. Turning steel to distribute solder. Fig. 33. Raising steel to allow solder to harden after pressing down on center rod. FIG. 34. Sealing with drop of solder after exhausting can and wiping vent hole. 


\section{PRINCIPLES OF JELLY MAKING}

To be satisfactory, jelly must be made from fruit juice containing pectin and acid. Pectin is a substance in the fruit which is soluble in hot water and which, when cooked with sugar and acid, gives, after cooling, the right consistency to jelly.

Fruits to be used should be sound, just ripe or slightly under-ripe, and gathered but a short time. Wash them, remove stems and cut large fruits into pieces. With juicy fruits add just enough water to prevent burning while cooking. In using fruits which are not juicy cover them with water. Cook slowly until the fruits are soft. Strain through a bag made of flannel or two thicknesses of cheesecloth or similar material.

\section{JELLY MAKING WITH PECTIN TEST}

To determine if the juice contains pectin, boil 1 tablespoonful and cool. To this add 1 tablespoonful of grain or wood alcohol and mix, gently rotating the glass. Let stand for a while. If a solid mass-which is pectincollects, this indicates that in making jelly one part of sugar or sugar substitute (corn syrup or honey) should be used to one part of juice. If the pectin collects in two or three masses, use $2 / 3$ to $3 / 4$ as much sugar or substitute as juice. If it collects in several small particles use half. If the presence of pectin is not shown as described, it should be supplied by the addition of the juice of slightly under-ripe fruits, such as sour apples, currants, crab-apples, green grapes, green gooseberries or wild cherries.

Measure the juice and sugar or substitute. Sugar may be spread on a platter and heated. Do not let it scorch. When the juice begins to boil add the sugar or substitute. Boil rapidly. This is important. The jelly point is reached when the juice drops as one mass from the side of a spoon or when two drops run together and fall as one from the side of the spoon. Skim the juice, pour into sterilized glasses and cool as quickly as possible. Currant and green grape juice require 8 to 10 minutes boiling to reach the jelly point while all other juices require from 20 to 30 minutes.

When the jelly is cold pour over the surface a layer of hot paraffin. A toothpick run around the edge while the paraffin is still hot will give a better seal. Protect the paraffin with a cover of metal or paper.
Three or more extractions of juice may be made from fruit. When the first extraction is well drained cover the pulp with water and let it simmer 30 minutes. Drain, and test juice for pectin. For the third extraction proceed in the same manner. The juice resulting from the second and third extractions may be combined. If the third extraction shows much pectin a fourth extraction may be made. The first pectin test should be saved for comparison with the others.

If the second, third or fourth extraction of juice is found thinner than the first extraction, boil it until it is as thick as the first, then add the sugar or substitute called for.

\section{JELLY MAKING WITH- OUT TEST}

The test for pectin is desirable, but it is not essential. A large percentage of housewives make jelly without this test, and satisfactory results may be obtained without it if care is taken to follow directions and to use the right fruits. For the inexperienced jelly maker the safe rule is to confine jelly-making to the fruits which are ideal for the purpose. These include currants, sour apples, crabapples, under-ripe grapes, quinces, raspberries, blackberries, blueberries, wild cherries, and green gooseberries. These contain pectin and acid in sufficient quantities.

In making jelly without the alcohol test, with the juice of currants and under-ripe grapes use 1 cup of sugar to 1 cup of juice. With raspberries, blackberries, blueberries, sour apples, crab-apples, quinces, wild cherries and green goosebe ries use $3 / 4$ cup of sugar to 1 cup of juice. This applies to the first extraction of juice and to the later extractions when they have been boiled to the consistency of the first extraction.

Satisfactory jelly may be made by using $1 / 2$ to 34 cup corn syrup or honey to 1 cup of fruit juice, following the general directions for jelly making. The proportion of sugar substitute will depend upon the acidity and pectin content of the fruit juice. On account of the water content of the corn syrup the juice will require a little longer cooking before the jelly point is reached.

Fruits which contain pectin but lack sufficient acid are peach, pear, quince, sweet apple and guava. With these acid may be added by the use of juice of sour apples, crab-apples or under-ripe grapes.

Strawberries and cherries have acidity but 
lack pectin. The pectin may be supplied by the addition of the juice of sour apples, crabapples or under-ripe grapes.

\section{GENERAL DIRECTIONS FOR JELLY MAKING}

Wash, remove stems, and with the larger fruits cut into quarters. Put into a saucepan and cover with water. Allow to simmer until the fruit is tender. Berries require the addition of only a small amount of water. A double boiler is excellent for heating a small quantity. Put into a bag to drain, after wringing the bag out in scalding water. If desired, test juice for pectin as described. Measure juice and sugar or syrup in proportions indicated by the test for pectin or as directed under "Jelly Making Without Test." Add the sugar or syrup when the juice begins to boil. The sugar or syrup may be heated before being added. This avoids chilling the juice. When the boiling juice reaches the jelly point as shown on page 16 , skim and pour into sterilized glasses.

\section{WINTER JELLY MAKING}

Fruit juices may be canned and made into jelly as wanted during the winter. The use of sugar is not necessary until the actual jelly making is undertaken.

To prepare for canning pour the juice into sterilized bottles or jars. Put into hot-water bath, with the water reaching to the neck of the containers. Allow to simmer 20 to $30 \mathrm{~min}$ utes. If jars are used half seal them during the simmering and complete seal when removed from the sterilizer. Put absorbent cotton into the necks of bottles and when the bottles are taken from the bath put in corks, forcing the cotton into the neck. Corks should first be boiled and dried to prevent shrinking. They may also be boiled in paraffin to make them air-tight. After corking the bottles apply melted paraffin to the tops with a brush, to make an air-tight seal. Each bottle should be labeled. In making jelly from these juices during the winter follow the "General Directions for Jelly Making."

Any fruit juice may be bottled following the above method and used for beverages and for flavoring desserts. Store jelly and bottled juices in a cool, dark, dry place.

The need for conserving sugar makes winter jelly making an especially useful form of conservation in these days of shortage.

\section{FRUIT BUTTERS}

Fruit butters may be made from good sound fruits or the sound portions of fruits which are wormy or have been bruised. Wash, pare and remove seeds if there are any. Cover with water and cook 3 or 4 hours at a low temperature, stirring often, until the mixture is of the consistency of thick apple sauce. Add sugar, syrup or honey to taste when the boiling is two-thirds done. Spices may be added to suit the taste when the boiling is completed. If the pulp is coarse it should be put through a wire sieve or colander. Pour the butter into sterilized jar, put on rubber and cover and adjust top bail. Put into a container having a cover and false bottom. Pour in an inch or so of water and sterilize quart jar or smaller jar 5 minutes after the steam begins to escape. Remove, push snap in place and cool.

\section{Apple Butter with Cider}

Four quarts of sweet or sterilized cider should be boiled down to 2 quarts. To this add 4 quarts of apples peeled and cut in small pieces. If the texture of the apples is coarse they should be boiled and put through a strainer before being added to the cider. Boil this mixture until the cider does not separate from the pulp. When two-thirds done add one pound of sugar, syrup or honey. One-half teaspoonful each of cinnamon, allspice and cloves may be added. Pour into sterilized jars and sterilize 5 minutes in steam.
Apple and pear butter may be made by following the directions for apple butter with cider but omitting the cider.

\section{Peach Butter}

Dip peaches in boiling water long enough to loosen the skins. Dip in cold water, peel and stone them. If peaches do not peel readily when dipped in boiling water, omit dipping and pare them. Mash and cook them without adding any water. Add half as much sugar, syrup or honey as pulp and cook until thick. Pour into sterilized jars and sterilize 5 minutes in steam.

Plum butter may be made following the directions for peach butter.

\section{Apple Butter with Grape Juice}

To every 4 quarts of strained apple sauce add 1 pint of grape juice, 1 cup of brown sugar, syrup or honey and $1 / 4$ teaspoonful of salt. Cook slowly, stirring often, until of the desired thickness. When done stir in 1 teaspoonful of cinnamon, pack in hot jars and sterilize 5 minutes in steam.

\section{Dried Peach Butter}

Soak dried peaches over night. Cook slowly until tender. To each 2 pounds of dried peaches add 1 quart of canned peaches and $13 / 4$ pounds of sugar, syrup or honey. If a fine texture is desired, strain pulp through a colander. Cook slowly, stirring often, until thick. Pack in hot jars and sterilize 5 minutes in steam. 


\section{PART II}

\section{HOME DRYING MANUAL}

Drying vegetables and fruits for winter use is one of the vital national needs. As a national need it becomes a patriotic duty. As a patriotic duty it should be done in every family.

Failure to prepare vegetables and fruits for winter use by Drying is one of the worst examples of American extravagance. During the summer nature provides an over-abundance. This year, with the planting of 5,285,000 home food gardens, stimulated by the National War Garden Commission and the United States Department of Agriculture, this abundance will be especially large. The excess supply is not meant to go to waste. The over-abundance of the summer should be made the normal supply of the winter. The individual family should conduct Drying on a liberal scale. In no other way can there be assurance that America's food supply will meet our own needs. In no other way, surely, can we answer the enormous demands made upon us for furnishing food for our European Allies.

\section{IMPORTANCE OF FOOD THRIFT}

Winter buying of vegetables and fruits is costly. It means that you pay transportation, cold-storage and commission merchants' charges and profits. Summer is the time of lowest prices. Summer, therefore, is the time to buy for winter use.

Every pound of food products grown this year will be needed to combat Food Famine. The loss that can be prevented, the money saving that can be effected and the transportation relief that can be brought about make it essential that every American household should make vegetable and fruit Drying a part of its program of Food Thrift. The results can be gained in no other way.

Vegetable and fruit Drying have been little practiced for a generation or more. Its revival on a general scale is the purpose of this Manual. There is no desire to detract from the importance of canning operations. Drying must not be regarded as taking the place of the preservation of vegetables and fruits in tins and glass jars. It must be viewed as an important adjunct thereto. Drying is important and economical in every home, whether on the farm, in the village, in the town, or in the city. For city dwellers it has the special advantage that little storage space is required for the dried product. One hundred pounds of some fresh vegetables will reduce to 10 pounds in drying without loss of food value or much of the flavor.

This year's need for vegetable and fruit Drying is given added emphasis by the shortage of tin for the manufacture of cans. This condition has created an unusual demand for glass jars. For this year, therefore, Drying is of more than normal importance. Dried products can be stored in receptacles that could not be used for canning. This is excellent conservation.

\section{DRYING IS SIMPLE}

A strong point in connection with vegetable and fruit Drying is the ease with which it may be done. The process is simple. The cost is slight. In every home the necessary outfit, in its simplest form, is already at hand. Effective Drying may be done on plates or dishes placed in the oven, with the oven door partially open. It may be done on the back of the kitchen stove, with these same utensils, while the oven is being used for baking. It may also be done on sheets of 
paper or lengths of muslin spread in the sun and protected from insects and dust.

Apparatus for home Drying on a larger scale may be made at home or bought at small cost. Still larger equipment may be bought for community drying operations in which a group of families combine for cooperative work, at a school or other con-

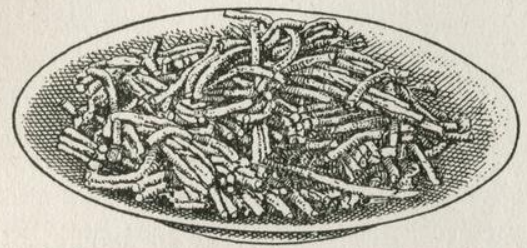

Fig. 2. Potatoes prepared by use of meat chopper.

venient center. This latter is especially recommended as giving the use of the most improved outfits at slight cost to the individual family. See "Community Work," page 3.

Best results are obtained by rapid drying, but care must be taken not to let the temperature rise above the limit specified in the directions and table.

One of the chief essentials in Drying is free circulation of air, in order that the moist air may escape and dry air take its place.

\section{METHODS OF DRYING}

For home Drying satisfactory results are obtained by any one of three principal methods. These are:

1. Sun Drying.

2. Drying by Artificial Heat.

3. Drying by Air-blast. (With an electric or other motor fan.)

These methods may be combined to good advantage.

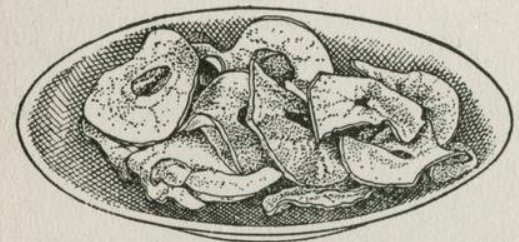

Fig. 3. Apples peeled and sliced for drying.

\section{SUN DRYING}

Sun Drying has the double advantage of requiring no expense for fuel and of freedom from danger of overheating. For sun Drying of vegetables and fruits the simplest form is to spread the slices or pieces on sheets of plain paper or lengths of muslin nailed to strips of wood and expose them to the sun. Muslin is to be preferred if there is danger of sticking. Trays should be used for large quantities. Sun Drying requires bright, hot days and a breeze. Once or twice a day the product should be turned or stirred and the dry pieces taken out. The drying product should be covered with cheesecloth tacked to a frame for protection from dust and flying insects. Care must be taken to provide protection from rain, dew and moths. During rains and just before sunset the products should be taken indoors for protection.

\section{TRAYS FOR SUN DRYING}

To make a tray cheaply for use in sun drying, take strips of lumber three-quarters of an inch thick and 2 inches wide for the sides and ends. To form the bottom, laths should be nailed to these strips, with spaces of one-eighth of an inch between laths to permit air circulation. A length of 4 feet, corresponding to the standard lengths of laths, is economical. Nail 3 strips across the bottom in the opposite direction from the laths to prevent warping and to allow space when the trays are stacked. The

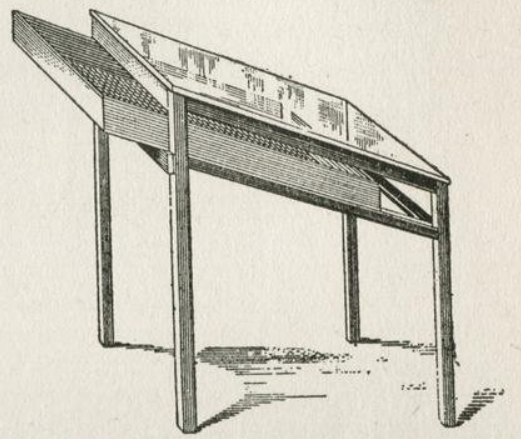

FIG. 4. Small outdoor drier, easily made at home. It has glass top, sloping for exposure to sun. Tray is shown partly projecting, to indicate construction.

trays should be of uniform size in order that they may be stacked together for convenience in handling. Never put trays directly on the ground. They should rest on supports a few feet above the ground and should face the south or southwest so as to receive the sun's rays the longest possible time.

A small homemade Sun Drier, easily constructed (Fig. 4), is made of light strips of wood, a sheet of glass, a small amount of galvanized wire screen and some cheesecloth. A convenient size for the glass top is 18 by 24 inches. To hold the glass make a light wooden frame of strips of wood $1 / 2$ inch thick and 1 inch wide. This frame should have legs of material 1 by $1 \frac{1}{2}$ inches, with a length of 12 inches for the front legs and 18 inches for those in the rear. This will cause the top to slope, which aids in circulation of air and gives direct exposure to the rays of the sun. As a tray support, nail a strip of wood to the legs on each of the four sides, about 
4 inches below the top framework and sloping parallel with the top. The tray is made of thin strips of wood about 2 inches wide and has a galvanized wire screen bottom. There will be a space of about 2 inches between the top edges of the tray and the glass top of the Drier, to allow for circulation. Protect both sides, the bottom and the front end of the Drier with cheesecloth tacked on securely and snugly, to exclude insects and dust without interfering with circulation. At the rear end place a cheesecloth curtain tacked at the top but swinging free below, to allow the tray to be moved in and out. Brace

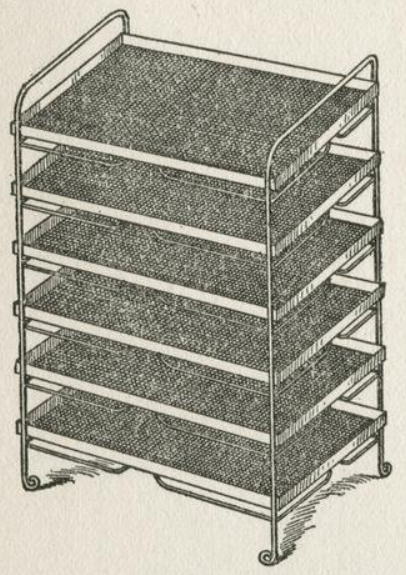

FIG. 5. Commercial drier for use in oven.

the bottom of this curtain with a thin strip of wood, as is done in window shades. This curtain is to be fastened to the legs by buttons when the tray is in place.

\section{DRYING BY ARTIFICIAL HEAT}

Drying by artificial heat is done in the oven or on top of a cookstove or range, in trays suspended over the stove or in a specially constructed drier built at home or purchased.

When drying with artificial heat a thermometer must be used. This should be placed in the drier and frequently observed.

\section{OVEN DRYING}

The simplest form of Oven Drying is to place small quantities of foodstuffs on plates in a slow oven. In this way leftovers and other bits of food may be saved for winter use with slight trouble and dried while the top of the stove is being used. This is especially effective for sweet corn. A few sweet potatoes, apples or peas, or even a single turnip, may be dried and saved. To keep the heat from being too great leave the oven door partially open. For oven use a simple tray may be made of galvanized wire screen of convenient size, with the edges bent up for an inch or two on each side. At each corner this tray should have a leg an inch or two in length, to hold it up from

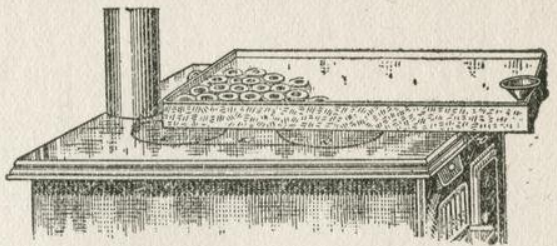

Fig. 6. Commercial drier which may be placed on top of cookstove or suspended over a lamp.

the bottom of the oven and permit circulation of air around the product.

An oven drier which can be bought at a low price is shown in Fig. 5.

\section{DRYING ON TOP OF OR OVER STOVE}

An effective Drier for use over a stove or range may be made easily at home. Such a Drier is shown in Fig. 9. For the frame use strips of wood $1 / 2$-inch thick and 2 inches wide. The trays or shelves are made of galvanized wire screen of small mesh tacked to the supports; or separate trays, sliding on strips attached to the framework, are desirable. This Drier may be suspended from the ceiling over the kitchen stove or range, or over an oil, gasoline, or gas stove, and it may be used while cooking is being done. If an oil stove is used there must be a tin or galvanized iron bottom 4 inches below the lowest tray, to prevent the fumes of the oilfrom reaching and passing through the material which is to be dried, and to distribute the

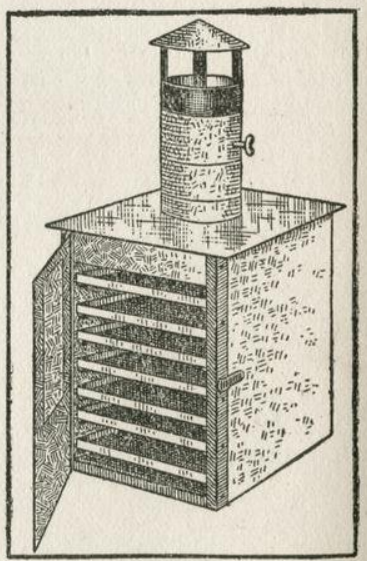
heat. A bottom of this kind may be easily attached to any Drier, either home-made or commercial. A framework crane as shown in Fig. 9 makes it possible for this Drier to be swung aside when not in use.

In Fig. 8 is shown another form of Homemade Cookstove Drier, more pretentious than that shown in Fig. 9, but still easily and cheaply made. A good size for this is: base, 16 by 24 inches; height, 36 inches. The lower part or supporting framework, 6 inches high, is made of galvanized sheet iron, 
slightly flaring toward the bottom, and with two ventilating holes in each of the four sides. The frame, which rests on this base, is made of strips of wood 1 or $11 / 2$ inches wide.

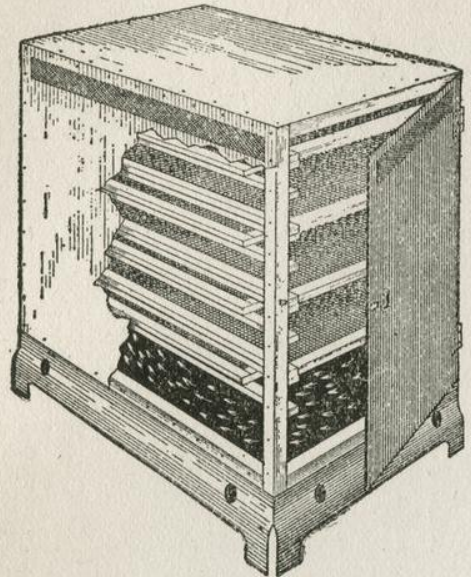

FIG. 8. Home-made drier of galvanized iron, for use on stove.

Wooden strips, $1 \frac{1}{4}$ inches wide, and 3 inches apart, serve to brace the sides and furnish supports for the trays.

In a Drier of the dimensions given there is room for eight trays. The sides, top and back are of galvanized iron or tin sheets, tacked to the framework, although thin

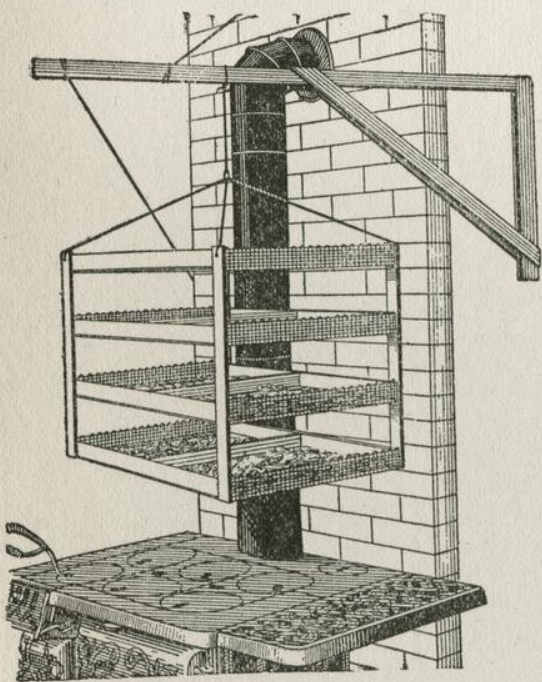

FIG. 9. Home-made drier with swinging crane.

strips of wood may be used instead of the metal. Small hinges and thumb-latch are provided for the door. Galvanized sheet iron, with numerous small holes in it, is used for making the bottom of the Drier. To prevent direct heat from coming in con- tact with the product, and also to distribute the heat by radiation, a piece of galvanized sheet iron is placed 2 inches above the bottom. This piece is 3 inches shorter and 3 inches narrower than the bottom and rests on two wires fastened to the sides.

The trays are made of wooden frames of 1 -inch strips, to which is tacked galvanized wire screen. Each tray should be 3 inches shorter than the Drier and enough narrower to allow it to slide easily on the supports in being put in or taken out.

In placing the trays in the Drier push the lower one back as far as it will go, leaving a 3-inch space in front. Place the next tray even with the front, leaving the space at the back. Alternate all the trays in this way, to facilitate the circulation of the heated air. It is well to have a ventilating opening, 6 by 2 inches, in the top of the Drier to discharge moisture. $\mathrm{Th}$ e trays should be shifted during the drying process, to procure uniformity of drying.

One of the simplest forms of homemade Drier

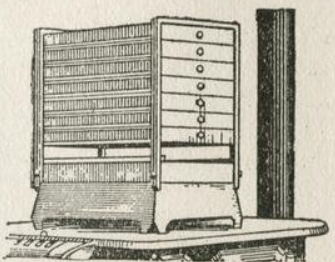

FIG. 10. Commercial drier. is a tray with bottom of galvanized wire screen, suspended over stove or range, as shown in Fig. 12.

\section{Commercial Driers}

Cookstove Driers are in the market in several types. One of these, shown in Fig. 7 , has a series of trays in a framework, forming a compartment. This is placed on top of the stove. A similar drier is shown in Fig. 10. Another, shown in Fig. 6, is a shallow metal box to be filled with water, and so constructed that one end may rest on the back of the stove and the other on a prop reaching to the floor, or it may be suspended over a lamp.

Commercial Driers having their own furnaces may be bought at prices ranging from $\$ 24$ to $\$ 120$. This type is pictured in Fig. 11. Some of these, in the smaller sizes, may be bought without furnaces, and used on the top of the kitchen stove, as Fig. 7. The cost is from $\$ 16$ upwards.

\section{AIR-BLAST - ELECTRIC FAN}

The use of an electric fan is an effective means of Drying. Fig. 15 shows how this household article is used. A motor fan run by kerosene or alcohol serves the same purpose. Sliced vegetables or fruits are placed on trays and the fan placed close to one end of the box holding the trays, with the current 
directed along the trays, lengthwise. Insects must be kept out by the use of cheesecloth or similar material. Drying by this proc-

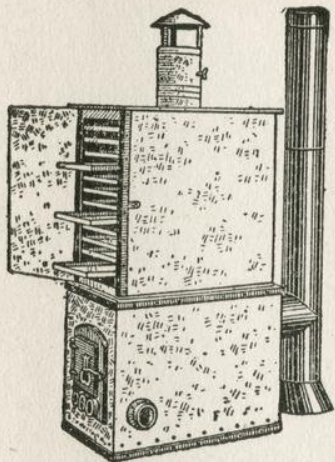

FIG. 11. Commercial drier with furnace. ess may be done in twenty-four hours or less. With sliced string beans and shredded sweet potatoes a few hours are sufficient, if the air is dry. Rearrange the trays after a few hours, as the drying will be more rapid nearest the fan.

As artificial heat is not used in fan drying it is important to blanch or steam the vegetables for the full specified time. It is also necessary that all fan-dried products be heated in an oven to $180^{\circ} \mathrm{F}$. for 10 or 15 minutes before storing.

\section{DETAILS OF DRYING}

As a general rule vegetables or fruits, for Drying, must be cut into slices or shreds, with the skin removed. In using artificial heat be careful to start at a comparatively low temperature and gradually increase. Details as to the proper scale of temperatures for various vegetables and fruits are given in the directions in this Manual and in the timetable on page 28 . To be able to gauge the heat accurately a thermometer must be used. An oven thermometer may be bought at slight cost. If the thermometer is placed in a glass of salad oil the true temperature of the oven may be obtained.

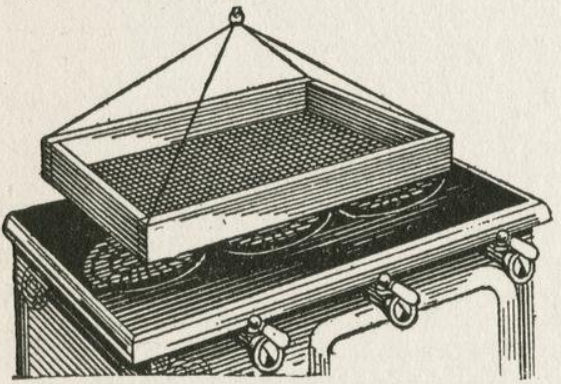

Fig. 12. Simple tray drier made at home.

In the detailed instructions on pages $25,26,27$ and 28, the temperatures used are Fahrenheit. The temperatures indicated are for Drying by artificial heat.

The actual time required for Drying cannot be given, and the person in charge must exercise judgment on this point. A little experience will make it easy to determine when products are sufficiently dried. When first taken from the Drier vegetables should be rather brittle, and fruits rather leathery and pliable. One method of determining whether fruit is dry enough is to squeeze a handful, if the fruit separates when the hand is opened, it is dry enough. Another way is to press a

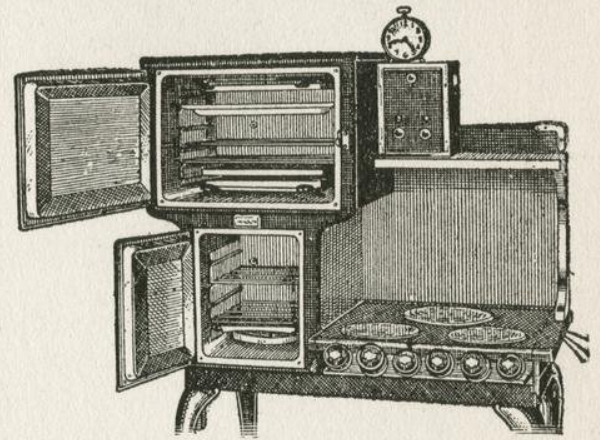

Fig. 13. Electric range, useful for drying.

single piece; if no moisture comes to the surface the piece is sufficiently dry. Berries are dry enough if they stick to the hand but do not crush when squeezed.

\section{PREPARING MATERIAL FOR DRYING}

A sharp kitchen knife will serve every purpose in slicing and cutting vegetables and fruits for Drying if no other device is at hand. The thickness of the slices should be from an eighth to a quarter of an inch. Whether sliced or cut into strips the pieces should be small so as to dry quickly. They should not, however, be so small as to make them hard to handle or to keep them from being used to advantage in preparing dishes for the table such as would be prepared from fresh products.

Food choppers, crout slicers or rotary slicers may be used to prepare food for drying.

Vegetables and fruits for Drying should be fresh, mature and in prime condition for eating. As a general rule vegetables will dry better if cut into small pieces with the skins removed. Berries are dried whole. Apples, quinces, peaches and

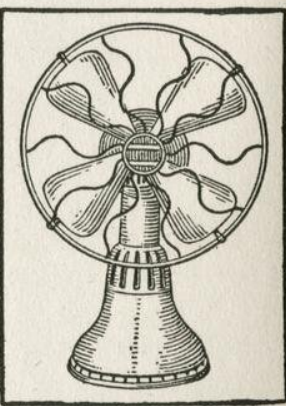

Fig. 14. Motor-fan, run by kerosene or alcohol. pears dry better if cut into rings or quarters. Cleanliness is imperative. Knives and slicing 
devices must be carefully cleansed before and after use. A knife that is not bright and clean will discolor the product on which it is used and this should be avoided.

\section{BLANCHING}

Blanching is desirable for successful vegetable Drying. Blanching gives more thorough cleansing, removes objectionable

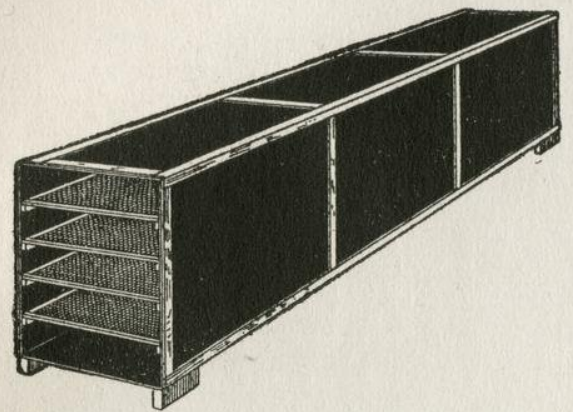

Fig. 15. Series of trays enclosed in wall-board box, for use with electric fan.

odors and flavors, kills protoplasm and softens and loosens the fiber, allowing quicker and more uniform evaporation of the moisture, stops destructive chemical changes, and gives better color. It is done by placing the vegetables in a piece of cheesecloth, a wire basket or other porous container and plunging them into boiling water. A more desirable way is to blanch in steam. For small quantities a pail or deep kettle is serviceable. A false bottom raised an inch or more is necessary. Upon this rests a wire basket or cheesecloth filled with the prepared vegetables. The water should be just below the false bottom and be boiling vigorously when the products are put in. Cover with a tight-fitting cover. Keep the water boiling during the blanching period. For larger

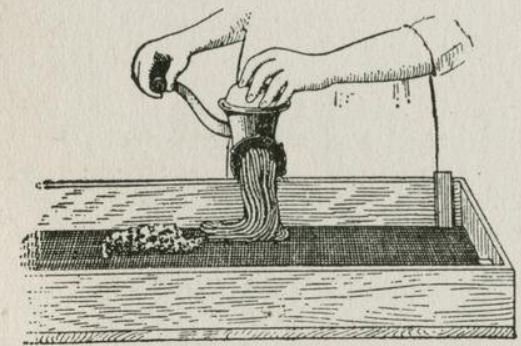

FIG. 16. Meat chopper for preparing vegetables.

quantities a wash-boiler partially filled with water is convenient. Bricks set on end or a wooden frame raised a few inches above the water make good supports for the containers.
Do not continue blanching longer than the prescribed time as some of the valuable constitutents will dissolve out, the color will be destroyed and the starch will be partially cooked to a paste.

The time required is short and varies with different vegetables. For the proper time in each case consult the directions given for Drying on pages $25,26,27$ and 28 and the time-table on page 28 .

After blanching, drain to remove moisture and arrange on trays.

\section{DANGER FROM INSECTS}

In addition to exercising great care to protect vegetables and fruits from insects during the Drying process, precautions should be taken with the finished product to prevent the hatching of eggs that may have been deposited. One measure that is useful is to subject the dried material to a heat of $180^{\circ}$ $\mathrm{F}$. for from 5 to 10 minutes. By the application of this heat the eggs will be killed. $\mathrm{Be}$ careful not to apply heat long enough to damage the product. Store as soon as removed from the oven.

\section{"CONDITION" BEFORE STORING}

The word "conditioning" as used in connection with drying vegetables and fruits simply means "thorough drying." It indicates the after treatment of products on their removal from the drying trays.

Put the dried products in bins, boxes, or, if the quantity is small, in bowls. Once a day for a period of ten days to two weeks, stir thoroughly or pour from one box to another. The cont a iners

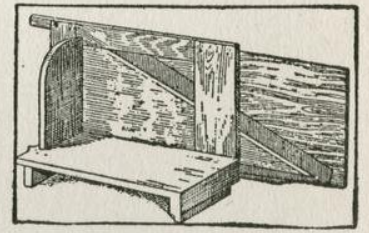

FIg. 17. Crout slicer.

should be in a clean, dry room, and protected from light and insects. Shutters and screens at the window are desirable. Otherwise protect the dried food by spreading clean cloths over it. If any part of the material is found to be moist, after this process, return it to the drier for a short time. When for several days no change in the moisture content has been noticed, and therefore no extra drying has been necessary, the products are ready to be stored.

Properly conditioned products can be stored without danger of spoiling, because spores and fungi cannot begin growth if there is uniform freedom from moisture on the surface.

PRACTICALLY ALL DRIED PROD. UCTS SHOULD BE CONDITIONED. 


\section{STORAGE FOR DRIED PRODUCTS}

Of importance equal to proper Drying is the proper packing and storage of the finished product. With the scarcity of tins and the high prices of glass jars it is recommended that other containers be used. Those easily available are baking-powder cans and similar covered tins, pasteboard boxes having tightfitting covers, strong paper bags, and patented

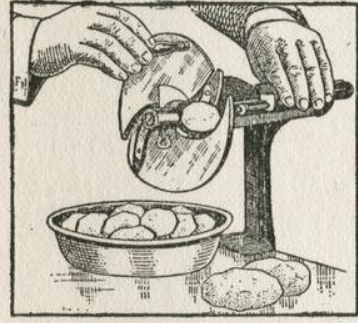

Fig. 18. Vegetable and fruit slicer. paraffin paper b oxes, which may be bought in quantities at comparatively low cost.

A paraffin con$t a$ in er of the type used by oyster dealers for the delivery of oysters will be found inexpensive and easily handled. If using this, or a baking-powder can or similar container, after filling adjust the cover closely. For storage on a larger scale use closely built wooden boxes with well-fitted lids. Line each box with paraffin paper in several layers. The paper should cover the top of the contents.

It is essential that the container should exclude light and insects but it should not be air-tight. Products stored in air-tight containers suffer damage through moisture which escapes from the product and condenses in the package.

If a paper bag is used, the top should be twisted, doubled over and tied with a string.

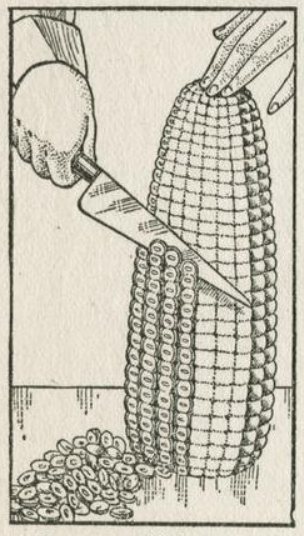

FIG. 19. Slicing corn.
Another good precaution is to store bags within an ordinary lard pail or can or other tin vessel having a fairly close-fitting cover.

The products should be stored in a warm, dry place, well ventilated and protected from rats, mice and insects. An attic or upstairsroom which is warmed by pipes or flues passing through makes a very satisfactory place. Shelves near a furnace also make a suitable storage place.

In sections where the air is very moist, especial care must be used. The containers should be opened occasionally and if any moisture has been taken up the contents should be placed in the oven until dry.
It is good practice to use small containers so that it may not be necessary to leave the contents exposed long after opening before use.

For convenience label all packages.

Before storing products prepared by sun drying, artificial heat must be applied to destroy possible insect eggs. To do this place the products in the oven, spread in thin

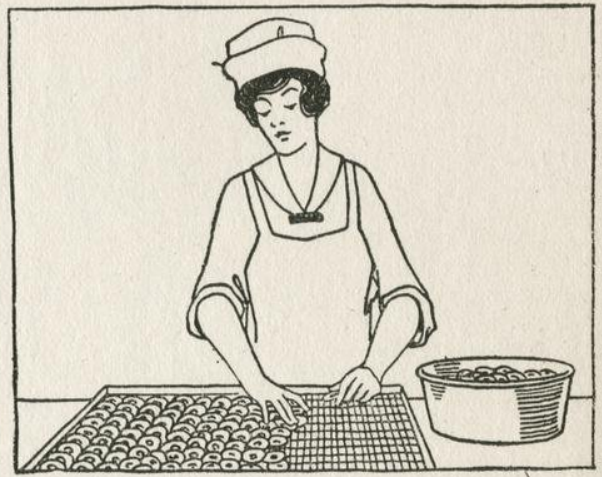

FIG. 20. Arranging vegetables or fruits on trays.

layers, and allow them to remain until the temperature reaches $180^{\circ} \mathrm{F}$. as indicated by a thermometer inside partially open oven.

\section{WINTER USE OF PRODUCTS}

In preparing dried vegetables and fruits for use the first process is to restore the water which has been dried out of them. All dried foods require soaking. After soaking the dried products will have a better flavor if cooked in a covered utensil at a low temperature for a long time. Dried products should be prepared and served as fresh products are prepared and served. They should be cooked in the water in which they have been soaked, as this utilizes all of the mineral salts, which would otherwise be wasted.

There can be no definite rule for the amount of water required for soaking dried products when they are to be used, as the quantity of water evaporated in the drying process varies with different vegetables and fruits. As a general rule from 3 to 4 cups of water will be required for 1 cup of dried material.

In preparing for use, peas, beans, spinach and like vegetables should be boiled in water to which there has been added soda in the proportion of $1 / 8$ teaspoonful of soda to 1 quart of water. This improves the color.

In preparing to serve dried vegetables season them carefully. For this purpose celery, mustard, onion, cheese and nutmeg give desirable flavoring, according to taste.

From 3 to 4 quarts of vegetable soup may be made from $4 \mathrm{oz}$. of dried soup vegetables. 


\section{DIRECTIONS FOR VEGETABLE DRYING}

\section{Potatoes}

Wash well, and pare very thinly. If a rotary peeler is used, the potatoes should be graded for size, and those of similar size pared in groups. The eyes will have to be removed by hand. Cut into slices $3 / 16$ to $1 / 4$ inch thick. Blanch in steam 1 to 3 minutes; or in boiling water 2 to 3 minutes. The water should boil vigorously enough to keep the pieces separated and in motion. Drain and place on drying trays in one-inch layers, then dry at once. The blanching should be just long enough to prevent darkening while the potatoes are drying. Start drying at a temperature of $125^{\circ} \mathrm{F}$. and raise gradually to $145^{\circ}$ to $150^{\circ} \mathrm{F}$. toward the end of the drying period. When dry enough, the pieces of potato will be free from opaque, spongy white places, and will rattle when stirred. $\mathrm{Re}-$ move from drier, condition and store.

\section{Beets, Carrots and Parsnips}

Wash well, scrape off skin, and cut into slices of a uniform thickness $-3 / 16$ to $1 / 4$ inch. Blanch 2 minutes in steam or boiling water. Drain well, spread on drying trays, and dry at an initial temperature of $120^{\circ} \mathrm{F}$. and not exceeding $145^{\circ} \mathrm{F}$. during the entire drying period. These products are sufficiently dry when the pieces break if an effort is made to bend them, and when no moisture shows if they are pressed between the fingers.

\section{Cabbage}

Take heads which are well developed. Remove all loose outside leaves and central stalk. Shred or cut into strips a few inches long. Blanch in steam 3 minutes, or in boiling water 4 minutes. Use a wire basket, fill not more than 6 to 8 inches deep; and stir well during the process. When drying, spread in layers not over 1 inch deep, and stir frequently until the product is dry enough not to stick together in close masses. Begin drying at $115^{\circ}$ to $125^{\circ} \mathrm{F}$. and when the cabbage is nearly dry, raise the temperature not to exceed $135^{\circ} \mathrm{F}$. Remove from drier when no moisture can be squeezed out of thicker pieces by strong pressure between the fingers.

\section{Cauliflower}

After cleaning, divide into small pieces. The head may be cut by a vegetable slicer, if preferred. Blanch 6 minutes in steam or 4 minutes in boiling water. Spread in thin

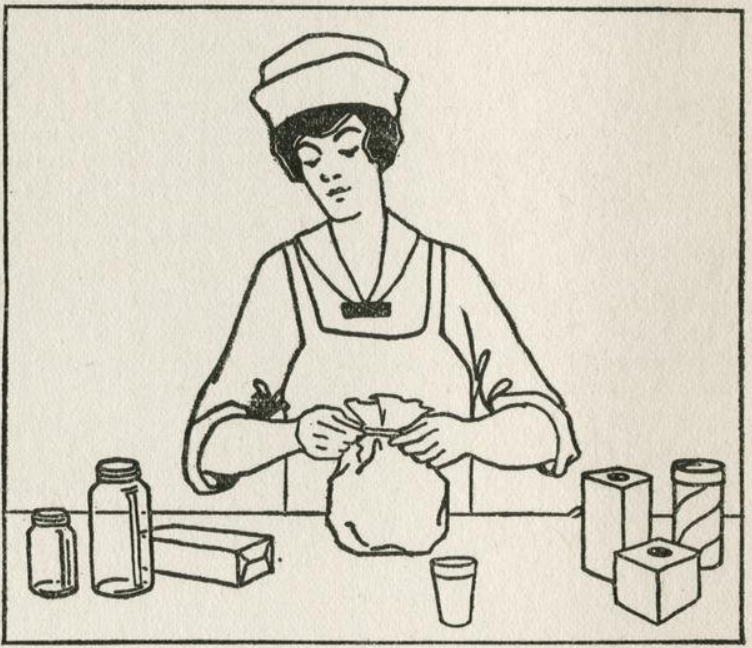

FIG. 21. Preparing dried products for storing.

layers on drying trays. Start at a temperature of $120^{\circ} \mathrm{F}$. and gradually increase to $130^{\circ} \mathrm{F}$. Although turning dark while drying, cauliflower will regain part of original color in soaking and cooking. The drying is complete when strong pressure between the fingers does not squeeze out moisture from the thicker pieces.

\section{Celery}

After washing, carefully cut into evenlength pieces- $3 / 4$ inch or 1 inch is a good measure. Blanch 3 minutes in steam or 2 minutes in boiling water. Drain well, and spread on drying trays in $1 / 2$ inch layers. Dry at $135^{\circ} \mathrm{F}$., stirring occasionally.

\section{Garden Peas}

If the pods are dusty, wash well before shelling. Garden peas with non-edible pod are taken when of size suitable for table use. Blanch 3 to 5 minutes according to size, then drain and spread on drying trays. A depth of $3 / 4$ to 1 inch is practicable, but single layers will dry quicker. Start the drying at

\section{FIRE PREVENTION}

In home drying care should be taken that danger from fire does not result. Driers made wholly or partly of wood should not be exposed to heat in such way that the woodwork might catch fire if accidentally overheated or left alone too long. DO NOT USE WOOD ON TOP OF A STOVE. 
a temperature of $115^{\circ}$ to $120^{\circ} \mathrm{F}$., raising it gradually to $140^{\circ} \mathrm{F}$. Stir occasionally. When sufficiently dry, peas will show no moisture near the center when split open.

For use in soups or puree, shell mature peas, pass them through a meat grinder, spread the pulp on trays and dry.

\section{Spinach}

Select plants which are well grown. Remove roots and wash well. Steam 2 minutes. Spread on tray and dry at a constant temperature of $130^{\circ} \mathrm{F}$. Remove from drier before the leaves break when handled.

\section{Green String Beans}

Select only such beans as are in perfect condition for table use. Wash carefully and string. If full grown they should be slit lengthwise or cut-not snapped-into pieces $1 / 4$ to 1 inch long. Blanch 5 to 8 minutes according to age. To set the color of nearly grown beans add 2 level tablespoonfuls of baking soda to every gallon of boiling water. Drain well after blanching and spread in thin layers on drying trays. Begin the drying at a temperature of $130^{\circ} \mathrm{F}$. and gradually raise it to $140^{\circ}$ or $145^{\circ} \mathrm{F}$. Drying is complete when no moisture can be pressed from freshly broken pieces.

\section{Lima Beans}

Choose mature beans. Shell and blanch 3 minutes in boiling water, keeping the beans well stirred by the motion of the rapidly bubbling water. Drain to remove surface moisture. Spread in thin layers on drying trays, and stir occasionally during the drying process. Start drying at $120^{\circ}$ to $130^{\circ} \mathrm{F}$. and raise this temperature gradually to $150^{\circ} \mathrm{F}$.

\section{Okra}

After washing, blanch young tender pods 2 to 3 minutes in boiling water or steam. Allow 2 minutes for older pods, which should be cut into halves or quarters. Dry the younger pods whole. Spread on trays in single layers and start drying at a temperature of $115^{\circ} \mathrm{F}$. to $120^{\circ} \mathrm{F}$. Gradually raise this to $135^{\circ} \mathrm{F}$.

Okra may also be dried by being strung on a string and hung over the stove. This should not be done except with young and tender pods. Heat in oven before storing.

\section{Onions}

Peel and cut into $1 / 8$ to $1 / 4$ inch slices. A rotary slicer is convenient for this. Blanching is not needed. Spread in thin layers, on drying trays and dry at a uniform temperature of $140^{\circ} \mathrm{F}$. Stir occasionally when the process is three-fourths done to prevent pieces scorching. Remove promptly from drier when pieces break on bending.

\section{Pumpkin and Squash (Summer and Winter)}

Pare, remove seeds and spongy portions. Cut into $1 / 2$ inch pieces. Blanch 3 to $6 \mathrm{~min}$ - utes, or until the pieces are semi-transparent. Spread on trays. Start drying at a temperature of $135^{\circ} \mathrm{F}$. and raise this slowly to $160^{\circ} \mathrm{F}$. These products will be pliable and leathery when dried enough, and show no moisture when cut.

The strips may be hung on strings and dried in the kitchen above the stove.

\section{Shell Beans and Peas}

Beans of different kinds, after maturing and drying on the vines, and being shelled, should be heated to $165^{\circ}$ to $180^{\circ} \mathrm{F}$. for 10 to 15 minutes to destroy any insect eggs which may be in them. This may be done in an oven. These heated beans cannot be used for planting, because they are devitalized and will not grow. Store in a dry place in bags.

Mature lima beans need only to be shelled and stored in bags. Cow peas or any field pea can be treated in the same way.

\section{Sweet Potatoes}

Wash, pare and slice, blanch 6 to 8 minutes and spread on drying trays. Dry until brittle, starting at a temperature of $145^{\circ}$ to $150^{\circ} \mathrm{F}$. and gradually raising it to $155^{\circ}$ to $165^{\circ} \mathrm{F}$., when the drying is nearly done. Remove from drier when pieces are brittle and break under pressure.

\section{Tomatoes}

Select fruit which is firm and well ripened. Blanch 1 or 2 minutes, or long enough to loosen the skins. When cool enough to handle, peel, and cut into slices $3 / 8$ to $1 / 2$ inch thick. Spread in single layers on drying trays, placing cheesecloth or other thin openmesh fabric over the tray bottoms if made of wire. Start drying at a temperature of $120^{\circ}$ $\mathrm{F}$. and raise it gradually to $140^{\circ} \mathrm{F}$. When dry enough the tomatoes will break when bent, on conditioning they will become somewhat pliable.

\section{Turnips}

Turnips for drying should be in prime condition and free from pithiness. Prepare as directed for potatoes. Blanch 1 to 2 minutes, drain and spread on drying trays. The drying temperature is $135^{\circ}$ to $140^{\circ} \mathrm{F}$. at the beginning, gradually raised to $160^{\circ}$ to $165^{\circ} \mathrm{F}$. When dry enough the pieces will rattle when stirred.

\section{Wax Beans}

These are dried in the same manner as lima beans.

\section{Soup Mixtures}

Vegetables for soup mixtures are prepared and dried separately. These are mixed as desired.

\section{Sweet Corn}

Select ears that are at the milk stage, prime for table use and freshly gathered. Blanch on cob in boiling water for 8 to 12 minutes to 
set milk. Drain thoroughly, and with a sharp knife cut off in layers or cut off half the kernel and scrape off the remainder, taking care not to include the chaff. Start at temperature of $130^{\circ} \mathrm{F}$, and raise gradually to $140^{\circ}$, stirring frequently.

Corn is dry when it is hard and semitransparent.

\section{DIRECTIONS FOR FRUIT DRYING}

Fruits may be dried in the sun until the surface begins to wrinkle, then finished in the drier. With stone fruits, such as peaches, plums, apricots and cherries, none but fruits that are fresh, ripe and in perfect condition should be used. With apples, pears and quinces, effective thrift calls for using the sound portions of fruit that may be partially wormy or imperfect. When properly dried, fruits should be entirely free from moisture when pressed between the fingers on removal from drier and should be leathery and pliable.

\section{Sulphuring Fruits}

Apples, pears, peaches and apricots are subject to chemical changes as soon as the skin is removed or the flesh exposed to the air. To stop these changes and so preserve the natural appearance, color and flavor, it is necessary, before drying, to sulphur these fruits, as they can not be blanched. Blanching causes loss of sugars in the blanching process and dripping of the juice occurs when blanched fruits are subjected to the heat of the drier. Sulphuring does not affect the food value of the fruits and is not injurious to persons using them.

Provide a box large enough to enclose a stack of trays. This may be a packing box or a frame covered with canvas, building paper or wall-board. Stack the filled trays on bricks or blocks of wood which will hold the bottom tray several inches above the ground. The trays should be separated from each other by blocks of wood. Beneath this stack place one or two sticks of sulphur in an old saucepan, shovel or other holder. Set fire to this sulphur by using coals or lighted shavings and invert the box to cover trays and reach to the ground. Add sulphur as needed during the time specified in the directions. The time varies with various fruits and is given in special directions on pages 27 and 28 .

\section{Apples and Pears}

Pare, core and slice, dropping slices into cold water containing eight level teaspoonfuls of salt to the gallon, if a light-colored product is desired. Leaving them for a short time in salt water will prevent discoloration. (If preferred, core the whole fruit, after peeling, and slice into rings, dipping these for a minute or two into cold salted water as described above.)

To sulphur spread in trays of wire 1 to $11 / 2$ inches deep. Put each tray as soon as filled into the sulphuring box for 20 to 30 minutes. When the product feels moist on the surface and shows a lightened color, the sulphuring is complete.

Begin drying at $130^{\circ} \mathrm{F}$. and raise this gradually to $175^{\circ} \mathrm{F}$. Stir or rearrange fruit occasionally to insure even drying. The fruit is dry when a handful of slices is pressed and separate when released, leaving no moisture on the hand.

\section{Apricots}

Select ripe fruit before it drops from the tree. Remove pits by cutting fruit open with a sharp knife. Apricots are usually dried with the skins on. Arrange the halves on trays with pit cavity uppermost, and dry. If desired, they may be sulphured before drying - the time $11 / 2$ to 2 hours, or until liquid collects in the stone cavity.

Start drying at a temperature of $130^{\circ}$ to $145^{\circ} \mathrm{F}$. and raise it gradually to $165^{\circ} \mathrm{F}$. Remove from the drier when pliable and leathery.

\section{Berries}

Dry as soon as possible after picking. Spread in thin layers and put each tray as soon as filled into the drier. It may be necessary to spread cheesecloth over wire mesh bottoms of trays to keep berries from falling through.

It is not advisable to dry such fruits as red raspberries, currants and strawberries, unless no other conservative methods are convenient.

Start the drying at a temperature of $135^{\circ}$ to $145^{\circ} \mathrm{F}$. and raise it gradually toward the end of the drying process to $150^{\circ}$ to $155^{\circ} \mathrm{F}$. Properly dried berries rattle somewhat when stirred and show no moisture when pressed.

\section{Cherries}

Pick over well and wash. Remove surface moisture by draining. Spread unpitted in thin layers.

Start drying at a temperature not above $120^{\circ} \mathrm{F}$ : and raise gradually to $150^{\circ} \mathrm{F}$. Properly dried cherries are leathery.

\section{Figs}

Select ripe figs and pick over thoroughly. Wash, drain well and spread in single layers on drying trays. If dried in the sun, turn daily, protect from insects by glass or netting, and bring indoors at night. When applying artificial heat, start drying at a temperature of $120^{\circ} \mathrm{F}$. and raise this gradually to $140^{\circ} \mathrm{F}$. When nearly dry, immerse figs for 2 or 3 minutes in boiling brine ( $1 / 4$ pound salt to every 3 quarts water, or 1 pound to 3 gallons.) Drain, and finish the drying. 


\section{Peaches}

Select fruit which is uniformly and fully ripe. Cut open with a sharp knife and remove the pits. Peaches are not usually pared, as the juice is lost by dripping if this is done. To sulphur arrange in single layers on trays with the pit surface up. Sulphuring will take from 1-2 hours and is complete when the juice collects in the pit. Care must be taken when transferring trays to drier to prevent loss of juice.

Start drying at a temperature of $130^{\circ}$ to $145^{\circ} \mathrm{F}$. and raise it gradually to $165^{\circ} \mathrm{F}$. when the process is nearly completed.

Properly dried peaches are pliable and leathery.

\section{Plums}

Select fruit which is ripe. Remove pits by cutting fruit open with a sharp knife. Arrange halves on trays in single layer with pit cavity uppermost.

Treat with sulphur fumes 20 to 25 minutes. When liquid collects in the pit cavity the plums are sulphured enough, and are ready to dry. Start drying at a temperature of $130^{\circ}$ to $145^{\circ} \mathrm{F}$. When the surface begins to wrinkle increase slowly to $175^{\circ} \mathrm{F}$.

Properly dried plums are leathery and pliable.

\section{Prunes}

Prunes which are fully ripe and have fallen from the trees are best for drying. Grade and dip into boiling lye for 16 to 20 seconds. Allow $1 \mathrm{oz}$. lye to 2 gallons water. When dipped long enough there will be a slight indication of cracking of the skin near the stem end, but the skin will not be broken. Too strong lye or too long a dip will cause the skin to split and peel off.

Rinse thoroughly in cold water and then spread on drying trays in single layers. Start drying at $130^{\circ} \mathrm{F}$. and when the surface begins to wrinkle, raise the temperature very gradually to $175^{\circ} \mathrm{F}$. Properly dried prunes show no moisture when cut or when pressed between the fingers.

\section{TABLE FOR BLANCHING AND DRYING}

The following table shows blanching time for vegetables and the temperatures to be used in drying by artificial heat.

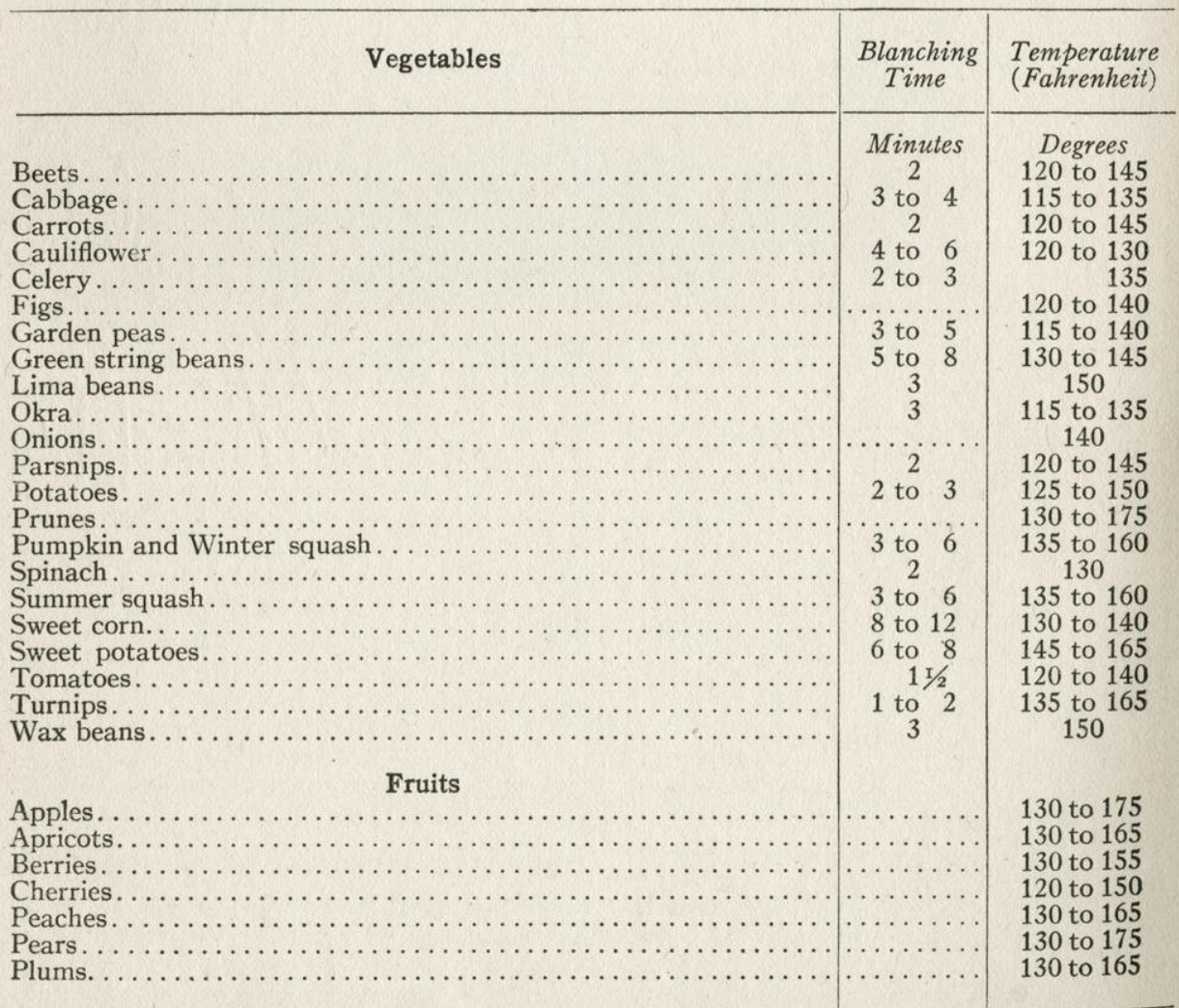




\section{FERIMENTATION AND SALTING}

The use of brine in preparing vegetables for winter use has much to commend it to the household. The fermentation method is in general use in Europe, and is becoming better known in this country as a means of making sour-crout and other food products which do not require the containers used for canning. No cooking is required by this process. Salt brine is the one requirement. The product may be kept in any container that is not made of metal and is water-tight. The vital factor in preserving the material is the lactic acid which develops in fermentation. An important feature is that vegetables thus prepared may be served

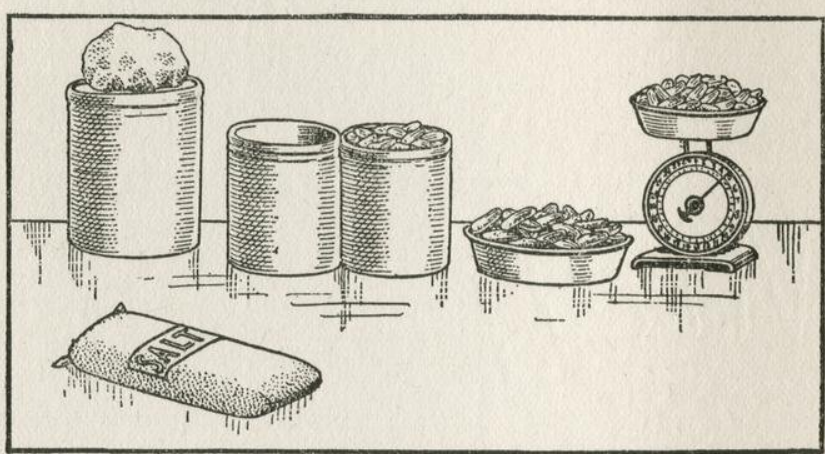

FIG. 22. Articles used in fermenting vegetables. as they are or they may be freshened by soaking in clear water and cooked as fresh vegetables.

\section{Sour-crout}

The outside leaves of the cabbage should be removed, the core cut crosswise several times and shredded very finely with the rest of the cabbage. Either summer growth or fall cabbage may be used. Immediately pack into a barrel, keg or tub, which is perfectly clean, or into an earthenware crock holding four or five gallons. The smaller containers are recommended for household use. While

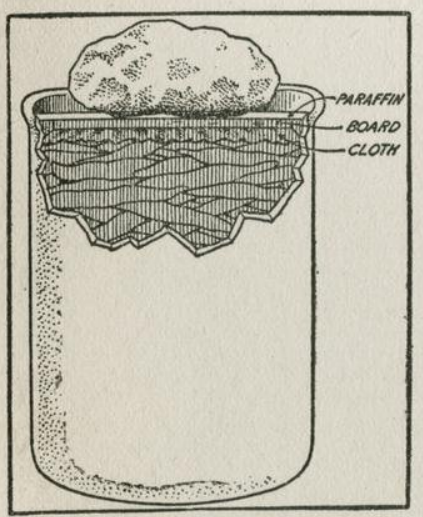
crock containing fermented products. Note the use of paraffin, board and cloth.

utensil like a potato masher. utensil like a potato masher. Repeat
with salt, cabbage and packing until the container is full or the shredded cabbage is all used. Press the cabbage down as tightly tribute salt as uniformly as possible, using 1 pound of salt to 40 pounds of $\mathrm{cabb}$ a ge. Sprinkle a little salt in the container and put in a layer of 3 or 4 inches of shredded cabbage and pack down gently with a wo o d e $n$
FIG. 23. Arrangement of cover on as possible and apply a cloth and then a glazed plate or a board cover which will go inside the holder. If using a wooden cover select wood free from pitch, such as basswood. packing disOn top of this cover place stones or other weights (using flint or granite and avoiding the use of limestone or sandstone). These weights serve to force brine above cover.

Allow fermentation to proceed for 10 days or two weeks, if the room is warm. In a cellar or other cool place three to five weeks may be required. Skim off the film which forms when fermentation starts and repeat this daily if necessary to keep this film from becoming scum. When gas bubbles cease to arise, if container is tapped, the fermentation is complete. If there is scum it should be removed. As a final step pour melted paraffin over the brine until it forms a layer from $1 / 4$ to $1 / 2$ inch thick to prevent the formation of the scum which occurs if the weather is warm or the storage place is not well cooled. This is not necessary unless the crout is to be kept a long time. The crout may be used as soon as the bubbles cease to rise. If scum forms and remains the crout will spoil. Remove scum, wash cloth cover and weights, pour off old brine and add new. To avoid this extra trouble it is wise to can the crout as soon as bubbles cease to rise and fermentation is complete. (To can, fill jars, adjust rubbers and partly seal. Sterilize 120 minutes in Hot-water Bath or 60 minutes in Steam Pressure Outfit at 5 to 10 pounds pressure.)

\section{SALTING WITHOUT FERMENTATION}

Preserving cabbage, string beans and greens for winter use by salting is a method which has long been used. To do this the vegetables should be washed, drained and weighed. The amount of salt needed will be one-fourth of the weight of the vegetables. Kegs or 
crocks make satisfactory containers. Put a layer of vegetables about an inch thick on the bottom of the container. Cover this with salt. Continue making alternate layers of vegetables and salt until the container is almost filled. The salt should be evenly distributed so that it will not be necessary to use more salt than the quantity required in proportion to the vegetables used. Cover the surface with a cloth and a board or glazed plate. Place a weight on these and set aside in a cool place. If sufficient liquor to cover the vegetables has not been extracted by the next day, pour in enough strong brine (1 pound of salt to 2 quarts of water) to cover surface around the cover. The top layer of vogetables should be kept under the brine to prevent molding. There will be some bubbling at first. As soon as this stops set the container where it will not be disturbed until ready for use. Seal by pouring very hot paraffin on the surface.

\section{THE USE OF BRINE}

This method is used for cucumbers, string beans, green tomatoes, beets, corn and peas, as these vegetables do not contain enough water for a good brine using only salt. Wash and put in a crock or other container within 3 or 4 inches of the top. Pour over them a brine made by adding to every 4 quarts of water used $1 / 2$ pint of vinegar and $3 / 4$ cup salt. The amount of brine needed will be about $1 / 2$ the volume of the material to be fermented. When fermentation is complete the container should be sealed as detailed for sour-crout.

\section{To Ferment Cucumbers}

Unless the cucumbers are from your own garden wash them carefully to insure cleanliness after indiscriminate handling. Pack them in a keg, barrel or crock, leaving space at the top for the cover. Cover them with a brine made by adding to every 4 quarts of water used $1 / 2$ pint of vinegar and $3 / 4$ cup of salt. The amount of brine needed will be one-half of the volume of the material to be fermented. Place a wooden cover or glazed plate on top of the contents and press it down by weighting it with a stone or other weight, to keep the cucumbers under the brine. Fermentation will require from 8 to 10 days in warm weather and from 2 to 4 weeks in cool weather. It is complete when bubbles cease to rise when the container is lightly tapped or jarred. When this stage is reached remove any scum which may have collected, pour hot paraffin over the cover and around the weight and store in a cool place.

\section{Green Tomatoes}

The process for green tomatoes is the same as that for cucumbers.

\section{Beets and String Beans}

Remove the strings from beans. Beets should be washed thoroughly and packed whole. Spices may be used, as with cucumbers, but these may be omitted if the vegetables are to be freshened by soaking, when they are to be used. The method is the same as with cucumbers.

\section{PREPARING FOR USE}

To prepare salted vegetables for use, soak in 3 or 4 times their volume of cold water to draw out excess salt. One or two changes of water will shorten this process. They should then be drained and rinsed well, put in cold water, brought slowly to a boil, and cooked until tender. They may then be prepared and served as fresh products are prepared and served.

Fermented vegetables should be rinsed in fresh water after removing from the container. To retain the acid flavor do not soak in water before cooking.

If cooked without soaking, fermented dandelions, spinach, kale and other greens will have flavor similar to that of the greens in their fresh state.

Fermented corn should be soaked several hours, with three or four changes of water. During the cooking also there should be one change of water. The corn may then be used in chowder, pudding, omelet, fritters or waffles.

Salted string beans should be soaked to remove the salt and then prepared and served as fresh beans are prepared and served. Fermented string beans may be cooked without soaking and served as the fresh beans are served. Young and tender string beans may be eaten raw.

\section{PICKLING VEGETABLES}

Pickling is an important branch of home preparedness for the winter months. Pickles have little food value, but they give a flavor to a meal which is liked by many. They should not be given to children.

In pickling, vegetables are usually soaked overnight in a brine made of 1 cup of salt and 1 quart of water. This brine removes the water of the vegetable and so prevents weakening of the vinegar. In the morning the brine is drained off.

Alum should not be used to make the vegetables crisp, as it is harmful to the human body. A firm product is obtained if the vegetables are not cooked too long or at too high a temperature. 
Spices, unless confined in a bag, give a dark color to the pickles.

Enameled, agate or porcelain-lined kettles should be used when cooking mixtures containing vinegar.

Pickles put in crocks should be well covered with vinegar to prevent molding.

Instructions for some of the most commonly used methods are given herewith.

\section{Tomato Catsup}

4 quarts ripe tomatoes, boil and strain.

Add 4 tablespoonfuls of salt.

2 cups of vinegar.

1 level teaspoonful each of cayenne pepper, cinnamon, cloves, allspice, mustard and black pepper.

Boil rapidly until thick. Pour into hot sterilized bottles. Put the corks in tightly and apply hot paraffin to the tops with a brush to make an airtight seal. All spices, except cayenne pepper, should be enclosed in cloth bag and removed when catsup is done.

\section{Chili Sauce}

2 dozen ripe tomatoes (dip in boiling water to peel). 6 peppers ( 3 to be hot).

3 onions.

$2 / 5$ cup of corn syrup.

2 tablespoonfuls of salt.

1 teaspoonful each of cloves, nutmeg and allspice.

1 quart of vinegar.

Simmer 1 hour. Pour into sterilized jars or bottles and seal while hot.

\section{Chow Chow}

2 pints cucumbers. (1 pint to be small ones).

1 cauliflower soaked in salted water for one hour.

2 green peppers.

1 quart onions.

Chop the above in small pieces. Sprinkle 1 cup of salt over them and let stand all night. Drain well in the morning.

The sauce for Chow Chow is made as follows:

2 quarts vinegar.

$1 / 4$ pound of mustard.

tablespoonful of turmeric.

$4 / 5$ cup of corn syrup.

$1 / 2$ cup of flour.

Make a paste of the mustard, turmeric, sugar, flour and a little vinegar. Stir this into the warm vinegar and boil until thick. Then add the vegetables and simmer for $1 / 2$ hour. Stir to prevent burning. Put in cans while hot.

\section{Cold Tomato Relish}

8 quarts firm, ripe tomatoes; scald, cold-dip and then chop in small pieces.

To the chopped tomato add:

2 cups chopped onion.

2 cups chopped celery.

2 cups corn syrup.

1 cup white mustard seed.

$1 / 2$ cup salt.

4 chopped peppers.

1 teaspoonful ground mace.

1 teaspoonful black pepper.

4 teaspoonfuls cinnamon.

3 pints vinegar.

Mix all together and pack in sterilized jars.
Corn Relish

1 small cabbage.

1 large onion.

6 ears of corn.

2 tablespoonfuls of salt.

2 tablespoonfuls of flour.

$11 / 2$ cups of corn syrup.

2 hot peppers.

1 pint of vinegar.

$11 / 2$ tablespoonfuls of mustard.

Steam corn 30 minutes. Cut from the cob and add to the chopped cabbage, onion and peppers. Mix the flour, sugar, mustard and salt - add the vinegar. Add mixture to the vegetables and simmer 30 minutes. Pour into sterilized jars or bottles and seal while hot.

\section{Cucumber Pickles}

Soak in brine made of 1 cup of salt to 2 quarts of water for a day and night. Remove from brine, rinse in cold water and drain. Cover with vinegar, add 1 tablespoonful brown sugar, some stick cinnamon, and cloves to every quart of vinegar used; bring to a boil and pack in jars. For sweet pickles use 1 cup of sugar to 1 quart of vinegar.

\section{Dill Pickles}

To make dill pickles follow the directions for fermenting cucumbers, page 30 , using alternate layers of dill leaves, whole mixed spices and cucumbers. The top layer should be of beet or grape leaves an inch thick.

\section{Green Tomato Pickle}

Take 4 quarts of green tomatoes, 4 small onions and 4 green peppers. Slice the tomatoes and onions thin. Sprinkle over them $1 / 2$ cup of salt and leave overnight in crock or enameled vessel. The next morning drain off the brine. Into a separate vessel put 1 quart of vinegar, 1 level tablespoonful each of black pepper, mustard seed, celery seed, cloves, allspice and cinnamon and 1 cup of corn syrup. Bring, to a boil and then add the prepared tomatoes, onions and peppers. Let simmer for 20 minutes. Fill jars and seal while hot.

\section{Green Tomato Pickle}

Wash and slice tomatoes. Soak in a brine of $1 / 4$ cup of salt to 1 quart of water overnight. Drain well. Put in a crock and cover with vinegar to which have been added stick cinnamon and 1 cup of corn syrup for every quart of vinegar used. Once a day for a week pour off vinegar, heat to boiling and pour over tomatoes again. Cover top of crock with a cloth and put on cover. This cloth should be frequently washed.

\section{Mustard Pickles}

2 quarts of green tomatoes.

1 cauliflower.

2 quarts of green peppers.

2 quarts of onions.

Wash, cut in small pieces and cover with 1 quart of water and $1 / 4$ cup of salt. Let stand 1 hour, bring to the boiling point and 


\section{PROLONG THE SEASON}

The season for home canning and drying does not end with summer or early autumn. Many things may be canned or dried in October and November. Among these are turnips, spinach, squash, pumpkin, carrots, parsnips, cabbage, celery, beets, late corn, kale, chard, salsify and tomatoes.

drain. Mix $1 / 2$ pound mustard, 1 cup of flour, 4 cups of corn syrup, and vinegar to make a thin paste. Add this paste to 2 quarts of vinegar and cook until thick, stir constantly to prevent burning. Add vegetables, boil 15 minutes and seal in jars.

\section{Piccalilli}

4 quarts of green tomatoes.

1 quart of onions.

1 hot red pepper.

2 cups of corn syrup.

$1 / 2$ cup of salt.

$11 / 2$ ounces each of mustard seed, cloves and allspice. 2 cups of vinegar.

Simmer 1 hour. Put into a covered crock.

\section{Pickled Onions}

Peel, wash and put in brine, using 2 cups of salt to 2 quarts water. Let stand 2 days, pour off brine. Cover with fresh brine and let stand 2 days longer. Remove from brine wash and pack in jars, cover with hot vinegar to which whole cloves, cinnamon and allspice have been added.

\section{Spiced Crab-Apples}

Wash apples, stick 3 or 4 whole cloves in each one and cover with vinegar to which have been added stick cinnamon and $13 \%$ cups corn syrup for every quart of vinegar used. Cook slowly at a low temperature until apples are heated through. These may be put in jar or stone crocks.

\section{Sweet Pickled Peaches}

Wipe peaches and stick 3 or 4 whole cloves in each one. Put in jars or crock and cover with hot vinegar, allowing $31 / 5$ cups of corn syrup to each quart of vinegar used. Every morning for a week pour off the vinegar, heat to boiling and pour over peaches again. On the last day seal jars or cover crock well.

\section{Chop:}

\section{Table Relish}

4 quarts of cabbage.

2 quarts of tomatoes, 1 quart to be green.

6 large onions.

2 hot peppers.

Add:

2 ounces of white mustard seed.

1 ounce of celery seed.

$1 / 4$ cup of salt.

6 cups of corn syrup.

2 quarts of vinegar.

Simmer 1 hour. Pour into sterilized jars or bottles and seal while hot.

This manual was prepared by the Commission's experts and is based on their own research and experience, supplemented by information procured from the United States Department of Agriculture, Agricultural Colleges, Experiment Stations, and other sources.

The National War Garden Commission, wishing to do all within its power to aid the War Industries Board in the very necessary economy in the use of paper, has limited the edition of this book and asks those who receive it in quantity to make the most careful distribution so that the book may reach the hands of none but those who will use it. IF THE INDIVIDUAL RECIPIENT CAN NOT USE THIS BOOK IT IS URGED THAT IT BE HANDED TO SOME ONE WHO WILL USE IT.

\section{TABLE OF CONTENTS}

\section{CANNING}

Advantages of Cold-pack Method.......

Arranging for canning................ 8

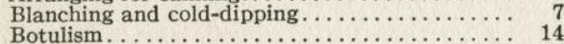

Canning in Tin.

Cold-pack Method in the South.

Community canning

Containers.

Equipment for Cold-pack Method

Fruit canning, directions.

Grading vegetables and fruits.

High Altitudes.

Methods of Canning

Steps in Cold-pack Method.

Tests for jars and rubbers.

Vegetable for blanching and sterilizing.

\section{DRYING}

Artificial heat.................... 20

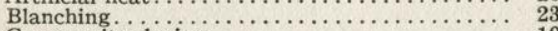

Community drying. ................... 19
DRYING (Continued) Page

Conditioning dried products . .............. 23

Details of drying . . . . . . . . . . . . . . . 22

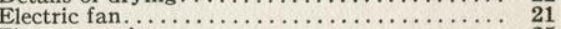

Fire prevention.................. 25

Fruit drying, directions. . . . . . . . . . . 27

Insects, protection from . . . . . . . . . . 23

Methods of drying.................. 19

On top of or over stove or range.......... 20

Oven drying. ..................... 20

Preparing food material for drying ......... 22

Storage of dried products.............. 24

Sun drying. $\ldots \ldots \ldots \ldots \ldots \ldots \ldots \ldots \ldots \ldots \ldots \ldots \ldots \ldots \ldots$

Time-table for drying $\ldots \ldots \ldots \ldots \ldots \ldots \ldots, 28$

Vegetable drying, directions............ 25

Winter use of dried products.............. 24

FERMENTATION AND SALTING........ 29

FRUIT BUTTERS. . . . . . . . . . . . . 17

JELLY MAKING . . . . . . . . . . . .

PICKLING ..................... 30

SOUR-CROUT . . . . . . . $29 \ldots \ldots \ldots \ldots \ldots{ }^{29}$ 


\section{UNITED STATES FOOD ADMINISTRATION}

Mobile, Alabama.

September 6th, 1918.

MR. P. S. RIDSDALE, Secretary,

National War Garden Commission,

WASHINGTON, D. C.

\section{Dear Mr. Ridsdale:}

I desire to tender my sincere thanks for the books which you have furnished for distribution and use among the war gardeners of Mobile, and as encouragement and assistance to others to take up this splendid work conducive not only to increased supply of food products, but to the health and happiness of those who wisely give Mother Earth the attention which just at this time she all the more richly deserves.

It is needless for me to assure you that the books have been extremely helpful. I consider them the most complete and serviceable ever produced; and excepting only the family Bible, the foundation of all ethics and morality as well as the common law, these books are of more vital importance to every householder, in fact, good citizens throughout the land, than most printed matter obtainable.

Your books on canning and drying are likewise of inestimable value, and your splendid co-operation in the common cause of increasing and conserving the food supply in our present crisis meets with the heartiest appreciation.

Very sincerely,

(Signed) HENRY A. FORCHHEIMER, Federal Food Administration Board.

\section{UNITED STATES FOOD ADMINISTRATION}

MR. P. S. RIDSDALE, Secretary,

Davenport, Iowa.

September 5, 1918.

National War Garden Commission, WASHINGTON, D. C.

My dear Mr. Ridsdale:

We have found your publications of great value in our work in this State and it gives me pleasure to thank you for your prompt and cordial compliance with all of our requests.

Your book on War Vegetable Gardening and the one devoted to Canning and Drying are filled with information of great value to the gardener and housewife.

It has been a source of great satisfaction to us to be able to distribute your books in every County in Iowa and we have used care to place them in the hands of people who need them and who are constantly calling for just the information contained in them.

We feel that your co-operation has been of great importance.

Faithfully yours,

(Signed) M. L. PARKER,

State Merchant Representative, Iowa Food Administration. 


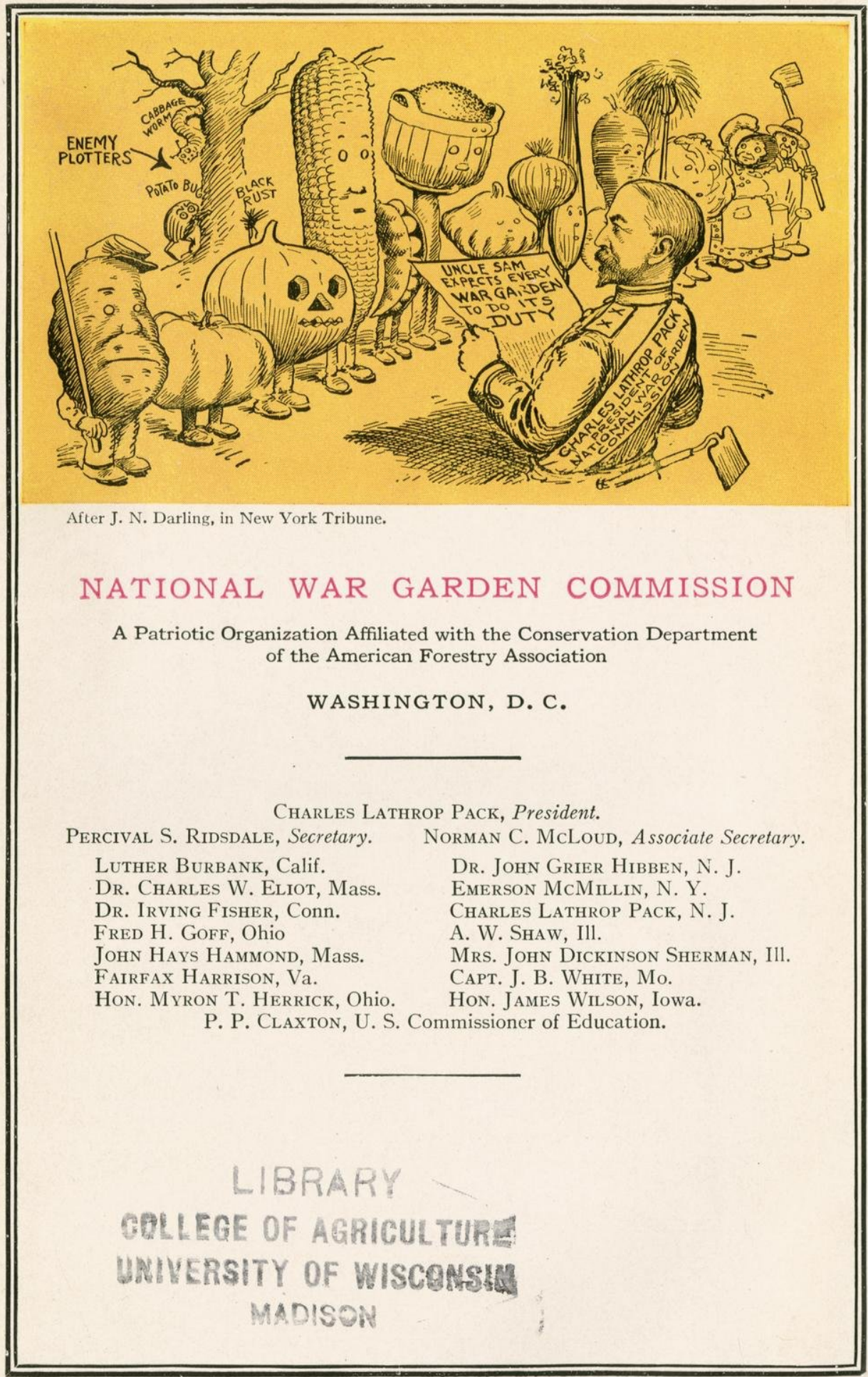



$M \quad 2.91974$

890371,75460

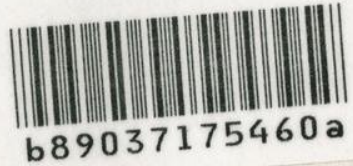




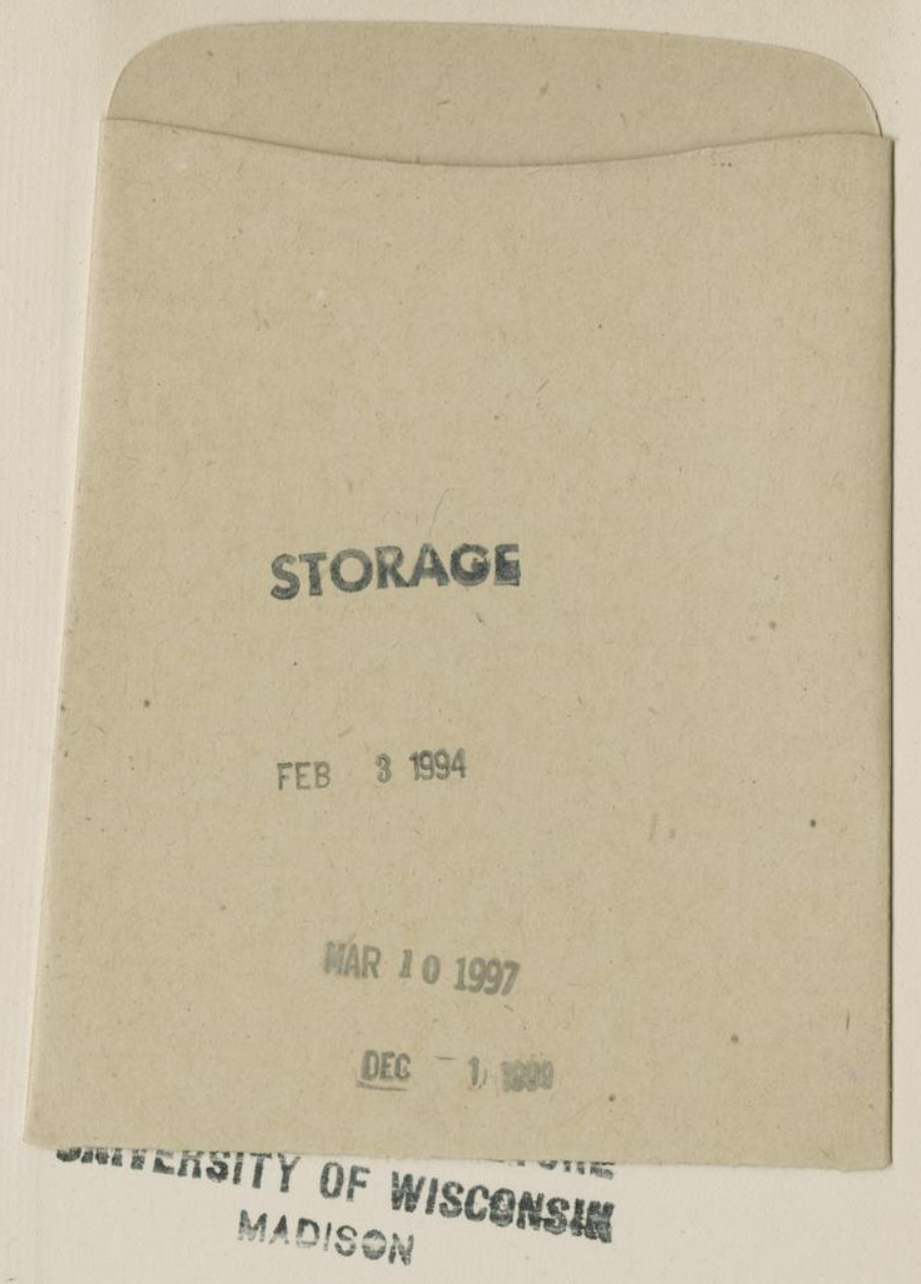




\section{0}

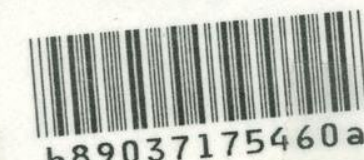

